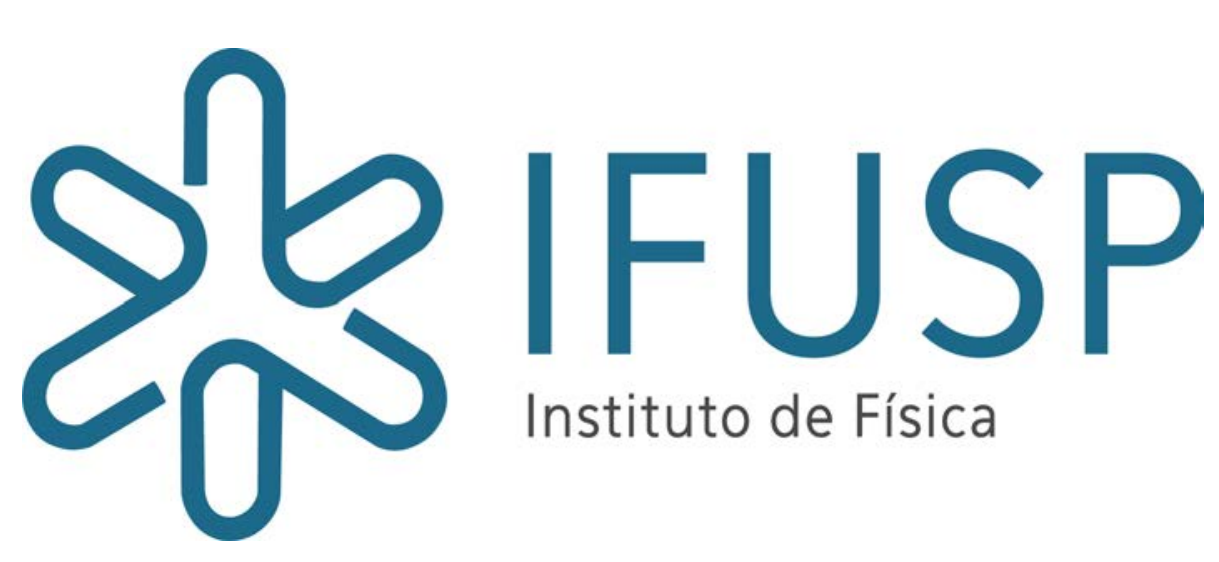

Universidade de São Paulo

\title{
Detetores semicondutores de fótons na investigação das interações dos elétrons e fótons com a matéria
}

Nora Lía Maidana

Texto que resume a obra de Nora Lía Maidana para a obtenção do título de Livre-Docente pelo Instituto de Física da Universidade de São Paulo

São Paulo

2021 
FICHA CATALOGRÁFICA

Preparada pelo Serviço de Biblioteca e Informação do Instituto de Física da Universidade de São Paulo

\section{Maidana, Nora Lia}

Detetores semicondutores de fótons na investigação das interações dos elétrons e fótons com a matéria. São Paulo, 2021.

Tese (Livre Docência) - Universidade de São Paulo. Instituto de Física. Depto. de Experimental

Área de Concentração: Física

Unitermos: 1. Detetores semicondutores; 2. Efeitos de deteç̧ão; 3. Eficiência de detecção; 4. Função resposta; 5 . Bremsstrahlung de elétrons; 6 . Ionização 


\section{Resumo}

Na quantificação das interações dos fótons e elétrons com a matéria, a detecção de fótons desempenha um papel central, de modo que a caraterização dos detetores de fótons é necessária para um amplo leque de experiências e aplicações. A determinação precisa da eficiência e resposta desses detetores requer longos e custosos experimentos. Apesar das muitas tentativas de criar um método baseado em simulações com códigos Monte Carlo, de modo a reduzir o esforço dispendido nesse processo, a obtenção da eficiência e resposta dos detetores tem baixa precisão quando não é guiada por experimentos complementares. Este trabalho relata o conjunto das metodologias que desenvolvemos para obter a resposta e eficiência de detetores com boa precisão, combinando experimento, simulação e a construção de funções analíticas. Tanto as simulações quanto as expressões analíticas levaram em conta parâmetros físicos, como as dimensões do cristal, espessuras das camadas mortas e de outros componentes do detetor, que foram medidos, modelados e/ou calculados para fazer coincidir, dentro da incerteza experimental, a eficiência medida de feixes de fótons colimados. Alguns dos resultados desses estudos revelaram um efeito secundário de detecção que ainda não estava relatado na literatura. Os detetores caracterizados foram usados em diversas medidas de seções de choque do bremsstrahlung e da ionização de camadas atômicas internas com o feixe de elétrons do Microtron de São Paulo, que trouxeram novas contribuições ao estudo das interações dos fótons e elétrons com a matéria.

Keywords: Detetores Semicondutores, Efeitos de Deteção, Eficiência de Deteção, Função Resposta, Bremsstrahlung de Elétrons, ionização 
$\longrightarrow$ 


\section{Abstract}

Photon detectors play a central role in the quantification of the interactions of photons and electrons with matter, therefore their characterization is necessary for a wide range of experiments and applications. Accurate determination of the efficiency and response of these detectors requires lengthy and costly experiments. The many attempts to reduce the effort spent in this process using simulations with Monte Carlo codes obtained efficiency and response of the detectors that did not reach the required accuracy when not guided by complementary experiments. This work reports the methodologies we developed to obtain the response and efficiency of detectors with good accuracy, combining experiment, simulation and the construction of analytic functions. Both the simulations and the analytical expressions took into account physical parameters, such as crystal dimensions, thicknesses of dead layers and other components of the detector, which were measured, modeled and/or calculated to match, within the experimental uncertainty, the measured efficiency of collimated photon beams. Some of the these studies led to find one detection secondary effect not previously reported in the literature. The characterized detectors were used in several measurements of cross sections of the bremsstrahlung and the ionization of atomic inner shells with the São Paulo Microtron electrons beams, which brought new contributions to the study of the interactions of photons and electrons with matter.

Keywords: Semiconductor Detectors, Detection Effects, Detection Efficiency, Response Function, Electron Bremsstrahlung, Ionization 
(20) 


\section{Agradecimentos}

Resulta difícil colocar uma ordem nos agradecimentos. Tem muitas pessoas às quais agradecer, tanto no aspecto pessoal, quanto profissional e a lista dos motivos é enorme! Não vou nomeá-los um por um, já que, se não aparecer o nome de alguém, estaria cometendo uma grande injustiça. O estímulo, a compreensão, amabilidade e dedicação, o companheirismo e respeito, o trabalho que cada um fez para que todo este estudo tenha chegado a um bom termo vá desde, obviamente. minha família, colegas e amigos, categorias as três que incluem os funcionários e pesquisadores na ativa e aposentados dos mais diversos setores, desde os técnicos aos administrativos, da biblioteca às oficinas, assim como as/os secretária/os da FEP, que com dedicação facilitam nossa vida com as pequenas/grandes ações do dia a dia. Particularmente agradeço ao pessoal dos Laboratórios: do Acelerador Linear, de Alvos Nucleares, do Grupo de Dosimetria das Radiações e Física Médica, de Análise de Materiais por Feixes Iônicos, de Materiais Magnéticos, e de Metrologia Nuclear, este último do IPEN e os demais do IF, sem os quais nada disto poderia ter sido feito.

A TODOS, muito, muito obrigada. 
$\longrightarrow$ 


\section{Índice}

Lista de Figuras $\quad$ xiii

\begin{tabular}{lll}
\hline 1 & Introdução & 1
\end{tabular}

\begin{tabular}{|lll}
2 & A física da detecção de raios-x e gamas & $\mathbf{7}$
\end{tabular}

2.1 O átomo . . . . . . . . . . . . . . . . . . . . . . 7

2.2 O núcleo . . . . . . . . . . . . . . . . . . . . 8

2.3 Produção de fótons em processos atômicos e nucleares . . . . . . . . . . . . 11

$2.3 .1 \quad$ Processos de produção de fótons . . . . . . . . . . . . . . . . 11

2.3.2 Seção de choque como medida da interação da radiação com a matéria. 15

2.3 .3 Caminho livre médio . . . . . . . . . . . . . . . 17

2.4 Mecanismos de interação da radiação eletromagnética e suas manifestações na

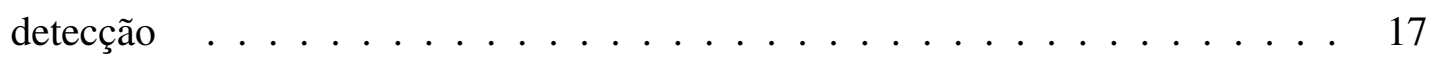

$2.4 .1 \quad$ Efeito Fotoelétrico $\ldots \ldots \ldots \ldots \ldots$

2.4 .2 Efeito Compton . . . . . . . . . . . . . . . 20

2.4 .3 Criação de pares $\ldots \ldots \ldots \ldots \ldots . \ldots \ldots$

2.5 Perda de energia dos elétrons $\ldots \ldots \ldots \ldots \ldots \ldots$

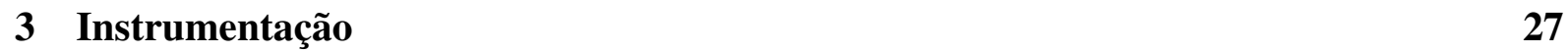

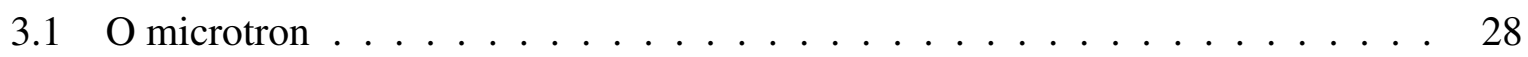

3.1 .1 Câmara de irradiação . . . . . . . . . . . . . . . . . . . . . 29

3.1 .2 Torre de alvos . . . . . . . . . . . . . . . . . . 31

3.2 Detetores de Fótons . . . . . . . . . . . . . . . . . . . . . . . 33

3.2 .1 Tipos . . . . . . . . . . . . . . . . . . . 33

3.2 .2 Os detetores de HPGe $\ldots \ldots \ldots \ldots \ldots$

3.2 .3 Os detetores de Sil . . . . . . . . . . . . . . . . . . . . . 36

3.2 .4 Detetores usados nos experimentos . . . . . . . . . . . . . . 37

3.2.4.1 Canberra . . . . . . . . . . . . . . 37

3.2 .4 .2 Planarde $5 \mathrm{cc} \ldots \ldots \ldots \ldots . \ldots . \ldots 37$

$3.2 .4 .3 \quad$ Planar de $8 \mathrm{cc} \ldots \ldots \ldots \ldots . \ldots . \ldots 38$

3.2 .4 .4 Coaxial de Janela de C . . . . . . . . . . . 38

$3.2 .4 .5 \quad \mathrm{Si}(\mathrm{Li})-(\mathrm{SLP}) \ldots \ldots \ldots \ldots$

$3.2 .4 .6 \quad \mathrm{SDD} \ldots \ldots \ldots \ldots \ldots \ldots$

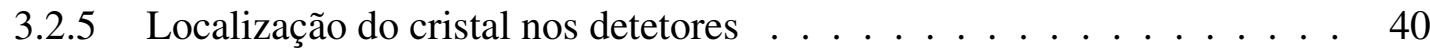


$3.2 .5 .1 \quad$ Imagens de raios- $\mathrm{x} . \ldots \ldots \ldots \ldots \ldots \ldots$. . . . . . . . 41

3.2 .5 .2 Imagens de raios $\gamma \ldots \ldots \ldots \ldots \ldots \ldots \ldots$

3.3 Colimadores . . . . . . . . . . . . . . . . . . . . . 44

3.3 .1 Determinação da camada morta do detetor HPGe . . . . . . . . . . 44

3.3 .2 Controle da fonte de radiação $\ldots \ldots \ldots \ldots$. . . . . . . . 44

3.4 Mapeamento dos detectores $\ldots \ldots \ldots \ldots \ldots \ldots \ldots \ldots$

3.4 .1 Detetor planar. . . . . . . . . . . . . . . . . . . 46

3.4 .2 Detetor coaxial . . . . . . . . . . . . . . . . . . . . . . . . . 47

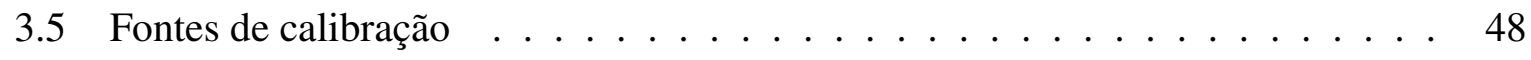

$3.5 .1 \quad$ Montagem em anéis de Al $\ldots \ldots \ldots \ldots$

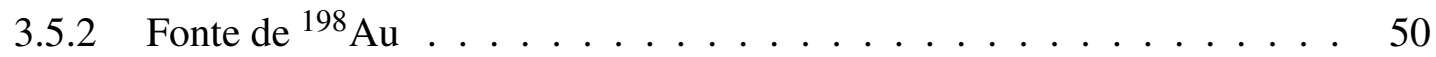

3.5 .3 Montagem em molduras de $\mathrm{C} \ldots \ldots \ldots \ldots \ldots$

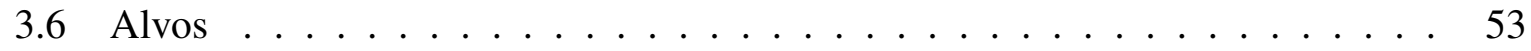

3.7 Montagem dos detetores nos arranjos da câmara de irradiação $\ldots \ldots \ldots$. . 58

\begin{tabular}{|lll}
\hline & Modelos de deteção de fótons & 61
\end{tabular}

4.1 Descrição esquemática da deteção $\ldots \ldots \ldots \ldots \ldots \ldots \ldots \ldots$

4.2 Desenvolvimento da pesquisa ao longo do tempo . . . . . . . . . . 62

4.3 Modelos analíticos . . . . . . . . . . . . . . . . . . . . 64

4.3 .1 Eficiência de deteç̧ão do pico de absorção total de energia . . . . . . . 66

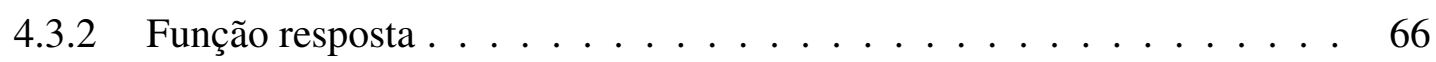

4.4 Modelos por simulação Monte Carlo . . . . . . . . . . . . . . . . . . . 67

5 Investigação da resposta de detetores semicondutores 71

5.1 Eficiência e resposta a energias acima de $4 \mathrm{MeV} \ldots \ldots \ldots \ldots \ldots 71$

$5.1 .1 \quad$ O terceiro escape - o que é e primeiras buscas . . . . . . . . . 73

5.1.2 Determinação experimental da intensidade do terceiro escape $\ldots . .76$

5.2 Eficiência e resposta de detetores para fótons de $100 \mathrm{keV} \mathrm{a} 4 \mathrm{MeV} \ldots \ldots$

$5.2 .1 \quad$ Mapeamento frontal $\ldots \ldots \ldots \ldots \ldots \ldots \ldots$

$5.2 .1 .1 \quad$ Resultados experimentais . . . . . . . . . . . . . 80

$5.2 .1 .2 \quad$ Resultados da simulação $\ldots \ldots \ldots \ldots$. . . . . . . . . . . 82

5.2.1.3 Simulação de espectros de ${ }^{137} \mathrm{Cs}$ colimados ao longo de um

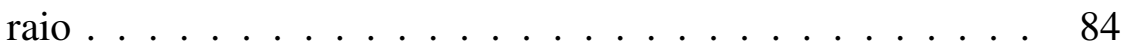

$5.2 .2 \quad$ Varredura lateral com uma fonte de ${ }^{137} \mathrm{Cs} \ldots \ldots$. . . . . . . . 85

5.2 .3 Medida experimental e simulação da detecção usando um colimador

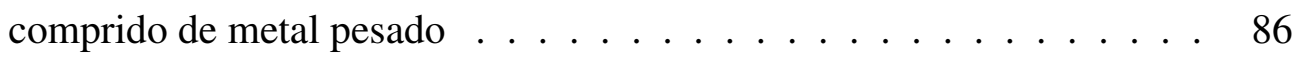

5.3 Detetores de fótons com energias menores que $100 \mathrm{keV} \ldots \ldots \ldots$. . . . . 90

$5.3 .1 \quad$ Detetor planar $5 \mathrm{cc} \ldots \ldots \ldots \ldots \ldots \ldots \ldots \ldots$

5.3 .2 Detetores de $\mathrm{Si}(\mathrm{Li})$ e SDD $\ldots \ldots \ldots \ldots$. . . . . . . . . . . . . 94

6 Pesquisas que usaram o estudo dos detetores 95

6.1 Secções de choque de Bremsstrahlung de elétrons com energias entre 10 e $100 \mathrm{keV} 96$

$6.1 .1 \quad$ A irradiação e o arranjo experimental . . . . . . . . . . . . 96 
$6.1 .2 \quad$ Correções do espectro experimental . . . . . . . . . . . . . . . . . . 98

6.1 .3 Determinação da energia do feixe . . . . . . . . . . . . . . . . . . . . . . . . . . . . . 98

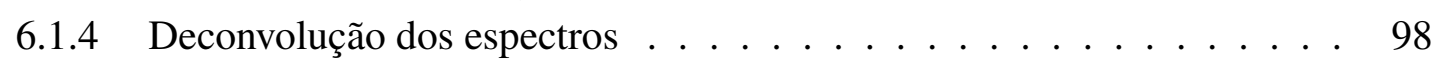

6.1 .5 Resultados . . . . . . . . . . . . . . . . . . . . 99

6.2 Secção de choque de ionização de camadas internas por impacto de elétrons . . 100

6.3 Determinação absoluta do Potássio na infusão de Chá por espectroscopia gama 101

\begin{tabular}{lll}
\hline 7 & Conclusão & 105
\end{tabular} 
$\longrightarrow$ 


\section{Lista de Figuras}

2.1 Níveis de energia dos elétrons das camadas internas de um átomo hipotético; para os elétrons de valência, a ordem desses níveis pode ser diferente. Energias fora de escala, mas o comprimento de cada linha é proporcional ao número de elétrons que podem ocupar o mesmo orbital. . . . . . . . . . . 9

2.2 Tabela de nuclideos, ref [50]. https://people.physics.anu.edu.au/ ecs103/chart/]. 10

2.3 Esquema dos níveis de energia do ${ }^{20} \mathrm{Ne}$, após a captura de um próton pelo ${ }^{19} \mathrm{~F}$. Após a fissão desse núcleo em ${ }^{16} \mathrm{O}$ e uma partícula $\alpha$, que pode possuir di-

ferentes energias cinéticas, o núcleo residual está em um dos níveis excitados
caracterizados pelos spins que aparecem na figura. [28] . . . . . . . . . . 12

2.4 Secções de choque para os processos de espalhamento elástico, fotoelétrico, Compton e criação de pares em função da energia do fóton, para Germânio [76]. 19

2.5 Esquema do efeito fotoelétrico. O fóton de energia $E$ interage com um elétron orbital, com energia de ligação $B_{i}$, de maneira que a energia cinética do elé\begin{tabular}{|c|}
\hline \hline tron ejetado é $E^{\prime}=E-B_{i}$. Logo após a vacância deixada por esse elétron é \\
\hline
\end{tabular}

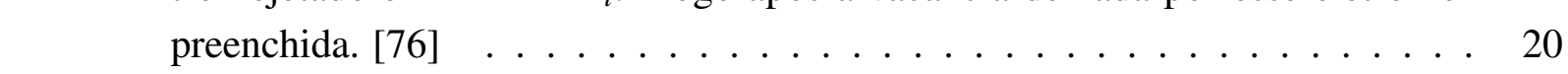

2.6 À esquerda, o espectro de ${ }^{57} \mathrm{Co}$ com um detetor planar e à direita o espectro de

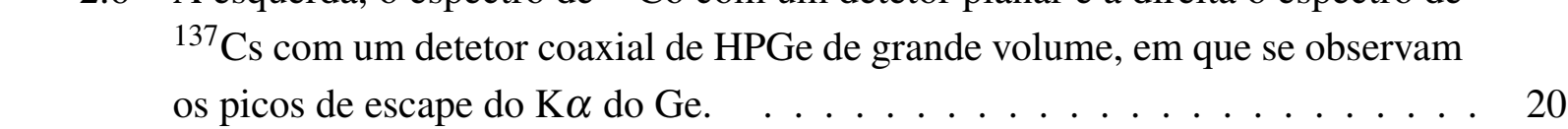

2.7 Eficiência de detecção de pico intrínseca para detetores planares de Ge em \begin{tabular}{|l|}
\hline função da energia, para feixes de fótons colimados, calculadas com o modelo \\
\hline \hline de Seltzer [83], apropriados para detetores planares com janela de Be (linhas \\
\hline \hline cheias) e um grande detetor coaxial com janela de C. Neste último caso, o feixe \\
\hline \hline de fótons incide fora do centro, de modo a evitar as superfícies cilíndricas tanto \\
\hline \hline a externa quanto a do furo central. . . . . . . . . . . . . . . . . . . . . . . . . 21 \\
\hline
\end{tabular}

2.8 Esquema do efeito Compton: o fóton de energia $E=h v$ interage com um \begin{tabular}{|c|}
\hline elétron ao que transfere energia, sendo espalhado em um ângulo $\phi$ e o fóton \\
\hline \hline emergente tem energia $E^{\prime}=h v^{\prime}$ e sua quantidade de movimento forma em um \\
\hline ângulo $\theta$ com a direção do movimento inicial. . . . . . . . . . . . . . 21
\end{tabular}

2.9 Distribuição angular dos fótons espalhados em função da energia do fóton incidente de acordo com a seção de choque de Klein-Nishina [49] . . . . . . . . . 22 
2.10 Comparação dos espectros experimental e simulados para uma fonte de ${ }^{137} \mathrm{Cs}$ incidindo sobe um detetor coaxial de HPGe [78]. No detalhe, a linha mais fina e de mudança abrupta corresponde ao cálculo sem incluir o efeito doppler devido ao movimento dos elétrons, enquanto a linha mais suave e irregular inclui esse efeito, o que realça a importância de levar em conta o movimento dos elétrons na distribuição angular dos fótons espalhados inelasticamente. . . . . . . . . . 23

2.11 Espectro simples de detecção dos gamas de decaimento da reação ${ }^{19} \mathrm{~F}(\mathrm{p}, \alpha \gamma){ }^{16} \mathrm{O}$.

A dispersão em energia é 0,536 keV/canal. Os picos DE e SE são os escapes duplo e simples, com energias 1022 e $511 \mathrm{keV}$, respectivamente, abaixo do pico

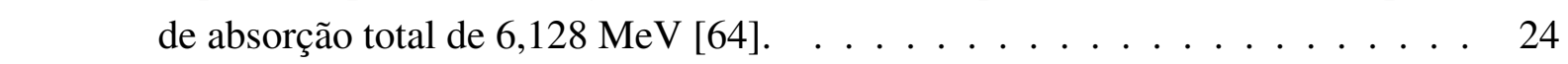

3.1 Esquema das linhas de irradiação do microtron. A grande caixa à esquerda do desenho representa a blindagem eletrostática da fonte de $100 \mathrm{kV}$ do canhão de elétrons. . . . . . . . . . . . . . . . . . 28

3.2 Câmara de irradiação antiga da linha de 1,9 MeV, usada para medir ionização da camada $\mathrm{K}$ de $\mathrm{Au}$ e Bi, por elétrons de 80 a $100 \mathrm{keV}$ [45]. Na imagem superior esquerda, se pode ver o aparelho que filma o interior e auxilia no correto posicionamento do alvo e na focalização do feixe. Na imagem superior direita, pode se observar o beam catcher (na horizontal à direita da imagem) e os flanges. A imagem inferior é uma vista de cima. . . . . . . . . . . . . . . . . . . 29

3.3 Câmara de irradiação da nova linha de $10-100 \mathrm{keV}$. Na imagem da esquerda, se destacam a faraday cup e o acionador da torre de alvos, na imagem da direita, um suporte/blindagem de cobre sendo alinhado com laser. . . . . . . . . . . 29

3.4 Esquema da câmara em vistas lateral e corte longitudinal, e imagem da câmara de irradiação de 10 a $100 \mathrm{keV}$, com a blindagem do copo de Faraday visível do lado direito e sustentada por um cabo de aço. . . . . . . . . . . . . . . . . . 30

3.5 Imagens do suporte de alvos com um alvo de Au junto ao view screen, no centro o tampo da câmara antiga com o suporte de fontes de calibração e a direita detalhe do suporte de fontes em anel de Al e uma fonte com moldura desse

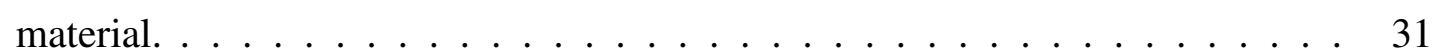

3.6 Ajuste da posição do alvo na posição de irradiação, vista no monitor da sala de controle. O disco escuro no centro do retângulo claro tem $10 \mathrm{~mm}$ de diâmetro e corresponde à região do alvo. . . . . . . . . . . . . . . . . . . . 32

3.7 Imagem da nova torre de alvos feita de fibra de carbono, com os slots de 1 a 4 carregados com alvos diferentes, no 5, uma moldura vazada de $8 \mathrm{~mm}$ e o 6 , com a moldura de $10 \mathrm{~mm}$. A imagem do view-screen, que está acima de todos eles,

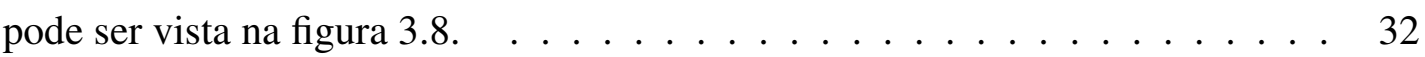

3.8 Imagem do view screen, em que o spot brilhante marca a posição e o perfil do feixe de elétrons que bate na parte central. . . . . . . . . . . . . . . . 33

3.9 Montagem do detetor de HPGe de 5 cc no arranjo de irradiação do Microtron, onde se observa a inclinação com que foi posicionada a cápsula do detector, a fim de que o eixo de simetria do cristal apontasse para o alvo. . . . . . . . . . . 36 
3.10 Imagens do arranjo dos detectores Canberra no arranjo experimental do LAMFI, que forneceram os dados das publicações [63, 62,64]. . . . . . . . . . . . . . 38

3.11 Cópia da página do manual do detetor ORTEC, em que estão especificadas as dimensões físicas do elemento ativo e sua cápsula.

3.12 Imagens de um SDD na montagem do arranjo de irradiação. À esquerda, o SDD com a extremidade do cristal dentro do posicionador de polimetilmetacrilato, e, no fundo o copo de Faraday. À direita, ressaltam-se as linhas brilhantes do laser que auxiliavam no correto posicionamento do detetor . . . . . . . . . . . . 40 40

3.13 Imagens do posicionamento do detetor e fonte de raios-X do IPEN. . . . . . . . . 41

3.14 Imagens de raios- $x$ do detetor Canberra (item 3.2.4.1) desde dois ângulos de incidência perpendiculares ao eixo. . . . . . . . . . . . . . . 42

3.15 Imagem de raio-x dos dois detetores planares dos trabalhos [60, 91]. A imagem da esquerda mostra que o cristal está descentrado e desalinhado no sentido longitudinal. A imagem da direita mostra o detetor planar de 8 cc bem alinhado com a cápsula, mas não perfeitamente centralizado. . . . . . . . . . . . . . 42

3.16 Imagem do raio-x do detetor $\mathrm{Si}(\mathrm{Li})$ do trabalho de Barros $[8] . \quad$. . . . . . . . . 43

3.17 Imagem de gamagrafia do cristal de HPGe coaxial, com fonte de ${ }^{60} \mathrm{Co}$, usado

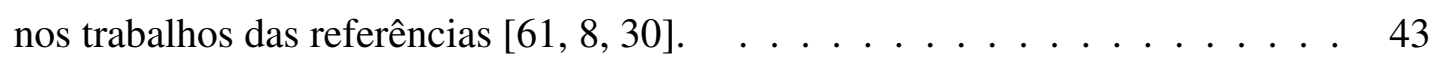

3.18 Imagens do colimador de forma trapezoidal para mapeamento manual. . . . . . 45

3.19 Desenho do colimador de metal pesado, fora de escala. . . . . . . . . . . . 45

3.20 Imagens do spot que os fótons da fonte radioativa produziam na placa durante $\mathrm{o}$ teste da precisão da mesa $x-y$. À esquerda, a verificação de varredura em duas direções perpendiculares; à direita, comprovação da repetitividade no posicionamento do conjunto fonte-colimador-detetor. . . . . . . . . . . . . . 46

3.21 Imagens do arranjo do mapeamento frontal, com a mesa $x-y$ manual. . . . . . 47

3.22 Exemplo do posicionamento do colimador à frente do Detector planar de $5 \mathrm{cc}$.

Nela podem ser vistos um esquema do colimador trapezoidal frente à cápsula de Al na imagem de raios-x desse detetor. . . . . . . . . . . . . . . . . . . 48

3.23 Imagens fotográficas da mesa $x-y$ com o suporte e o colimador. As estruturas de alumínio fixavam os motores de passo. A imagem de cima direita mostra o detetor fixado entre duas placas de polietileno com o colimador a frente. $\mathrm{O}$ colimador com coração de metal pesado pode ser visto nas duas últimas imagens. 49

3.24 Imagens das fontes de ${ }^{241} \mathrm{Am} \mathrm{e}{ }^{57} \mathrm{Co}$ confeccionadas entre duas folhas de Mylar fixadas por um aro de Al sobre um anel do mesmo material. . . . . . . . . . . . 50

3.25 Imagem da fonte de ${ }^{198} \mathrm{Au}$ e certificado de calibração. . . . . . . . . . . . . . . 51

3.26 Etapas da fabricação das fontes de calibração. Na imagem: superior esquerda a micropipeta depositando uma gota de material radioativo sobre o filme de Collodion, superior direita fontes à espera da secagem da gota, inferior direita e esquerda, fontes de ${ }^{152} \mathrm{Eu} . . \ldots \ldots \ldots \ldots \ldots 53$

3.27 Fontes de ${ }^{133}$ Ba fabricadas no LMN-IPEN/CNEN-SP. . . . . . . . . . . . . 53

3.28 Certificado de calibração e fontes de ${ }^{109} \mathrm{Cd}$. . . . . . . . . . . . . . 54 
3.29 À esquerda, dispositivo de fixação das molduras com substrato de C para depósito do elemento de interesse. Os furos, com $8 \mathrm{~mm}$ de diâmetro permitem que o material do alvo de interesse só seja depositado sobre o filme de C nessa região. À direita, suporte de alvos com máscara na pré-câmara de sputtering. . . . . . . 56

3.30 Imagem de um alvo de Au em moldura de fibra de C. . . . . . . . . . . . . 56

3.31 Espectro experimental da observação dos gamas emitidos da reação ${ }^{19} \mathrm{~F}(\mathrm{p}, \alpha \gamma){ }^{16} \mathrm{O}$.

O alvo que gerou esse espectro não possuía a camada de Au para brecar o recuo do produto da reação. A dispersão em energia é $1,1 \mathrm{keV} / \mathrm{canal}$. . . . . . . . . . 57

3.32 Alvos de $\mathrm{CaF}_{2}$ no suporte de irradiação e irradiados. Pode-se ver que os que fo\begin{tabular}{|c|}
\hline ram irradiados apresentam uma mancha escura no lugar onde o feixe de prótons \\
\hline
\end{tabular}

3.33 Imagens da montagem de um detetor na posição de medida. As primeiras cor-

respondem ao cubo de Cobre da blindagem interna, com o colimador central que tem inserido um tampão de Al. Em algumas se observam as linhas de laser para corroborar o correto posicionamento do colimador, e as medidas da

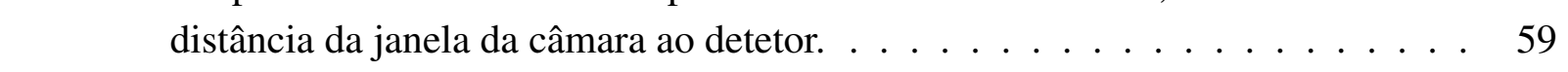

4.1 Esquema da geometria cilíndrica empregada por Seltzer [81] no seu modelo. \begin{tabular}{|c|}
\hline Está esboçada também a trajetória de um fóton que interage com o cristal e \\
\hline
\end{tabular} espalha inelasticamente por um ângulo $\theta$. . . . . . . . . . . 65

4.2 Representação esquemática simplificada do código Monte Carlo para simulação \begin{tabular}{|c|c|}
\hline do transporte de fótons e elétrons na matéria, válida para o PENELOPE e o MCNP. 67 \\
\hline
\end{tabular}

5.1 Esquema do alvo, flange, separador e detetor na posição de irradiação do LAMFI \begin{tabular}{|c|}
\hline na medida dos espectros das reações $(\mathrm{p}, \gamma)$ em ${ }^{27} \mathrm{Al} \mathrm{e}{ }^{23} \mathrm{Na}[37]$, usado na simu- \\
\hline
\end{tabular}

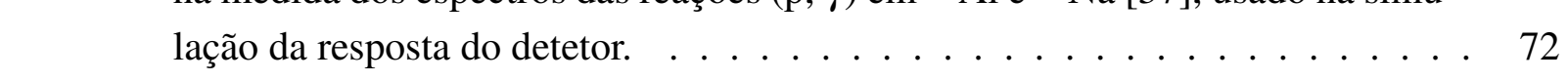

5.2 Esquemas da geometria simulada na medida do espectro de gamas da reação \begin{tabular}{|l|}
\hline${ }^{19} \mathrm{~F}(\mathrm{p}, \alpha \gamma){ }^{16} \mathrm{O}$. A figura de cima é um corte no plano horizontal, e a de baixo, \\
\hline \hline no plano vertical. As superfícies em azul representam o Al da câmara, a cápsula \\
\hline que contêm o detetor e a parte externa do dedo frio; em vermelho, o cristal de \\
\hline Ge, em roxo o cobre do dedo frio e em rosa o nitrogênio líquido [89]. Nesses \\
\hline \hline esquemas, também pode ser apreciado o desalinhamento do detetor mostrado \\
\hline na figura $3.14 . \ldots \ldots \ldots \ldots \ldots \ldots \ldots \ldots$ \\
\hline
\end{tabular}

5.3 Espectros provenientes de fótons monocromáticos de 1,$173 ; 1,332 ; 2 ; 4 ; 6$; \begin{tabular}{|c|}
\hline $8 ; 10 ; 12 ;$ e $14 \mathrm{MeV}$ simulados pelo MCNP. Na ordenada é representada a \\
\hline
\end{tabular}

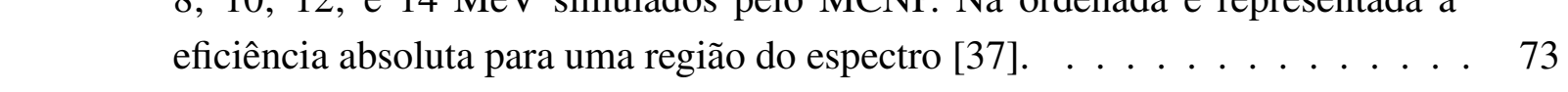

5.4 Diagrama que descreve os modelos empíricos de formação do terceiro escape \begin{tabular}{|c|}
\hline no lado esquerdo e do segundo escape no direito. A legenda dos símbolos está \\
\hline
\end{tabular} na parte inferior da figura $[63] . \ldots \ldots \ldots$. . . . . . . . . . . . 74

5.5 Comparação do pico do terceiro escape esperados na simulação sobrepostos ao contínuo e experimental, onde não se observa dito pico. A dispersão em energia do espectro é $7,5 \mathrm{keV} /$ canal $[63] . \ldots \ldots \ldots \ldots \ldots \ldots \ldots$. . . . . . . . 76 
5.6 Arranjo experimental usado na detecção do terceiro e quarto escapes. Acima, uma imagem dos detetores, o que está alinhado com a saída do feixe possui os BGO em volta, o detetor de HPGe que aparece à direita do colimador é o \begin{tabular}{ll|l|l|l|} 
que registrou o espectro simples mostrado na figura & 3.31 & O esboço de baixo
\end{tabular} representa o arranjo experimental simulado com o código PENELOPE, onde os números representam: atenuadores $1(\mathrm{Al}), 2(\mathrm{Cu}), 3(\mathrm{Cd}), 4(\mathrm{~Pb}) ; 5$ colimador e absorvedor de $\mathrm{Pb} ; 6$ detetores de $\mathrm{BGO} ; 7$ janela de Be do detetor de HPGe; 8 end cap do HPGe em Al; 9 Cristal de Germânio; 10 furo interno e 11 dedo frio de Cobre. [64]. . . . . . . . . . . . . . . . . . . . . . . 77

5.7 Terceiro e quarto escapes nas coincidências com $n=3$ BGOs (figuras a e b, respectivamente) e quarto escape no espectro de coincidências com $n=4$ BGOs [64] (figura c). . . . . . . . . . . . . . . . . . . . . 79

5.8 Eficiência de pico para o mapeamento frontal dos picos de escape dos raios-X $\mathrm{K} \alpha$, quociente entre os picos raios- $\mathrm{K} \beta$ e $\mathrm{K} \alpha$, e quociente entre escape do raios-x K $\alpha$ e K $\alpha$ (valores de $x$ e $y$ em $\mathrm{mm}$ ). . . . . . . . . . . . . . . . . . . 81

5.9 Eficiência de pico para as energias de 31, 81, 276 e $356 \mathrm{keV}$, correspondentes a fótons que seguem o decaimento do ${ }^{133} \mathrm{Ba}$, em função da posição $x-y$ da superfície frontal, obtidas com o mapeamento automático do detetor coaxial. . . 82

5.10 comparação da eficiência de detecção experimental e simulada em função da distância ao eixo central do elemento ativo. As linhas contínuas representam os valores simulados para a espessura da camada morta especificada pelo fabricante e espessuras iguais a 0,7 e 1,4 mm e a linha tracejada, $1,0 \mathrm{~mm}$. . . . . . . 83

5.11 Desenho dos componentes do detetor de HPGe simulado, com um corte longitudinal para apreciar as diferentes partes. O cristal de Ge está em roxo, destacando o furo interno em azul, o dedo frio de cobre em vermelho e em azul o alumínio da capa externa. . . . . . . . . . . . . . . . . . 83

5.12 Comparação da resposta para o mapeamento frontal experimental (esquerdo) e simulado (direito) para o pico de raios- $x$ de $35 \mathrm{keV}$ que segue o decaimento do ${ }^{133} \mathrm{Ba}$ (valores de $x$ e $\left.y \mathrm{em} \mathrm{mm}\right) . \ldots \ldots \ldots . \ldots . \ldots . \ldots 84$

5.13 Comparação da resposta para o mapeamento frontal (esquerdo) e simulado (direito) para o pico gama de $356 \mathrm{keV}$ que segue o decaimento do ${ }^{133} \mathrm{Ba}$ (valores

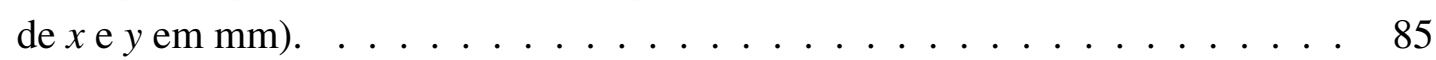

5.14 Razão entre a área do espectro no intervalo de energias entre 180 e $220 \mathrm{keV}$ e a área do pico de absorção total do ${ }^{137} \mathrm{Cs}$ em função da posição do feixe em relação ao centro do cristal. A curva superior corresponde à simulação com camada morta interna de 1,4 mm e a inferior, 1,0 mm. Do gráfico, deduz-se que um colimador de $1 \mathrm{~cm}$ de diâmetro deve ter seu eixo posicionado entre 13 e $15 \mathrm{~mm}$ de distância do eixo do detetor a fim de maximizar a relação entre a eficiência de pico e a total. . . . . . . . . . . . . . 86 
5.15 Mapeamento lateral da eficiência de pico para fótons de a) 31 e b) $662 \mathrm{keV}$ do ${ }^{137}$ Cs. As cotas das curvas de nível estão desenhadas conforme a barra lateral colorida, e os valores das coordenadas $x$ e $y$ estão em $\mathrm{mm}$. O eixo do detetor é paralelo ao eixo $x$ e ocupa a cota $y=-30 \mathrm{~mm}$, aproximadamente. . . . . . . . . 87

5.16 Esquema do posicionamento do colimador frente à superfície frontal do detetor

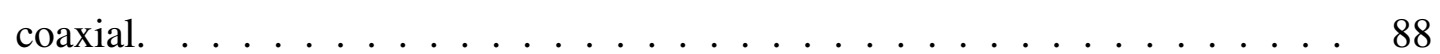

5.17 À esquerda, a geometria simulada do detetor dentro da blindagem de chumbo,

\begin{tabular}{|c}
\hline com a fonte enxergando a totalidade da superfície frontal do detetor. À direita, \\
\hline \hline a geometria simulada do detetor com colimador de metal pesado dentro de uma
\end{tabular} blindagem de $\mathrm{Pb} . \ldots \ldots \ldots \ldots$. . . . . . . . . . . . . . . 89

5.18 Espectro de deteção no HPGe de uma fonte de ${ }^{137} \mathrm{Cs}$ medido e simulado, com a imagem esquerda da geometria da figura 5.17 . . . . . . . . . . . . . . . 89

5.19 Espectros de detecção no HPGe de uma fonte de ${ }^{137} \mathrm{Cs}$ medido e simulados, com as secções de choque Compton das tabelas e com modificações de + e $2 \%$ delas, com o conjunto fonte-detetor dentro de uma blindagem como a da configuração direita da figura $5.17 \mid$ A radiação de fundo no espectro experimental foi subtraída. . . . . . . . . . . . . . . . . . 90

5.20 Eficiência de detecção do detetor planar de 5 cc [60]. . . . . . . . . . . . . . 92

5.21 Modelo de camadas mortas do cristal do detetor planar de 5cc [60]. . . . . . . 92

5.22 Frações do número total de eventos detetados devidos aos diferentes mecanismos de deposição de energia em função da energia do fóton incidente [32]. .. 93

6.1 Esquema da câmara (fora de escala) e posicionamento dos detetores. . . . . . 97

6.2 A imagem da esquerda mostra o cha em um recipiente cilíndrico de polietileno, a imagem da direita o $\mathrm{KCl}$ em um recipiente idêntico ao anterior. . . . . . . . . 101

6.3 Espectro dos fótons de $1461 \mathrm{keV}$ que seguem o decaimento do ${ }^{40} \mathrm{~K}$ nas folhas de chá antes e após preparada a infusão, no filtro de papel e no fundo natural

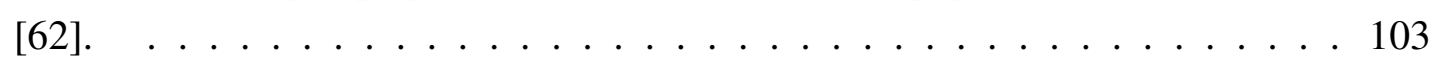


$\longrightarrow$ 


\section{Capítulo 1}

\section{Introdução}

A. Contexto. O programa experimental do Microtron busca avançar na compreensão e descrição detalhada das interações dos fótons e elétrons com a matéria. O grupo tem publicado diversos trabalhos que representam avanços importantes na medida da produção de bremsstrahlung por elétrons de baixa energia, da ionização de camadas internas por impacto de elétrons e de outros efeitos atômicos. Essas linhas de pesquisa requerem a quantificação e caraterização precisa do fluxo de fótons que chega aos detetores. Cálculos apurados de secções de choque de elétrons dependem de vários fatores:

- da quantificação do número de elétrons que atingem a amostra.

- do número de átomos do alvo atingidos pelo feixe.

- da eficiência de detecção e resposta dos detetores em uso.

Todos esses valores devem ser conhecidos com a melhor precisão possível, já que disso depende a incerteza dos resultados a obter. Buscávamos conseguir precisões relativas melhores que $10 \%$ para essas secções de choque, razão pela qual a precisão de cada uma das grandezas participantes do cálculo devia ser melhor que $5 \%$. A eficiência de detecção e resposta dos detetores é o assunto destacado neste trabalho. Os dois primeiros itens serão tratados no Capítulo 3.

A pesquisa experimental das interações dos elétrons com a matéria é dificultada pela ocorrência simultânea das várias formas de interação: colisões elásticas e inelásticas, e a produção tanto de radiação característica dos átomos quanto de bremsstrahlung, todas associadas à dispersão angular e à perda de energia das partículas do feixe incidente. Nos experimentos efetuados, procuramos condições que realçassem um aspecto e minimizassem os demais, mas como os fenômenos são concorrentes, o modelo para discriminar os efeitos desejados dos não desejados é elaborado e complexo, exigindo considerar muitas características desses fenômenos nos arranjos e cálculos para obter os resultados finais. Todo experimento de sucesso é precedido por medidas preliminares, seguido de repetições mais refinadas, até atingir o propósito e precisão desejados.

Este trabalho tem como protagonista o detetor de radiação eletromagnética dispersivo em energia, tanto como instrumento nos arranjos experimentais sobre as interações dos fótons e elétrons, quanto como componente cuja resposta é determinada por essas mesmas interações. 
B. Detetores de fótons. Os detetores de fótons em intervalos de energias que vão dos poucos $\mathrm{keV}$ até vários $\mathrm{MeV}$ têm evoluído ao longo dos tempos, em um desenvolvimento que inclui sua fabricação com novos materiais, de acordo com o tipo de partícula a medir, a faixa de energia de interesse e das condições de medida. Em particular, os de germânio (Ge), que começaram como Ge(Li) na década de 1960, hoje em dia se transformaram em monocristais de Germânio Hiper Puro (HPGe) e apresentam um melhor compromisso entre resolução em energia e eficiência de detecção. Encontram-se detetores cujos elementos ativos têm diversas formas, como os planares, coaxiais e até segmentados, cada um dos quais cumpre requisitos de detecção específicos para uma grande variedade de estudos [25].

O funcionamento e a aplicação dos detetores semicondutores de fótons é investigado neste trabalho em toda a ampla faixa de energia em que são usados. Alguns outros exemplos de sua aplicação são:

a) física básica: na determinação de modos de excitação dos núcleos pela medida dos raios gama do decaimento de estados excitados, do spin de um nível nuclear a partir da medida da distribuição ou correlação angular dos fótons emitidos, na comparação de modelos de estrutura nuclear pela medida de observáveis de estados nucleares excitados, na medida de secções de choque de partículas, no estudo de fenômenos nucleares que revelam a estrutura de núcleos exóticos, entre outras.

b) física aplicada: na identificação e quantificação de elementos radioativos, que permitem também caracterizar o espectro de nêutrons em diferentes posições de reatores de pesquisa, na determinação da radioatividade de amostras ambientais e no estudo de absorção de diversos materiais pelas plantas com traçadores radioativos, na determinação de elementos usados em obras de arte ou utensílios arqueológicos, na determinação de contaminantes para proteção radiológica, em inúmeras aplicações de controle de qualidade e pesquisa em física médica, entre outras.

Os detetores podem ser usados em medidas diretas ou em arranjos de sistemas em coincidência. Os referidos aqui são os semicondutores de Si(Li), HPGe e SDD isolados, mas também foi usado um sistema de coincidência com um detetor de HPGe e cintiladores BGO (germanato de bismuto).

C. Calibração de detetores Todas as aplicações desses detetores possuem uma caraterística comum, precisam da eficiência de detecção e/ou da resposta do detetor para toda a faixa de energia de trabalho. Processos de caracterização dos detetores são estudados desde sua invenção [49, 75]. Os métodos experimentais de calibração para energias até uns poucos MeV são normalmente baseados em fontes radioativas com atividade conhecida. A eficiência e resolução desses detetores continuam aceitáveis para energias maiores, mas os processos de calibração de eficiência se tornam mais complicados, porque não existem fontes radioativas padrão que emitam raios gama acima dos $5 \mathrm{MeV}$ [29, 44].

A revisão da literatura mostra que não há uma única, ideal e sistemática maneira de caracterizar um detetor, isto é, de obter as funções que descrevem como esse detetor responde para fótons de energias específicas. Todos os diversos métodos são demorados e trabalhosos, e a 
precisão dos resultados depende em forma direta da qualidade dessa caraterização. A curva de eficiência de detecção normalmente é obtida: a) pela medida de fontes radioativas de nuclídeos com dados padronizados, ou seja, cujos gamas e raios- $x$ de decaimento tenham energias e intensidades por decaimento bem conhecidos, fazendo-se posteriormente o ajuste dos parâmetros de uma função empírica a fim de interpolar os valores de eficiência para as energias de interesse; b) por simulação Monte Carlo, onde as interações ao longo da trajetória dos fótons são acompanhadas, assim como os produtos das interações destes e as partículas secundárias, produtos dessas interações, e c) com expressões analíticas que descrevem a física das interações nos diferentes materiais que compõem o detetor. Note-se que os métodos b) e c) também requerem medidas para sua validação, embora não se necessite fontes de radiação que cubram uniformemente toda a região de interesse, o que reduz o esforço experimental envolvido.

O conhecimento prévio da resposta do detetor, que corresponde ao espectro registrado quando a fonte é monocromática, pode prover uma maneira de minimizar a quantidade de medições necessárias no processo de calibração. A resposta do detetor pode ser prevista pelos mesmos métodos mencionados para obtenção da curva de eficiência, isto é, experimentalmente com fontes radioativas, por simulação do transporte da radiação no cristal com diferentes códigos que utilizam técnicas de Monte Carlo (MC), por modelagem dos efeitos físicos que ocorrem no cristal ou por modelos híbridos de simulação e analíticos [81]. Aqui há dois grandes problemas do ponto de vista experimental, que dificultam a validação dos resultados dos modelos de detecção. Por um lado, são raras as fontes radioativas monocromáticas com meia vida adequada para uso rotineiro. Por outro lado, o resto do arranjo experimental e todo o ambiente provocam a indesejada detecção de fótons por espalhamento, o que, em alguns casos, é muito importante no cálculo da eficiência de detecção e da função resposta.

A calibração com fontes radioativas deve considerar os efeitos de soma de pulsos, associados à detecção de dois fótons, simultânea ou em um intervalo de tempo menor que a resolução temporal do sistema. Estes processos dependem da atividade da fonte, do arranjo experimental e do esquema de decaimento do nuclídeo medido, que podem chegar a ser muito significativos quando se posiciona a fonte de calibração perto do detetor. Há vários métodos, analíticos e empíricos, que consideram esses efeitos e se aplicam também a outros tipos de detetores [23. 26. 72, 8]. O código Monte Carlo desenvolvido por Sima e Arnold leva em conta correções para auto-atenuação e efeitos de soma e coincidência, fornecendo um bom ajuste, mas só para o pico de absorção total de energia [85].

Na calibração pelo método de Monte Carlo, a maioria dos autores modifica, além da espessura das camadas mortas, as dimensões do cristal em relação aos valores nominais fornecidos pelos fabricantes. Essa metodologia foi seguida por Guerra e Jurado-Vargas [47] com o código de transporte de partículas PENELOPE [76, 7, 84]. Outros testaram diferentes códigos Monte Carlo, como o GEANT, EGS4 e MCNP5 [55, 2, 17, 71] obtendo precisões entre 5 e $10 \%$. Em geral, nenhum desses métodos alcançou um nível ótimo de repetitividade para a calibração, já que sua acurácia depende de criar um modelo para cada detetor, por exemplo, Hardy e Helmer [38, 41, 40] conseguem precisões subpercentuais a custas de modificar o tamanho do cristal em função das energias das fontes de calibração.

Por outro lado, Utsunomiya e colaboradores [90] observaram eventos em que o fóton depo- 
sita toda sua energia no volume ativo do detetor, mas não é contada no pico de absorção total, o que foi atribuído a um dreno de elétrons da banda de condução para canais de superfície, o que faz com que parte da carga seja coletada após a geração do pulso, com a consequente coleção incompleta das cargas.

Eles propuseram um modelo empírico para a coleção incompleta de carga e realizaram a simulação com o código Monte Carlo EGS4. Com essa metodologia, não precisaram modificar o tamanho do cristal para reproduzir os valores experimentais do pico de absorção total, mas verificaram que, quando esses efeitos não eram introduzidos no modelo, era necessário alterar as dimensões fornecidas pelo fabricante. Concluíram que, se não forem feitas modificações substanciais nos valores nominais das dimensões relevantes do detetor, nem introduzidos esses efeitos de coleção incompleta de carga, é impossível reproduzir a realidade dos fenômenos observáveis do sistema de detecção, com as seções de choque das interações dos fótons e elétrons usadas no modelo.

D. Histórico das aplicações. A necessidade de realizar um estudo sistemático para a caraterização dos detetores foi, e continua, relacionada aos trabalhos de detecção e deconvolução do Bremsstrahlung de elétrons produzidos no Microtron de São Paulo, assim como as medidas de secções de choque de ionização por impacto de elétrons. As condições de operação propostas para o Microtron foram mudando, e não se pretende acelerar os elétrons até $31 \mathrm{MeV}$ em prazo curto. Dado que a linha de $6 \mathrm{MeV}$ também se atrasava e havia interesse da comunidade em conhecer com melhor precisão as secções de choque para elétrons de baixa energia, foi construída uma linha que usa os elétrons provenientes do canhão com energias de 10 a $100 \mathrm{keV}$ [91], desviando os elétrons antes da primeira estrutura aceleradora, o que nos obrigou a mudar de detetores para cobrir adequadamente essa faixa de energias. Aquelas condições de operação não foram definitivamente descartadas, pelo que continuamos com o objetivo de deconvoluir o espectro de Bremsstrahlung de elétrons, medir as seções de choque de ionização de diversos elementos para a ampla faixa de energia desde os $10 \mathrm{keV}$ até aquela que a máquina consiga fornecer, mas a maior parte do trabalho recente desenvolveu-se com a detecção de fótons de raios-x até $100 \mathrm{keV}$.

E. Relevância/contribuição. Este trabalho pretende estabelecer uma metodologia sistemática que ofereça a acurácia necessária às medidas no Microtron. É preciso destacar que este trabalho envolve uma grande colaboração entre seis laboratórios:

- Laboratório do Acelerador Linear, responsável pela construção e operação do Microtron do departamento de Física Experimental;

- Laboratório de Alvos Nucleares e Grupo de Dosimetria das Radiações e Física Médica, ambos do departamento de Física Nuclear;

- Laboratório de Análise de Materiais por Feixes Iônicos (LAMFI) do departamento de Física Aplicada;

- Laboratório de Materiais Magnéticos do departamento de Física dos Materiais, e

- Laboratório de Metrologia Nuclear 
este último do IPEN/CNEN-SP e os demais do Instituto de Física da USP. Os procedimentos, métodos e produtos desses Laboratórios usados nas pesquisas descritas aqui não só incorporam a competência específica de seus pesquisadores, como também foram seus técnicos que desenharam e construíram colimadores, alvos, substratos para alvos, suportes para fontes e alvos, dispositivos eletrônicos e outras peças importantes para o trabalho, sem os quais nada teria sido realizado.

Minha principal contribuição no trabalho experimental do Microtron está associada à obtenção dos padrões de intensidade de raios-x e gama, e sua transferência para medidas realizadas a partir dos espectros de fótons adquiridos por detetores semicondutores. Isso inclui a calibração e o modelamento dos detetores, colimadores e atenuadores empregados usando métodos analíticos e de simulação Monte Carlo, com o desenvolvimento de metodologias que permitiram alcançar resultados com precisão superior à dos experimentos relatados anteriormente na literatura.

Além desses trabalhos acerca das interações dos fótons e elétrons em experimentos com detecção de fótons, este documento relata as pesquisas em que se procurou avançar na compreensão dos mecanismos de detecção dos fótons, que determinam a função resposta e eficiência de detecção dos detetores usados.

F. Organização do texto. Este documento sistematiza um conjunto de trabalhos realizados a fim de atender as necessidades das pesquisas com o Microtron e apresenta o desenvolvimento da instrumentação usada nas aplicações específicas e que foram determinantes para sua realização. Como a prática da divulgação científica exige textos concisos, nos trabalhos publicados, os arranjos iniciais, resultados intermediários e medidas de validação dos métodos de análise somente são indicados, mas são essenciais no cotidiano do físico experimental e determinam a qualidade do resultado final. Assim, uma parte deste texto completa a descrição dos trabalhos efetuados, minimizando repetir o que consta nas publicações. Inclui também uma síntese das publicações efetuadas, descreve as tarefas importantes para o sucesso dos trabalhos que, no entanto, estão descritas sumariamente ou não foram incluídas nas publicações, pelos motivos mais variados, por exemplo: alongavam demais o texto; eram técnicas que, embora raramente empregadas, já estavam descritas na literatura; desviavam a atenção do que a publicação tinha de mais importante. Note-se que, à época de algumas dessas publicações, não se adotava o procedimento de incluir material complementar, o que agora é rotineiro.

Os capítulos depois desta Introdução estão organizados da seguinte forma:

A física da detecção de raios-x e gamas esboça elementos das interações dos fótons e elétrons com a matéria, abrangendo aspectos importantes para o funcionamento dos instrumentos, as questões que foram investigadas nos trabalhos concluídos e os pontos específicos dos métodos experimentais adotados que foram necessários para a determinação das grandezas de interesse, ainda que sejam tópicos elementares e conhecidos.

$\mathrm{Na}$ Instrumentação, depois de uma apresentação genérica dos detetores de radiação eletromagnética, o texto se concentra nos detetores semicondutores de fótons e delineia as propriedades que caracterizam os quatro tipos de detetores usados nos trabalhos publicados e definem a escolha feita em cada aplicação. Algum material dos artigos está reproduzido aqui, uma vez que nossas publicações representam avanços no entendimento da resposta desses detetores e 
não se encontram nos livros especializados.

Em Modelos de detecção de fótons, detalha-se a construção dos modelos de detecção baseados nas propriedades físicas das interações e suas probabilidades, associadas às características dos materiais dos arranjos de detecção, tanto por simulação Monte Carlo quanto pela obtenção de funções analíticas. Ambas as formas de encaminhar a construção dos modelos físicos foram usadas nos trabalhos.

O capítulo Investigação da resposta de detetores semicondutores descreve os trabalhos publicados com foco no instrumento e no estudo das interações dos elétrons com a matéria, incluindo material complementar, seja por não ter sido enviado à publicação na época, seja por que foi obtido posteriormente.

O texto Pesquisas que usaram o estudo dos detetores resume os artigos que relatam experimentos sobre as interações dos fótons e elétrons com a matéria, que dependeram da determinação experimental do fluxo de fótons, e deveram seu sucesso e precisão aos trabalhos descritos nos dois capítulos anteriores.

A Conclusão encerra o texto.

As referências bibliográficas foram ordenadas alfabeticamente pelo sobrenome do primeiro autor. 


\section{Capítulo 2}

\section{A física da detecção de raios-x e gamas}

A medição dos fótons produzidos no decaimento ou desintegração do núcleo representa um desafio, uma vez que são partículas neutras e bastante penetrantes, de modo que sua observação será sempre indireta e exigirá o uso de corpos extensos. Isso é um pouco menos verdadeiro para os raios-x, que são fótons produzidos em processos atômicos, particularmente no decaimento do átomo ionizado ou no bremsstrahlung de elétrons. Esses fótons trazem informação do sistema que os produziu, por exemplo, os raios-gama provenientes de estados ligados do núcleo atômico são praticamente monocromáticos enquanto os raios-x têm uma largura natural, como se verá nos espectros mostrados neste trabalho. Assim, a estrutura nuclear ou atômica se revela nos espectros medidos mesmo que a observação dos fótons não tenha o propósito de investigá-las, de modo que este capítulo começa com uma visão geral desse assunto, seguida pela discussão da produção de gamas e raios-x. Depois, aborda-se o conceito de seção de choque usado na quantificação das interações dos fótons e dos elétrons com a matéria, descritos nas últimas seções.

\subsection{O átomo}

Foi Niels Bohr quem primeiro descreveu o átomo de Hidrogênio quantizado, e propôs que os elétrons no átomo estão confinados a órbitas específicas, limitando as energias a valores quantizados e bem definidos. Mas a teoria de Bohr não podia explicar corretamente os níveis de energia de outros átomos ou íons com mais de um elétron ou, porque certas linhas de excitação eram mais intensas que outras, ou mesmo a estrutura fina de certas linhas. Assim, a mecânica quântica, desenvolvida por Schrödinger, Heisenberg, Born e Dirac permitiu descrever os átomos e núcleos, suas interações e características de uma maneira totalmente nova, baseada em probabilidades, obtidas pela solução da equação de onda, e regidos pelo princípio de incerteza. A equação de Schrödinger para sistemas estacionários leva à quantização da energia, já que ela fornece uma ou mais soluções para um determinado problema, e cada uma das funções de onda corresponde a um determinado valor de energia de acordo às condições de contorno de cada caso.

A interação que liga elétrons e núcleo no sistema atômico é conhecida — a interação Coulombiana - sendo possível encontrar um esquema geral abrangente para descrever as estruturas 
dos átomos de todos os elementos químicos. Os orbitais dos elétrons são diferenciados por quatro números quânticos. O principal, $n=1,2,3, \ldots$, indica a camada, relacionada à distância média ao núcleo do átomo, com os nomes $\mathrm{K}, \mathrm{L}, \mathrm{M}, \mathrm{N}, .$. respectivamente; pelo número de momento angular, que se relaciona com o formato do orbital e pode assumir valores inteiros até $n-1$, sendo que os valores $\ell=0,1,2,3,4, \ldots$ correspondem às subcamadas representadas respectivamente por $s, p, d, f, g$, seguindo em ordem alfabética. O terceiro número quântico separa os elétrons que ocupam a mesma camada e subcamada, e relaciona-se com o momento magnético orbital $\left(m_{\ell}\right)$ com valores $-\ell,-\ell+1, \ldots, \ell-1, \ell$; define a direção espacial do orbital. Finalmente, o momento magnético de spin $\left(m_{s}\right)$ que pode tomar os valores $1 / 2$ ou $-1 / 2$. O princípio de Exclusão de Pauli estabelece que dois elétrons em um átomo não podem ter os quatro números quânticos iguais, cada um deles está numa posição que caracteriza uma energia definida. $O$ fato da interação ser coulombiana faz com que as energias de ligação dos elétrons nas diferentes camadas seja aproximadamente proporcional a $\frac{\left(Z^{*}\right)^{2}}{n^{2}}$, em que $Z^{*}=Z-S$ é a carga efetiva, que é diminuída em relação à carga nuclear em consequência da blindagem pelos elétrons das camadas internas. Em uma aproximação que ignora a variação da blindagem com a distância ao núcleo, Clementi e Raimondi [21, 22] tabelam valores $S_{n \ell}$, dependendentes dos números quânticos principal e de momento angular, para átomos com 2 a 86 elétrons.

A descrição como feita até aqui, porém, ignora a interação spin-órbita, que acopla os momentos angulares orbital e de spin, de modo que, nos átomos neutros, é o momento angular total

$$
\mathbf{J}=\mathbf{L}+\mathbf{S}
$$

que é determinante; normalmente os estados de mesmo $\mathbf{J}$ e diferentes $J z$ são degenerados. $\mathrm{O}$ esquema desses níveis acoplados no átomo está representado na figura 2.1, em que cada nível é representado pelos números quanticos $n \ell j$, bem como pela notação atômica convencional. A energia do átomo é mínima quando ele está no estado fundamental, de modo que a configuração eletrônica deve ser tal que garanta esse mínimo, o que corresponde a preencher totalmente as camadas atômicas mais internas do átomo.

\subsection{O núcleo}

Núcleos são sistemas ligados formados por números inteiros de prótons, $Z$, e nêutrons, $N$, e possuem massa significativamente menor que a soma das massas dos seus constituintes isoladamente. O número de massa $A=Z+N$ é o número de núcleons. Os nuclídeos podem ser representados graficamente na chamada carta de nuclídeos [50], que aparece na figura 2.2. Cada quadrícula no plano representa um nuclídeo, com os números de nêutrons $N$ e prótons $Z$ definidos pelas abscissa e ordenada, respectivamente. Assim, cada linha horizontal representa a família de isótopos de um elemento definido pelo seu número de prótons, e cada linha vertical define uma família de isótonos, que correspondem a átomos com igual número de nêutrons. Na 


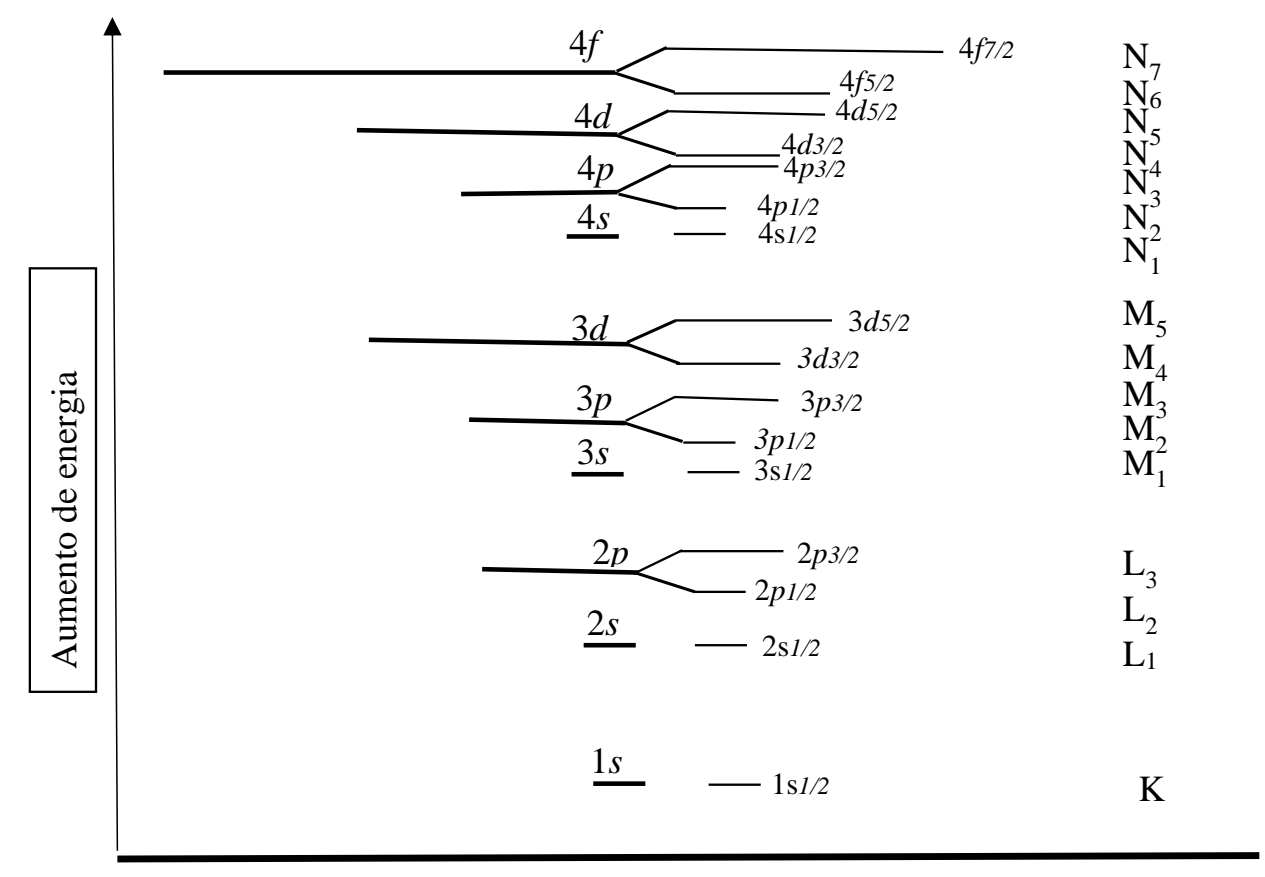

Figura 2.1: Níveis de energia dos elétrons das camadas internas de um átomo hipotético; para os elétrons de valência, a ordem desses níveis pode ser diferente. Energias fora de escala, mas o comprimento de cada linha é proporcional ao número de elétrons que podem ocupar o mesmo orbital.

diagonal com $Z=N$ encontram-se os nuclídeos simétricos, as paralelas à diagonal principal aqueles com mesmo número isobárico $I=N-Z$ (que pode ser positivo ou negativo, denotando o excesso de prótons ou nêutrons), e nas diagonais secundárias estão os isóbaros (nuclídeos com igual número de núcleons, mas com diferente $Z$ ). Na natureza, há uma grande quantidade de elementos radioativos, mas muitos mais podem ser criados.

Os elementos que estão no menor nível de energia possível para um dado número de massa A e que são estáveis aparecem em cor negra, na figura 2.2. Os outros, estão em estado excitado e perdem a energia sobrante pela emissão de variados tipos de radiação. É a combinação de diferentes tipos de interação: eletromagnética (predominantemente de repulsão entre os prótons), nuclear forte (predominantemente atrativa entre todos os núcleons) e nuclear fraca, que permite a existência dos diferentes elementos químicos e seus isótopos, tais como aparecem na carta de nuclídeos.

Uma das primeiras características estudadas dos núcleos foi a determinação da energia de separação do nêutron ou próton, que é a energia necessária para remover o último núcleon. Verificou-se que aparecem picos de energia nos chamados núcleos mágicos cujo número de prótons ou nêutrons são 2, 8, 20, 28, 50, 82, 126 e 184 (estes dois últimos destinados só para nêutrons). Eles possuem uma série de características particulares como: há mais isótopos estáveis se o número de prótons é mágico e mais isótonos se o número de nêutrons é mágico; se o número de nêutrons é mágico, a secção de choque de absorção de nêutrons é menor que outros 


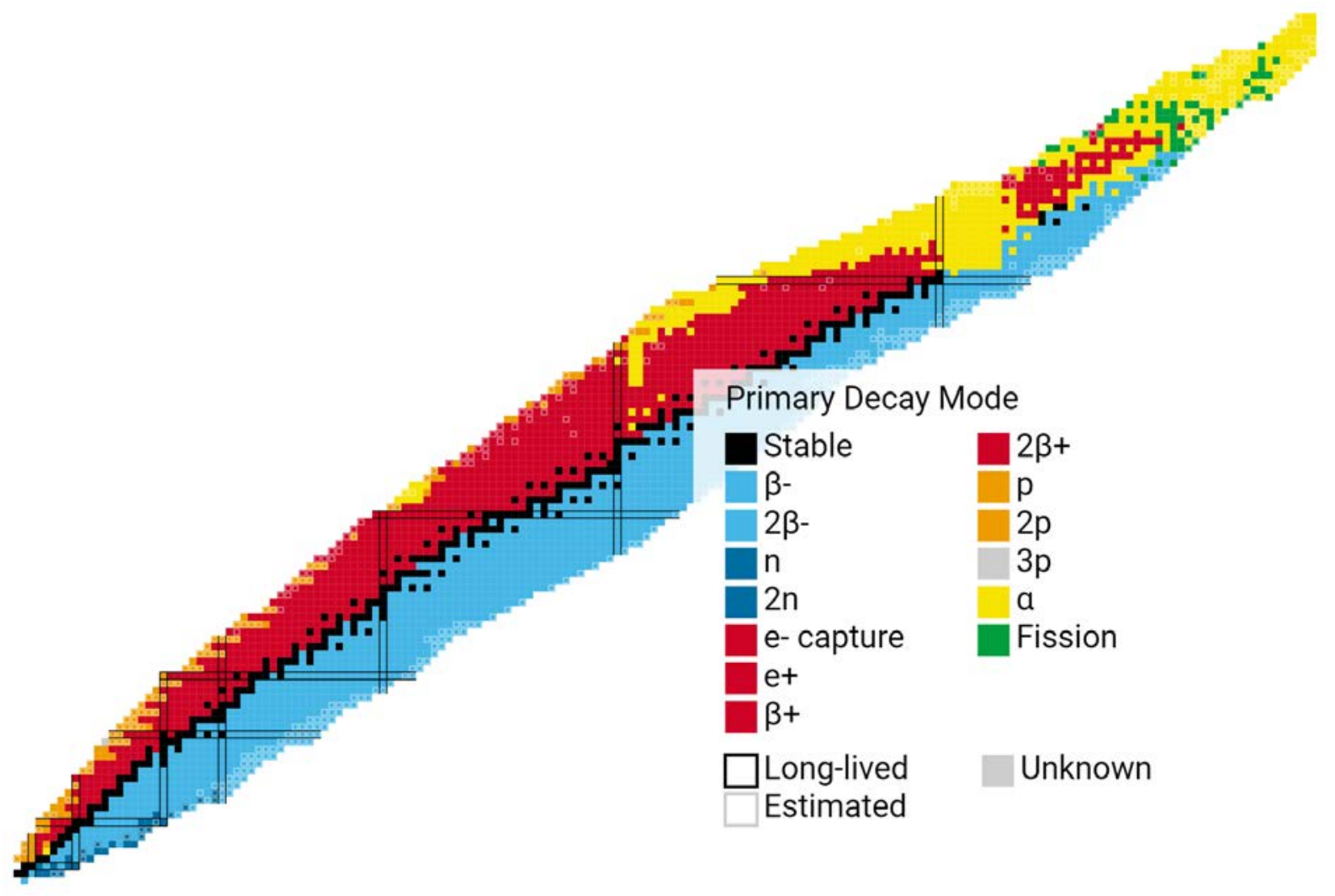

Figura 2.2: Tabela de nuclideos, ref [50]. https://people.physics.anu.edu.au/ ecs103/chart/

núcleos e, finalmente, elementos com um número mágico de prótons são mais abundantes na natureza que os elementos vizinhos. A energia de separação do último núcleon varia com os números de nêutrons e prótons, mas, com exceção dos núcleos muito leves, situa-se em torno de $10 \mathrm{MeV}$.

A interação nuclear, ao contrário da Coulombiana, é de curto alcance e fortemente repulsiva quando os núcleos estão muito próximos, de modo que o núcleo tem um raio bem definido, $R \approx r_{0} A^{1 / 3}$ e $r_{0} \sim 1,2 \mathrm{fm}$. Os dois modelos que descrevem a estrutura básica dos núcleos são:

a) O modelo da gota líquida propõe estimar os valores médios das grandezas nucleares, usando o fato do volume do núcleo ser proporcional ao número de núcleons, assim como o volume de um líquido é proporcional ao número de moléculas. Considera que os prótons são distinguíveis dos nêutrons e supõe que ocupem níveis de energia com uma separação constante. Os efeitos observados a energias acima do nível fundamental podem ser interpretados como movimentos de oscilação e distorção de uma gota. Descreve bem a instabilidade dos núcleos pesados, que pode levar à fissão espontânea ou induzida pela captura de uma partícula, como um nêutron, quando a deformação da superfície seja suficiente para provocar a fissão. Este modelo não se aplica a núcleos leves, $\operatorname{com} A<20$, nem permite descrever as energias de ligação dos átomos com número mágico de nêutrons ou prótons.

b) O modelo de camadas, similar ao do átomo com os elétrons localizados em camadas, justifica a existência dos números mágicos, havendo, porém, camadas separadas para 
prótons e nêutrons. Este modelo considera que cada núcleon se movimenta de forma independente no potencial médio dos demais núcleons e é sujeito ao princípio de exclusão de Pauli, com uma variação média do potencial suave, devido à presença de todos os outros núcleons. O potencial do oscilador harmônico serve de aproximação de ordem zero desse potencial médio, uma vez que define uma superfície para o núcleo; a energia de separação das camadas é $\hbar \omega \sim 41 A^{-1 / 3} \mathrm{MeV}$, e um estado da camada $N$ tem energia $(N+3 / 2) \hbar \omega$, com $N \geq 0$ e paridade $(-1)^{N}$, portanto alternando camadas de paridade + com - . O momento angular orbital, $\ell$, é restrito a zero ou inteiros positivos até $(N)$, somente os valores pares ou ímpares, conforme a paridade da camada. A interação spinórbita no núcleo tem natureza diferente daquela no átomo e favorece energeticamente o estado $j=\ell+1 / 2$, ao contrário do átomo, e é mais intensa, o suficiente para que o estado de maior momento angular da camada $N, j=\ell_{\max }+1 / 2=N+1 / 2$, tenha energia semelhante aos estados da camada $N-1$. Assim, embora o potencial nuclear não misture paridades como o atômico, cada camada nuclear tem um orbital de paridade oposta à paridade natural da camada, chamado orbital intruso. O estado de cada núcleon pode ser identificado por $n, \ell$ e $j$ em que $n$ numera os orbitais de mesmo momento angular em ordem crescente de energia, começando em 1.

O modelo de camadas descreve bem os estados fundamentais dos núcleos, mas exige a consideração de muitas configurações para descrever adequadamente a maior parte dos estados excitados, a ponto de frequentemente não ser útil para essa finalidade. É possível uma descrição precisa dos núcleos considerando-se modos normais do movimento conjunto dos núcleons, em particular os modos rotacionais e vibracionais.

\subsection{Produção de fótons em processos atômicos e nucleares}

Da figura 2.2 pode-se concluir que há um grande número de nuclídeos, a maioria deles radioativos, naturais ou criados. Cada nuclídeo radioativo possui características particulares como tipo de radiação a emitir, a energia de excitação que possui, a energia que a radiação vai carregar e o tempo médio para o decaimento, caracterizado pela meia-vida, que é o intervalo em que o número inicial de átomos se reduz à metade. A figura 2.3 [28] mostra um esquema da reação usada para obter os fótons de $6,128 \mathrm{MeV}$, após a emissão de uma partícula $\alpha$ pelo ${ }^{20} \mathrm{Ne}$, usados em alguns dos nossos trabalhos [63, 62, 64, 89].

\subsubsection{Processos de produção de fótons}

A lista abaixo relaciona os processos de produção de fótons, começando com mecanismos basicamente atômicos ou nucleares, passando por aqueles em que uma interação no núcleo dispara um processo atômico e termina com os basicamente eletromagnéticos.

a) Colisão elétron-átomo e Colisão fóton-átomo. Denomina-se raio-x ao fóton produzido em um fenômeno atômico, particularmente no preenchimento de uma vacante eletrônica ou na colisão de um elétron com o átomo, que analisaremos neste trabalho. As energias 


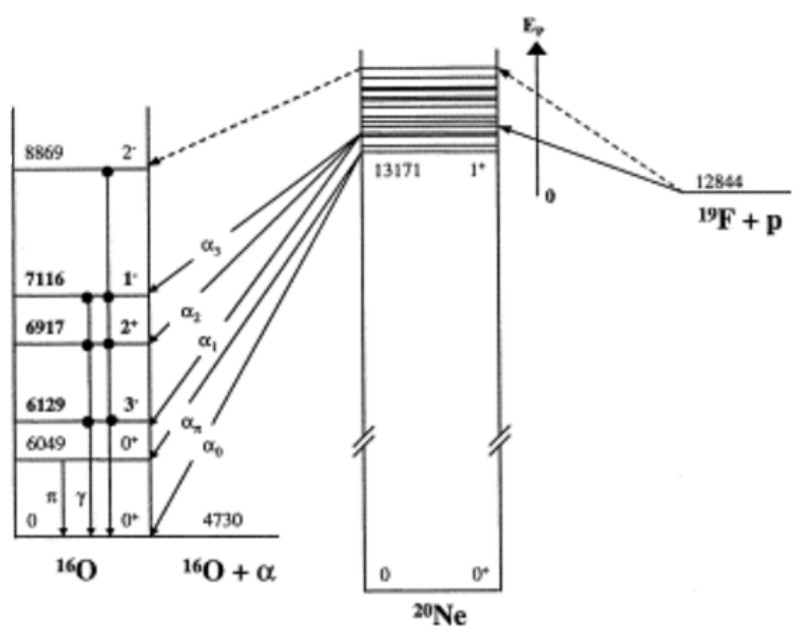

Figura 2.3: Esquema dos níveis de energia do ${ }^{20} \mathrm{Ne}$, após a captura de um próton pelo ${ }^{19} \mathrm{~F}$. Após a fissão desse núcleo em ${ }^{16} \mathrm{O}$ e uma partícula $\alpha$, que pode possuir diferentes energias cinéticas, o núcleo residual está em um dos níveis excitados caracterizados pelos spins que aparecem na figura. [28]

dos raios- $x$ nos experimentos que realizamos cobriram uma faixa que abrange desde poucos $\mathrm{keV}$ até $100 \mathrm{keV}$. Não há uma divisão energética clara entre raios-x e $-\gamma$, que são diferenciados pelo fenômeno que os produziu.

A radiação de freamento (Bremsstrahlung) é um dos processos de perda de energia dos elétrons ao interagir com a matéria. É produzida quando um elétron (ou pósitron) colide ou passa pelo campo elétrico de um átomo e sofre uma aceleração que dá lugar a emissão de radiação, normalmente chamada radiação de freamento (porque, ao final, o elétron perde energia). Nesse percurso, a partícula passa de uma energia cinética $E_{0}$ e quantidade de movimento $\overrightarrow{p_{1}}$, a uma energia cinética $E_{e}$ e quantidade de movimento $\overrightarrow{p_{2}}$, emitindo de maneira brusca um fóton de energia $W$ e quantidade de movimento $\vec{k}$ [39]. Se o estado do átomo não variar durante esse processo, a quantidade de movimento transferida, $\vec{q}$, é $\vec{q}=\vec{p}_{1}-\overrightarrow{p_{2}}-\vec{k}$.

Se $M$ for a massa do alvo e $m_{e}$ a do elétron, pode-se obter a energia de recuo do núcleo como $E_{r} \approx \frac{q^{2}}{2 M}$, que pode ser desconsiderada para valores de $E_{0} \ll \frac{\left(M c^{2}\right)}{2} A \approx 469 A \mathrm{MeV}$ (com $A=$ número de massa do núcleo). Assim, a energia desse fóton é $W \approx E_{0}-E_{e}$. Entendemos assim que a energia do fóton (quantum de luz) depende da energia inicial do projétil e da quantidade de movimento transferido, de maneira que o espectro gerado é contínuo e abrange energias desde próximas a zero $\mathrm{keV}$ até a energia máxima do espectro, que corresponde à energia cinética do projétil $E_{0}$; nessa energia, a intensidade não é nula e a porção do espectro na sua vizinhança é denominada "tip" (quando toda energia cinética do elétron é transferida a um fóton). Seltzer e Berger [82] tabelaram as secções de choque de Bremsstrahlung para energias de $1 \mathrm{keV}$ a $1 \mathrm{GeV}$, para átomos com número atômico $Z$ entre 1 e 100 .

Sobreposto a esse espectro contínuo, encontram-se os picos de raios-x característicos associados aos elementos do alvo. Sua emissão se dá quando um elétron, ao atravessar o material, colide com um elétron orbital e cede parte da sua energia a este, expulsando-o do átomo. Assim, este processo possui uma energia de limiar que depende da camada e 
subcamada onde se localizava o elétron ejetado. O buraco deixado pelo elétron ejetado é preenchido por outro de uma camada mais distante, de maneira que a diferença de energia entre essas camadas define a da transição, que nem sempre é radiativa; no processo de rearranjo dos elétrons durante a desexcitação, um outro elétron atômico pode ser emitido, carregando como energia cinética a diferença das energias de ligação - os chamados elétrons Auger. A razão entre as intensidades da transição radiativa e total é chamada yield fluorescente. Essas transições nas camadas mais internas, que obedecem às regras de seleção, são muito rápidas, de modo que as transições atômicas têm largura apreciável, variando exponencialmente de $1 \mathrm{eV}$ para $100 \mathrm{eV}$ quando $Z$ varia de 20 a 90 [52]. Como essas larguras são próximas da resolução do detetor, os picos de raios-x de elementos de $Z>20$ apresentam caudas decorrentes do perfil Lorentziano de emissão.

b) Transição nuclear eletromagnética. Os chamados raios gama são fótons provenientes das transições entre níveis do mesmo nuclídeo; no caso da figura 2.3, viriam das transições entre os níveis do ${ }^{16} \mathrm{O}$. Assim, quanto seguem o decaimento nuclear de um radioisótopo, sua energia é necessariamente menor que a energia disponível para o decaimento. Se diz ser caraterístico, porque, a menos de um pequeno recuo do núcleo residual, leva a energia da diferença de níveis própria de cada nuclídeo. Genericamente se expressa esse decaimento com:

${ }_{Z}^{A} X^{*} \rightarrow{ }_{Z}^{A} X^{(*)}+\gamma$

O nuclídeo residual pode, por sua vez, continuar excitado e decair emitindo um novo fóton gama. As energias desses fótons variam entre uns poucos $\mathrm{keV}$ e vários $\mathrm{MeV}$, mas aqueles com energia maior normalmente seguem decaimentos de radioisótopos com meias vidas muito curtas e são medidos online, enquanto os usados como fontes de calibração para espectroscopia gama não ultrapassam os $5 \mathrm{MeV}$. A probabilidade de acontecer esse tipo de transição é função, além da energia, do momento angular e da paridade dos níveis inicial e final, havendo regras de seleção. Os estados ligados dos núcleos têm meias vidas relativamente longas, quase sempre maiores que $\sim 1 \mathrm{ps,} \mathrm{chegando} \mathrm{a} \sim 1 \mathrm{fs}$ em casos particulares, como veremos adiante no decaimento do ${ }^{16} \mathrm{O}$ produzido na desintegração do ${ }^{20} \mathrm{Ne}$. Assim, a largura em energia de um nível nuclear ligado é menor ou da ordem de um $\mathrm{eV}$, portanto seis ordens de grandeza abaixo da sua energia e algumas ordens de grandeza abaixo da resolução dos detetores, de modo que os fótons que seguem os decaimentos nucleares podem, para todos os efeitos práticos, serem considerados monocromáticos.

Os nuclídeos que, na sequência da desintegração, emitem fótons de energias mais altas são produto de reações nucleares, seja em um reator ou em um acelerador; esse decaimento é geralmente detectado em linha com a máquina nuclear. Algumas reações (n, $\gamma$ ), ( $\mathrm{p}, \gamma$ ) e aquelas com feixe de íons pesados produzem elementos com energias de excitação tais que podem emitir fótons com energias acima de $5 \mathrm{MeV}$. Alguns dos trabalhos desta compilação foram feitos no acelerador tipo Pelletron-Tandem do Laboratório de Análise de Materiais por Feixes Iônicos (LAMFI-USP) [LAMFI], na ocasião da deteção de fótons com energias até $\sim 12 \mathrm{MeV}$ [37]. 
c) Criação interna de pares. Este processo, que corresponde a transições de monopolo elétrico, foi descrita por Wilkinson em 1969 [92]. Quando o núcleo excitado decai para outro de mesmo spin e paridade, é possível ocorrer a emissão de um par elétron-pósitron, se existir uma diferença de energia entre os níveis superior a $2 m_{e} c^{2}$ :

${ }_{Z}^{A} X^{*} \rightarrow{ }_{Z}^{A} X^{(*)}+e^{+}+e^{-}$

As probabilidades de transição nuclear para a formação do par são muito menores que as dos outros processos de decaimento eletromagnéticos, mas pode chegar a ser apreciável no caso em que a emissão de fótons seja proibida, nas transições $0^{+} \rightarrow 0^{+}[92]$; um exemplo é o decaimento do estado do ${ }^{16} \mathrm{O}$ com $6049 \mathrm{keV}$ de energia de excitação, representado na figura 2.3 e que influiu no planejamento do arranjo experimental das medidas descritas na seção 5.1.2. Esse processo gera fótons na subsequente aniquilação do pósitron, descrita no item f) mais abaixo.

d) Conversão interna. Durante uma transição eletromagnética, a energia de excitação do núcleo pode ser transferida a um elétron orbital, que é ejetado com uma energia cinética equivalente à energia da transição menos a energia de ligação desse elétron (e a de recuo do núcleo, que normalmente pode ser ignorada). A vacância deixada pelo elétron ejetado é preenchida por outro de camadas mais externas, com a consequente emissão dos raios-X caraterísticos (processo a) acima). Os elétrons da camada $K$ possuem maior probabilidade de serem ejetados quando a energia da transição é suficiente, mas outros de camadas mais distantes também podem levar a energia de excitação do núcleo, assim, este processo gera grupos de linhas de conversão no espectro de elétrons e raios-x de muitas energias no espectro eletromagnético.

e) Captura eletrônica. Esta é uma das formas do decaimento beta, em que um núcleo excitado diminui sua energia interna capturando um elétron orbital. Além da emissão dos raios-x característicos quando há o preenchimento da vacância decorrente da captura por um elétron de uma camada mais externa, o elétron, ao ser capturado, pode, com probabilidade relativamente baixa, gerar fótons de Bremsstrahlung e produzir um espectro contínuo de energia, chamado Bremsstrahlung interno.

f) Aniquilação elétron-pósitron. Um pósitron pode aniquilar-se com um elétron do meio gerando os chamados fótons de aniquilação, simbolizados $\gamma_{ \pm}$. Quando o pósitron, com energia cinética nula, se aniquilar com um elétron parado, os fótons de energia $E=$ $m_{e} c^{2} \approx 511 \mathrm{keV}$ cada, irão sair em direções opostas. A aniquilação do pósitron pode se dar em voo ou após termalizar no meio, sendo que é o segundo processo que interessa neste trabalho e é detalhado a seguir. Como os elétrons do meio estão ligados ao material, com uma energia de ligação $B_{i}$, em que $i$ identifica a camada atômica ou banda de ligação do elétron, as energias dos fótons somam $2 m_{e} c^{2}-B_{i}$. Além disso, considerando a quantidade de movimento do elétron ligado, os fótons de aniquilação levarão essa quantidade de movimento (ou o que é equivalente, apresentarão deslocamentos Doppler), de modo que provavelmente um terá energia acima dos $511 \mathrm{keV}$ esperados e o outro, abaixo, além de que não serão emitidos em direções exatamente opostas. Esse espectro complexo pode 
ser observado em experimentos em coincidência como aqueles dos trabalhos [66, 67], obtidos em nosso grupo de pesquisa.

Apesar da energia média desse fóton ser conhecida, ele não é usado como padrão para energia por causa do deslocamento em energia do pico que depende do material em que ocorre a aniquilação, que é causado pela energia de ligação do elétron. Também não é usado na calibração em eficiência de pico, pois normalmente o pico possui caudas e uma largura a meia altura (FWHM) bastante superior aos picos dos fótons de decaimento, o que, aliás, o torna facilmente distinguível nos espectros.

\subsubsection{Seção de choque como medida da interação da radiação com a ma- téria}

A secção de choque descreve quantitativamente o processo de colisão ou interação de partículas e fornece a medida da probabilidade de ocorrência desse processo. Ela pode ser definida como a relação entre o número de partículas incidente e número de possíveis centros de interação por unidade de tempo e área do alvo. Os modos de interação da radiação com a matéria dependem do projétil e do material do meio, seja um núcleo, um átomo como um todo ou algum elétron ligado, isto é, o processo depende do canal habilitado para tal. Essas probabilidades estão governadas pelas leis da mecânica quântica. A intensidade relativa depende das interações básicas envolvidas, das energias das partículas incidentes e de outras propriedades das partículas participantes, tal como seus spins.

As interações das partículas carregadas, como os prótons, alfas, íons pesados e elétrons, se dão predominantemente por múltipla colisão do íon com átomos do meio; em cada uma, o íon transfere uma pequena quantidade de energia para o meio pela ionização e/ou excitação dos átomos do alvo, até que a partícula carregada seja freada totalmente. A taxa de perda de energia por unidade de comprimento, chamado "poder de freamento" $\left(-\frac{d E}{d x}\right)$, é uma caraterística do íonmeio, e existem tabelas obtidas de cálculos empíricos para materiais alvo e projéteis em função da energia do íon ou elétron.

A probabilidade dos processos de interação com nêutrons e fótons também depende da energia destes, mas são muito diferentes daqueles que ocorrem com partículas carregadas. Podem acontecer processos de captura (n, $\gamma$ ), captura com emissão de outro nuclídeo, $(n, 2 n)$, $(n, p),(n, \alpha),(\gamma, n),(\gamma, p),(\gamma, \alpha)$ espalhamento $\left(n, n^{\prime}\right)$, formação de "núcleo composto", etc., que podem levar a formação de outros núcleos estáveis ou não, mas normalmente excitados, que emitem fótons, partículas ou ambos no processo de decaimento.

A seção de choque para a interação $C, \sigma_{t o t}^{C}$, é definida de modo que o número de partículas que interagiram, $N_{\text {tot }}^{C}$, se relaciona com o número $n_{A}$ de partículas incidentes sobre um alvo que tem um número de centros de reação por unidade de área $n_{b}$ pela expressão [18]:

$$
N_{\text {tot }}^{C}=n_{A} n_{b} \sigma_{\text {tot }}^{C}
$$


Se considerarmos a soma das seções de choque para todos os canais de interação habilitados para esse feixe incidente com uma determinada energia, $\sigma_{t o t}$, o número total de interações é:

$$
N_{t o t}=N_{A} n_{b} \sigma_{t o t}
$$

Consideremos agora o caso de um feixe de $N$ partículas, monoenergético, que incida perpendicularmente sobre um alvo com $n$ partículas por unidade de área, fino o suficiente para que se possa considerar que cada partícula do feixe interage uma única vez. O feixe tem diâmetro menor que o alvo, de modo que $N$ é o valor integrado na área do feixe, bem como no tempo, exatamente como se procede na prática. Se $d N^{\prime}$ for o número de partículas espalhadas em um diferencial de ângulo sólido $d \Omega$ na direção $(\theta, \phi), \operatorname{com} \theta$ e $\phi$ as coordenadas polares em relação à direção $z$ do feixe incidente, encontramos:

$$
d N^{\prime}=N n \sigma(\theta, \phi) d \Omega
$$

$\operatorname{com} d \sigma(\theta, \phi)=\sigma(\theta, \phi) d \Omega=\frac{d \sigma}{d \Omega} d \Omega$ a seção de choque diferencial. Podemos obter a seção de choque total se levarmos em conta todos os ângulos, assim:

$$
\sigma_{t o t}=\int \frac{d \sigma}{d \Omega}(\theta, \phi) d \Omega=\int_{0}^{2 \pi} d \phi \int_{0}^{\pi} d \theta \operatorname{sen} \theta \frac{d \sigma}{d \Omega}(\theta, \phi)
$$

A seção de choque se relaciona com o caminho livre médio de uma partícula em um meio, que é um parâmetro importante na fabricação e caracterização de detetores, espessuras de alvos, e estimativas de doses. Essa relação será explorada na próxima seção.

No nosso caso, a secção de choque (seja de Bremsstrahlung ou de ionização de camadas atômicas) é determinada experimentalmente do número de fótons de interesse observados pelo detetor, $N_{r}$. Por sua vez, para conhecer a quantidade de fótons emitidos pelo alvo como consequência da interação dos elétrons do feixe com os átomos deste, devemos saber:

1. O ângulo sólido subtendido pelo detetor (ou colimador) $\Omega$.

2. O número de elétrons que atingem o alvo, $N_{e}$.

3. O número de átomos por unidade de volume do alvo, $N_{V}$.

4. A espessura do alvo, $\delta$.

5. O ângulo $\alpha$ entre a direção normal à superfície do alvo e a direção do feixe de elétrons.

6. A eficiência intrínseca do detetor para o fóton de energia $E_{x}, \varepsilon\left(E_{x}\right)$. 


$$
\sigma_{r}\left(E_{e}\right)=\frac{\cos \alpha 4 \pi N_{r}}{N_{V} N_{e} \delta \Omega \varepsilon\left(E_{x}\right)}
$$

\subsubsection{Caminho livre médio}

É definido como a distância média que uma partícula percorre entre colisões sucessivas que modificam sua direção, energia ou outras propriedades, portanto tem unidade de comprimento. Está associado à probabilidade de uma partícula atravessar uma distância $x$ no material que contenha vários centros de interação, sem interagir. Também pode-se interpretar como a probabilidade de sobrevivência entre a coordenada $x$ e $x+d x$, dada pela expressão [54]:

$$
P(x+d x)=P(x)\left(1-\sigma N_{V} d x\right)
$$

onde $P(x)$ é a densidade de probabilidade (por unidade de comprimento) de não interagir até a distância $x$, e $\sigma N_{V} d x$ é a probabilidade de ter uma interação entre $x$ e $x+d x$. Daí se deduz

$$
P(x)=\sigma N_{V} e^{-\sigma N_{V} x}
$$

já propriamente normalizada. A probabilidade que a partícula não tenha sofrido nenhuma colisão após um deslocamento $x$ cai exponencialmente com a distância percorrida.

Pode assim ser calculada a distância $\lambda$, que é o valor médio da distância entre interações sucessivas, denominado caminho livre médio:

$$
\lambda=\frac{\int x P(x) d x}{\int P(x) d x}=\frac{1}{N_{V} \sigma}=\frac{1}{\Sigma}
$$

que está relacionada à densidade dos centros de interação e à secção de choque para pequenas espessuras $\delta$. A grandeza $\Sigma$ é chamada seção de choque macroscópica.

\subsection{Mecanismos de interação da radiação eletromagnética e suas manifestações na detecção}

A radiação eletromagnética interage com a matéria por alguns mecanismos:

- efeito fotoelétrico, onde, em uma única colisão, o fóton transfere toda sua energia. 
- espalhamento incoerente (Compton), no qual o fóton transfere parte da sua energia a um elétron.

- espalhamento coerente (Rayleigh), onde o fóton não perde energia nem outros elétrons são ejetados do átomo na colisão.

- formação de pares, que ocorre principalmente no campo elétrico do núcleo, em que o fóton desaparece e são criados um elétron e um pósitron; o mesmo acontece no campo elétrico do elétron, mas a probabilidade, no conjunto dos elétrons do átomo, é muito menor.

- reações fotonucleares, que não serão tratadas no presente trabalho por nos centrarmos em energias muito abaixo do limiar de sua produção, já que para esse tipo de interação os fótons devem possuir energias acima dos $5 \mathrm{MeV}$.

Para essas interações, a seção de choque macroscópica $\Sigma$ da relação 2.9 é conhecida como coeficiente de atenuação linear, simbolizada por $\mu$. Os gráficos dos coeficientes de atenuação de fótons em função da energia para o Ge podem ser observados na figura 2.4, com os saltos característicos nas energias de ligação das camadas eletrônicas do elemento químico; os dados foram obtidos de [76].

\subsubsection{Efeito Fotoelétrico}

A teoria corpuscular de Einstein, em 1905, propôs que a luz podia ser interpretada como consistente de partículas, quanta ou fótons que carregam a energia $E=h v=h c / \lambda$ (com $h$, a constante de Planck $=6,626 \cdot 10^{-34} \mathrm{~J} \cdot \mathrm{s}=4,135 \cdot 10^{-15} \mathrm{eV} \cdot \mathrm{s}$ e $v$ a frequência do fóton).

No processo de depósito de energia da radiação eletromagnética na matéria está o chamado Efeito Fotoelétrico, esquematizado na figura 2.5. Nele, um fóton de energia $E$ colide com um elétron orbital com energia de ligação, $B_{i}$, ejetado do átomo com uma energia cinética dada pela diferença entre a energia original do fóton, $E$, e a energia de ligação desse elétron:

$$
E_{\text {cin }}=E-B_{i}
$$

O elétron ejetado no processo de interação do fóton com a matéria deixa um buraco na camada $K, L$, etc. que estava ocupada pelo elétron ejetado. Esse buraco é preenchido por um elétron de camadas mais afastadas com mais energia. Nesse processo, a diferença de energia entre as camadas pode ser liberada na forma de um raio-x caraterístico, que permite identificar cada elemento.

A fim de gerar um evento correspondente a toda a energia do fóton incidente, é necessário que o fotoelétron deposite toda a energia no volume ativo e que o raio-x característico proveniente do preenchimento da vacância interaja com os outros elétrons e também deposite toda sua energia na região sensível do detetor. Os eventos em que toda a energia do fóton incidente é depositada no volume ativo do detetor formam o pico de absorção total. 


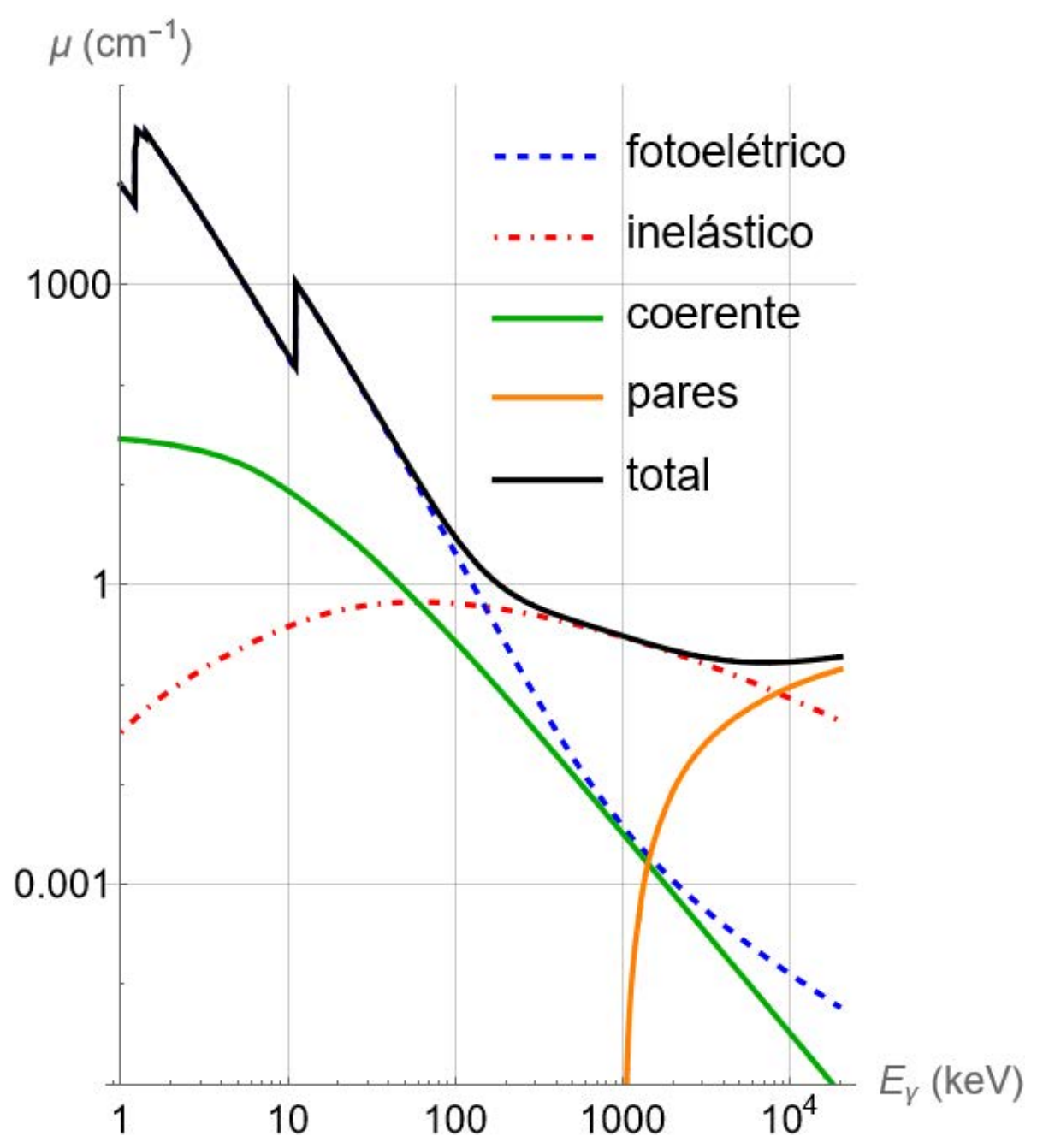

Figura 2.4: Secções de choque para os processos de espalhamento elástico, fotoelétrico, Compton e criação de pares em função da energia do fóton, para Germânio [76].

Se esse raio-x não produzir outra interação no volume ativo do detetor, a energia depositada no cristal será igual à diferença entre a energia da radiação original e a energia desse raio-x, de maneira que o evento adicionará uma contagem não mais no pico de absorção total, mas no chamado pico de escape daquele raio-x que escapou, $\mathrm{K} \alpha$ ou $\mathrm{K} \beta$.

Esses picos se encontram à esquerda do pico de absorção total, como pode ser observado na figura 2.6. A contagem computa-se no chamado pico de escape e representa a perda de um evento no pico de absorção total. Também é computada como perda quando o fotoelétron ejetado escapa do volume ativo sem interagir. Isso acontece quando a primeira interação se dá próxima à superfície do cristal, nas imediações da camada morta.

Detetores de raios- $\mathrm{x}$ fabricados a partir de cristais de Germânio costumam ter forma cilíndrica com $\approx 1 \mathrm{~cm}$ de espessura, chamados planares, com camadas mortas frontais muito finas, da ordem de micrômetros. Mudanças na espessura dessas camadas afetam em grande medida a detecção desses raios, principalmente quando possuem energias abaixo dos $50 \mathrm{keV}$. Os escapes produzem uma queda na eficiência de detecção, como pode ser observado na figura 2.7, que detalha a eficiência intrínseca de detetores planares com elementos ativos e janelas de Be de espessuras variadas, para o pico de absorção total em função da energia dos fótons. Nela se 


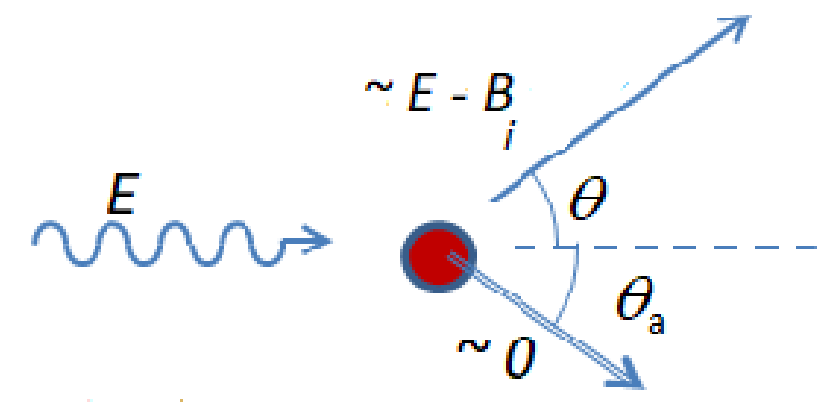

Figura 2.5: Esquema do efeito fotoelétrico. O fóton de energia $E$ interage com um elétron orbital, com energia de ligação $B_{i}$, de maneira que a energia cinética do elétron ejetado é $E^{\prime}=E-B_{i}$. Logo após a vacância deixada por esse elétron é preenchida. [76]
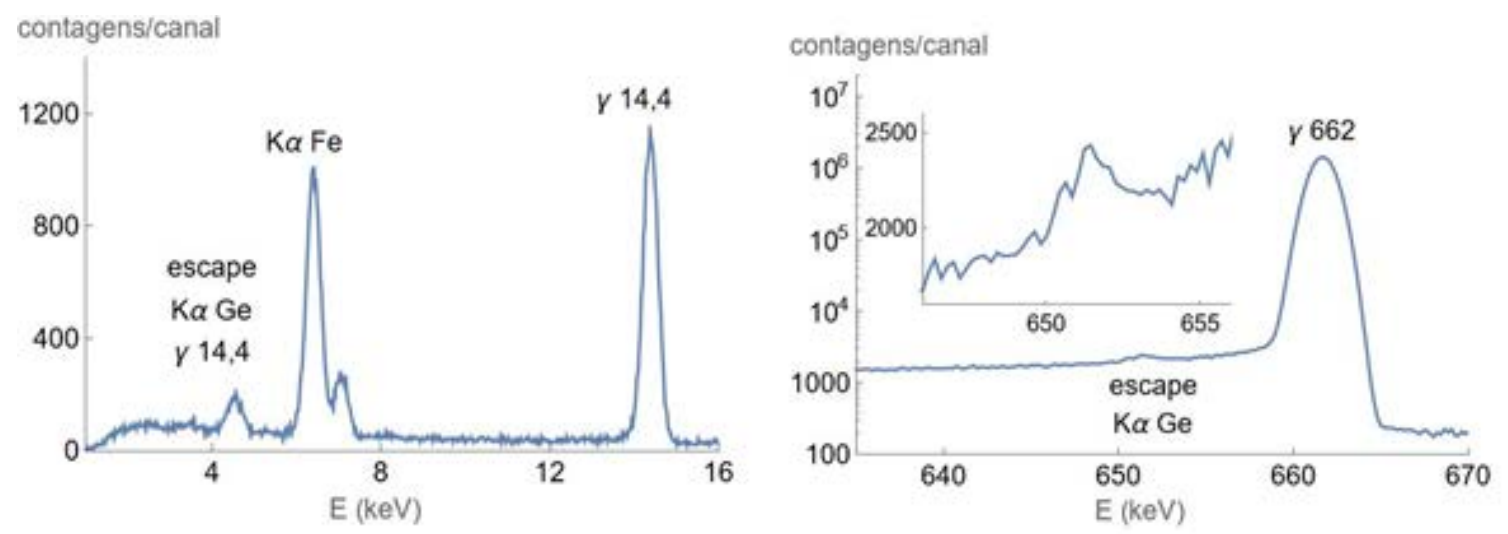

Figura 2.6: À esquerda, o espectro de ${ }^{57} \mathrm{Co}$ com um detetor planar e à direita o espectro de ${ }^{137} \mathrm{Cs}$ com um detetor coaxial de HPGe de grande volume, em que se observam os picos de escape do $\mathrm{K} \alpha$ do Ge.

observa a queda brusca da eficiência na energia de $11 \mathrm{keV}$, correspondente à energia de ligação da camada $K$ do Ge. A figura também inclui a eficiência de um detetor de Ge de grande volume, com janela de $\mathrm{C}$, que, uma vez colimado, foi usado nas medidas de bremsstrahlung de elétrons, detalhada adiante.

\subsubsection{Efeito Compton}

O espalhamento Compton é uma colisão inelástica com um elétron do cristal, em que apenas uma fração da energia é transferida, com, em geral, uma brusca mudança na energia do fóton. A energia que o elétron adquire na colisão é depositada no cristal, e o evento fará parte do contínuo do espectro, se o fóton espalhado não interagir novamente de maneira a depositar toda sua energia no volume ativo. 


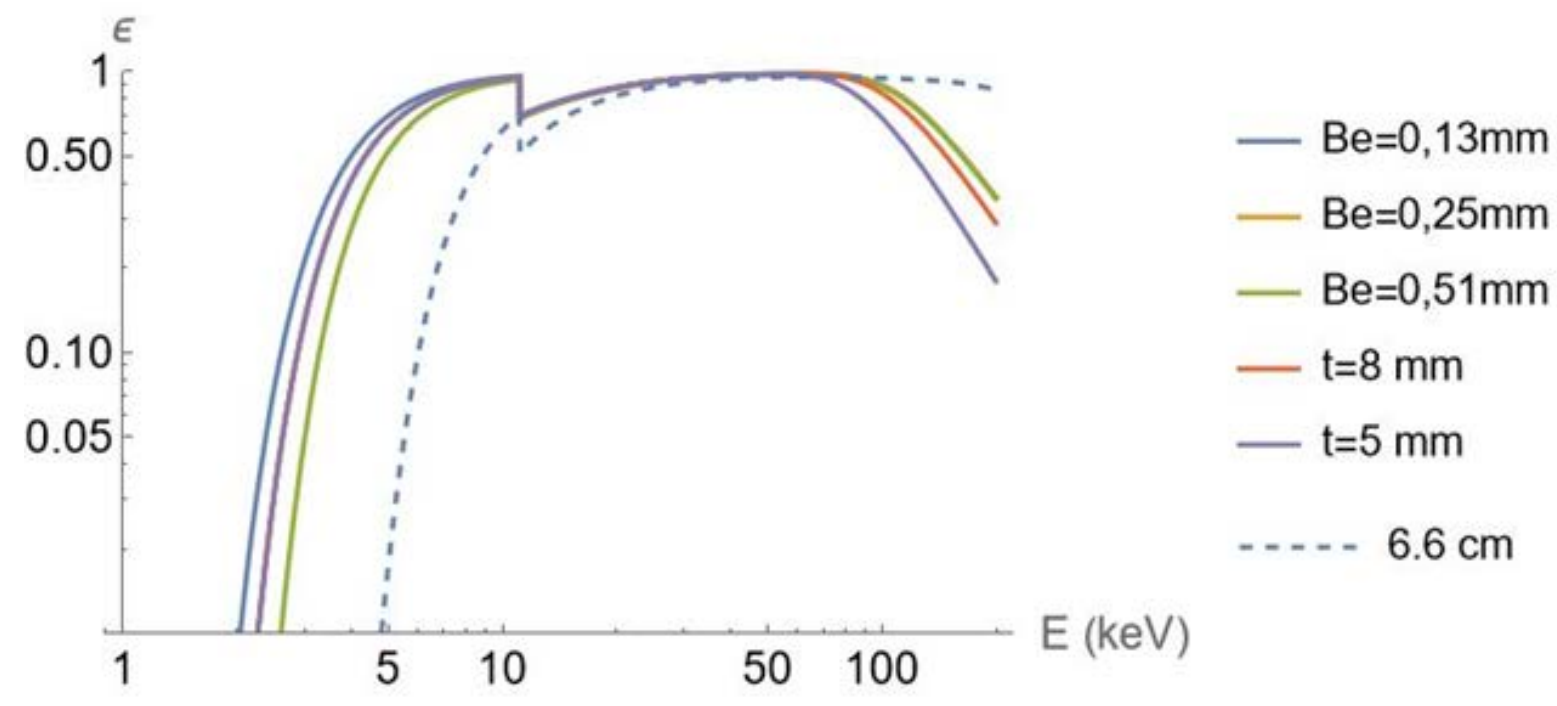

Figura 2.7: Eficiência de detecção de pico intrínseca para detetores planares de Ge em função da energia, para feixes de fótons colimados, calculadas com o modelo de Seltzer [83], apropriados para detetores planares com janela de Be (linhas cheias) e um grande detetor coaxial com janela de C. Neste último caso, o feixe de fótons incide fora do centro, de modo a evitar as superfícies cilíndricas tanto a externa quanto a do furo central.

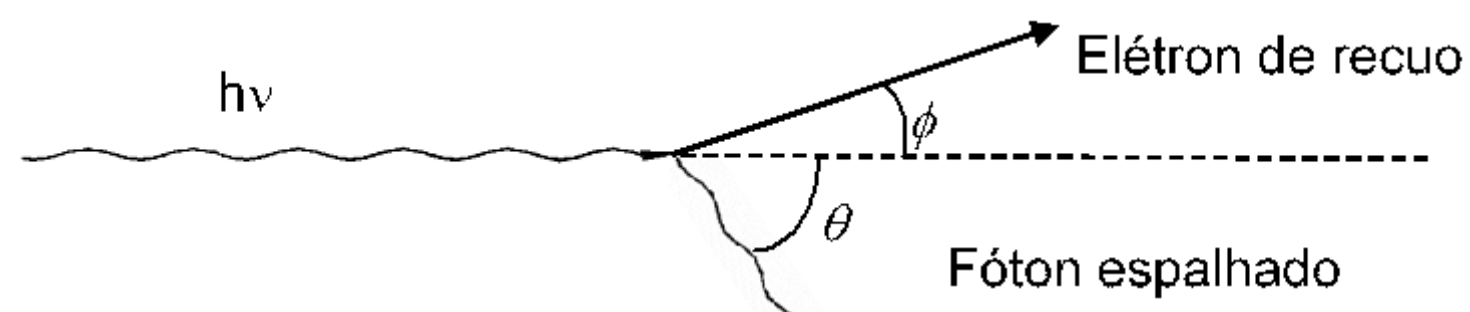

Figura 2.8: Esquema do efeito Compton: o fóton de energia $E=h v$ interage com um elétron ao que transfere energia, sendo espalhado em um ângulo $\phi$ e o fóton emergente tem energia $E^{\prime}=h v^{\prime}$ e sua quantidade de movimento forma em um ângulo $\theta$ com a direção do movimento inicial.

No modelo esquematizado na figura 2.8 em que o elétron é livre, a energia do fóton espalhado resulta:

$$
E^{\prime}=\frac{E}{1+\kappa(1-\cos \theta)}
$$

onde $\kappa=E / m_{e} c^{2}$ é a razão entre a energia do fóton e a energia de repouso do elétron $(\simeq$ $511 \mathrm{keV})$. Para pequenos ângulos de espalhamento, a perda de energia é mínima, mas quando se trata de um retro espalhamento, a perda de energia é máxima, e a energia cinética do elétron 
espalhado, $T$, se calcula como:

$$
\begin{aligned}
T & =h v_{0}-h v^{\prime} \\
& =h v_{0}\left(\kappa \frac{(1-\cos \theta)}{(1+\kappa(1-\cos \theta))}\right)
\end{aligned}
$$

Quando a energia do fóton incidente é muito maior que a energia de ligação dos elétrons ao átomo, o espalhamento Compton é função do número de elétrons do material absorvedor, por isso essa probabilidade aumenta com o número atômico $Z$. A seção de choque de espalhamento diferencial $\frac{d \sigma}{d \Omega}$ dos fótons espalhados numa interação inelástica é dada pela expressão de KleinNishina [49] :

$$
\frac{d \sigma}{d \Omega}=Z r_{e}^{2}\left(\frac{1}{1+\kappa(1-\cos \theta)}\right)^{2}\left(\frac{1+\cos ^{2} \theta}{2}\right)\left(1+\frac{\kappa^{2}(1-\cos \theta)^{2}}{\left(1+\cos ^{2} \theta\right)[1+\kappa(1-\cos \theta)]}\right)
$$

onde $r_{e}$ é o raio clássico do elétron. A ilustração dessa distribuição angular reproduzida na figura 2.9 se encontra na literatura [49] e mostra uma clara tendência a espalhamentos para a frente quanto maior é o valor da energia do fóton.

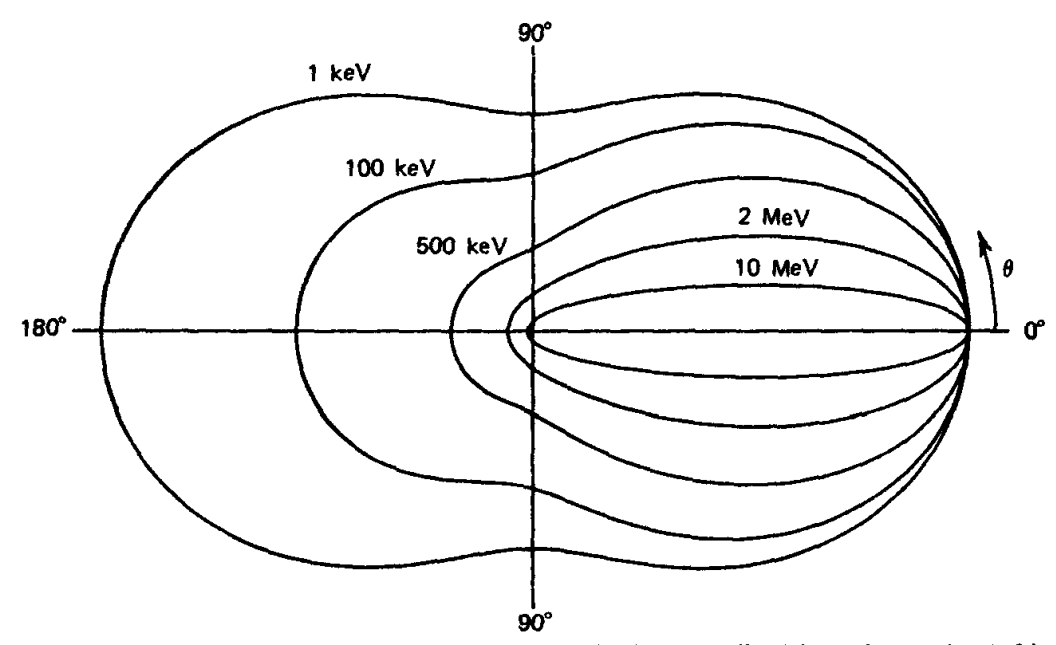

Figura 2.9: Distribuição angular dos fótons espalhados em função da energia do fóton incidente de acordo com a seção de choque de Klein-Nishina [49]

As expressões que descrevem a probabilidade de que um fóton de energia $E^{\prime}$ escape do cristal, após interagir com um elétron em movimento com uma energia de ligação determinada, num certo ângulo, dependerá das dimensões do cristal, dos coeficientes de atenuação, etc. [32].

Cálculos mais apurados deste efeito devem considerar a energia de ligação do elétron e o alargamento Doppler causado pelo movimento do elétron no átomo, especialmente quando os fótons tiverem energia abaixo de $100 \mathrm{keV}$; o primeiro fenômeno é importante especialmente para ângulos traseiros e pode ser claramente observado na reprodução da borda Compton. A 
figura 2.10 mostra os espectros experimental e simulado de uma fonte de ${ }^{137}$ Cs observada por um detetor de germânio [78]. A parte da borda Compton ampliada mostra o resultado do código MCNP quando rodado na opção default, a qual não adiciona a correção pelo movimento dos elétrons no átomo.

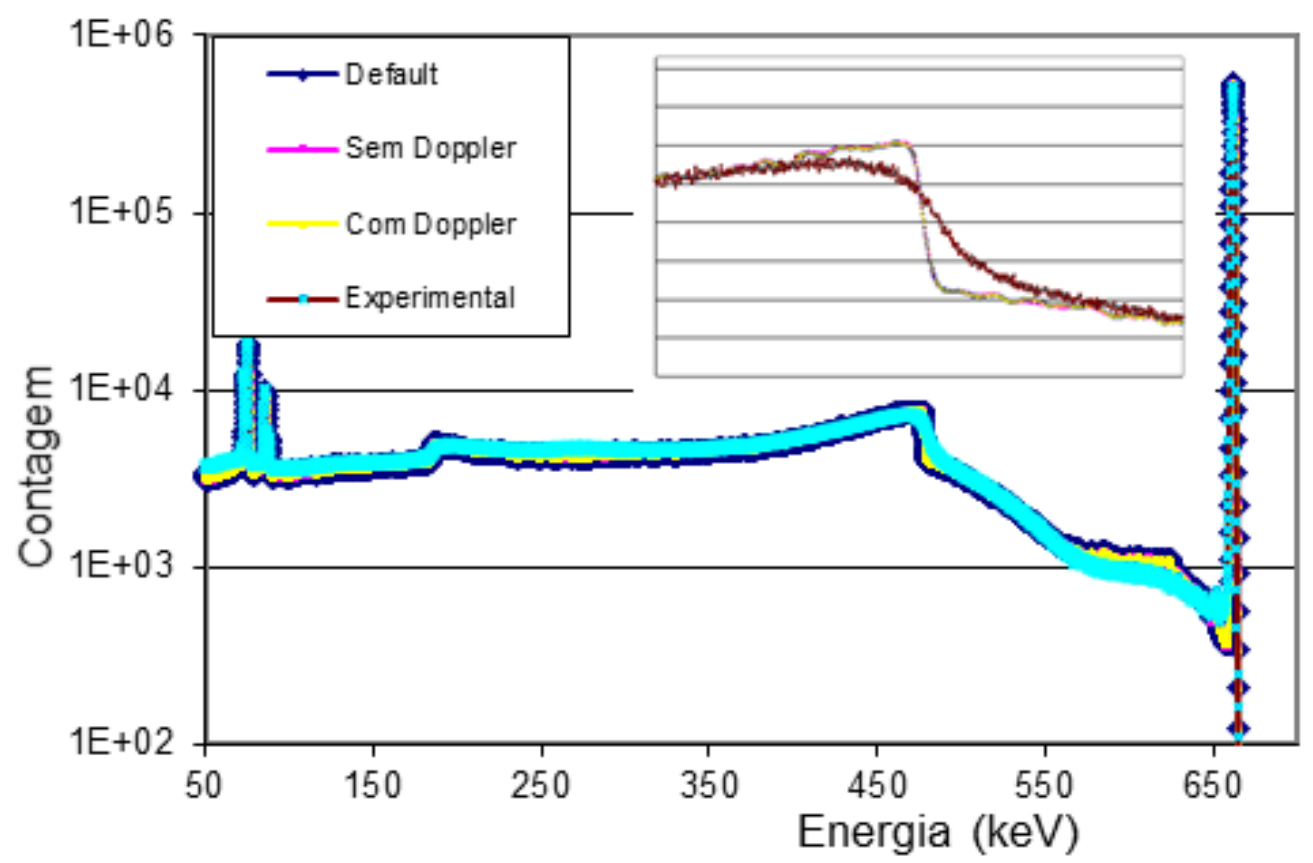

Figura 2.10: Comparação dos espectros experimental e simulados para uma fonte de ${ }^{137} \mathrm{Cs}$ incidindo sobe um detetor coaxial de HPGe [78]. No detalhe, a linha mais fina e de mudança abrupta corresponde ao cálculo sem incluir o efeito doppler devido ao movimento dos elétrons, enquanto a linha mais suave e irregular inclui esse efeito, o que realça a importância de levar em conta o movimento dos elétrons na distribuição angular dos fótons espalhados inelasticamente.

\subsubsection{Criação de pares}

Podemos deduzir da figura 2.5, que nos mostra as seções de choque para os diferentes processos de interação, que a partir de aproximadamente os $8 \mathrm{MeV}$ de energia, o processo de criação de pares é o dominante em um detetor de Ge. Assim, em detetores desse material, a aniquilação do pósitron gera fótons de $511 \mathrm{keV}$, de modo que, de maneira semelhante ao que acontece com os raios- $x$ do Ge e descrito no item 2.4.1, aparecem os chamados picos de primeiro e segundo escapes, mas neste caso com energias 511 e $1022 \mathrm{keV}$, respectivamente, abaixo do pico de absorção total, que se pode ver na figura 2.11][64].

Quanto maior for a energia desse fóton original, a energia sobrante daquela gasta para criar o par se converte em maior energia cinética das partículas. Como elétrons e pósitrons têm carga, com mais energia, eles têm uma probabilidade razoável de produzirem um fóton de bremsstrahlung nas imediações de um núcleo. Esse processo foi investigado e será detalhado na seção 5.1 . 


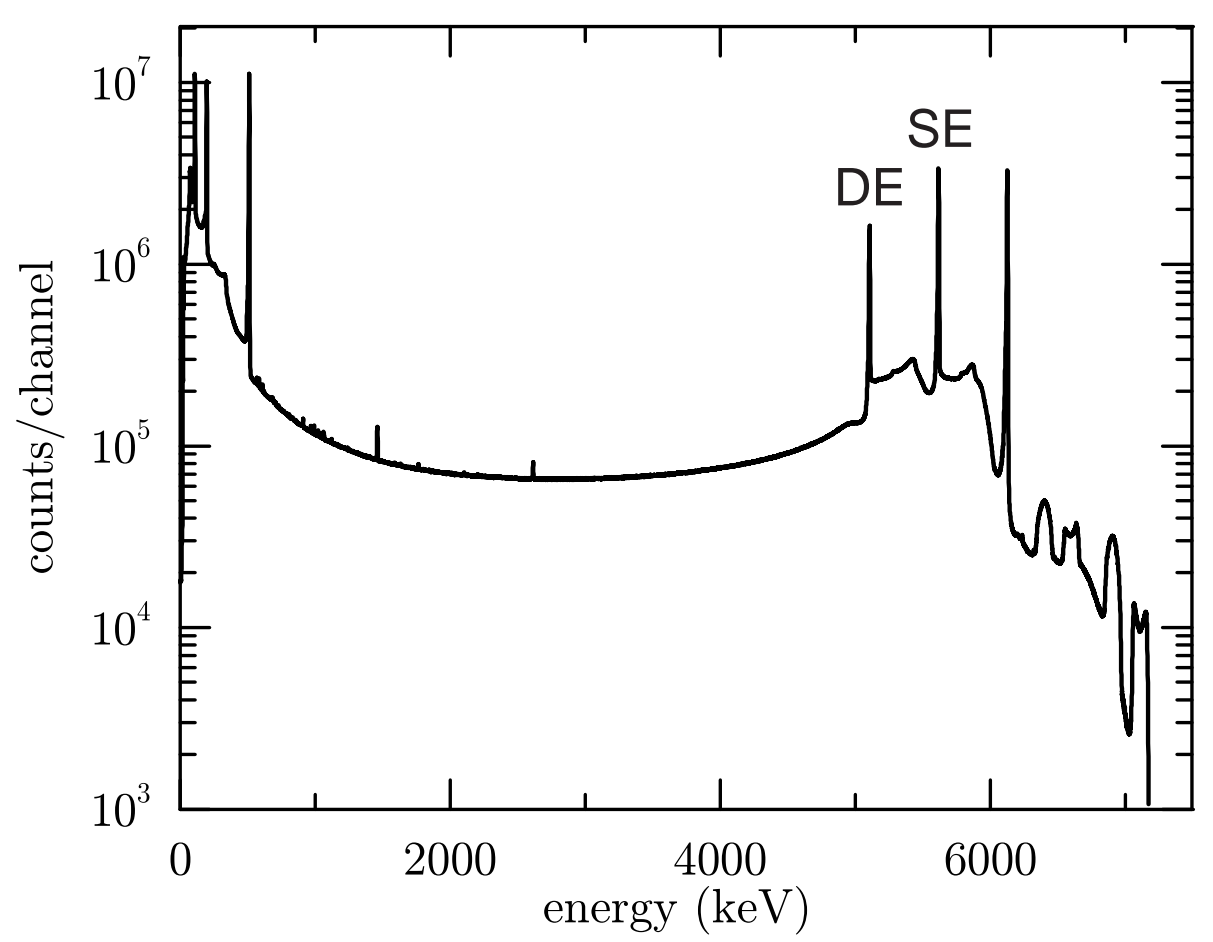

Figura 2.11: Espectro simples de detecção dos gamas de decaimento da reação ${ }^{19} \mathrm{~F}(\mathrm{p}, \alpha \gamma){ }^{16} \mathrm{O}$. A dispersão em energia é 0,536 keV/canal. Os picos DE e SE são os escapes duplo e simples, com energias 1022 e $511 \mathrm{keV}$, respectivamente, abaixo do pico de absorção total de 6,128 MeV [64].

\subsection{Perda de energia dos elétrons}

Os elétrons têm um papel central neste trabalho. Por um lado, são os projéteis com que trabalhamos no Microtron e, por outro, são os diferentes mecanismos de sua interação com a matéria que permitem a transferência de energia proveniente do fóton para uma forma que pode ser quantificada. Os elétrons podem colidir elasticamente com um átomo, excitá-lo, ionizá-lo, produzir radiação de Cherenkov, Bremsstrahlung e mesmo reações nucleares, quando possuem alta energia.

Os detetores baseiam-se em processos que usam a energia que os fótons transferem aos elétrons do elemento ativo por algum dos processos citados na seção 2.4. Esses elétrons primários colidem com os do volume ativo do detetor e lhes transferem parte da sua energia cinética, promovendo elétrons da banda de valência para a banda de condução. Um campo elétrico permite a coleção dessa carga, que é proporcional à energia do fóton incidente.

O mecanismo de perda de energia por colisões dos elétrons é similar ao de qualquer outra partícula carregada, mas deve ser levado em conta a reduzida massa deles e os termos de troca entre os elétrons incidente e alvo. Duas características muito importantes devem ser destacadas: a primeira delas é que as partículas carregadas (pesadas) após a colisão não alteram (ou alteram pouco) a direção original, mas os elétrons podem alterar radicalmente a trajetória. A outra resulta da indistinguibilidade do elétron que carrega a energia do fóton (elétron primário) com os elétrons do meio. Depois que um elétron primário interage com um elétron do meio, não se pode distinguir qual deles era o projétil e qual o do alvo; convencionalmente, chama-se primário ao de maior energia e secundário, o de menor, mas ambos são elétrons idênticos e 
indistinguíveis. A fórmula de Bethe pode ser adaptada considerando a indistinguibilidade entre os elétrons, incluindo correções relativísticas e levar em consideração o efeito de densidade de carga, assim como os efeitos da localização dos elétrons em camadas. Essa fórmula algumas vezes chamada Bethe-Bloch, pode ser calculada para avaliar a transferência de energia, que é um parâmetro quantificável, e é expressa por [54]:

$$
\left(-\frac{d E}{d x}\right)_{\mathrm{tot}}=\left(-\frac{d E}{d x}\right)_{\mathrm{rad}}+\left(-\frac{d E}{d x}\right)_{\mathrm{el}}
$$

em que o subscrito rad e el identificam o processo como, respectivamente, radiativo e transferência de energia aos elétrons atômicos por colisão inelástica. A fórmula de Bethe para elétrons fica:

$$
\left(-\frac{d E}{d x}\right)_{\mathrm{el}}=2 \pi N_{A} r_{e}^{2} m_{e} c^{2} \rho \frac{Z}{A} \frac{1}{\beta^{2}}\left[\ln \left(\frac{T}{I}\right)^{2}+\ln \left(1+\frac{\tau}{2}\right)+F^{-}(\tau)-\delta\right]
$$

onde:

$$
\begin{array}{ll}
N_{A}=\text { número de Avogadro } & r_{e}=\text { raio clássico do elétron } \\
m_{e}=\text { massa do elétron } & \rho=\text { densidade do material absorvedor } \\
Z=\text { número atômico do absorvedor } & A=\text { massa atômico do abservedor } \\
\beta=v / c \text { da partícula incidente } & T=\text { energia cinética do elétron } \\
I=\text { energia média de excitação } & \tau=T \text { em unidades de } m_{e} c^{2} \\
F^{-}(\tau)=\left(1-\beta^{2}\right)\left[1+\frac{\tau^{2}}{8}-(2 \tau+1) \ln 2\right] & \delta=\text { correção de densidade }
\end{array}
$$

A radiação de freamento ou Bremsstrahlung é a emissão de radiação eletromagnética pela aceleração causada pela presença de um campo elétrico, como discutido no item a) da seção 2.3.1. Assim, há uma perda de energia do elétron, de modo que o resultado final é freálo. Como a intensidade desse processo é inversamente proporcional ao quadrado da massa da partícula, esse é um processo importante somente para os elétrons (e pósitrons), podendo ser ignorada para todas as demais partículas.

Os valores de secções de choque para os diferentes processos de transferência e perda de energia estão tabulados em função da energia do fóton incidente [82]. A grande maioria desses valores resultaram de cálculos que consideram várias teorias, mas algumas delas foram corrigidas por valores medidos de secções de choque [73]. Essas secções de choque são amplamente usadas em estimativas para a construção de máquinas que acelerem os projéteis, atividades aplicadas como a dosimetria, cálculos de blindagens, ativação de materiais, reações nucleares e comportamento de detetores de radiação, entre outras. 
$\overline{(20}$ 


\section{Capítulo 3}

\section{Instrumentação}

O trabalho de caracterizar os detectores iniciou-se com a determinação experimental das suas eficiências e respostas, buscando alcançar a melhor precisão possível nas medidas de secções de choque. Foram comparados os resultados experimentais às simulações com diferentes códigos e, finalmente, adotaram-se funções analíticas para o cálculo das eficiências e respostas dos detectores.

Este trabalho abrangeu vários detectores, diversas metodologias e técnicas de medida, e o uso dos códigos de simulação Monte Carlo MCNP5 e MCNPX [86] assim como o PENELOPE [76].

Este capítulo irá tratar o que considero fazer parte da instrumentação e abordará assuntos como: os componentes dos detectores, a eletrônica associada às medições de espectros de energia, sua utilização em irradiações com feixes de elétrons e prótons, os alvos a serem irradiados, além de fontes radioativas usadas na sua calibração. A instrumentação descrita aqui destina-se a fótons em uma faixa de energia muito ampla (de alguns $\mathrm{keV}$ até $10 \mathrm{MeV}$ ) e tem especificidades definidas pelo plano de pesquisa das interações dos fótons e elétrons com a matéria seguido pelo Microtron.

Como já comentado no Capítulo 1, o projeto original do Microtron previa acelerar elétrons desde 6 a $38 \mathrm{MeV}$ [65], de modo que buscamos caracterizar nossos detetores para fótons na faixa de energia mais ampla possível. As fontes radioativas com dados de decaimento padronizados emitem fótons com energias menores que $5 \mathrm{MeV}$; raios gama de energias superiores só podem ser conseguidos com reações nucleares. Em vista disso, membros do grupo orientaram trabalhos para o estudo da função resposta dos detetores para fótons com energias ao redor dos $10 \mathrm{MeV}$ [37, 89], e trabalhamos no desenvolvimento de padrões gama de alta energia produzidos por reações nucleares. Nessa faixa de energia, o processo de formação de pares por fótons desempenha um papel importante na detecção, e a atenuação dos fótons é menor, de modo que a característica mais relevante do detetor é seu volume.

Na etapa inicial de funcionamento do Microtron, o canhão de elétrons foi usado para alimentar uma nova câmara de irradiação com elétrons de 10 a $100 \mathrm{keV}$ [91]. Começamos assim novos temas de pesquisa, para os quais era necessária a obtenção prévia da função resposta dos detetores, mas numa faixa de energia muito mais baixa que a prevista originalmente com o acelerador, e se fez necessário desenvolver padrões de intensidade de fótons nas energias tí- 
picas dos raios-x, a fim de minimizar a atenuação que é determinante na construção do arranjo experimental, inclusive na escolha do detetor.

As pesquisas realizadas incluíram a determinação das secções de choque de bremsstrahlung de elétrons e de ionização das camadas K e L por impacto de elétrons de alguns elementos. Nessas medidas, as fontes de radiação foram os próprios alvos, por isso desenvolveu-se a metodologia de confecção desses alvos, a fim de evitar efeitos secundários indesejados. Já as fontes de calibração foram construídas de modo a facilitar a transferência das funções eficiência e resposta obtidas a partir delas para as medidas realizadas durante as irradiações.

\subsection{O microtron}

Um esquema do Microtron, com suas linhas de irradiação, pode ser observado na figura 3.1 [65]. Atualmente, possui câmaras de irradiação em três linhas de feixe com energias diversas. A primeira linha de 10 a $100 \mathrm{keV}$ usa os elétrons diretamente do canhão, desviados por um dipolo magnético, saindo a $45^{\circ}$ com relação à linha do feixe; a de $1,9 \mathrm{MeV}$ que recebe os elétrons após passarem pelas duas estruturas aceleradoras e serem desviados por outro dipolo magnético; e a de $5 \mathrm{MeV}$, energia que se chega após a recirculação dos elétrons pelo Microtron principal. Nessas câmaras, é possível irradiar os alvos e medir os fótons produzidos com os diferentes detetores, conforme as energias em jogo.

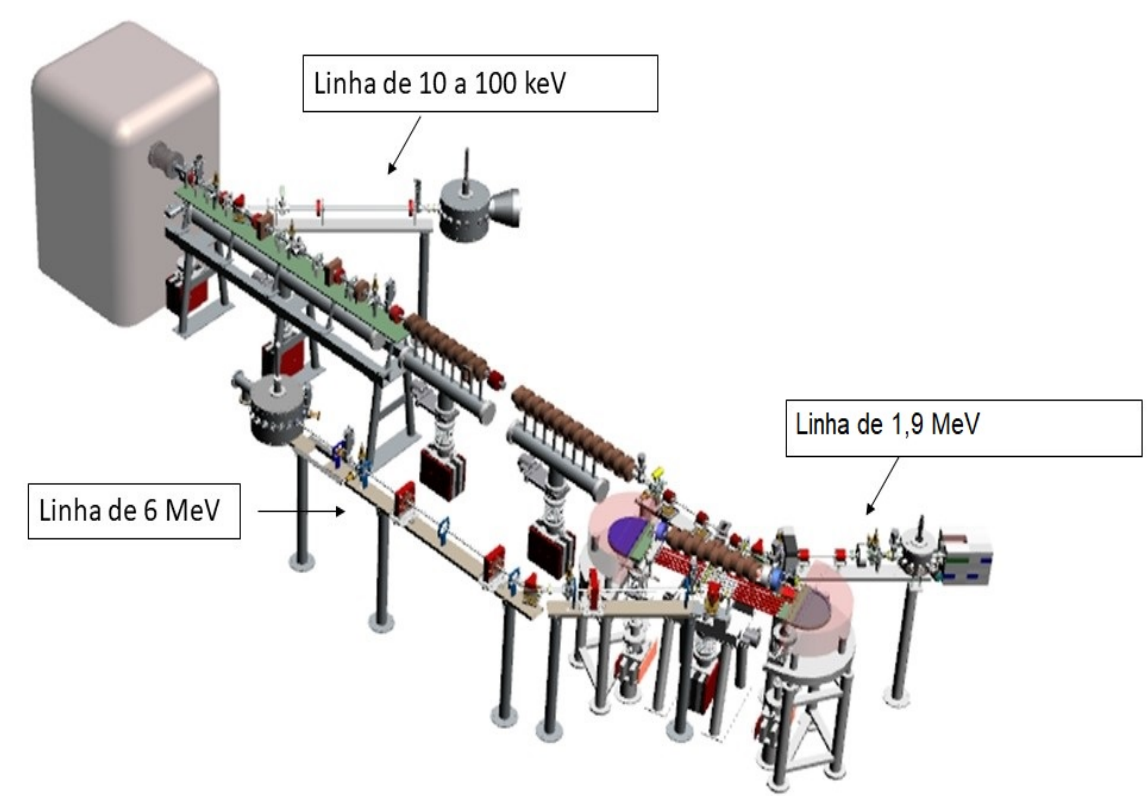

Figura 3.1: Esquema das linhas de irradiação do microtron. A grande caixa à esquerda do desenho representa a blindagem eletrostática da fonte de $100 \mathrm{kV}$ do canhão de elétrons. 


\subsubsection{Câmara de irradiação}

Nas figuras 3.2 e 3.3 podem ser vistas imagens da câmara de irradiação original e atual, respectivamente.

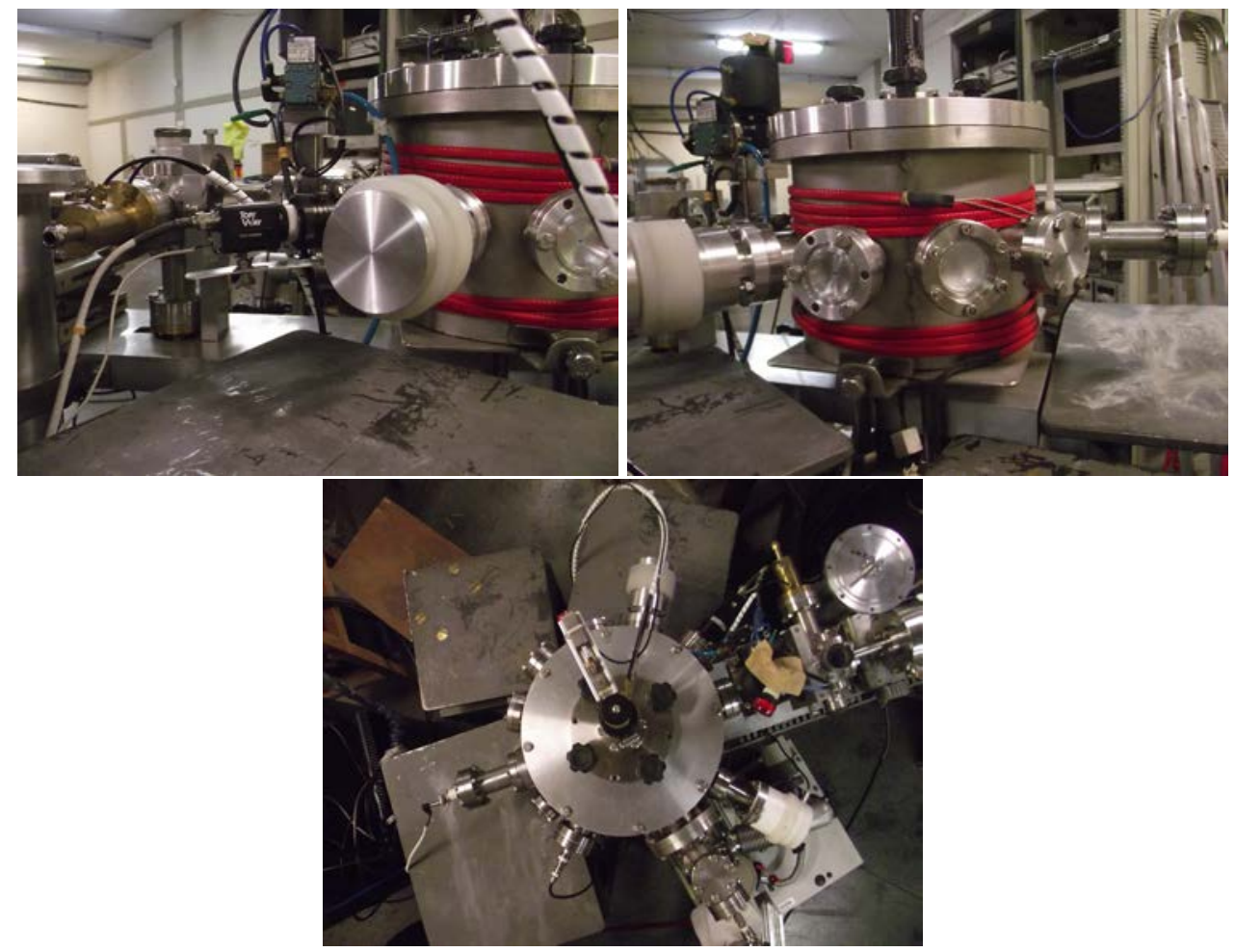

Figura 3.2: Câmara de irradiação antiga da linha de 1,9 MeV, usada para medir ionização da camada K de Au e $\mathrm{Bi}$, por elétrons de $80 \mathrm{a} 100 \mathrm{keV}$ [45]. Na imagem superior esquerda, se pode ver o aparelho que filma o interior e auxilia no correto posicionamento do alvo e na focalização do feixe. Na imagem superior direita, pode se observar o beam catcher (na horizontal à direita da imagem) e os flanges. A imagem inferior é uma vista de cima.
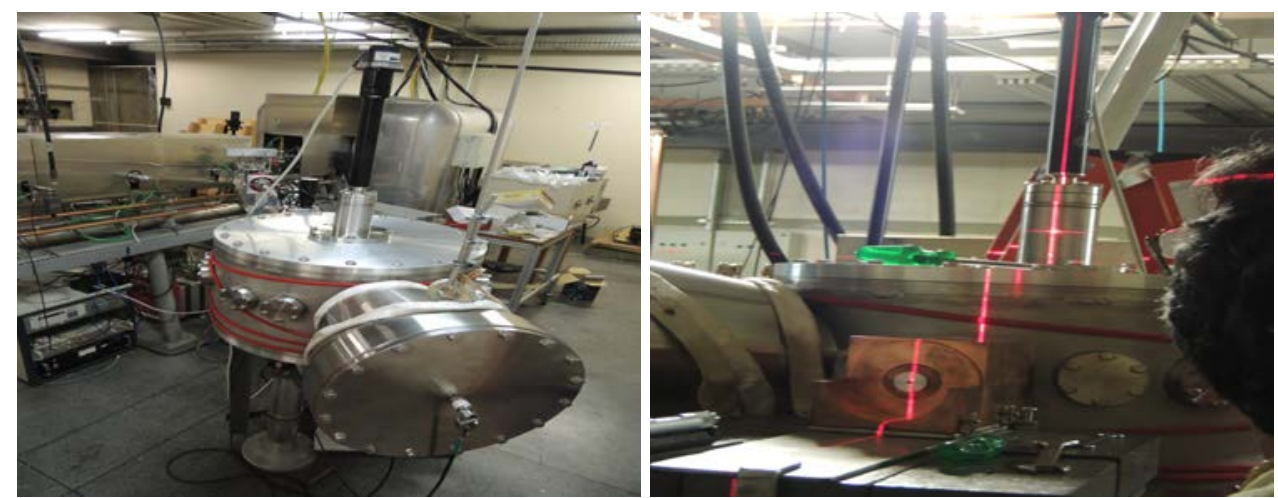

Figura 3.3: Câmara de irradiação da nova linha de 10 - $100 \mathrm{keV}$. Na imagem da esquerda, se destacam a faraday cup e o acionador da torre de alvos, na imagem da direita, um suporte/blindagem de cobre sendo alinhado com laser.

Antes de cada irradiação, o spot do feixe é ajustado, mas a máquina, apesar de ser bastante estável, pode mudar suas condições ao longo do tempo de irradiação. Um dos valores necessários para efetuar os cálculos de secções de choque é o número de elétrons, $N_{e}$, que atingiram o alvo. Esse valor se obtém pela integração da corrente de elétrons, coletada em três locais: i) o 
copo de Faraday, com semi-abertura de 12 graus; ii) um anel de Carbono instalado na saída da câmara/entrada do copo de Faraday, cobrindo a faixa angular entre 12 e 23 graus; iii) a câmara de irradiação, que está em contato elétrico com a torre de alvos. Esses três elementos estão isolados entre si e da Terra, e a corrente coletada por cada um desses elementos passa por um integrador de corrente (ORTEC 43). O copo de Faraday é blindado em aço com $3 \mathrm{~cm}$ de espessura, de modo a minimizar a radiação ambiente, que contribui para o fundo observado pelos detetores de fótons. Um desenho e uma imagem da câmara podem ser observados na figura 3.4 [91].
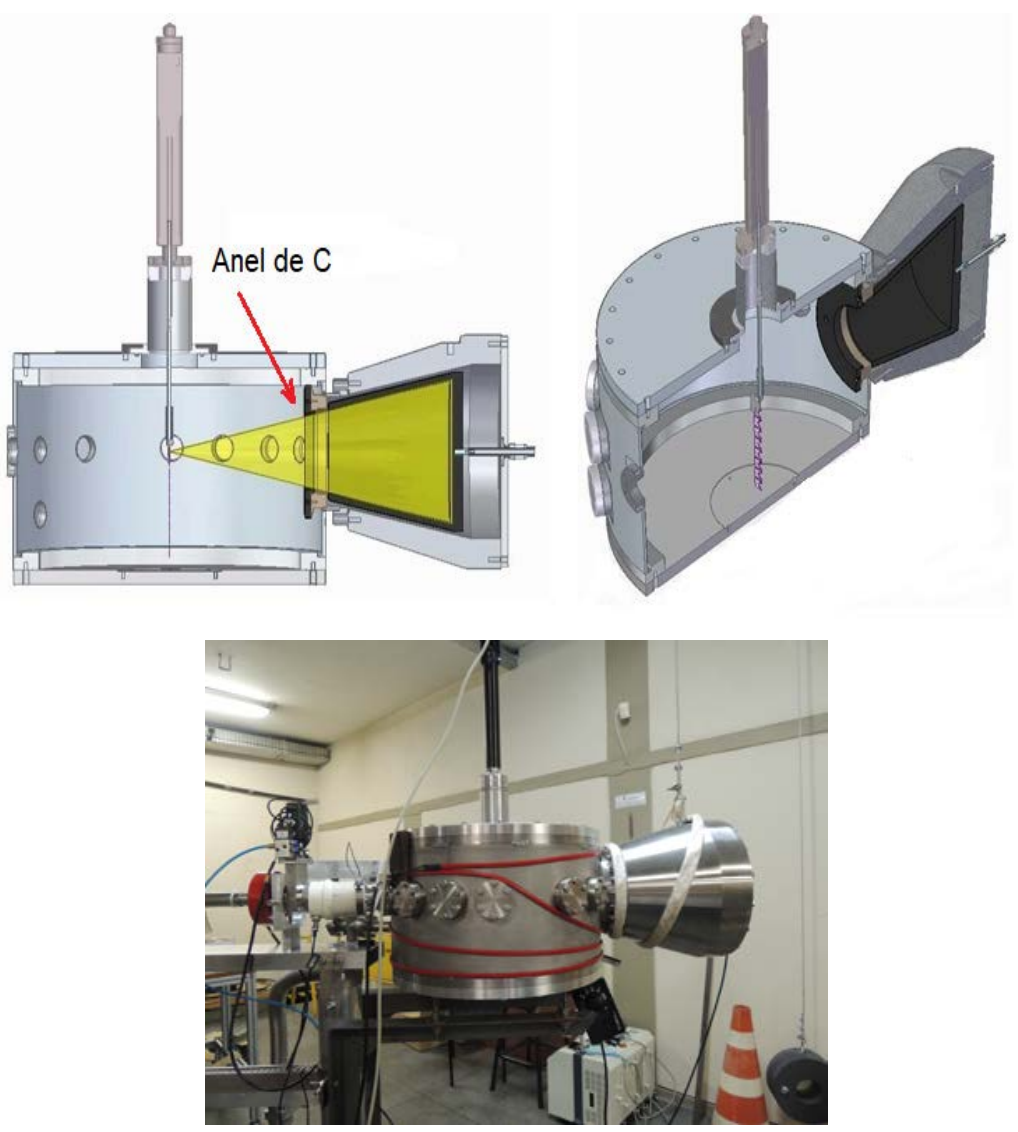

Figura 3.4: Esquema da câmara em vistas lateral e corte longitudinal, e imagem da câmara de irradiação de 10 a $100 \mathrm{keV}$, com a blindagem do copo de Faraday visível do lado direito e sustentada por um cabo de aço.

Os elétrons são espalhados quando interagem com o alvo, de modo que se coleta carga no copo de Faraday, no anel e na câmara. Se o alvo for fino, uma grande porção deles continua sem interagir ou desvia pouco, chegando ao copo de Faraday que é profundo e feito de C para minimizar o fundo de fótons na região do alvo, mas os elétrons espalhados podem adquirir qualquer direção. O quociente entre as correntes no anel e no copo de Faraday permite controlar se as condições de irradiação permanecem estáveis ou se o feixe, por alguma razão, alterou-se ou colidiu com a moldura do alvo. Nesse caso, a irradiação deve ser interrompida e ajustado novamente o foco de elétrons na posição do alvo, antes de continuar com as medidas.

As janelas dos flanges que permitem a medida dos fótons em estudo foram feitas com Kapton metalizado e Al, para conduzir as cargas que poderiam eletrizá-las. As janelas onde foram instalados os detetores SDD são de Kapton $(25 \mu \mathrm{m})$ metalizado de um lado só, mas não foram 
capazes de garantir a estanqueidade da câmara, razão pela qual foi adicionada uma folha de Al com $5 \mu \mathrm{m}$ de espessura; por sua vez, o Al dessa espessura não tinha resistência mecânica suficiente para suportar a diferença de pressão entre o ambiente externo e o vácuo da câmara. Essa combinação de Kapton e Al permitiu minimizar a atenuação de raios-x de $5 \mathrm{keV}$ ao mesmo tempo que garantiu a estanqueidade da câmara. Mais detalhes desta câmara de irradiação podem ser obtidos no artigo de Vanin [91].

\subsubsection{Torre de alvos}

A torre de alvos original estava localizada no centro da câmara, fixada ao tampo. Na figura 3.5 podemos ver o suporte de alvos original, fixo a uma tampa de Al, com uma fonte de calibração da Amersham (imagem no meio), que era localizada no centro da câmara. A figura da esquerda destaca o view screen junto a um alvo de irradiação. A movimentação para o feixe atingir o view screen ou o alvo era feita com um sistema pneumático. Dependendo dos ângulos de medida onde eram colocados os detetores, a torre de alvos podia ser rodada em torno de um eixo vertical de modo a inclinar o alvo em relação ao feixe de elétrons para minimizar efeitos do espalhamento ou absorção dos fótons na própria moldura das fontes; por outro lado, as correções relacionadas ao aumento da espessura do alvo vista pelos elétrons era considerada em todos os casos. O espalhamento de fótons na massa desproporcional de Al desses suportes de fontes de calibração e de alvos fornecia umas estruturas nos espectros detetados.
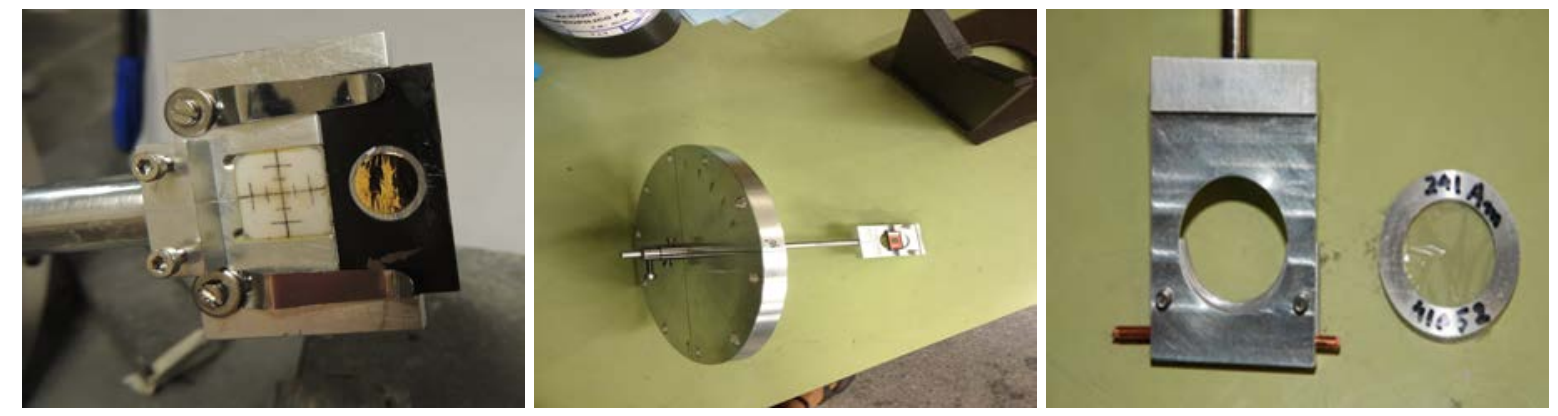

Figura 3.5: Imagens do suporte de alvos com um alvo de Au junto ao view screen, no centro o tampo da câmara antiga com o suporte de fontes de calibração e a direita detalhe do suporte de fontes em anel de $\mathrm{Al}$ e uma fonte com moldura desse material.

A figura 3.6 mostra a imagem de um alvo na posição de irradiação, vista em um monitor da sala de controle. Isto é possível já que em um dos flanges foi instalada uma câmara de vídeo (ver figura 3.2), que mostra em um monitor de video as imagens do centro da câmara em tempo real. A cruz é desenhada em uma folha de acetato que está fixada ao monitor para melhor ajuste e repetitividade da posição de irradiação.

Já a torre de alvos nova, feita em fibra de C, como as molduras dos alvos, figura 3.7, é acionada por um motor de passo. A vantagem de ter uma torre com essas características era minimizar o tempo de preparo da irradiação, já que conseguiam-se obter os dados de vários alvos e diferentes energias de elétrons sem abrir a câmara de irradiação com a consequente demora de quebrar o vácuo e voltar aquele ideal para uma nova irradiação. Nela, podem ser observados os alvos e o view screen na parte superior. O passo com que se move a torre é muito 


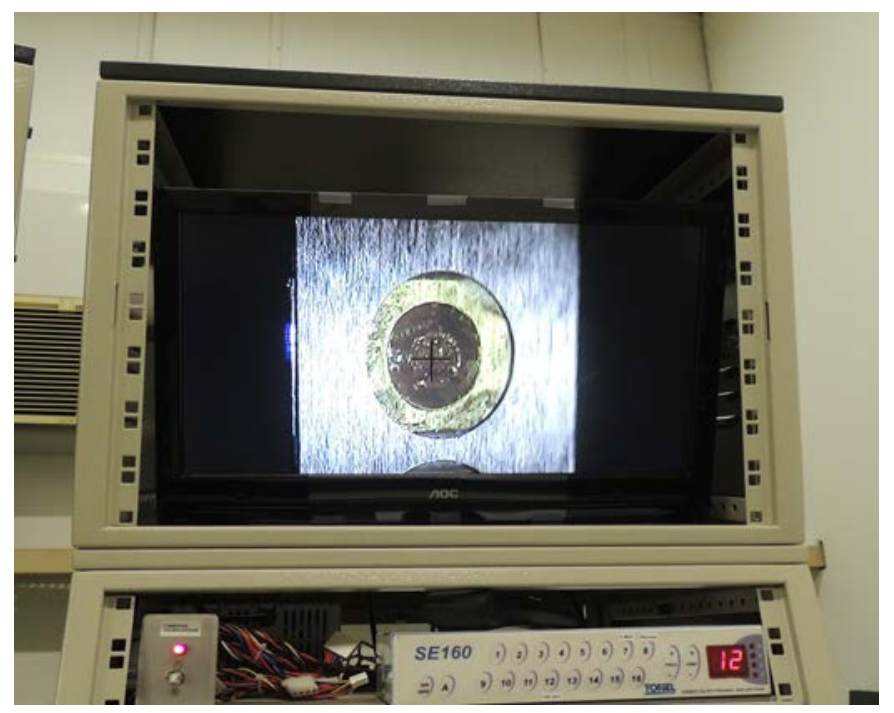

Figura 3.6: Ajuste da posição do alvo na posição de irradiação, vista no monitor da sala de controle. O disco escuro no centro do retângulo claro tem $10 \mathrm{~mm}$ de diâmetro e corresponde à região do alvo.

pequeno, de maneira que é possível centralizar os alvos com repetitividade.

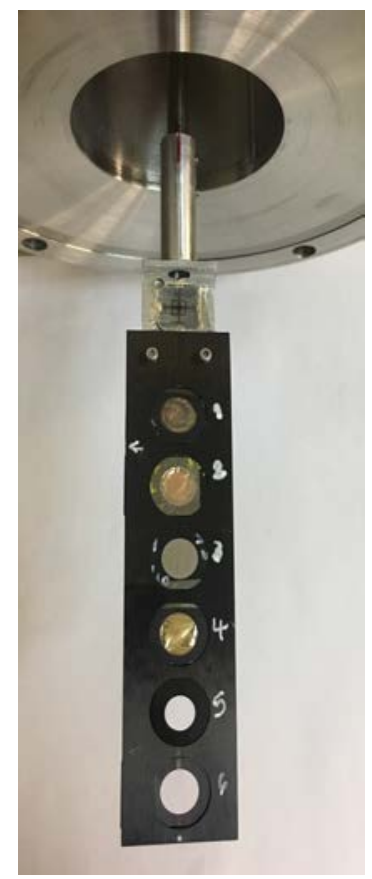

Figura 3.7: Imagem da nova torre de alvos feita de fibra de carbono, com os slots de 1 a 4 carregados com alvos diferentes, no 5, uma moldura vazada de $8 \mathrm{~mm}$ e o 6 , com a moldura de $10 \mathrm{~mm}$. A imagem do view-screen, que está acima de todos eles, pode ser vista na figura 3.8

Na figura 3.8 aparece o view screen com uma mancha brilhante, no centro. Feito de $\mathrm{BeO}$, material fluorescente, brilha quando os elétrons batem nele. As linhas desenhadas distam $2 \mathrm{~mm}$ entre si, de maneira que a mancha observada desde a sala de controle do Microtron no monitor da figura 3.6, ajuda na focalização e localização do feixe. 


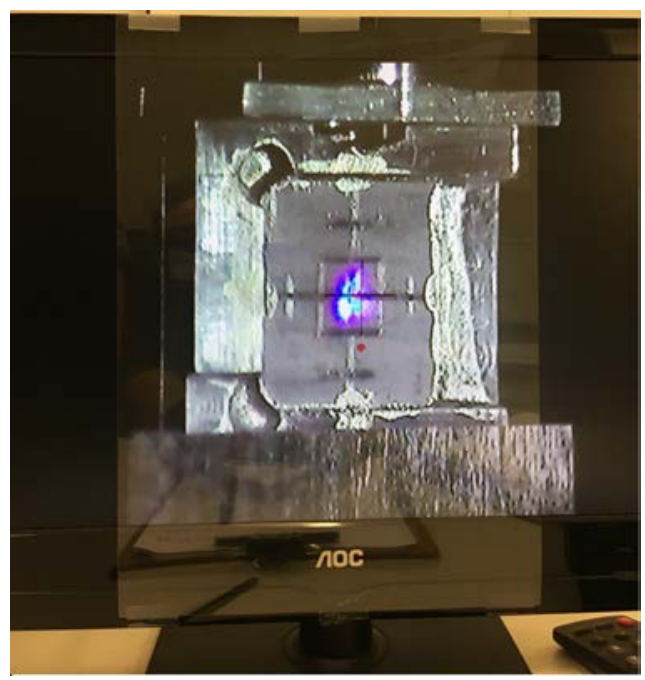

Figura 3.8: Imagem do view screen, em que o spot brilhante marca a posição e o perfil do feixe de elétrons que bate na parte central.

\subsection{Detetores de Fótons}

Chamamos detetor ao conjunto formado pelo elemento ativo para a detecção - o cristal de Ge ou Si - com os elementos de montagem - suporte, janela, criostato - e os circuitos eletrônicos que transformam a energia depositada pela radiação no elemento ativo, num pulso elétrico quantificável após outros processos de interpretação da informação primária. A detecção de cada tipo de radiação irá usar elementos ativos de diferentes materiais, formas, arranjos etc., a fim de observar melhor o que se pretende medir. É assim que poderão se encontrar detetores para partículas carregadas, neutras ou para radiação eletromagnética.

Existem vários tipos de aparelhos que detetam radiação eletromagnética, cuja observação, ao não possuir carga, dependerá dos mecanismos de transferência de energia que, por sua vez, dependem da energia original dos fótons a estudar, como descrito na seção 2.4

\subsubsection{Tipos}

Os detetores se classificam de acordo ao método usado nas medidas de espectroscopia, já que eles podem trabalhar pela dispersão em energia (energy-dispersive spectroscopy - EDS), em que a informação sobre a energia do fóton incidente é preservada e armazenada, ou pela dispersão em comprimento de onda (wavelength-dispersive spectroscopy-WDS), em que um primeiro detetor seleciona os fótons de um certo comprimento de onda (normalmente por difração de Bragg em um cristal), e um segundo detetor sinaliza a chegada de um fóton.

Dentre os detetores dispersivos em energia, se encontram os gasosos, cintiladores (líquidos ou sólidos), semicondutores e criogênicos, e entre os WDS, se encontram os espectrômetros de cristal com contadores proporcionais gasosos, que não irei detalhar. Além disso, o funcionamento dos detetores de fótons tipo EDS dependem da transferência de energia do fóton incidente para um elétron, seja por efeito fotoelétrico, espalhamento Compton ou formação de pares; é esse elétron que interage com a porção ativa do material do detetor e será o responsável pelo depósito de energia. O texto que segue se limita a detetores EDS e fica subentendido que 
ocorreu a transferência da energia do fóton, total ou parcial, para partículas carregadas, capazes de depositar energia na estrutura molecular ou cristalina do elemento detetor.

Os detetores cintiladores podem usar compostos orgânicos ou inorgânicos para o componente ativo e se baseiam no aumento da energia interna da estrutura molecular ou atômica do material detetor pela radiação. A radiação deposita energia ao longo da trajetória, que dá origem à luz que será detetada com instrumentos sensíveis ao comprimento de onda emitido pelo material detetor. Entre os cintiladores inorgânicos se encontram os BGO (Germanato de Bismuto), $\mathrm{NaI}(\mathrm{Tl}), \mathrm{CsI}(\mathrm{Tl}), \mathrm{CsI}(\mathrm{Na}), \mathrm{CaF}_{2}(\mathrm{Eu}), \mathrm{GSO}(\mathrm{Ce}), \mathrm{YAP}(\mathrm{Ce}), \mathrm{LaBr} 3(\mathrm{Ce}), \mathrm{LiI}(\mathrm{Eu})$, etc., cada um deles com emissão de luz em comprimentos de onda entre 350 e $480 \mathrm{~nm}$, tempo de decaimento de 16 a 4200 ns e 8200 a 65000 fótons por $\mathrm{MeV}$ de rendimento de luz [36]. Esses detetores são hermeticamente fechados, e a luz gerada no interior atravessa o cristal para ser coletada num dispositivo sensível a esse comprimento de onda, como os tubos fotomultiplicadores, fotodiodos ou microchannel plates, onde a luz de entrada é convertida em um pulso elétrico, que é amplificado e permite quantificar a energia transferida do fóton incidente para os elétrons do material.

Os detetores semicondutores usam o fato de que a radiação promove elétrons da banda de valência para a de condução, deixando lacunas positivas, que irão sendo preenchidas por outros elétrons fazendo com que essas lacunas e elétrons se movimentem no cristal em sentidos opostos devido ao campo elétrico aplicado ao cristal, gerando um pulso de corrente. As superfícies que coletam as cargas devem ser passivadas pela introdução de dopantes a fim de converter esses cristais em diodos. Os volumes onde são introduzidos esses dopantes só conduzem as cargas, não detetando a radiação incidente, razão pela qual são chamadas camadas mortas. Estes detetores se caracterizam por ter uma resolução em energia muito boa, porque bastam de 2 a $5 \mathrm{eV}$, em média, para formar um par elétron-buraco. Detetores semicondutores podem ter configurações com geometria planar ou coaxial, e os materiais que os conformam podem ser: $\mathrm{Si}, \mathrm{Ge}, \mathrm{GaAs}, \mathrm{CdTe}, \mathrm{Cd}_{0.8} \mathrm{Zn}_{0.2} \mathrm{Te}, \mathrm{HgI}_{0.2}$ [49].

A corrente da coleta de carga liberada no diodo pela radiação incidente se apresenta em forma de pulsos que são pouco intensos, de modo que todo detetor incorpora um pré-amplificador. O sistema de aquisição de dados integra cada pulso de corrente, e é a distribuição de amplitudes desses pulsos que permite identificar a energia da radiação incidente. O chamado "espectro" que surge do analisador multicanal e programas de computador é um histograma construído pela distribuição diferencial de altura de pulso, em que a escala horizontal está em unidades de altura de pulso (volts), e nas ordenadas é representado o número de vezes que um pulso de determinada altura foi observado. Essa escala horizontal pode ser transformada para energia por meio da calibração com fontes radioativas cujos fótons de decaimento tenham energias bem conhecidas.

O sucesso da análise nos trabalhos de espectroscopia da radiação depende em como o sistema "resolve" a radiação incidente em energia, isto é, se consegue separar os picos de energias próximas. A capacidade de resolução é quantificada por um parâmetro, sendo habitual adotar a largura do pico de absorção total a meia altura do pico (FWHM = Full Width at Half Maximum), tomada acima das componentes contínuas do fundo. A resolução, $R$, resulta do quociente entre a largura e a energia correspondente à posição de um dado pico, número adimensional, frequen- 
temente expresso em porcento. Alguns fatores do sistema de detecção, como o ajuste da linha de base do amplificador e a conexão à terra, na eletrônica analógica, ou os ajustes de flat-top, cusp, tempo de subida do pulso, etc. nos sistemas digitais, contribuem para que o sistema tenha boa resolução em energia.

\subsubsection{Os detetores de HPGe}

O elemento ativo de um detector de HPGe é um diodo produzido com um monocristal semicondutor de Ge de extrema pureza (com uma concentração de impurezas da ordem de $10^{10}$ átomos $/ \mathrm{cm}^{3}$ ) [49]. Esse material é caraterizado pela pequena diferença de energia entre as bandas eletrônicas de condução e de valência, de modo que precisa ser operado a baixa temperatura a fim de minimizar a corrente de fuga e permitir a observação dos pequenos pulsos de corrente produzidos pela migração no interior do cristal dos elétrons e buracos formados pelas colisões dos elétrons arrancados pelos fótons.

Estes diodos são construídos por crescimento do cristal. Os chamados coaxiais resultam de uma vez crescido o cristal, fazer um furo ao longo do eixo; as superfícies externas e internas são dopadas, criando as chamadas camadas mortas onde a radiação não é detectada, e farão o papel de eletrodos [25]. No caso dos detetores planares, o diodo é formado com a passivação da superfície anterior e posterior. O tamanho e as espessuras das camadas mortas são normalmente fornecidos pelo fabricante e a precisão desses dados é essencial para determinar, tanto por simulação como analiticamente, a eficiência e a resposta do detetor.

Nos cálculos realizados por simulação, é necessário construir as chamadas "geometrias" que resultam da interseção de cilindros e planos que contém os materiais constituintes do arranjo. Dependendo da precisão necessária, essas geometrias podem ser simplificadas ou bastante complexas com a adição detalhada dos materiais, formas, e posições dos objetos do entorno. Para definir essas geometrias é necessário conhecer, além das dimensões, a posição exata do cristal, que está dentro da cápsula feita de $\mathrm{Al}$, opaca à luz visível. Por outro lado, quando se calibra o detetor com fontes radioativas, ou quando se coloca um destes detetores em um arranjo de irradiação, normalmente se considera a posição da cápsula alinhada com o material a medir. No caso específico dos trabalhos de Garcia [30, 32, 34, 33], ao saber como estava localizado o cristal na cápsula, esta foi posicionada de forma a compensar o desalinhamento do cristal.

No item 3.2.5.1 está detalhada a metodologia usada para detetar o desalinhamento do cristal detetor dentro da cápsula. Na figura 3.9 pode ser observado como foi montado esse detetor no arranjo. A imagem superior esquerda é uma vista vertical, em que se observa a parte traseira do detetor, inclinada em relação à blindagem de cobre. Na imagem superior direita, a cápsula sendo introduzida em anéis de polimetilmetacrilato, que foram usinados descentrados e estavam fixos à blindagem de cobre por ranhuras. Na imagem inferior esquerda, outra vista vertical, onde se observa uma estrutura de cor negra, que pertence ao mecanismo de movimentação da torre de alvos. Na imagem inferior direita, aparece a blindagem de cobre com o colimador, também desse material.

A eletrônica associada aos detetores de HPGe usados neste trabalho foi desde a analógica à digital. A primeira delas é normalmente composta por alguns módulos separados: fonte de 


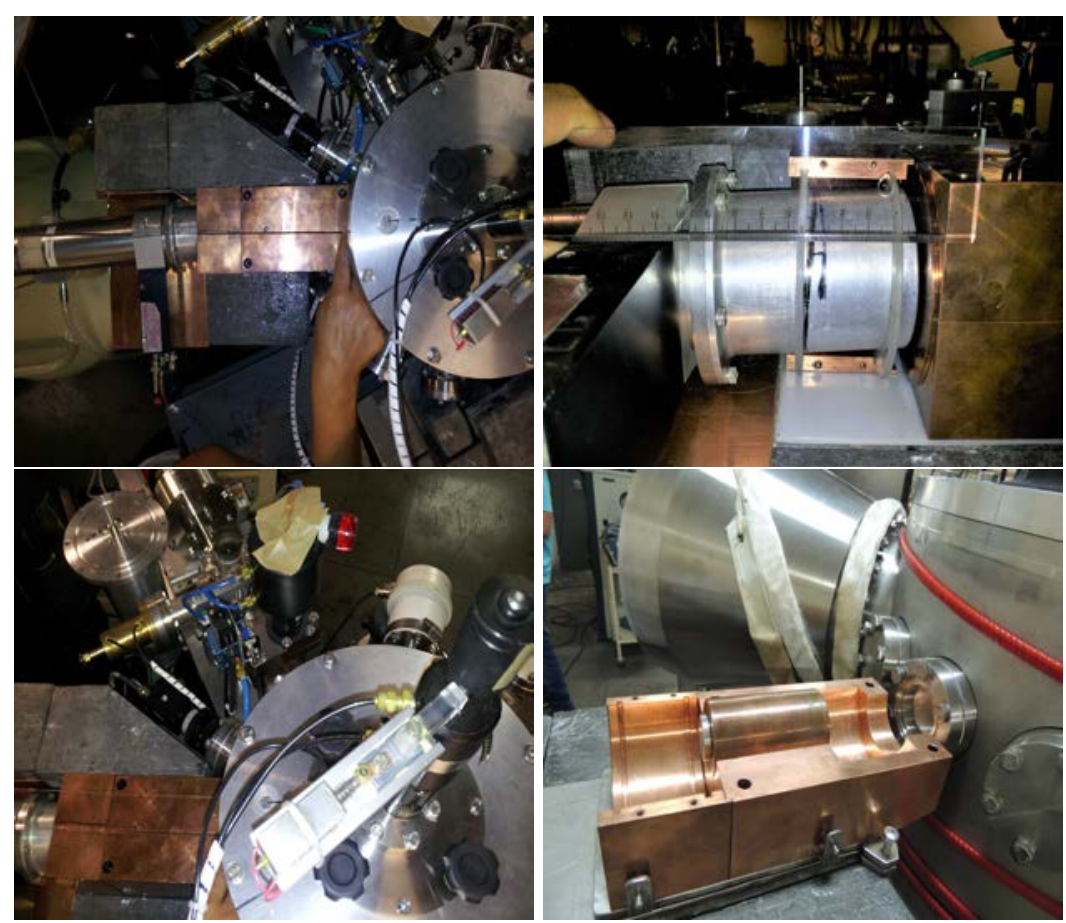

Figura 3.9: Montagem do detetor de HPGe de 5 cc no arranjo de irradiação do Microtron, onde se observa a inclinação com que foi posicionada a cápsula do detector, a fim de que o eixo de simetria do cristal apontasse para o alvo.

tensão, pré-amplificador, filtro de alta tensão, amplificador, analisador multicanal e micro computador. Um programa de aquisição permite lançar as medidas, escolher o tempo de contagem, obter e armazenar os espectros. Já no sistema digital, um único módulo digitaliza o pulso do pré-amplificador e fornece a tensão de operação do detetor e do pré-amplificador, eliminando o amplificador; essa centralização costuma evitar problemas de malha de terra que são frequentes nesses detetores. Quando usamos eletrônica digital o programa Maestro da Ortec realizou a tarefa de levantar a tensão do detetor, escolher os parâmetros eletrônicos adequados para o tipo e taxa de medida, lançamento e obtenção dos espectros. Esse espectrômetro digital pode ser programado para ser usado com pré-amplificadores tanto Transistor Reset como Resistive Feedback e controla os parâmetros do amplificador e filtro numérico, ao construir numericamente uma função trapezoidal a partir dos dados digitalizados do pulso do pré. Essa função numérica é caracterizada por um tempo de subida e um flat top, cuja duração e inclinação podem ser ajustados para alcançar uma melhor resolução. É a amplitude dessa função que é proporcional à energia depositada no cristal.

\subsubsection{Os detetores de $\mathrm{Si}$}

Detetores de Si possuem uma eficiência menor que os HPGe por conta do menor número atômico do Si comparado ao Ge. São ideais para detetar fótons com energias menores que $30 \mathrm{keV}$. Possuem uma eficiência intrínseca de detecção de $100 \%$ perto dos $10 \mathrm{keV}$, desde que tenham janela de entrada suficientemente fina [36]. Os detetores de Si comportam-se melhor que os de Ge em razão do maior gap entre as bandas de valência nos respectivos materiais, de modo que os de Si não precisam ser resfriados a temperaturas muito baixas para alcançarem 
uma boa resolução.

Silicon Drift Detectors (SDD) são detetores com alta resolução e suportam alta taxa de contagem, com baixo ruído eletrônico e tempos de conformação do pulso curto, que trabalham no modo dispersivo em energia [87]. O dispositivo de detecção é composto por um disco de Si com uma área ativa de 10 a $20 \mathrm{~mm}^{2}$ montado em um cooler termoelétrico tipo peltier que refrigera o cristal a uma temperatura abaixo dos $-20^{\circ} \mathrm{C}$. Isso facilita seu uso, já que evita a necessidade de resfriá-lo com nitrogênio líquido, como com os detectores de HPGe. Possuem dopagens com propriedades diferentes nas superfícies frontais e posterior, e a janela de entrada possui uma junção p-n ao longo de toda a região passivada. A superfície oposta apresenta uma estrutura de anéis concêntricos dopados para fazer do chip um semicondutor tipo p. Um pequeno anodo que se encontra no centro da superfície posterior faz com que a configuração toda tenha uma capacitância pequena, diminuindo as contagens de ruído, o que melhora a resolução dos espectros medidos.

\subsubsection{Detetores usados nos experimentos}

Detetores de Si com dimensões e sistema eletrônico similares comportam-se de maneira análoga, mas isso não ocorre com detetores de HPGe, em que pequenas diferenças podem mudar a resposta e mesmo exemplares de mesmas dimensões podem responder de modo diferente. Abaixo, descrevemos os detetores usados neste trabalho, fornecendo mais detalhes para aqueles cujas respostas foram determinadas com mais precisão e conseguimos informações mais detalhadas.

\subsubsection{Canberra}

Usamos dois detetores coaxiais manufaturados pela CANBERRA, modelo GR6024, de iguais dimensões, com janela de berílio, $250 \mathrm{~cm}^{3}$ de volume $(72,5 \mathrm{~mm}$ de diâmetro e $60,5 \mathrm{~mm}$ de comprimento) e eficiência de $60 \%$ para fótons de $1332 \mathrm{keV}$. Na figura 3.10, se observam esses detectores montados em um arranjo para detetar os fótons provenientes de uma amostra atingida pelo feixe externo do LAMFI, um deles alinhado com o feixe de prótons do LAMFI, rodeado por 6 Detetores cintiladores de $\mathrm{BGO}$ e o outro, posicionado a $90^{\circ}$ com relação à linha de feixe sem nenhum tipo de blindagem. $O$ primeiro deles foi blindado frontalmente com um cone truncado de $\mathrm{Pb}$ e outros materiais absorvedores como descrito no item 5.1.2. Estes detetores foram usados nos trabalhos das referências [63, 62, 64].

\subsubsection{Planar de 5 cc}

HPGe Planar Ortec 1000 Series Hyperpure Germanuim, com um cristal de 12,5 mm de raio e $10 \mathrm{~mm}$ de espessura, janela de entrada de Be de 0,25 mm de espessura. Relacionado aos trabalhos das referências [60, 30, 34, 33]. Este detetor trabalhou conectado a uma eletrônica analógica da ORTEC, composta por: uma fonte de tensão; um amplificador 572 e um multicanal (ASPEC 927). O software Maestro foi usado na aquisição de dados. Inicialmente este detetor trabalhou dentro de uma blindagem de cobre com um colimador que subtendia toda a área 

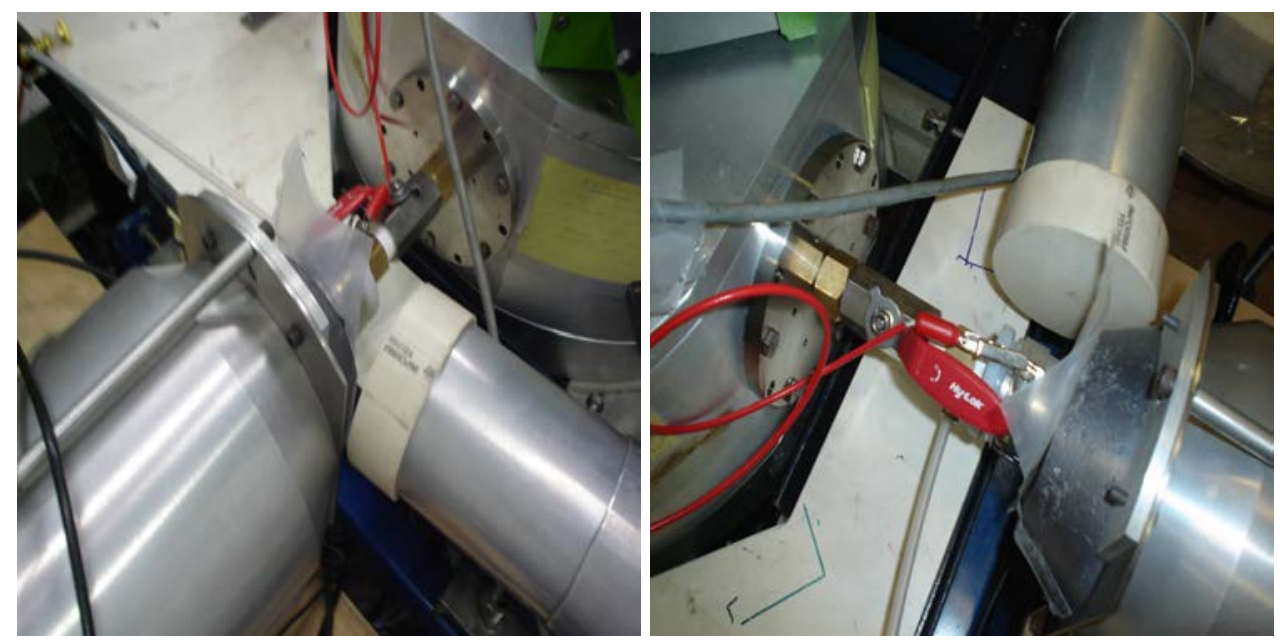

Figura 3.10: Imagens do arranjo dos detectores Canberra no arranjo experimental do LAMFI, que forneceram os dados das publicações [63, 62, 64].

frontal. Após os resultados do trabalho do Viktor Janhke [45], do mapeamento frontal e saber que o detetor possuía uma camada morta frontal irregular, usamos, além daquela blindagem de cobre, anéis de alinhamento e um colimador de cobre com $2 \mathrm{~mm}$ de diâmetro, como mostra a imagem inferior direita da figura 3.9 .

\subsubsection{Planar de 8 cc}

HPGe Planar Ortec 1000 Series Hyperpure Germanium, com um cristal de raio igual a $16 \mathrm{~mm}$ e $10 \mathrm{~mm}$ de espessura, janela de entrada de Be de $0,25 \mathrm{~mm}$ de espessura, com o qual foram adquiridos os espectros para o doutorado de Garcia das referências [30, 34, 33]. Na maioria dessas medições, foi usado um espectrômetro digital DSPEC da ORTEC, controlado pelo software Maestro.

\subsubsection{Coaxial de Janela de C}

HPGe marca ORTEC Solid-State Photon Detector model GMX30P4-70-CW-SMN (ORTEC Advanced Measurement Technology, OakRidge, USA), com 58 mm de diâmetro e 66,3 mm de comprimento, cujo esboço está na figura 3.11 . O furo interno de $10 \mathrm{~mm}$ de diâmetro e $58 \mathrm{~mm}$ de profundidade está enchido parcialmente pelo dedo frio, encarregado de extrair o calor e leválo até a temperatura ideal de operação. O fabricante informou que as camadas mortas do furo interno e das superfícies externas têm espessuras de $700 \mu \mathrm{m}$ e $0,3 \mu \mathrm{m}$, respectivamente, mas medidas posteriores verificaram que a camada morta externa é mais espessa, como veremos adiante. A cápsula que rodeia o cristal é de $\mathrm{Al}$ e possui um diâmetro externo de 69,5 mm, e a janela frontal é feita de C com $0,9 \mathrm{~mm}$ de espessura. Entre a janela e o cristal, o detetor possui uma blindagem infravermelha de $0,03 \mathrm{~mm} / 0,03 \mathrm{~mm} \mathrm{Al} / \mathrm{Mylar}$ à frente da cápsula interna de $\mathrm{Al}$. Todo este conjunto está em vácuo. A eletrônica de aquisição foi o espectrômetro digital DSPEC Jr. e controlado pelo software Maestro. Usamos rejeição de empilhamento e correção do tempo morto. Com este detetor, foram realizados os trabalhos das referências [61, 30, 34, 33]. 

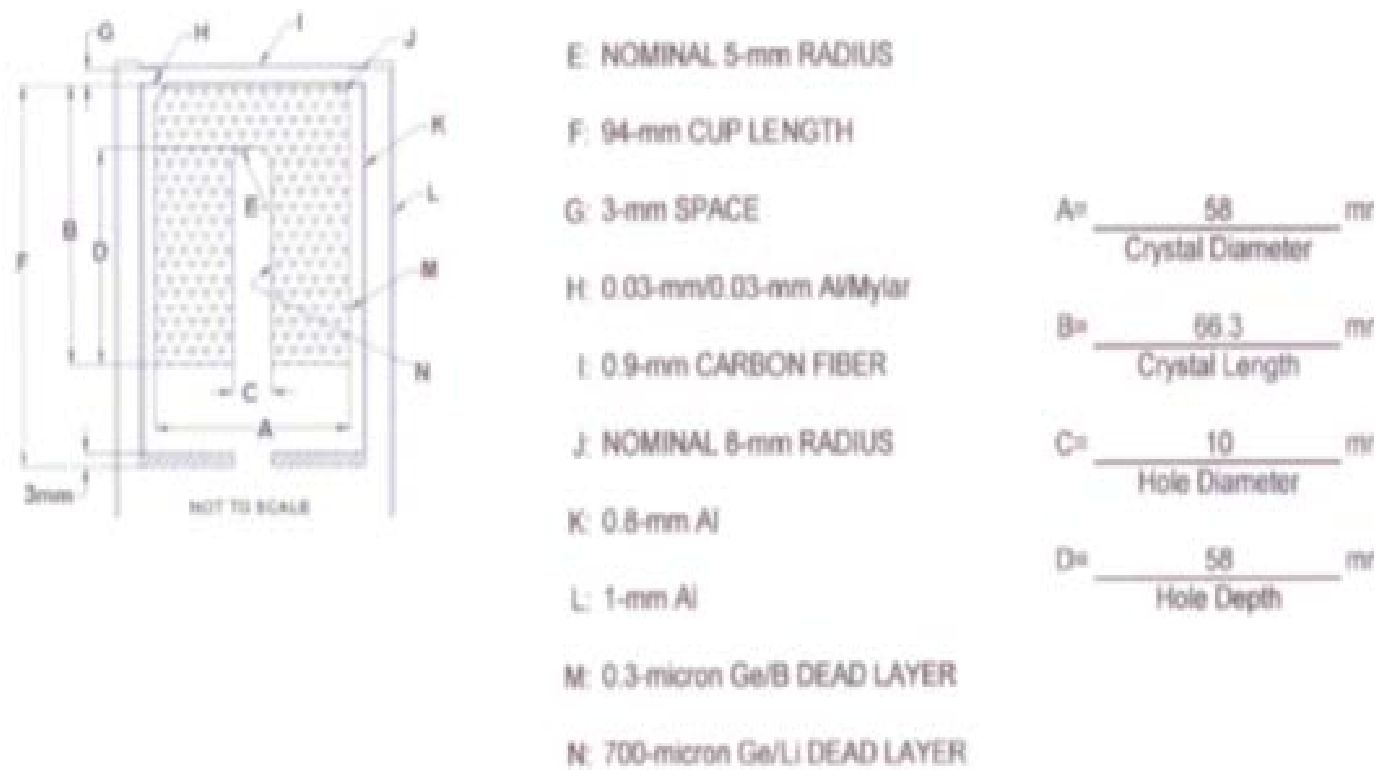

Figura 3.11: Cópia da página do manual do detetor ORTEC, em que estão especificadas as dimensões físicas do elemento ativo e sua cápsula.

\subsubsection{5 $\mathrm{Si}(\mathrm{Li})-(\mathrm{SLP})$}

Si(Li), marca Ortec (Oak Ridge, TN, USA) modelo SLP 10180 P, com diâmetro e espessura de 12 e 4,9 mm, respectivamente, contato frontal de Au com 0,0045(25) $\mu \mathrm{m}$ e janela de Be de $25,4 \mu \mathrm{m}$. Foi usado um espectrômetro digital (DSPEC) que fornecia a voltagem, análise e registro dos pulsos, controlado pelo software Maestro, relacionado ao trabalho de Barros [8].

\subsubsection{SDD}

SDD da Amptek (Bedford, MA, USA). com uma área frontal de $25 \mathrm{~mm}^{2}$, espessura 0,5 mm, com um colimador interno graduado de W, Cr, Ti e Al deixando uma área livre de $17 \mathrm{~mm}^{2} \mathrm{e}$ janela de Be de $12,7 \mu \mathrm{m}$, com o cristal a uma distância de 1,4 mm da janela de entrada. A eletrônica de aquisição consiste em um pré-amplificador, um filtro associado ao ADC, com dois canais de processamento digital (lento e rápido), cada um dos quais possui um discriminador com limiar ajustável, controlado por um analisador multicanal com dois canais de análise. $\mathrm{O}$ canal lento possui melhor resolução e pode também optar por usar a rejeição por empilhamento baseado no canal rápido. Relacionado ao trabalho de doutorado de Barros [11].

Os detetores SDD podem trabalhar a altas taxas de aquisição, mas nos nossos espectros, a quantidade de fótons detetados por unidade de tempo a baixas energias somavam mais da metade dos eventos que o detetor podia resolver quando as taxas de contagem alcançavam os $56 \mathrm{kHz}$. Como o tempo de processamento de pulso é proporcional à energia depositada no evento, as perdas por empilhamento dos pulsos deviam ser corrigidas. Para isso foi proposto um modelo analítico que compensava o espectro medido, já que quando há perdas por empilhamento, a contagem não é depositada em nenhuma das energias dos fótons que empilharam, mas em uma energia que resulta da soma desses dois eventos. A metodologia proposta pode 
corrigir as regiões de baixas energias (L) ou uma fração grande do espectro (ML) quando os espectros são adquiridos a altas taxas de contagens com uma precisão entre 0,5 a 1,0 \% [13]. Duas imagens de um SDD podem ser observadas na figura 3.12 , onde à esquerda se aprecia o detetor sobre a base que o nivelava e o posicionador de polimetilmetacrilato, que garantia a repetitividade na montagem; na imagem da direita, se vê esse detetor sendo alinhado com o auxílio de um nível de laser.
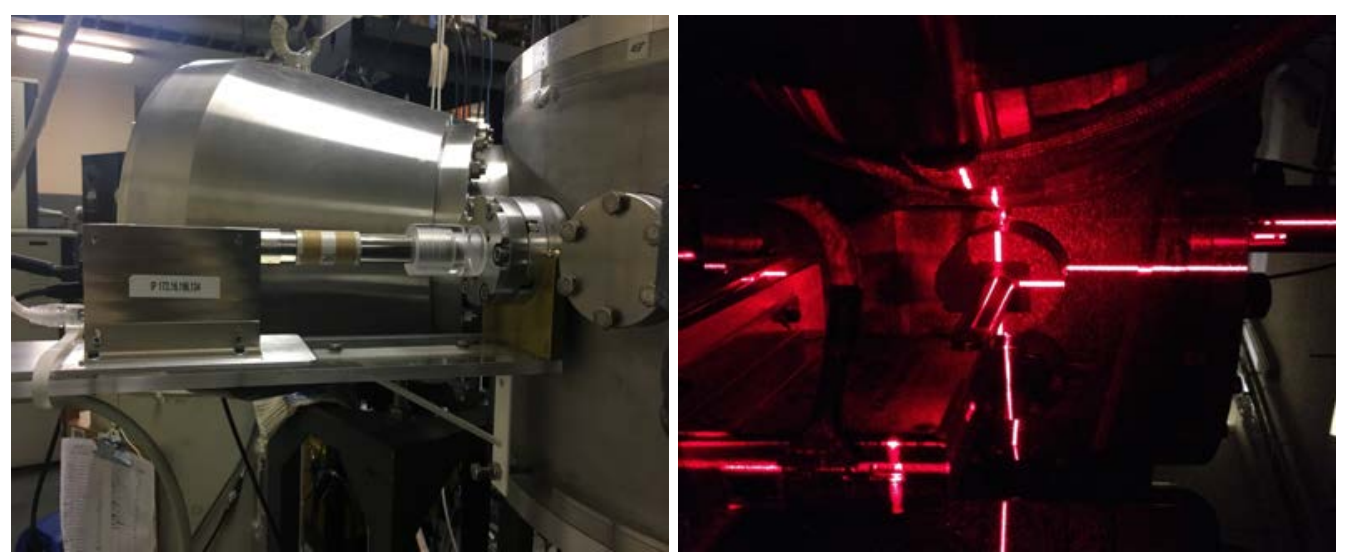

Figura 3.12: Imagens de um SDD na montagem do arranjo de irradiação. À esquerda, o SDD com a extremidade do cristal dentro do posicionador de polimetilmetacrilato, e, no fundo o copo de Faraday. À direita, ressaltam-se as linhas brilhantes do laser que auxiliavam no correto posicionamento do detetor

\subsubsection{Localização do cristal nos detetores}

As cápsulas de vácuo dos detetores de HPGe raramente são abertas, porque a superfície do cristal, que é o elemento ativo, pode oxidar e mudar suas propriedades físicas. Os cristais de Ge são montados sobre uma peça de cerâmica, dentro de um duplo revestimento de alumínio, e faz-se vácuo no interior da cápsula. O criostato permite o esfriamento do detetor, já que uma das extremidades está submersa no nitrogênio líquido contido em um dewar, e a outra extremidade penetra como um "dedo frio" no furo ao longo do eixo do cristal nos detetores coaxiais ou encosta na placa de cerâmica em que os detetores planares são montados. A fim de caracterizar os detetores, é necessário conhecer a posição e as dimensões exatas do cristal, e outros detalhes da peça que conforma o detetor, que estão alojados na cápsula de vácuo, invisíveis ao olho humano.

Assim, desenvolvemos técnicas para encontrar a posição, tamanho e outros detalhes importantes para definir as geometrias de simulação ou parametrizar as funções analíticas. Isto nos trouxe surpresas, como detalhado no artigo [60], em que se verificou que o detetor se encontrava desalinhado em relação à cápsula, e no trabalho que estudou a resposta e eficiência de um detetor HPGe [61], em que se observa uma marcada perda de eficiência no centro do cristal da figura 5.9 .

As técnicas usadas foram: imagens de raios-x ou de raios- $\gamma$ e mapeamento com fontes radioativas. As imagens de raios- $x$ nos forneciam a posição exata do cristal na cápsula de alumínio e detalhes vários, como posição de componentes eletrônicos, mas não as espessuras das camadas mortas, que apesar de serem passivadas com a implantação de outros materiais, 
possuem a mesma densidade que o próprio volume ativo, mas podem ser determinadas por mapeamento com pincéis de fótons. Com frequência, os valores experimentais das espessuras das camadas mortas estão em desacordo com os dados fornecidos nos manuais dos detetores entregues pelos fabricantes. Os raios- $\gamma$ foram necessários para determinar a estrutura interna dos cristais de HPGe. Essas técnicas serão detalhadas a seguir.

\subsubsection{Imagens de raios-x}

Usamos duas fontes de raios-x diferentes. Uma delas, do Instituto de Pesquisas energéticas e Nucleares, que impressionavam placas radiográficas tradicionais de emulsão fotográfica. Imagens do posicionamento de um dos detetores Canberra na inspeção por raios-X se observam na figura 3.13, e os próprios raios-x desde dois planos de observação perpendiculares desse detetor, na figura 3.14. Dessas imagens, soubemos que o cristal de um desses detetores não estava alinhado com a cápsula externa, de $\mathrm{Al}$.

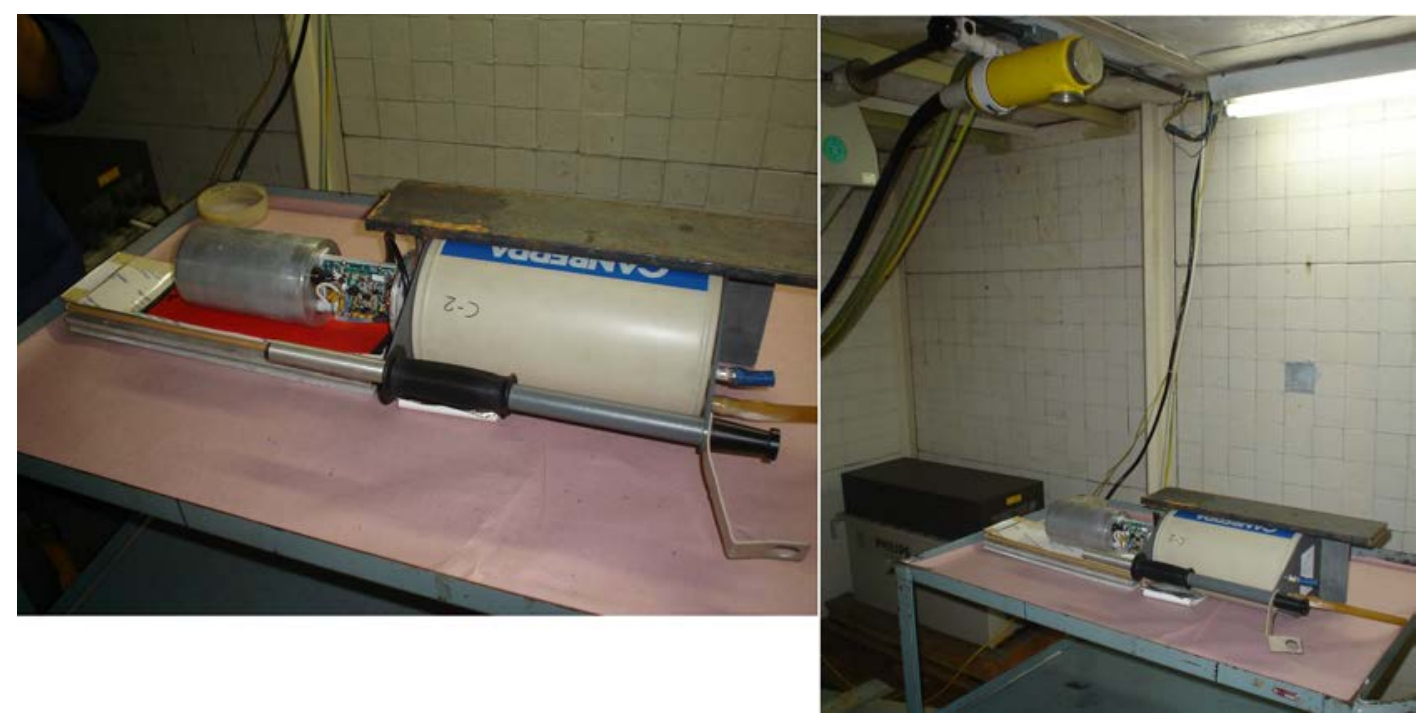

Figura 3.13: Imagens do posicionamento do detetor e fonte de raios-X do IPEN.

Posteriormente, obtivemos imagens dos outros detectores com um sistema Highly Stabilized $x$-rays MG225/450 marca Philips, que sensibilizava placas digitais que eram depois processadas no sistema Agfa tipo 5175/100 CR-30. Este sistema é acoplado a um computador com um programa que interpreta, faz o gráfico da informação extraída da chapa e gera um arquivo digital, como a mostrada na figura 3.15 dos detetores planares de 5 e $8 \mathrm{cc}$. Todo o sistema pertence ao grupo de Dosimetria das Radiações do Departamento de Física Nuclear do IFUSP.

Nesta segunda etapa de obtenção de imagens dos cristais, os detetores eram colocados a 3,2 m do aparelho e a placa, a 20,5 cm atrás do centro do detetor, alinhado por meio de um nível a laser. As condições de operação para adquirir as imagens foram $50 \mathrm{kV}, 10 \mathrm{~mA}$ durante $30 \mathrm{~s}$.

$\mathrm{O}$ detector de $\mathrm{Si}(\mathrm{Li})$ também foi radiografado. A imagem correspondente aparece na figura 3.16. Não foi possível encontrar o manual deste detetor, mas conseguimos determinar a posição e o tamanho do cristal por meio dessa placa radiográfica. 

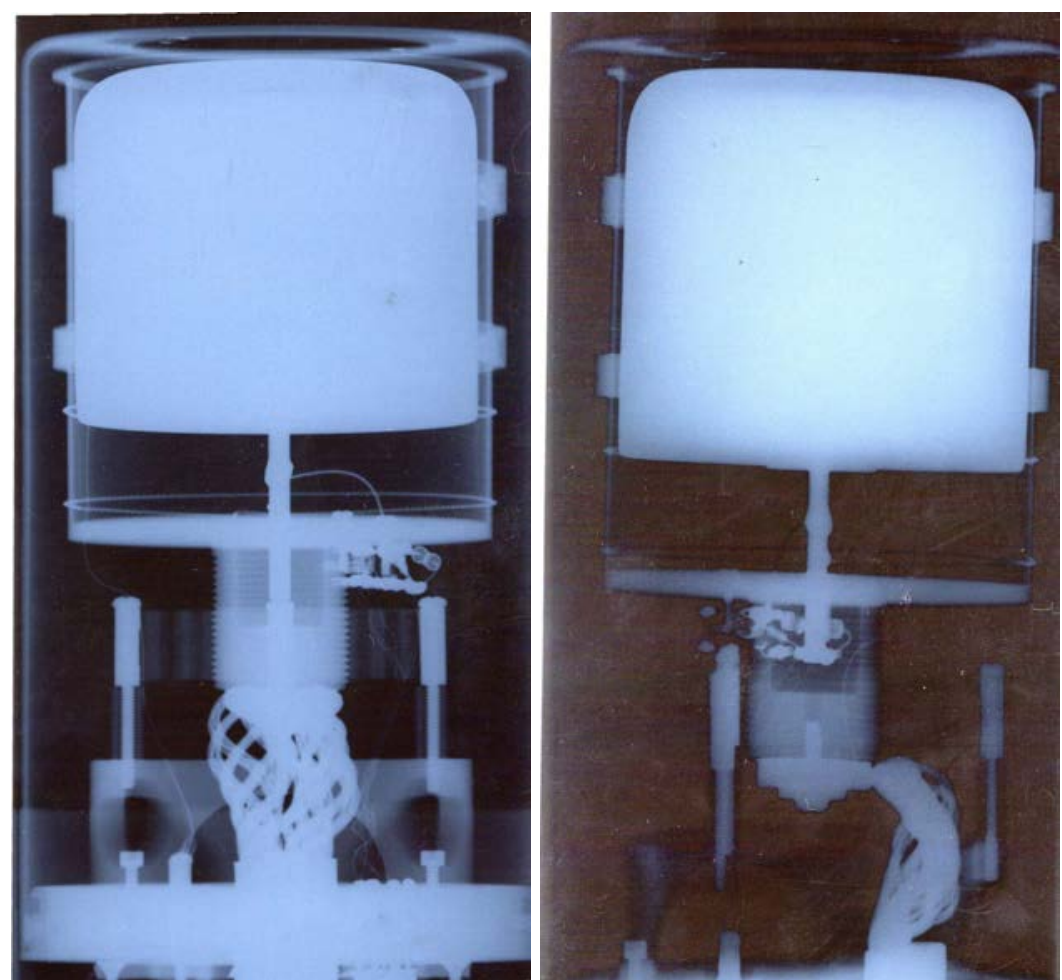

Figura 3.14: Imagens de raios-x do detetor Canberra (item 3.2.4.1) desde dois ângulos de incidência perpendiculares ao eixo.

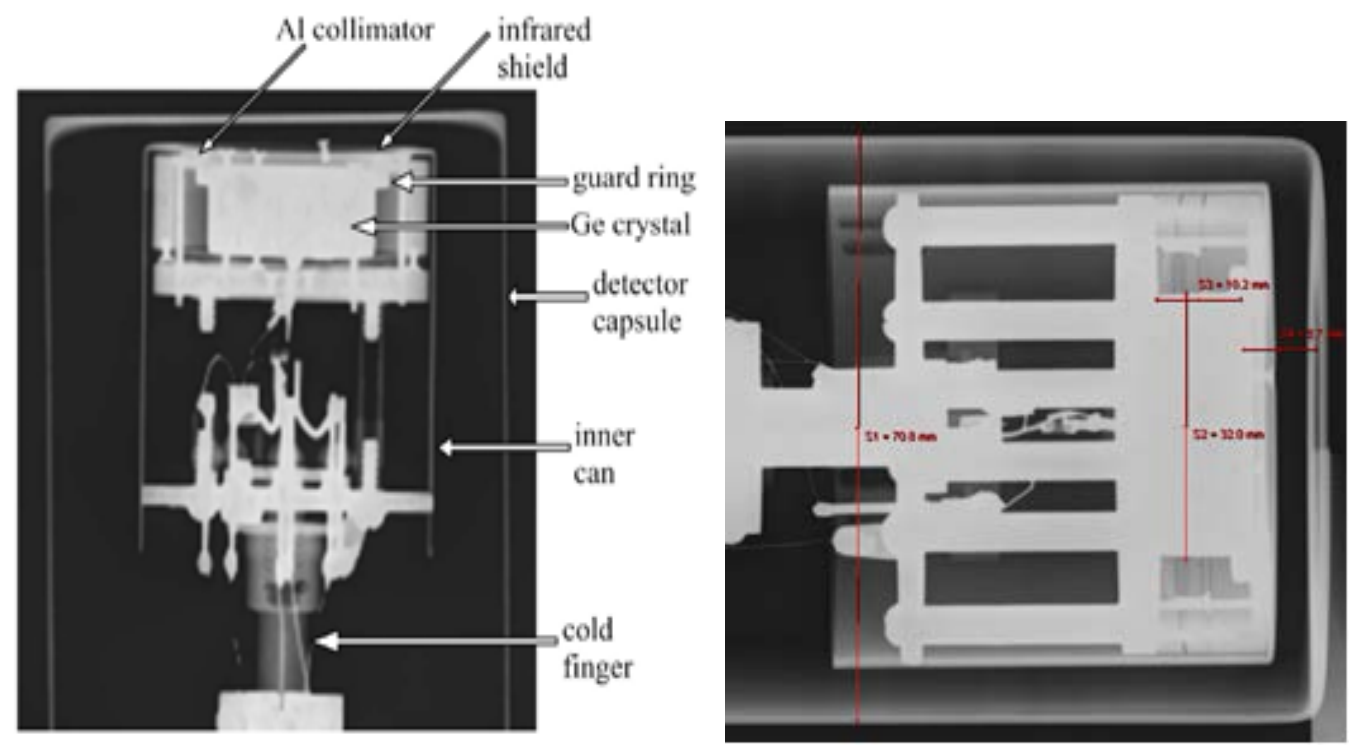

Figura 3.15: Imagem de raio-x dos dois detetores planares dos trabalhos [60, 91]. A imagem da esquerda mostra que o cristal está descentrado e desalinhado no sentido longitudinal. A imagem da direita mostra o detetor planar de $8 \mathrm{cc}$ bem alinhado com a cápsula, mas não perfeitamente centralizado.

\subsubsection{Imagens de raios $\gamma$}

Os aparelhos usados para radiografar os detetores não fornecem fótons com energia suficiente para penetrar um cristal coaxial de Ge e observar a profundidade do furo interno, nem mensurar quanto o dedo frio penetra nesse furo. A maneira de obter fótons mais energéticos foi usar a fonte de ${ }^{60} \mathrm{Co}$ do grupo de Dosimetria das Radiações do DFN, cujos fótons de 1173 


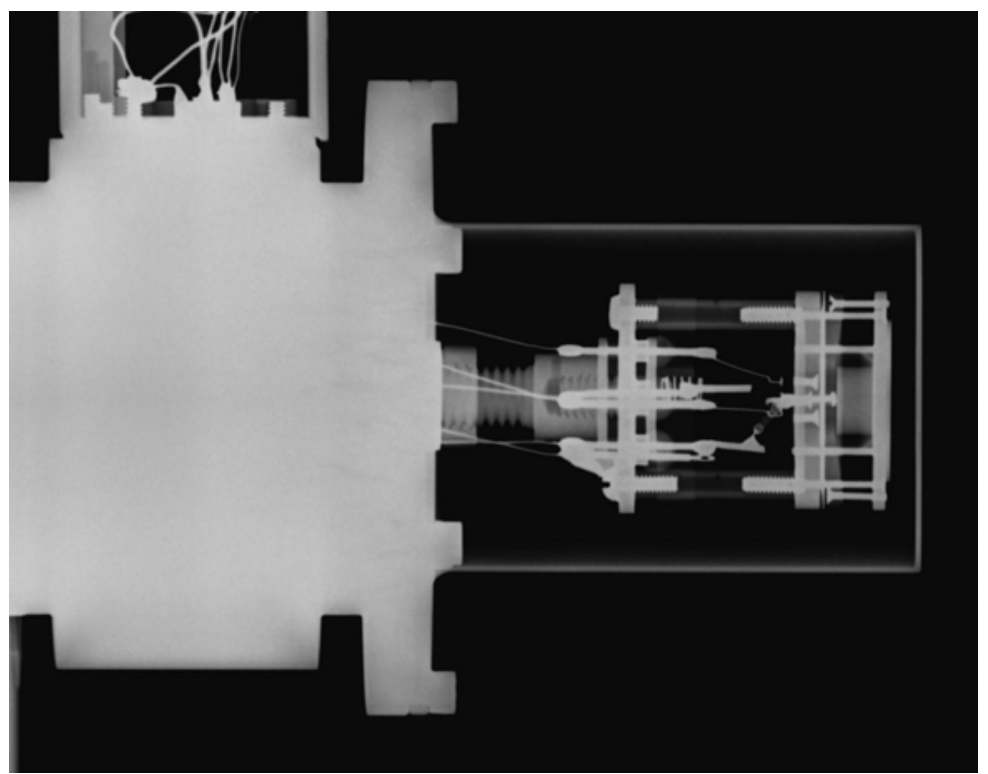

Figura 3.16: Imagem do raio-x do detetor $\mathrm{Si}(\mathrm{Li})$ do trabalho de Barros [8].

e $1332 \mathrm{keV}$ permitiram discriminar esse tipo de detalhes, como se observa na figura 3.17. As linhas sobrepostas a imagem do cristal à direita foram desenhadas com o programa que interpreta os dados da placa. Nessas imagens também pode ser observado o furo interno, com um diâmetro de 9,9 mm (mas entendemos que a medida sobre a imagem tem uma incerteza, então aceitamos o valor informado no manual). Por outro lado, dado que a forma e dimensão do quanto do dedo frio penetra nesse furo não é informado, estimamos que penetrava algo assim como um $40 \%$, que, contrariamente ao suposto, não preenche o volume todo do furo.
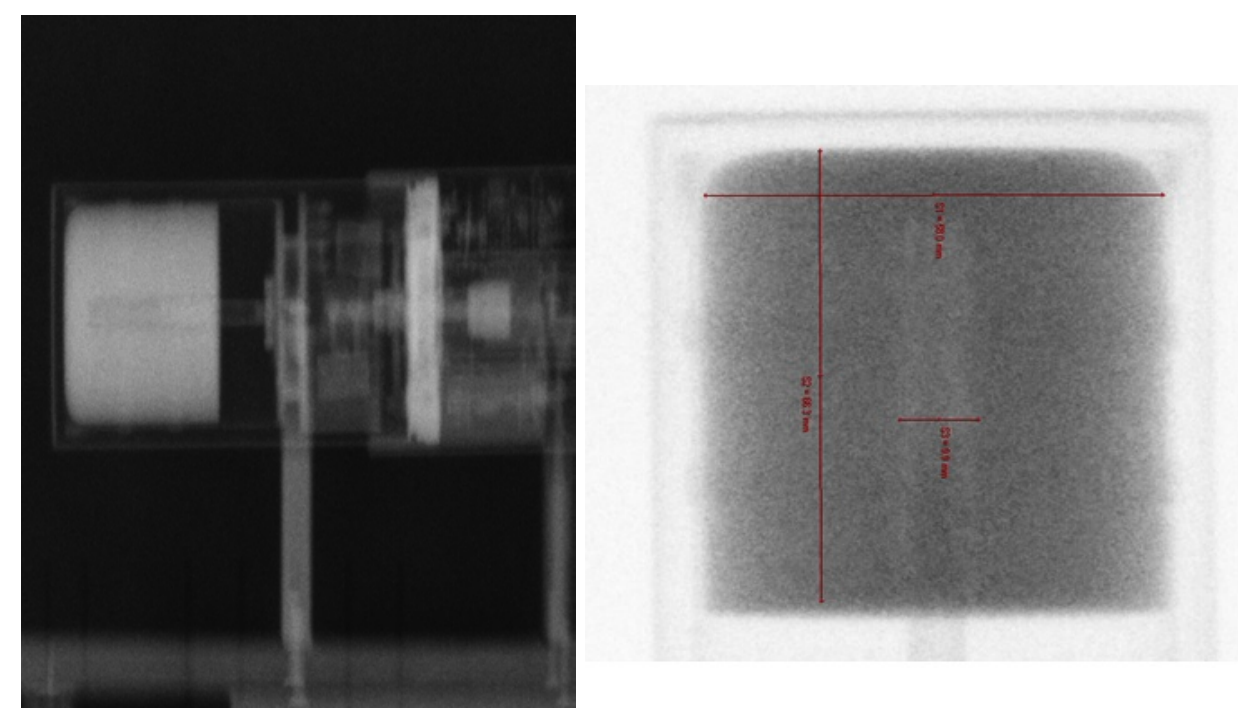

Figura 3.17: Imagem de gamagrafia do cristal de HPGe coaxial, com fonte de ${ }^{60} \mathrm{Co}$, usado nos trabalhos das referências [61, 8, 30]. 


\subsection{Colimadores}

O uso de colimadores tem sido uma constante nos nossos experimentos. Já a partir de 2004, fizemos trabalhos de iniciação científica [77] usando colimadores e testando diferentes formas por simulação para escolher aquele que menores efeitos secundários trouxesse. As aplicações foram as seguintes:

- Garantir incidência normal dos fótons sobre o detetor. Como será explicado no ítem 4.3. o modelo de Seltzer para o cálculo da resposta supõe feixe de fótons paralelo e bem colimado.

- Selecionar uma região do elemento ativo do detetor. No caso do detetor planar de $5 \mathrm{cc}$ cuja camada morta frontal era irregular [60], permitiu limitar o feixe de fótons à área com camada morta fina e uniforme. No caso do detetor coaxial de HPGe no arranjo da medida de bremsstrahlung, limitou a detecção à região do volume ativo com melhor eficiência e que pode ser modelada com precisão para fótons de energia $<100 \mathrm{keV}$.

- Definir o ângulo de emissão ou espalhamento do fóton. Necessário nas medidas de distribuição angular dos fótons de bremsstrahlung e dos raios-x L provenientes da ionização por impacto.

- Determinar a espessura da camada mortal frontal dos detetores de HPGe. O item 3.3.1 detalha este uso.

- Minimizar a detecção de eventos por espalhamento no ambiente. Além de usados nos detetores colocados junto à câmara de irradiação, foi aplicado na determinação da função resposta do detetor coaxial, como será detalhado no item 3.3 .2 .

\subsubsection{Determinação da camada morta do detetor HPGe}

Construiu-se um bloco de chumbo de seção trapezoidal, com $10 \mathrm{~cm}$ de espessura, que permitia a incidência a $90^{\circ}$ e $45^{\circ}$ dos fótons provenientes de fontes de calibração, através de um pequeno furo de $2 \mathrm{~mm}$ de diâmetro; a seção 3.4 detalha como medidas com esse colimador permitem determinar a camada morta. Não era aconselhável que o furo por onde atravessariam os fótons fosse feito diretamente no próprio chumbo, dada a particularidade desse material ser muito maleável e perder a forma ante qualquer pequeno impacto, o que causaria a perda da forma e área, que devia ser uniforme, ao longo da espessura. Solicitamos então que fosse fabricado pela empresa Brassinter um colimador de metal pesado, com $2 \mathrm{~cm}$ de diâmetro externo e 2 mm de diâmetro interno, da liga NF3515, que possui 90 \% de W e o restante de Ni e Fe. Esse colimador foi usado no mapeamento do detetor coaxial do item 3.4 .2 .

\subsubsection{Controle da fonte de radiação}

O outro colimador também foi construído em metal pesado com $1 \mathrm{~cm}$ de diâmetro interno $2 \mathrm{~cm}$ de diâmetro externo e $18 \mathrm{~cm}$ de comprimento de acordo ao desenho da figura 3.19 (correspondente ao trabalho de doutorado de López [56], e García-Alvarez descrito no item 5.2.3]. 


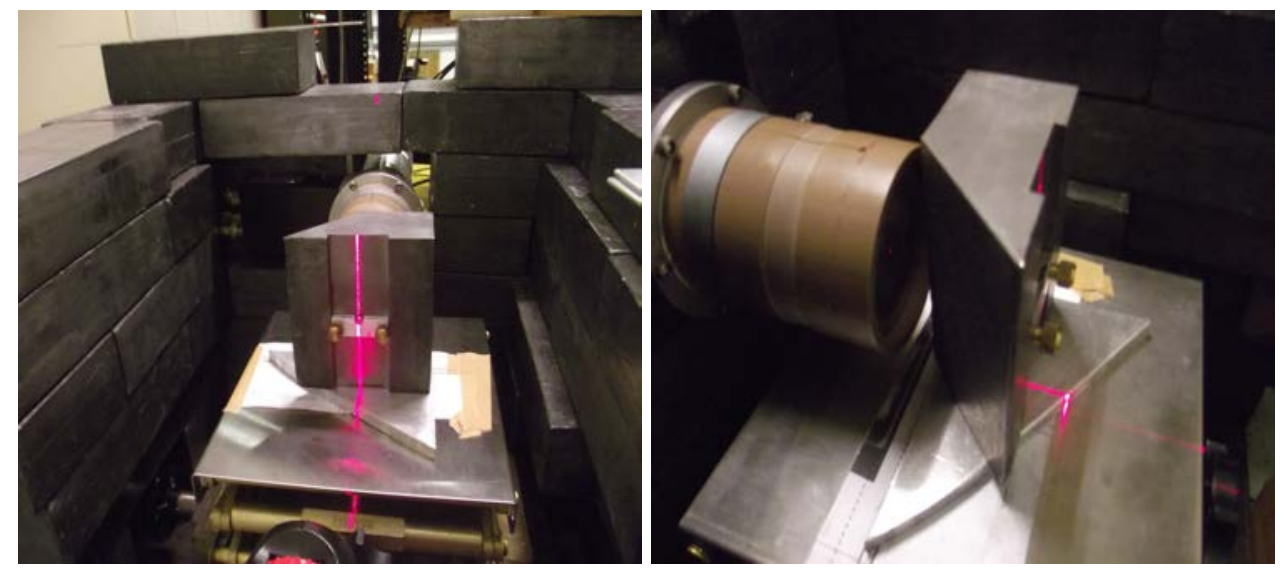

Figura 3.18: Imagens do colimador de forma trapezoidal para mapeamento manual.

Tinha esse comprimento a fim de ser usado nas medidas de López [56], quando irradiamos amostras com elétrons de $1,9 \mathrm{MeV}$, por outro lado, o alargamento na base facilitava a fixação dentro de um bloco de chumbo e garantia a blindagem fora do furo.

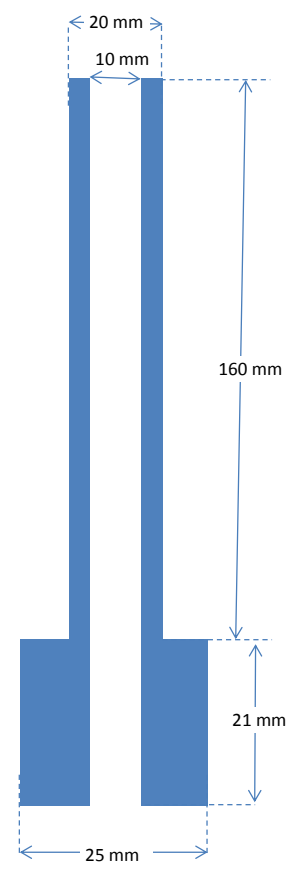

Figura 3.19: Desenho do colimador de metal pesado, fora de escala.

\subsection{Mapeamento dos detectores}

Como já comentado, as superfícies interna e externa ou frontal e posterior dos cristais de Ge nos detetores coaxiais e planares são dopadas a fim de formar os eletrodos e polarizar o cristal, de modo a permitir a coleção dos elétrons promovidos à banda de condução no interior do cristal. 
Além da posição e dimensões precisas do cristal na cápsula, as espessuras dessas camadas mortas precisam ser conhecidas para calcular a função resposta e a eficiência dos detetores. Normalmente, esse dado é fornecido pelo fabricante, mas há relatos sobre o aumento da espessura das camadas mortas com o decorrer do tempo [43, 42, 53].

O mapeamento da espessura da camada morta dos detetores iniciou-se com um sistema manual, descrito abaixo na seção 3.4.1. Os resultados obtidos com esse mapeamento apontaram a necessidade de um sistema automatizado, descrito na seção 3.4.2.

Para verificar a resolução e reprodutividade espaciais do mapeamento, uma placa radiográfica foi colocada no lugar da superfície frontal do cristal de germânio e, com uma fonte de ${ }^{241}$ Am presa ao colimador trapezoidal da figura 3.18 , posicionado sobre uma mesa móvel, foi realizada a sequência de operações explicada a seguir.

A figura 3.20 mostra: a) um traço horizontal e outro vertical, que provêm das varreduras em duas direções perpendiculares, com $2 \mathrm{~h}$ de tempo de exposição para cada ponto; b) as marcas do teste realizado para verificar a repetitividade do posicionamento do colimador. Neste último teste, a placa radiográfica foi colocada na posição mencionada e, após o tempo de impressão, a mesa foi movimentada para outras três posições, foi retirada da montagem e foi novamente colocada na posição do detetor para uma nova rodada de pontos. Os pontos mais escuros correspondem a maior tempo de exposição. Verificou-se desta maneira que a mesa voltava à posição, na precisão da medida.

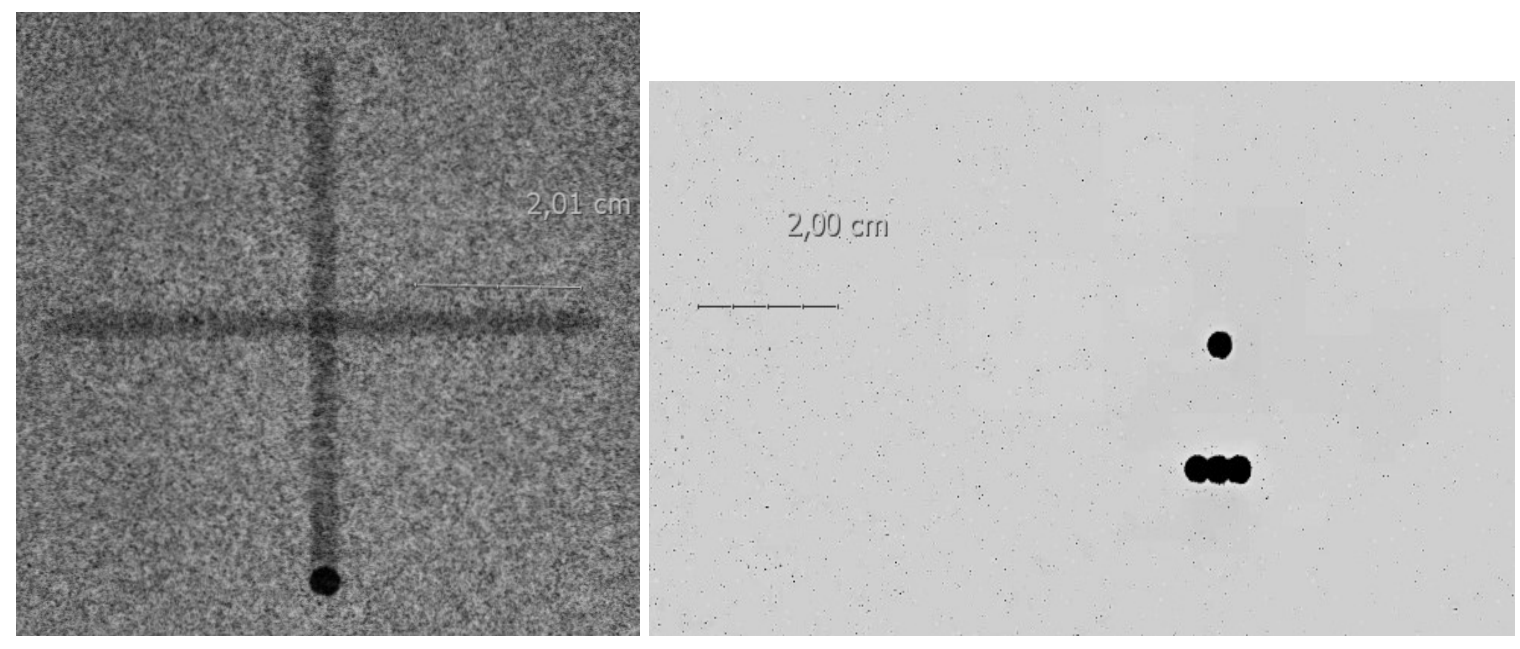

Figura 3.20: Imagens do spot que os fótons da fonte radioativa produziam na placa durante o teste da precisão da mesa $x-y$. À esquerda, a verificação de varredura em duas direções perpendiculares; à direita, comprovação da repetitividade no posicionamento do conjunto fonte-colimador-detetor.

\subsubsection{Detetor planar}

O mapeamento frontal do detetor planar foi realizado para determinar a espessura da camada morta frontal, que foi estudada com um arranjo que consistia em uma mesa $x-y$ cujo movimento nas direções horizontal e vertical era realizado manualmente. A fonte radioativa foi posicionada na parte posterior do colimador de $\mathrm{Pb}$, como o da figura 3.18, similar ao do trabalho de Boson [17]. O detetor estava blindado por 5 lados, a exceção daquele onde era operada a 
mesa $x-y$. Detalhes desse arranjo podem ser observados na figura 3.21. As medidas foram obtidas numa grade de $3 \times 3 \mathrm{~mm}^{2}$. O centro da janela frontal foi identificado com um nível de laser e o mapeamento foi realizado com fontes calibradas de ${ }^{241} \mathrm{Am}$ e ${ }^{152} \mathrm{Eu}$ da Amersham. Os detalhes da montagem desse mapeamento podem ser vistos nas imagens das figuras 3.21 e na figura 3.22 .
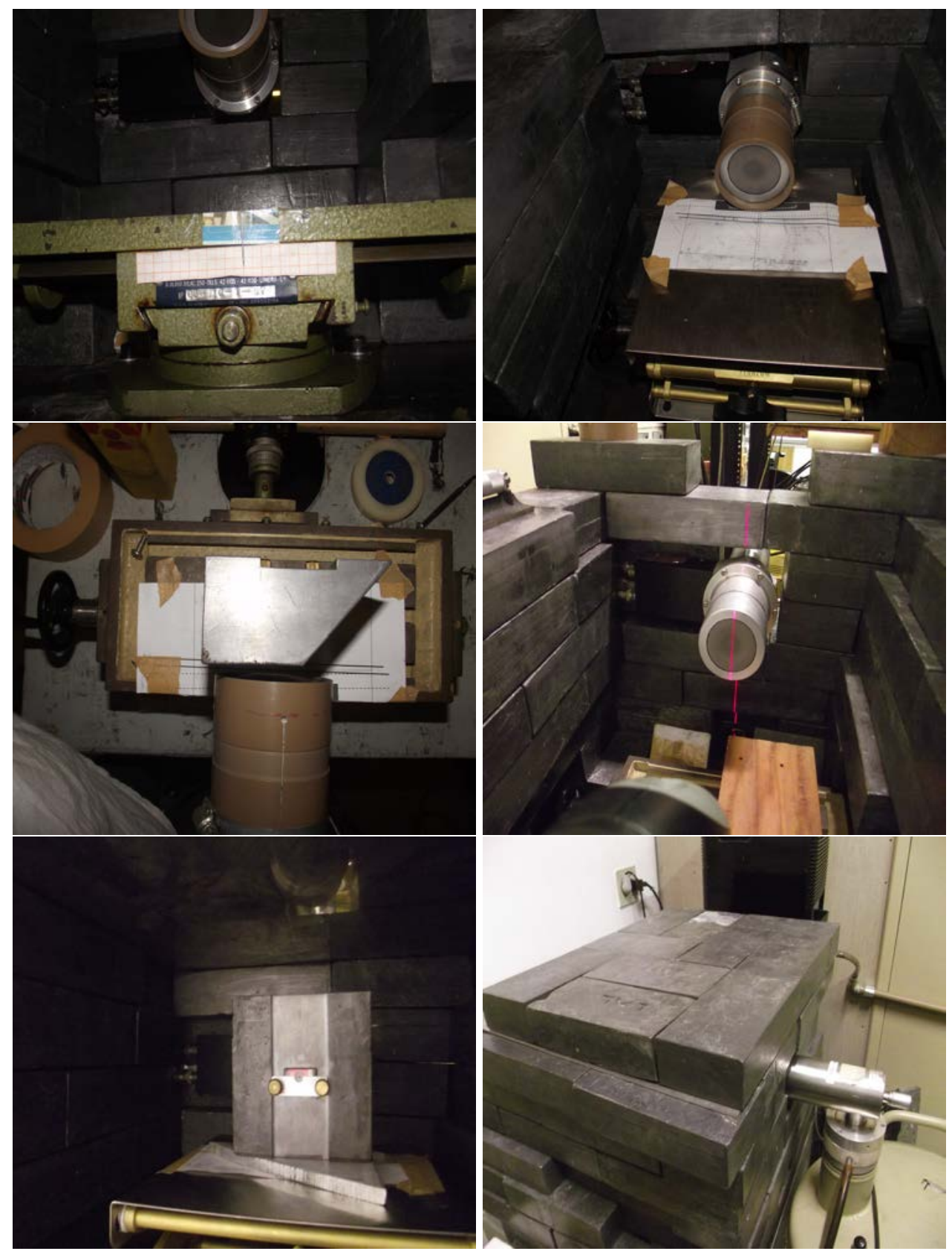

Figura 3.21: Imagens do arranjo do mapeamento frontal, com a mesa $x-y$ manual.

\subsubsection{Detetor coaxial}

A fim de corroborar os valores das espessuras das camadas mortas especificadas pelo fabricante do detetor coaxial GMX30P4-70-CW-SMN, foram feitos os mapeamentos frontal e lateral. No primeiro deles foi usada uma fonte de ${ }^{133} \mathrm{Ba}$ e para o mapeamento lateral uma de 


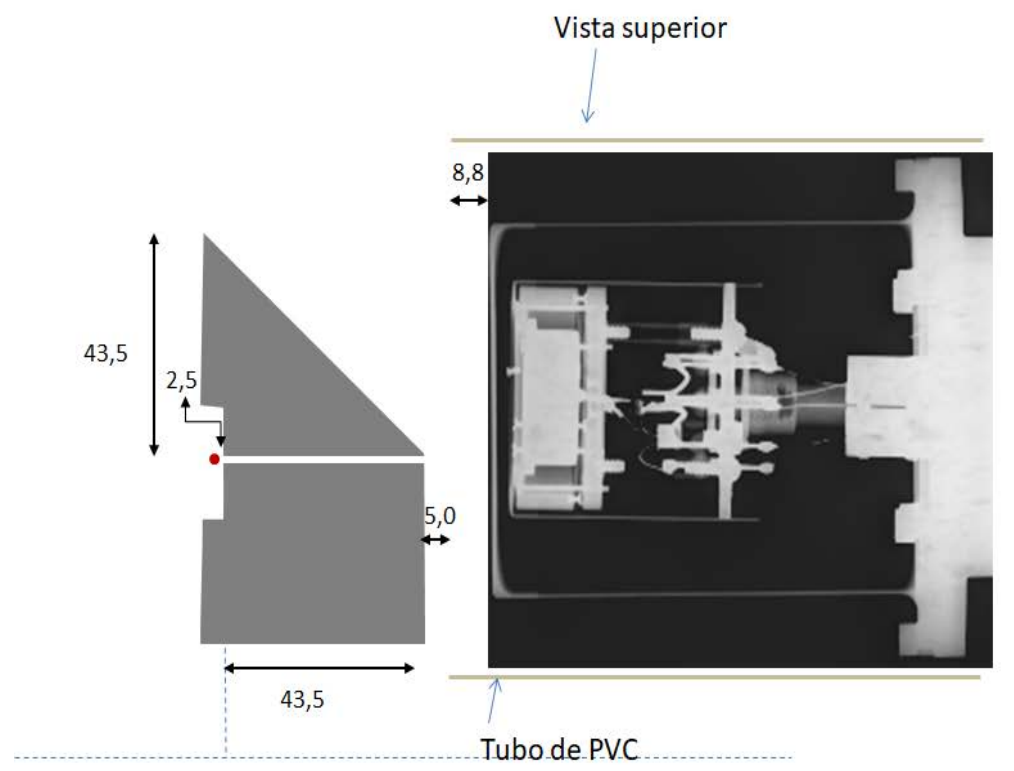

Figura 3.22: Exemplo do posicionamento do colimador à frente do Detector planar de $5 \mathrm{cc}$. Nela podem ser vistos um esquema do colimador trapezoidal frente à cápsula de $\mathrm{Al}$ na imagem de raios-x desse detetor.

${ }^{137} \mathrm{Cs}$, ambas da Amersham. Imagens do arranjo podem ser vistas na figura 3.23 . Desta vez, trabalhamos com uma mesa $x-y$ automatizada, a qual era movimentada por dois motores de passo, de maneira a varrer as superfícies de interesse com espaçamento entre os centros dos spots de $3 \mathrm{~mm}$ em cada direção. A movimentação era realizada por software e permitiu o deslocamento com precisão de centésimo de $\mathrm{mm}$. Para isso, a fonte de calibração foi posicionada no colimador com forma irregular, na parte posterior do bloco de chumbo, em cujo interior foi colocado o colimador de metal pesado de $2 \mathrm{~mm}$ de diâmetro interno descrito na seção 3.3 .

A varredura lateral consistiu em medir, em aproximadamente 700 pontos, a eficiência de pico com fótons de $31 \mathrm{keV}$ e $661 \mathrm{keV}$ provenientes de uma fonte de calibração de ${ }^{137} \mathrm{Cs}$.

\subsection{Fontes de calibração}

Na equação (2.6), usada para obter os resultados de secções de choque, aparecem todos os parâmetros com os quais se calcula dita grandeza; entende-se então que a precisão desses parâmetros define a precisão do resultado. A eficiência de detecção, $\varepsilon(E)$, é determinada experimentalmente pela medida de fontes radioativas calibradas em geometrias reprodutíveis, e buscávamos obter uma calibração de eficiência com precisão melhor que $5 \%$. Na tentativa de minimizar as incertezas, decidimos investir na precisão dessa calibração, que estava diretamente ligada aos materiais e metodologia de medida das fontes padronizadas. Para energias abaixo de $100 \mathrm{keV}$, são importantes todos os materiais interpostos entre a fonte e o volume ativo do detetor, usados para construir as fontes, os alvos e as janelas da câmara, bem como as distâncias que os fótons percorrem no ar. Assim, as espessuras e composições químicas de todos esses atenuadores deviam ser conhecidas com precisão para efetuar as correções necessárias.

As fontes usadas normalmente para calibração de eficiência e energia são fornecidas por empresas qualificadas e são robustas, o que atenua radiação de energia mais baixa. Temos assim 

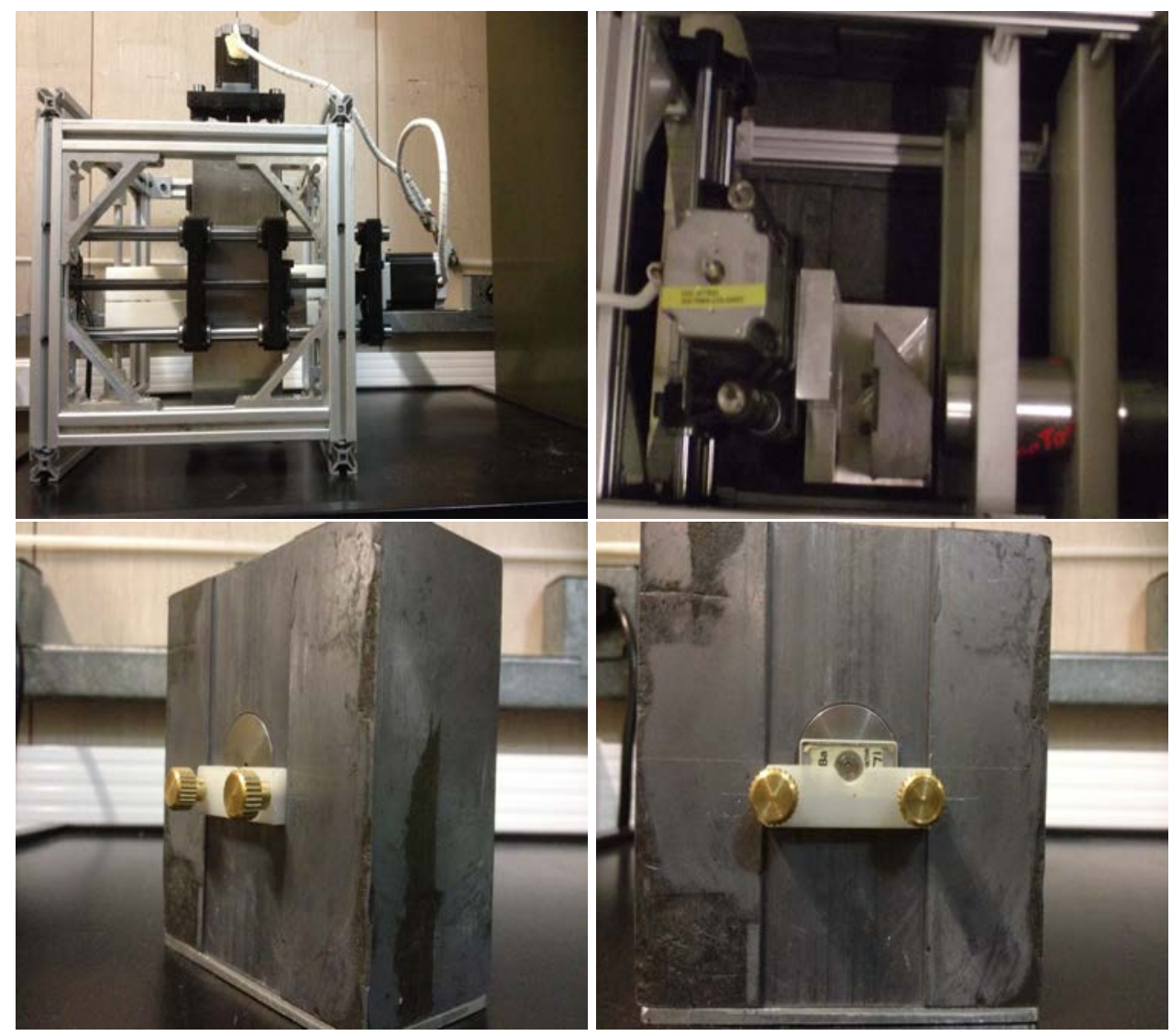

Figura 3.23: Imagens fotográficas da mesa $x-y$ com o suporte e o colimador. As estruturas de alumínio fixavam os motores de passo. A imagem de cima direita mostra o detetor fixado entre duas placas de polietileno com o colimador a frente. $\mathrm{O}$ colimador com coração de metal pesado pode ser visto nas duas últimas imagens.

as fontes Amersham, que consistem em pequenas matrizes de polimetilmetacrilato com uma espessura de aproximadamente $3 \mathrm{~mm}$, com o material radioativo localizado no centro, podendo ser consideradas pontuais. A Agência Internacional de Energia Atômica (AIEA-ONU) forneceu fontes encapsuladas em discos de $\mathrm{Al}$, com espessura similar à anterior. O Laboratório de Metrologia Nuclear do IPEN produz fontes encapsuladas em polietileno com aproximadamente $1 \mathrm{~mm}$ de espessura. Todas essas cápsulas atenuam fortemente os fótons abaixo dos $30 \mathrm{keV}$, mas como a menor energia de calibração usada normalmente corresponde ao gama de $59 \mathrm{keV}$ do ${ }^{241} \mathrm{Am}$, isso não é um problema comum. No entanto, precisávamos de alta precisão a energias bem mais baixas, de modo que as fontes de calibração usadas foram desenvolvidas especialmente para os experimentos que efetuamos.

\subsubsection{Montagem em anéis de Al}

A figura 3.5 mostra o suporte de fontes da torre original, que consistia em um suporte de $\mathrm{Al}$ onde eram fixadas as fontes. Nos primeiros trabalhos, as calibrações usaram fontes radioativas padrão da Amersham e algumas confeccionadas no Laboratório de Metrologia Nuclear do IPEN/CNEN-SP. As primeiras delas foram montadas entre duas folhas de polietileno fixadas por um par de aros de Al, mas a espessura do polietileno absorvia os fótons de baixa energia. Foi assim que foram confeccionadas novas fontes entre duas folhas de mylar com o mesmo tipo 
de fixação, veja a figura 3.24

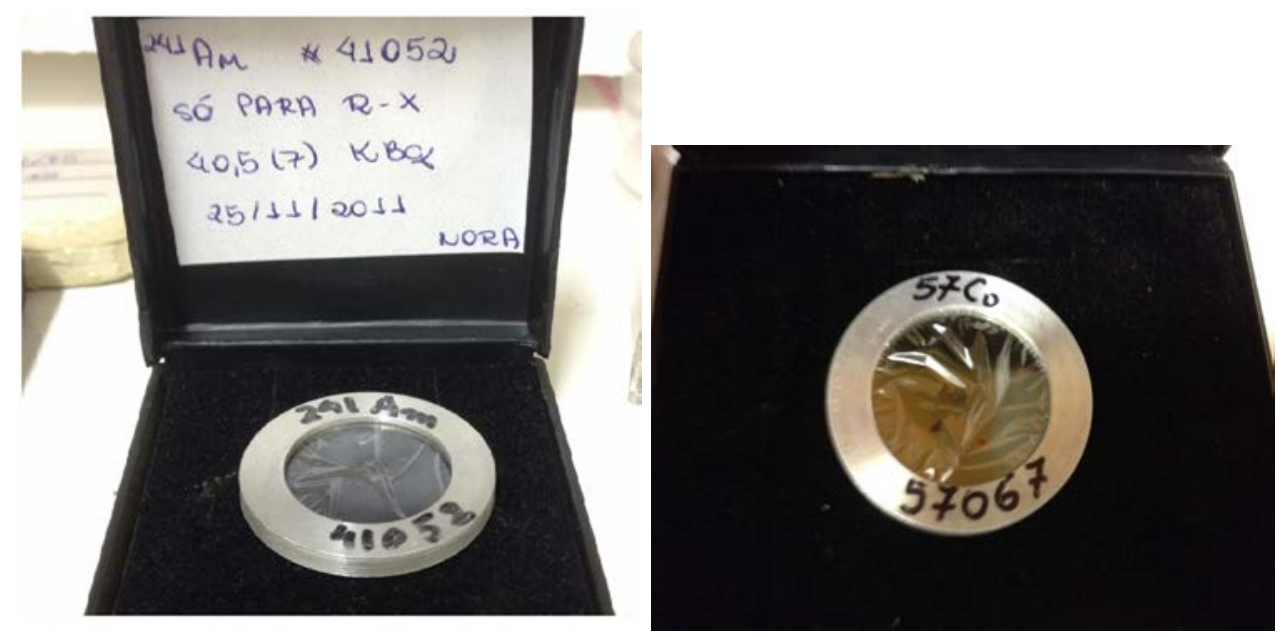

Figura 3.24: Imagens das fontes de ${ }^{241} \mathrm{Am} \mathrm{e}{ }^{57} \mathrm{Co}$ confeccionadas entre duas folhas de Mylar fixadas por um aro de Al sobre um anel do mesmo material.

\subsubsection{Fonte de ${ }^{198} \mathrm{Au}$}

A fim de verificar o comportamento irregular observado na curva de eficiência do detetor planar de $5 \mathrm{cc}$ (item 5.3.1, foi confeccionada uma fonte de ${ }^{198} \mathrm{Au}$, que possui uma meia vida de $2,7 \mathrm{~d}$, decaindo por $\beta^{-}$para o ${ }^{198} \mathrm{Hg}$; as transições gama no filho convertem e causam a emissão de raios- $\mathrm{x}$ do $\mathrm{Hg}, \mathrm{K} \alpha 1$ de $70,82 \mathrm{keV}$ com uma probabilidade de emissão por decaimento de 1,369(24)\% e x K $\alpha 2$ de 68,90 keV com uma probabilidade de emissão de 0,807(15)\% [15].

A fonte foi confeccionada com uma porção de folha de Au 99,99\% de pureza irradiada no reator IEA-R5 do IPEN. A mesma foi encapsulada entre duas folhas de mylar presas em anéis de Al, como mostra a imagem 3.25, tomada sobre uma folha de papel milimetrado; na figura, também está uma cópia do certificado de calibração da mesma. A imagem escaneada da fonte sobre o papel quadriculado teve o objetivo de determinar a área da porção da folha de Au.

Para calcular a autoatenuação dos raios-x dessa fonte, precisávamos saber sua espessura, que foi calculada com os dados de área igual a $8 \pm 1 \mathrm{~mm}^{2}$. Sua massa foi medida e era igual a $0,001552 \mathrm{~g}$. Sabendo a densidade do Au, consideramos que a espessura era de 0,0010 cm e a densidade superficial de massa de $20 \pm 3 \mathrm{mg} / \mathrm{cm}^{2}$. Como o coeficiente de atenuação de massa a $70 \mathrm{keV}$ é $3,0 \mathrm{~cm}^{2} / \mathrm{g}$, a auto-atenuação resultou ser de aproximadamente $3 \%$ dos fótons $\mathrm{K} \alpha 1$ de $\mathrm{Hg}$ emitidos. Essa autoatenuação não foi considerada quando da calibração dessa fonte, que usou o gama de $411 \mathrm{keV}$, energia em que a atenuação por essa espessura pode ser ignorada.

\subsubsection{Montagem em molduras de C}

Nos trabalhos das publicações [30, 34, 34, 9, 11, 14, 12], as medições foram realizadas com o detetor encostado numa janela da câmara de irradiação, que está evacuada. As calibrações ideais requeriam medidas com geometrias tão similares quanto possível, aquelas usadas nas medidas dos fótons gerados pela interação dos elétrons com os diferentes alvos, isto é, os 

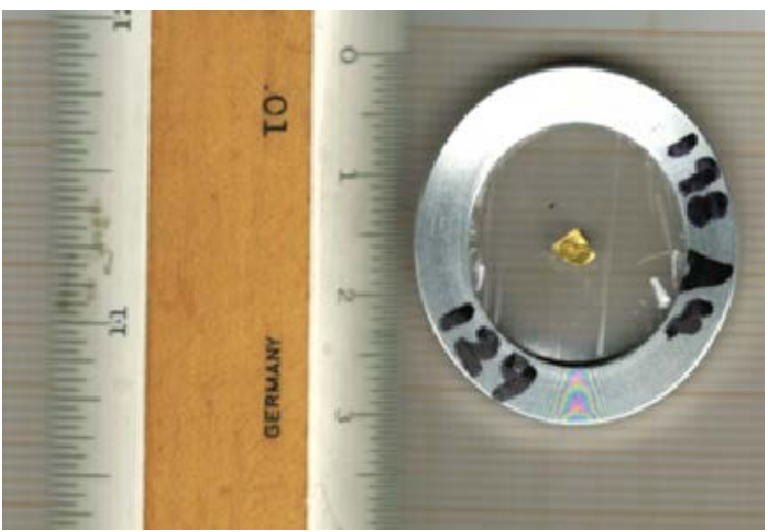

$-((c-))$

toen

Imn LABORATÓRIO DE METROLOGIA NUCLEAR

CENTRO DO REATOR DE PESQUISAS

CERTIFICADO DE CALIBRACGÃO DE FONTES RADIOATIVAS

Certificado $n^{\circ}:$ AEC- 02/2012

Destinatário: IFUSP Dra. Nora Lia Maidana

Data: $\quad 25 / 05 / 2012$

\begin{tabular}{|c|c|c|c|c|}
\hline Radionuclideo & $\begin{array}{c}\text { Fonte } \\
\mathrm{n}^{2}\end{array}$ & $\begin{array}{c}\text { Atividade } \\
(\mathrm{kBq})\end{array}$ & $\begin{array}{c}\text { Incerteza* } \\
\%\end{array}$ & $\begin{array}{c}\text { Data Ref. } \\
00: 00 \mathrm{~h}\end{array}$ \\
\hline${ }^{198} \mathrm{Au}$ & 129 & 195 & 1,6 & $25 / 04 / 2012$ \\
\hline
\end{tabular}

"Nivel de confiança : $68 \%$.

Obs.: Calibraçăo efetuada em espectrômetro gama de HPGe, calibrado com fontes padröes da Agência Internacional de Energia Atômica.

A atividade fornecida é a atividade incorporada.

Fontes recobertas com 3,8 $\mu$ m de Kapton do lado de cima (inscrição)

Fontes em substrato de polietileno de $0,4 \mathrm{~mm}$.

Anexo: Dimensöes do suporte da fonte.
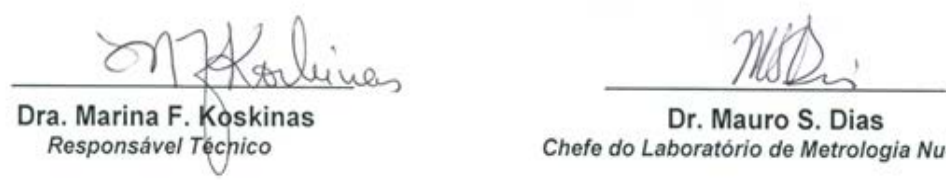

Técnico

Dr. Mauro S. Dias

Chefe do Laboratório de Metrologia Nuclear

\footnotetext{
Comissão Nacional de Energia Nuclear Instituto de Pesquisas Energéticas e Nucleares Av. Prof. Lineu Prestes, 2242 Cidade Universitátia - CEP 05508-000 AV. Prof. Lineu Prestes, 2242 Cidade Universitaria - CEP 05508-000
Caixa Postal 11049 - CEP 05422-970. Pinheiros - Sa Paulo-SP - Brasi Telefone: (011) 3133-8822 Fax (011) $3133-9960$ e-mail: sacognet ipen.br
}

Figura 3.25: Imagem da fonte de ${ }^{198} \mathrm{Au}$ e certificado de calibração. 
fótons emitidos pelas fontes deviam atravessar o espaço desde o centro da câmara de irradiação, as janelas tanto da câmara quanto dos próprios detetores e penetrar no volume ativo deles. Precisávamos fontes de calibração estanques, cujo material pudesse ser bem identificado, e que não degradasse com a radiação, que suportassem o vácuo da câmara para não contaminar as bombas, a própria câmara de irradiação ou outras partes da linha de alimentação de elétrons com o material radioativo, mas que o invólucro do material radioativo fosse o mais fino e de baixa atenuação possível. Escolheu-se o Kapton HN com espessura de 7,5 $\mu \mathrm{m}$, com densidade $1,42 \mathrm{~g} / \mathrm{cm}^{2}$ da Dupont. De fato, nas irradiações, medimos as fontes no ar e tiramos o atenuador no cálculo.

Essas fontes forneceram os espectros para calibrar as curvas de energia e eficiência. Para isso, as fontes foram colocadas na torre de alvos (figura 3.7), na mesma posição que os alvos, dispensando qualquer correção para a posição da fonte na calibração de eficiência. Os ajustes que davam origem às formas dos dubletos ou multipletos dos raios-x dessas fontes foram realizados por funções Voigt ou Gaussianas (dependendo da resolução dos detetores) a fim de determinar as áreas dos respectivos picos [8]. As áreas experimentais dos picos de absorção total foram comparadas com as obtidas com cálculos usando os modelos de eficiência a partir de funções analíticas baseados nos trabalhos de Seltzer [81], O'Meara e Campbell [70] e simulações com o código PENELOPE [76], Barros, et al. [8] e Maidana, et al. [60] .

As fontes de calibração de ${ }^{57} \mathrm{Co},{ }^{109} \mathrm{Cd},{ }^{133} \mathrm{Ba},{ }^{137} \mathrm{Cs},{ }^{152} \mathrm{Eu}$ e ${ }^{241} \mathrm{Am}$ foram construídas e calibradas no Laboratório de Metrologia Nuclear-Instituto de Pesquisas Energéticas e Nucleares/Comissão Nacional de Energia Nuclear-SP (LMN-IPEN/CNEN-SP), junto à Professora Marina Koskinas. Elas deviam ter as mesmas características dos alvos, já que o ideal era que fossem medidas na mesma torre de alvos usada nas irradiações. Assim, foram confeccionadas em molduras do mesmo material, dimensões e características, que aqueles (fibra de carbono), de modo a ser posicionadas no suporte dos alvos da figura 3.7. Para isso, foi colado um filme fino de kapton com 7,5 $\mu \mathrm{m}$, e sobre ele foi aderido um filme de collodion. Em seguida, as molduras foram colocadas sobre papel com marcas como mostra a figura 3.26 e nivelados para evitar escorregamento da solução. Com o auxílio de uma micro pipeta coletou-se a solução radioativa de interesse e depositou-se $5 \mu \mathrm{L}$ em cada montagem. A figura 3.26 mostra a micropipeta depositando uma gota sobre uma dessas montagens, nas outras aparecem as fontes sem a cobertura de kapton e nas últimas com o kapton já colado, mas sem o acabamento.

As soluções foram deixadas para secagem com uma lâmpada de luz infravermelha nas capelas desse laboratório. Quando a solução secou, se pôde observar uma mancha de $\approx 4 \mathrm{~mm}$ de diâmetro. Para garantir a fixação do material radioativo, um outro filme de collodion foi aderido sobre a amostra e sobre ele um segundo filme de kapton com a mesma espessura que o anterior. $\mathrm{Na}$ figura 3.27 aparecem as fontes de Ba no processo de construção e na figura 3.28 o certificado de calibração e as fontes de $\mathrm{Cd}$.

Uma vez confeccionadas as fontes, fizemos alguns testes de estanqueidade fora da câmara de irradiação. Em primeiro lugar, produzimos cápsulas idênticas às das fontes, substituindo o material radioativo por uma gota de corante em solução com $\mathrm{HCl}$ com o mesmo material e $\mathrm{pH}$ das soluções radioativas. Uma vez secas as gotas, foram fechadas da mesma maneira que as fontes verdadeiras. Essas cápsulas de corante foram colocadas na câmara à qual se fez 


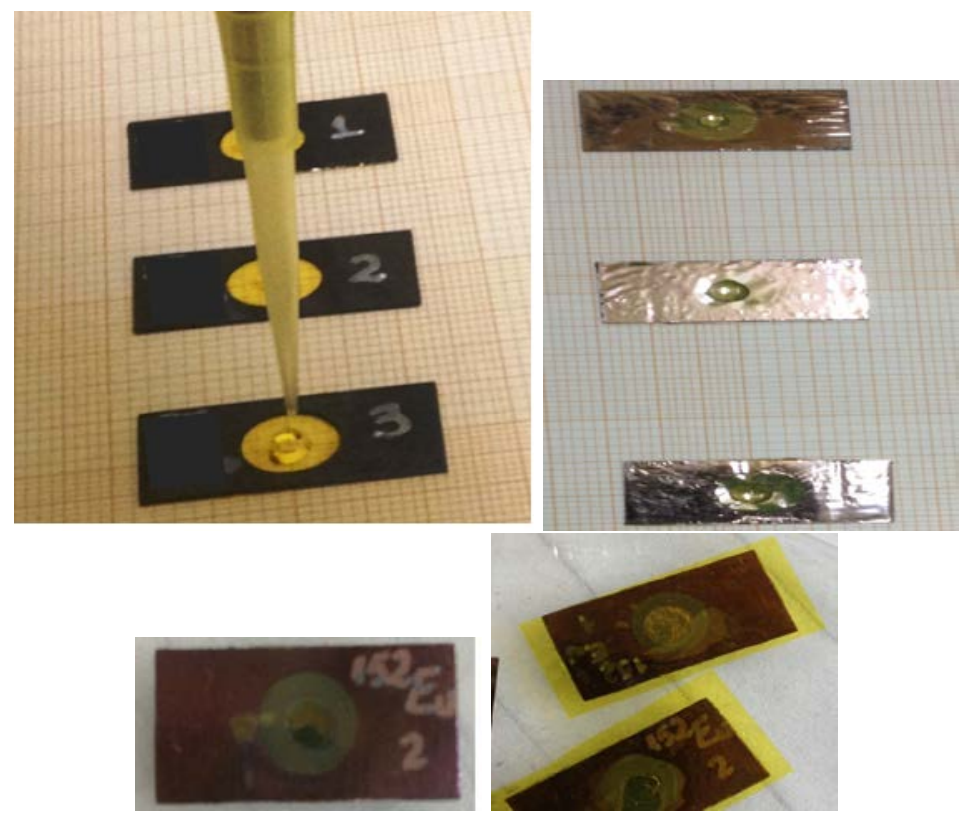

Figura 3.26: Etapas da fabricação das fontes de calibração. Na imagem: superior esquerda a micropipeta depositando uma gota de material radioativo sobre o filme de Collodion, superior direita fontes à espera da secagem da gota, inferior direita e esquerda, fontes de ${ }^{152} \mathrm{Eu}$.

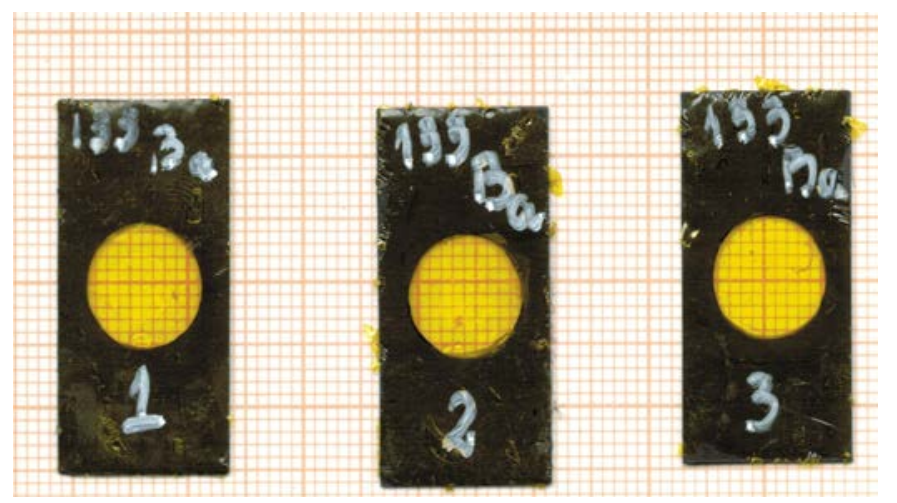

Figura 3.27: Fontes de ${ }^{133}$ Ba fabricadas no LMN-IPEN/CNEN-SP.

vácuo, com uma pressão de base igual a $5 \times 10^{-5}$ torr. Extraídas da câmara, procedeu-se a um esfregaço com papel toalha para verificar se o corante tinha surgido na superfície externa do Kapton. Dado que o papel não ficou tisnado, consideramos que as fontes podiam ser usadas nas câmaras onde podia se fazer vácuo. Atualmente, essas fontes foram medidas por vários dias em vácuo, sem que haja sinal de perda de atividade dos radionuclídeos, confirmando sua estanqueidade.

\subsection{Alvos}

Os alvos usados nos experimentos do Microtron descritos neste trabalho foram construídos de maneira diferente do usual. Eles têm espessuras $\ell$ menores que $\frac{\sigma(E)}{(d E / d x)}$, em que $\sigma(E) \sim 100 \mathrm{eV}$ é a dispersão em energia do feixe na faixa de 10-100 keV, de maneira que a perda de energia no alvo de espessura, $\delta(E) \approx \ell \frac{d E}{d x}$, pode ser ignorada e assim trabalhar com a hipótese de que 


\section{$((c-))$ \\ I0en

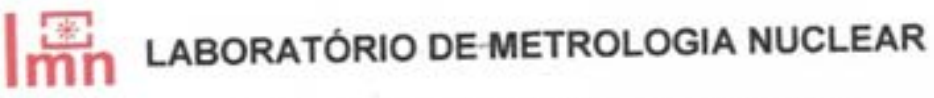 \\ CENTRO DO REATOR DE PESQUISAS}

CERTIFICADO DE CALIBRAÇĀO DE FONTES RADIOATIVAS

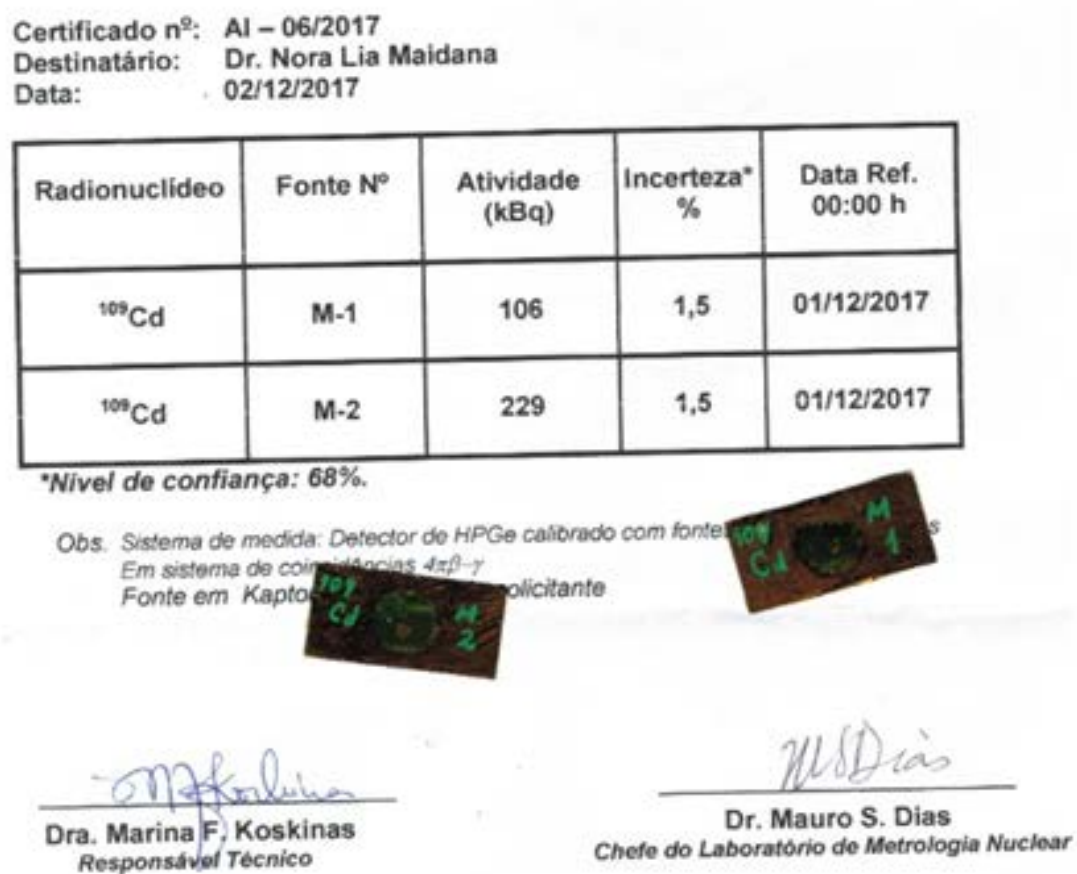

Comissio Nacional de Energia Nuclear

Instituto do Pesquisas Energeticas e Nucloares

Ar. Prot. Lineu Prestes, 2242 Cidado Unwersiakia - CEP OS $500-000$

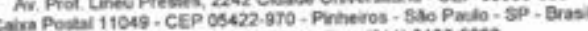

Telelone: (011) $3133-8122$ Fac (011) 31339600

omak socegiven be

Figura 3.28: Certificado de calibração e fontes de ${ }^{109} \mathrm{Cd}$.

todas as partículas têm a mesma energia ao interagir, já que aquele elétron que interatua, o faz uma única vez devido à espessura do alvo e a probabilidade de interação.

Descrevemos abaixo como seu projeto foi evoluindo ao longo dos experimentos até chegar na montagem usada atualmente.

Alvos para as medidas de Bremsstrahlung e ionização de camadas atômicas

Para evitar que os elétrons tivessem mais de uma colisão com os átomos do material em estudo, era necessário produzir alvos com poucas camadas atômicas de espessura e facilitar a determinação do processo responsável pela produção de um fóton detectado. Assim, fabricamos alvos com espessuras da ordem de 10 a $20 \mu \mathrm{g} / \mathrm{cm}^{2}$. Consideramos os elétrons do feixe se 
deslocando em trajetórias paralelas, ao atravessar o alvo, mas qualquer colisão, mesmo mole, desvia o elétron e distorce a distribuição angular.

Os primeiros alvos, para o trabalho de Neivy López Pino [56], que trabalhou com elétrons de $1,9 \mathrm{MeV}$, foram montados em moldura de aço, com dimensões $30 \times 10 \times 0,5 \mathrm{~mm}^{3}$, com um furo central de $7 \mathrm{~mm}$. Sobre esse suporte eram "pescados" os filmes do material a ser estudado. Esse procedimento não foi satisfatório, já que os resultados obtidos naquela tese apontaram um fundo de fótons elevado, sobreposto ao Bremsstrahlung gerado pelo alvo, o que foi atribuído ao halo do feixe de elétrons, formado pelos elétrons acelerados que se movem longe do eixo da canalização do acelerador. Assim, quando os elétrons do halo batiam na moldura, cuja espessura era ordens de grandeza maior que a do material em estudo, os fótons produzidos podiam estar em uma proporção superior aos gerados nas interações esperadas, mesmo que os elétrons do halo fossem uma pequena fração do feixe principal ( $<1 / 1000$ da corrente de feixe).

Decidiu-se então mudar o material das molduras e da torre de alvos, atualmente feitas de fibra de $\mathrm{C}$ com $0,3 \mathrm{~mm}$ de espessura, um material de baixo $\mathrm{Z}$ e relativamente baixa densidade, com rigidez suficiente para ser colocado na torre de irradiação e ao qual aderissem os alvos. As dimensões externas da moldura são iguais às anteriores de aço, mas com um furo central maior, com 10 mm de diâmetro, que não é todo ocupado pelo material do alvo, como será descrito adiante. A mudança do material da moldura, de aço para $\mathrm{C}$, reduz muito a radiação proveniente da moldura, uma vez que a produção de bremsstrahlung de elétrons é proporcional a $Z^{2}$ e os elétrons perdem energia por muitas colisões inelásticas não radiativas, de modo que, com menos energia em média, produzem raios-x mais moles, com menos potencial de interferirem nas medições.

Os alvos foram construídos com técnicas de deposição física de vapores no Laboratório de Alvos do Pelletron, que usou o bombardeamento eletrônico com focalização eletromagnética e efeito Joule, ou no Laboratório de Materiais Magnéticos do departamento de física Geral, por pulverização catódica (também conhecido como magnetron sputtering).

A construção é feita em várias etapas. Inicialmente um filme fino de $\mathrm{C}$ é elaborado por bombardeio eletrônico focalizado, que deixa o filamento incandescente e provoca a evaporação do $\mathrm{C}$ sobre um vidro previamente tratado. Esse filme era descolado por submersão do vidro em água desmineralizada e "pescado" nos molduras de $\mathrm{C}$, de modo a formar o substrato para deposição do alvo, na superfície inferior desse filme. Isto era necessário, já que os alvos eram introduzidos de lado nas posições da torre e se o material em estudo estivesse na superfície externa do filme, na colocação, o material do alvo iria ser danificado por fricção com o da torre. As molduras com os filmes de $\mathrm{C}$ aderidos eram colocados em um suporte de $\mathrm{Al}$ com uma máscara com furos de $8 \mathrm{~mm}$ de diâmetro centrada com o furo de $10 \mathrm{~mm}$ da moldura, de modo a depositar o material em um círculo. Desta maneira, o material em estudo era depositado sobre o substrato por qualquer das duas técnicas usadas. A figura 3.29 mostra o suporte usado no Laboratório de Materiais Magnéticos. Este procedimento elimina todo o material que, na técnica usual de pescar o alvo com a moldura, fica fora da região do alvo que intercepta o feixe de elétrons; essa sobra seria uma fonte potencial de interferência, porque produziria os mesmos raios-x característicos quando impactado por fótons e elétrons de background. A figura $3.29 \mathrm{se}$ refere à construção de alvos por pulverização catódica, em que se vê o arranjo de preparação 
com a máscara na pré-câmara para ser levada à câmara de sputtering. A imagem de um alvo de Au pode ser vista na figura 3.30 .
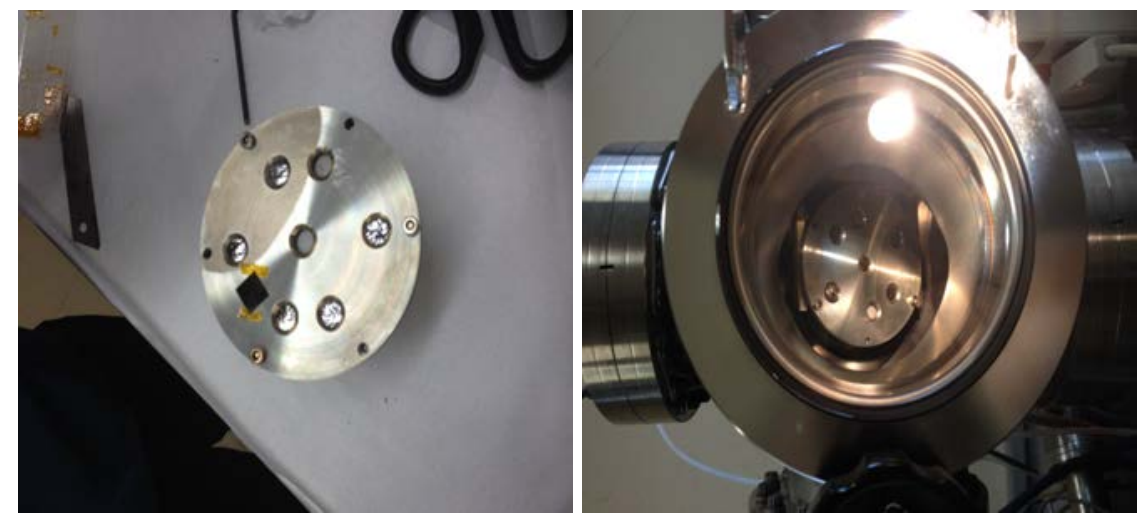

Figura 3.29: À esquerda, dispositivo de fixação das molduras com substrato de C para depósito do elemento de interesse. Os furos, com $8 \mathrm{~mm}$ de diâmetro permitem que o material do alvo de interesse só seja depositado sobre o filme de C nessa região. À direita, suporte de alvos com máscara na pré-câmara de sputtering.

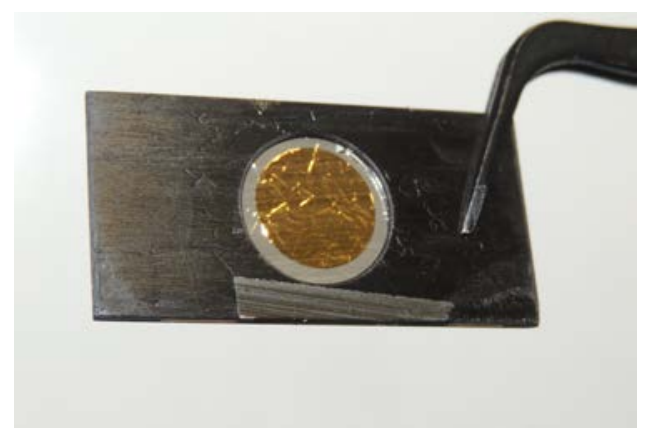

Figura 3.30: Imagem de um alvo de Au em moldura de fibra de C.

A espessura dos alvos foi determinada pela técnica de Rutherford Back Scattering (RBS) no LAMFI. Dado que nossos alvos tinham dimensões e especificações distintas de outros que habitualmente são irradiados lá, construímos um porta alvos que permitisse a fixação das molduras, com ranhuras para poder colocá-los e retirá-los do mesmo. O problema é que a moldura, feita de fibra de $\mathrm{C}$, é flexível e muitas vezes o processo de colocação ou retirada fazia com que o alvo, extremamente fino, se rompesse. Essa é a razão pela qual os alvos de um mesmo elemento eram produzidos em lotes com cerca de 10 unidades, a fim de garantir que alguns deles sobrevivessem ao processo de fabricação, medição da espessura no LAMFI e irradiação com elétrons no Microtron. Muitos alvos se rompem nos processos de: alcançar ou quebrar o vácuo tanto no LAMFI quanto no Microtron, colocarar e remové-los dos suportes de preparação, irradiação, armazenamento em atmosfera de nitrogênio e transporte entre os laboratórios envolvidos.

\section{Alvos para as medidas relacionadas ao terceiro e quarto escapes}

As medidas para caracterização dos detetores com fótons de energias acima de $5 \mathrm{MeV}$ foram realizadas no LAMFI e deram origem ao trabalho acerca do fenômeno que dá título a esta seção [63]. Os alvos preparados para esta medida tiveram características especiais ditadas pela reação nuclear usada na produção dos fótons de alta energia, $\mathrm{p}+{ }^{19} \mathrm{~F} \rightarrow{ }^{20} \mathrm{Ne}^{*} \rightarrow \alpha+{ }^{16} \mathrm{O}^{*} \rightarrow{ }^{16} \mathrm{O}$ $+\gamma(6,1 \mathrm{MeV}) ; \mathrm{o}^{20} \mathrm{Ne}$ fissiona em voo e são emitidos uma partícula $\alpha$ e um núcleo de ${ }^{16} \mathrm{O}^{*}$ que 
decai para o nível fundamental ao emitir fótons de 6,1298, 6,9 e 7,1 MeV, o primeiro deles com meia vida de 18,4 ps e os outros com 4,7 e 8,3 fs, respectivamente [51]. A taxa de produção do estado excitado de interesse depende da energia do projétil. Para maximizar a produção do gama de $6,1298 \mathrm{MeV}$, escolheu-se a ressonância de prótons de 1,378 MeV, que tem largura de $12 \mathrm{keV}$ [51, 88]. O recuo do ${ }^{16} \mathrm{O}^{*}$ na fissão, com energia cinética de $\approx 100 \mathrm{keV}$, é suficiente para removê-lo do alvo, quando esse nuclídeo é emitido para dentro da câmara e, como a meia-vida da transição eletromagnética é suficientemente longa, parte dos fótons são emitidos em voo, o que ocasiona um deslocamento Doppler significativo. Por isso, os alvos foram construídos de modo a evitar a emissão em voo sem, porém, aumentar demais a dispersão em energia do feixe de prótons, uma vez que a ressonância de prótons de interesse é relativamente estreita.

Inicialmente, usamos alvos de $\mathrm{CaF}_{2}$, confeccionados no laboratório de alvos do departamento de Física Nuclear. Eles possuíam $\approx 150 \mu \mathrm{g} / \mathrm{cm}^{2}$, evaporados sobre um suporte de tântalo de $0,1 \mathrm{~mm}$ de espessura. Nas primeiras irradiações, observávamos o pico de absorção total de 6,1 MeV com uma cauda a esquerda, como mostra a região ampliada da figura 3.31 .

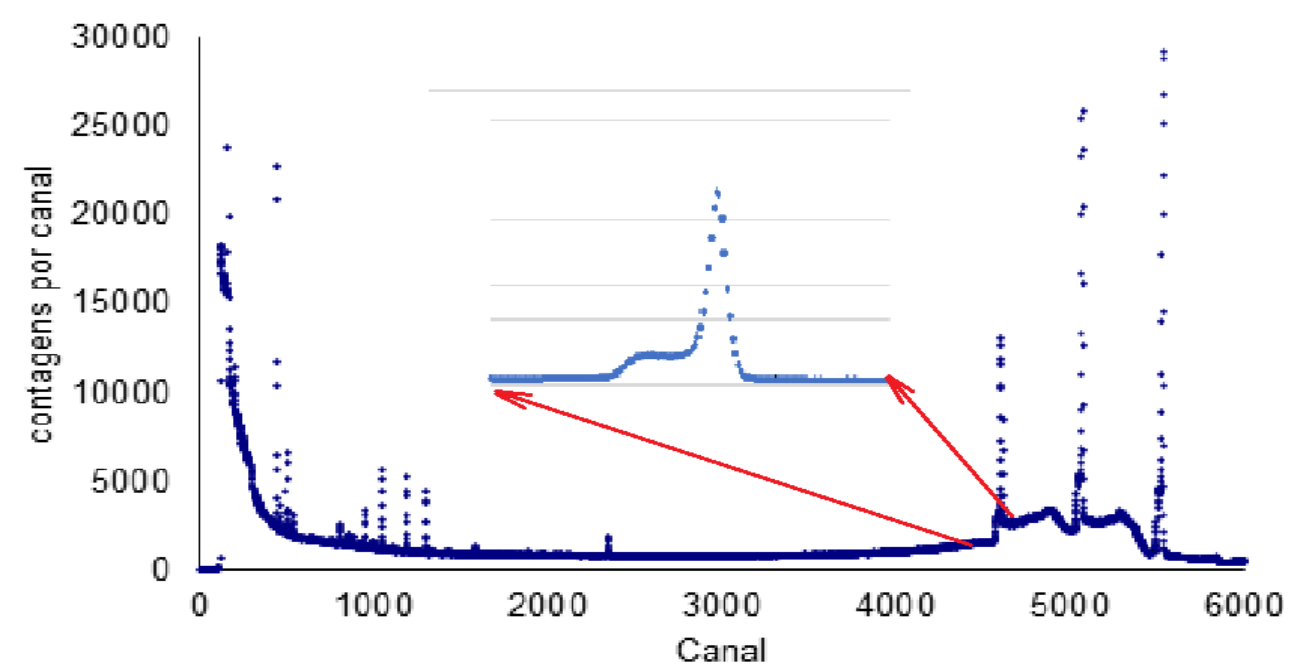

Figura 3.31: Espectro experimental da observação dos gamas emitidos da reação ${ }^{19} \mathrm{~F}(\mathrm{p}, \alpha \gamma){ }^{16} \mathrm{O}$. O alvo que gerou esse espectro não possuía a camada de Au para brecar o recuo do produto da reação. A dispersão em energia é 1,1 $\mathrm{keV} / \mathrm{canal}$

A maneira encontrada para minimizar essa distorção no pico de interesse foi cobrir os alvos com $300 \mu \mathrm{g} / \mathrm{cm}^{2}$ de $\mathrm{Au}$, valor calculado com o stopping power de ${ }^{16} \mathrm{O}$ em $\mathrm{Au}$ ([69] e referências lá citadas). Com o depósito de $\mathrm{Au}$ sobre o alvo de $\mathrm{CaF}_{2}, \mathrm{o}{ }^{16} \mathrm{O}$ produzido na fissão do ${ }^{20} \mathrm{Ne}$ era brecado quase totalmente no alvo, de maneira que o fóton era emitido com a maioria dos núcleos já em repouso, melhorando a qualidade da medida. A perda média de energia dos prótons nessa espessura de ouro é de ordem de $16 \mathrm{keV}$, calculado com o stopping power de [69], dispersando pouco a energia do feixe de prótons de $\approx 1,4 \mathrm{MeV}$.

Uma imagem dos alvos com o depósito de Au, junto ao suporte de alvos do LAMFI, pode se observar na figura 3.32 


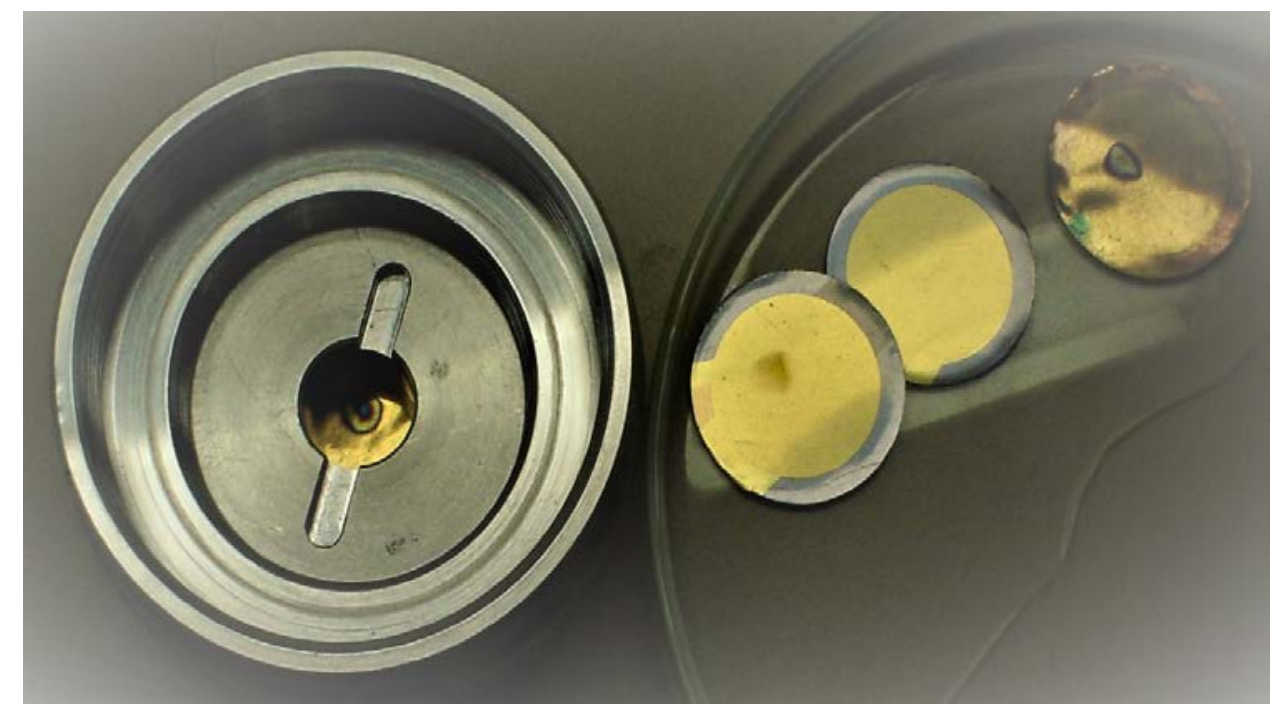

Figura 3.32: Alvos de $\mathrm{CaF}_{2}$ no suporte de irradiação e irradiados. Pode-se ver que os que foram irradiados apresentam uma mancha escura no lugar onde o feixe de prótons bateu.

\subsection{Montagem dos detetores nos arranjos da câmara de irra- diação}

Na montagem dos detetores na câmara de irradiação do Microtron, o colimador de cobre da figura 3.9, de $2 \mathrm{~mm}$ de diâmetro interno, devia estar alinhado com o centro do alvo, que estavam ocultos à vista. Usinou-se um tampão de alumínio, com um furo central, que era introduzido no colimador, para marcar o centro deste, e que servia de referência para o alinhamento, efetuado com o auxílio de níveis de lasers. A superfície externa da câmara de irradiação possui um traço horizontal, que marca o plano que coincide com o centro do feixe de elétrons, por outro lado, a parte externa da torre de alvos também possui uma marca vertical, que coincide com seu centro. Dessa maneira, ao alinhar a interseção das linhas do laser com o centro do tampão, a linha horizontal com as linhas laterais das blindagens de Cobre, a marca da câmara e a vertical com a da torre de alvos, tínhamos certeza que o colimador estava alinhado com o centro da posição de irradiação. As imagens da figura 3.33 mostram os trabalhos de alinhamento do colimador.

No caso do detetor coaxial, um colimador com diâmetro interno de $1 \mathrm{~cm}$ foi colocado descentrado, para evitar a redução na eficiência pelo furo central, como será visto no item 5.2 .3 . 


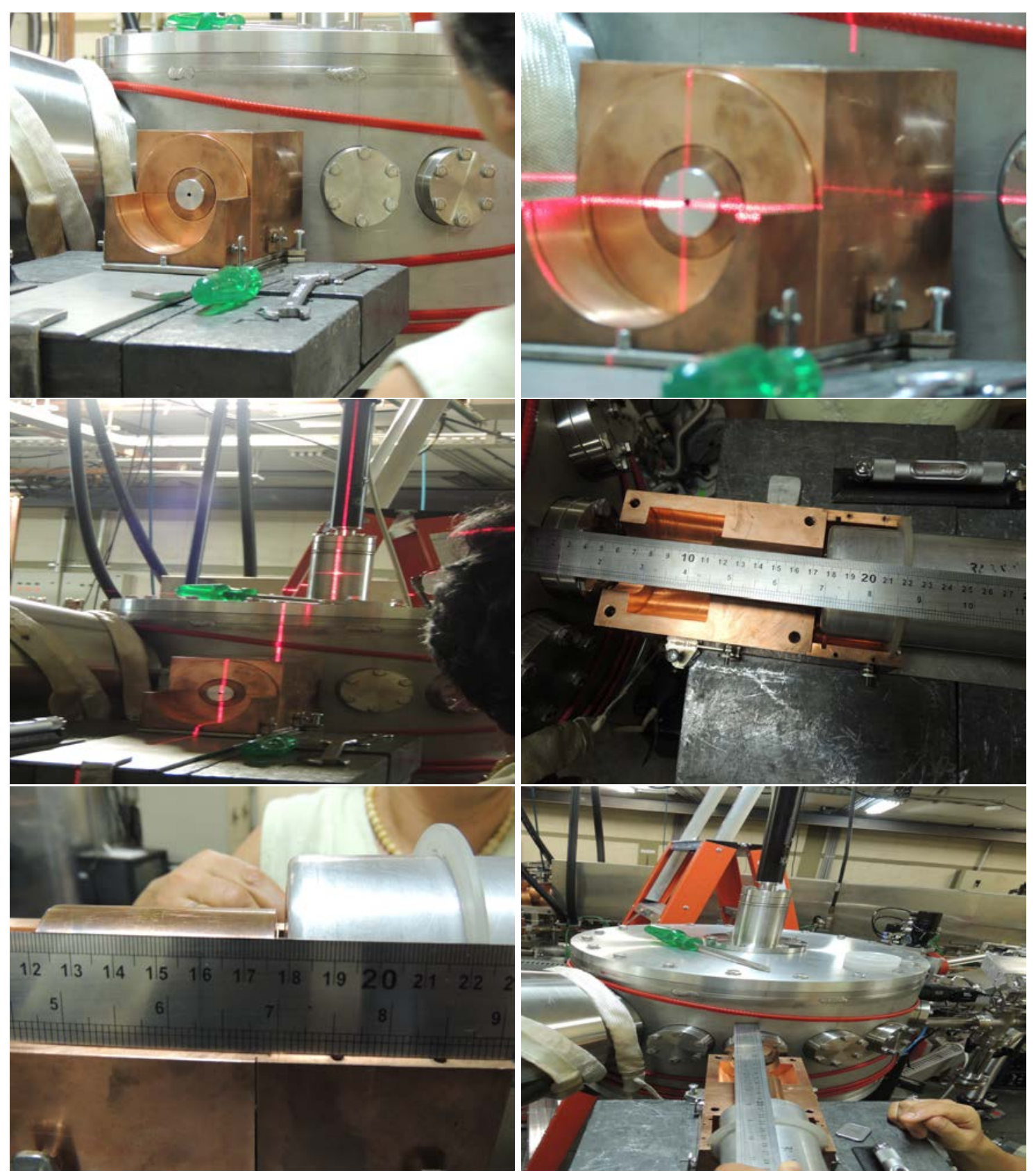

Figura 3.33: Imagens da montagem de um detetor na posição de medida. As primeiras correspondem ao cubo de Cobre da blindagem interna, com o colimador central que tem inserido um tampão de Al. Em algumas se observam as linhas de laser para corroborar o correto posicionamento do colimador, e as medidas da distância da janela da câmara ao detetor. 


\section{Capítulo 4}

\section{Modelos de deteção de fótons}

\subsection{Descrição esquemática da deteção}

Quando um fóton penetra no volume ativo de um detector, deposita energia em decorrência dos diferentes tipos de interação vistos na seção 2.4; desde que não seja um espalhamento elástico (porque nesse caso não haveria depósito de energia), a energia depositada é recolhida, o sinal é amplificado, o pulso é digitalizado e, após apropriada manipulação de sinais, obtém-se o histograma que representa a quantidade de eventos dentro de um intervalo de energias. Algumas vezes, o fóton sofre uma interação Compton e, dependendo do lugar da interação, o fóton espalhado escapa do volume ativo, de maneira que só parte da energia incidente é depositada. Outras vezes, principalmente na interação fotoelétrica, o átomo fica ionizado em consequência da ejeção do elétron, e um raio-x, produzido na volta do átomo ao estado fundamental, pode escapar, o que resulta no pico de escape dos raios-x do material do detetor.

A quantidade de energia que cada elétron espalhado deposita tem uma distribuição aproximadamente gaussiana, cuja largura é relacionada ao Fator de Fano [49], fazendo com que aqueles picos que resultam da coleção completa de cargas tenham uma largura que depende da energia do fóton. A largura do pico observado resulta da composição dessa largura com a que é devida ao ruído do sistema eletrônico de amplificação de pulsos. Enfim, após todo esse conjunto de eventos, um feixe de fótons mono energético produzirá um espectro contínuo, em que haverá registro do depósito desde baixas energias até um pouco acima da energia do precursor dos eventos, onde se localiza o chamado pico de absorção total de energia. Esse pico é frequentemente chamado, erroneamente, de fotopico, uma vez que uma fração dos eventos nesse pico provém de eventos com muitos espalhamentos inelásticos, que é o fenômeno predominante para energias acima de $300 \mathrm{keV}$ em detetores de Ge.

O espectro observado possui características conhecidas, com uma série de regiões relacionadas aos diferentes tipos de interações e suas probabilidades, que dependem da energia do fóton original, da forma, tamanho do cristal e materiais próximos a ele. Normalmente, a todo espectro medido é subtraído o espectro da radiação de fundo natural (aquela devido ao decaimento dos isótopos radioativos naturais e raios cósmicos ou os produtos de reação destes), que elimina várias estruturas daquele. A manifestação dos efeitos antes mencionados conforma um espectro ou um histograma de contagens em função da energia, que é a resposta do detetor, que no caso 
do germânio (Ge), vem sendo estudada desde sua invenção. Nos modelos ou simulações para obter a função resposta, frequentemente são incluídos os materiais que se interpõem ao cristal desde a fonte emissora, mas devem ser levados em conta outros materiais próximos, para que também sejam computados o espalhamento de fótons nesses materiais que cheguem ao detetor, bem como os raios x produzidos nas interações fotoelétricas. São característicos desses efeitos o pico de retro espalhamento na parede oposta ao detetor ou no dedo frio dos detetores coaxiais e os raios x de chumbo em detetores dentro de blindagens. É por essa razão que nossos detetores eram posicionados dentro de estruturas de Cobre e por fora por blindagem de chumbo, para que a primeira absorvesse os raios- $x$ da segunda, como foi comentado no item 3.2.2.

\subsection{Desenvolvimento da pesquisa ao longo do tempo}

Há vários métodos para prever a resposta do detetor. As mais usadas são baseadas em simulação, como é o caso das publicações de Brendt ou Graaf [19, 35], e as que constroem funções analíticas [81, 32]. Os resultados de ambos métodos devem ser comparados aos obtidos experimentalmente. Alguns autores buscam expressões analíticas, que geram formas semelhantes a partes do espectro, e ajustam seus parâmetros a uma série de espectros de diferentes energias; não discutiremos este método aqui.

Neste trabalho, procuramos usar funções analíticas baseadas em modelos teóricos para descrever os espectros observados. Na detecção de fótons há sempre muitos efeitos secundários, em parte relacionados ao ambiente em que o detetor está e, por isso, em experimentos com arranjos mais sofisticados, os modelos devem incluir mais detalhes, de maneira que os resultados desses cálculos tenham uma melhor aproximação ao observado experimentalmente.

No caso particular das funções analíticas desenvolvidas para calcular a resposta dos detetores deve ser especificada a partícula primária (no nosso caso, um fóton), sua energia, os materiais que se interpõem em sua trajetória original (janelas, camadas mortas, ar, colimadores, etc.), as dimensões do cristal e outras características físicas deste, por exemplo, no caso de detetores coaxiais, os detalhes relacionados ao furo para o dedo frio e quanto ele penetra no cristal. Em geral, os modelos de resposta não incluem o ambiente, como blindagens ou outras fontes emissoras, simplesmente focam no detetor.

Se a função resposta de um detetor for conhecida, pode-se encontrar a probabilidade de que um fóton de energia $E$ produza um pulso de altura $h$, correspondente a essa energia no multicanal, além dos outros pulsos decorrentes de todas as possíveis interações que esse fóton possa fazer. Com o histograma de eventos em função da energia, é possível realizar o processo inverso de deconvoluir espectros contínuos emitidos pela fonte de radiação.

Além de serem usadas no cálculo da função resposta, as simulações são uma ferramenta valiosíssima para a compreensão da origem e importância das diferentes estruturas dos espectros obtidos com detetores de fótons. Os resultados de simulação, porém, dependem criticamente das bibliotecas de secções de choque para os diversos processos de interação dos fótons e elétrons com os materiais que compõem o conjunto. Os códigos de simulação possuem mecanismos que agilizam os cálculos das simulações, mas o número de histórias necessárias para alcançar uma precisão confiável faz com que o tempo de computação não possa competir com 
um feixe de elétrons - um segundo de feixe traz um número de elétrons cujas histórias levariam da ordem de um ano para ser calculado por um único processador por alguns dos códigos atualmente usados. No item 4.4, descrevo sinteticamente o mecanismo de alguns programas de simulação Monte Carlo bem conhecidos: GEANT4 [1], MCNP [86], PENELOPE [76] e EGS [57].

No capítulo 5, serão descritos os usos das simulações Monte Carlo nos modelos adotados para os experimentos. A determinação da função resposta e da eficiência de detetores de HPGe têm sido uma constante nos meus trabalhos, desde a tese de doutorado [58]. Estão resumidos aqui alguns, onde funções analíticas e/ou simulações foram usadas:

- iniciamos nossas simulações com o código MCNP para a dissertação dos estudantes de mestrado Cesar Guimarães [37] e Diogo Tridapalli [89] nos trabalhos da determinação da eficiência de detetores de HPGe para fótons de alta energia (4 a $12 \mathrm{MeV}$ );

- os achados nesses trabalhos nos levaram a buscar o terceiro escape dos fótons de aniquilação em detetores de HPGe, quando a simulação apontou corretamente a existência de um fenômeno ainda desconhecido, mas o MCNP5 estimava sua intensidade errada por ordem de grandeza [63, 62, 64];

- o trabalho de doutorado, de Neivy López-Pino [56], também usou o MCNP para quantificar fótons de alta energia ou nêutrons das reações foto nucleares e as respectivas blindagens no início do trabalho, quando esperávamos ter o Microtron operando com elétrons de alta energia, mas no decorrer do tempo, com a máquina operando até $1,9 \mathrm{MeV}$, focamos na simulação da reposta do detetor para proceder à deconvolução dos espectros e obter o espectro de Bremsstrahlung próximo ao tip;

- quando foi preciso verificar informação sobre os parâmetros do detetor que não são visíveis, como as espessuras das camadas mortas e a localização do cristal na cápsula, por exemplo, se ele está centrado ou fora do eixo, como ressaltado no trabalho que tratou da calibração da eficiência de um detetor de HPGe para raios-x [60];

- na simulação do depósito de energia em detetores semicondutores, ficou claro que os parâmetros que ajustam a eficiência de pico são diferentes daqueles que ajustam a eficiência total, de modo que não existe um conjunto de dados que simule corretamente toda a função resposta [61]; nesse trabalho observamos que na comparação do mapeamento frontal com a simulação, esta última não consegue fornecer detalhes característicos do perfil experimental, embora no conjunto o acordo seja satisfatório, um resultado que sugere que um colimador possa evitar que os fótons atinjam a região onde a simulação discorda com os resultados experimentais;

- a simulação mostrou-se indispensável na quantificação do K no chá, ao avaliar a auto atenuação dos fótons em uma amostra de grande volume, dispensando a inconveniente construção de uma fonte radioativa específica para o experimento, que precisaria ser descartada após o uso [59]; 
- nos trabalhos da determinação da eficiência do detector planar [20] foi usado o PENELOPE, assim como nos trabalhos de García-Álvarez [30, 32, 31] e de Barros [11, 14]. Em todos os casos, ficou claro que é fundamental validar experimentalmente os resultados da simulação do transporte de fótons e elétrons na matéria; os resultados só se mostraram adequados após modificações na parametrização original, guiadas pelos resultados experimentais.

No item 6.1.4 está detalhada a importância e necessidade dos cálculos provenientes da função resposta e das simulações na obtenção das secções de choque do Bremsstrahlung de elétrons.

\subsection{Modelos analíticos}

Um modelo analítico que calcula os efeitos de interação ao longo da trajetória dos fótons e partículas secundárias no cristal é o que Seltzer publicou em 1981 [81], para calcular a função resposta e a eficiência intrínsecas para o pico de absorção total de energia em detetores planares de Ge bem colimados, em que os fótons atingem a região central do detector, perpendicularmente à superfície. Seltzer indicou que seus cálculos valeriam para fótons com energias de até $\approx 300 \mathrm{keV}$. Esse modelo pode ser generalizado para uma variedade de materiais que constitua os detetores, sempre que bem caracterizados, isto é, sempre que conhecidas suas dimensões e demais detalhes. Os efeitos incluídos nesse modelo consideram os raios-x K emitidos após a interação fotoelétrica (predominantemente com elétrons da camada K) e espalhamento inelástico dos fótons primários pelo material do cristal, que escapam do volume ativo do detetor. A transmissão do feixe de fótons incluso no modelo usa a lei de Beer-Lambert, que considera os processos de atenuação da radiação como $I / I_{0}=e^{-\mu x}$, em que $I$ e $I_{0}$ são as intensidades dos feixes transmitido e primário. Baseados nesses cálculos, consideramos que nossos trabalhos obtiveram resultados satisfatórios para energias de até $136 \mathrm{keV}$ (maior energia usada com esse modelo) quando comparado tanto às medidas experimentais quanto outros métodos de construção da função resposta, como simulações MC puras.

Aplicamos o modelo de Seltzer pela primeira vez no cálculo da eficiência de pico do detector de camada morta irregular das publicações [60, 20], onde trabalhamos na faixa de energias entre 13 e $136 \mathrm{keV}$. Nelas, os valores experimentais foram comparados com cálculos de funções analíticas adaptando as expressões de Seltzer ao nosso caso particular, além de realizar simulações Monte Carlo com o código PENELOPE. Posteriormente continuamos o estudo da função resposta analítica no trabalho de Garcia Alvarez [30, 32, 31, 34].

Especificamente, o modelo de Seltzer [81] adota um feixe de fótons fino e colimado, de energia $E$, que incide no eixo de um cilindro de Ge de raio $r$ e comprimento $z$, que corresponde ao volume ativo do detetor, conforme ilustrado pela figura 4.1. O cálculo considera detalhadamente uma única interação desse fóton levando em conta as condições geométricas e faz uma pequena correção para o duplo espalhamento. A probabilidade de um fóton de energia $E$ 
depositar a energia $\xi$ nesse cilindro de Ge por unidade de energia é $D(E, \xi, z, r)$ dada por

$$
\begin{aligned}
D(E, \xi, z, r)= & p_{f}(E, z, r) \delta(\xi-E)+ \\
& P_{x \alpha}(E, z, r) \delta\left(\xi-E+E_{\alpha}\right)+P_{x \beta}(E, z, r) \delta\left(\xi-E+E_{\beta}\right)+C(E, \xi, z, r),
\end{aligned}
$$

na qual $\delta(x)$ é a função delta de Dirac da variável $x, p_{f}(E, z, r)$ é a probabilidade de que a energia $E$ do fóton seja completamente absorvida, $P_{x \alpha}(E, z, r)$ e $P_{x \beta}(E, z, r)$ são as probabilidades de que a energia do fóton seja completamente absorvida, exceto as energias dos raios-x $K \alpha$ e $K \beta$ do Ge respetivamente, e $C(E, \xi, z, r)$ descreve o contínuo de Compton, que é a soma da função calculada analiticamente para uma única colisão com uma pequena correção para dois ou mais espalhamentos, descrita por uma função triangular entre as energias da borda Compton de um espalhamento e a energia máxima para dois espalhamentos, com intensidade estimada a partir da simulação.

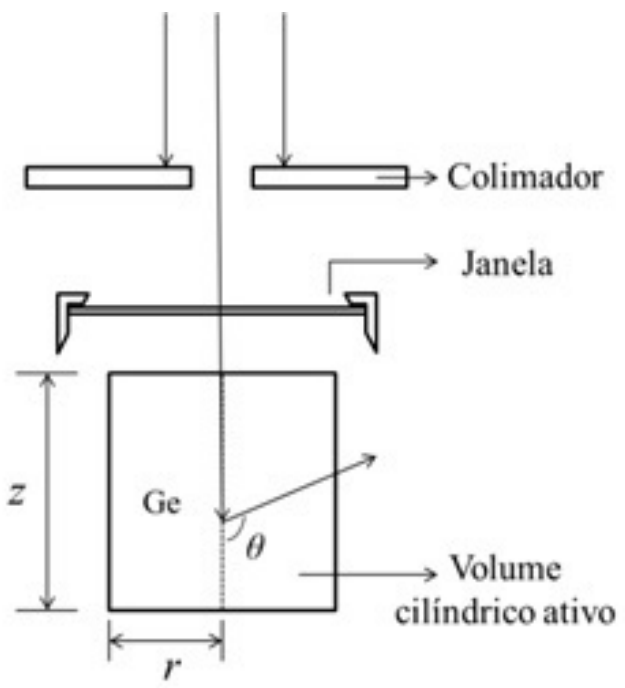

Figura 4.1: Esquema da geometria cilíndrica empregada por Seltzer [81] no seu modelo. Está esboçada também a trajetória de um fóton que interage com o cristal e espalha inelasticamente por um ângulo $\theta$.

O cálculo das intensidades dos picos de escape dos raios-x $\mathrm{K}, P_{x \alpha}$ e $P_{x \beta}$, é realizado analiticamente. Se representamos a energia remanescente no detetor como $E_{i}=E-E_{K i}$ em que $i$ identifica a transição $K \alpha$ ou $K \beta$ do elemento que constitui o material do cristal, e tomando $E_{K \alpha}$ e $E_{K \beta}$ como as energias médias entre as transições $K \alpha$ ou $K \beta$, respectivamente, podemos aplicar a expressão da probabilidade de escape descrita por Seltzer [81] e García-Álvarez [30]:

$$
\begin{aligned}
P_{K i}(\xi, E)= & \frac{1}{2} \omega_{k} p_{k i} q_{k}(E) \frac{\mu_{G e}^{p e}(E)}{\mu_{G e}(E)} \times \\
& \left\{1-\frac{\mu_{G e}\left(E_{K i}\right)}{\mu_{G e}(E)} \ln \left[1+\frac{\mu_{G e}(E)}{\mu_{G e}\left(E_{K i}\right)}\right]\right\} \delta\left(\xi-\left(E-E_{K i}\right)\right),
\end{aligned}
$$

onde $\omega_{k}$ é o yield fluorescente da camada $\mathrm{K}, p_{K i}$ representa a probabilidade de emissão de raios-x $K_{\alpha}$ ou $K_{\beta}$ [80], $q_{K}(E)$ é a probabilidade do fóton de energia $E$ ionizar a camada $\mathrm{K}$ em 
relação à probabilidade de ionizar o átomo, $\mu_{G e}^{p e}$ e $\mu_{G e}$ são os coeficientes de atenuação para o Ge fotoelétrica e total exclusive espalhamento elástico, respectivamente.

\subsubsection{Eficiência de detecção do pico de absorção total de energia}

A eficiência intrínseca de pico, $p_{f}$, pode ser deduzida do espectro de energia depositada, integrando ambos membros da equação 4.1 e usando

$$
\int D(E, \xi, z, r) d \xi=1-e^{-\mu z}
$$

obtendo-se a expressão:

$$
p_{f}(E)=1-e^{-\mu z}-P_{x \alpha}(E)-P_{x \beta}(E)-\int C(E, \xi ; z, r) d \xi .
$$

Antes de chegar no cristal, os fótons atravessam uma série de atenuadores e a janela do detetor. Define-se $T(E)$ como a fração dos fótons que é transmitida através das várias camadas de atenuadores existentes entre a fonte e o volume sensível do detetor (função de atenuação das janelas, camada morta, ar se estiver fora do vácuo), calculada como

$$
T(E)=\exp \left[-\sum_{i} \mu_{i}(E) d_{i}\right]
$$

em que $i$ identifica cada um dos materiais, com espessura $d_{i}$.

O último detalhe a considerar para calcular a eficiência de pico é o ângulo sólido com que a fonte, suposta puntiforme, vê o detetor, que é o ângulo $\Omega$ subtendido pelo colimador ou pelo elemento ativo do detetor, o que for menor.

Assim, a eficiência de pico, levando em conta a eficiência geométrica e a absorção de fótons pelos materiais entre a fonte emissora e o volume ativo do detetor é:

$$
\varepsilon_{F E}(E)=\frac{\Omega}{4 \pi} T(E) p_{f}(E)
$$

\subsubsection{Função resposta}

A fim de incluir os fenômenos de espalhamento nos materiais externos ao detetor, GarciaÁlvarez [30] adicionou o depósito parcial de energia depois da interação do fóton na camada morta frontal, na janela de Be e noutros materiais próximos ao volume ativo. Assim, o depósito de energia da radiação pode ser expresso por [30]:

$$
\mathscr{D}(\xi, E ; z, r)=D(\xi, E ; z, r)+\sum_{j} P_{j}(\xi, E ; z, r)
$$

onde $P_{j}(\xi, E ; z, r)$ representa a densidade de probabilidade para que um fóton de energia $E$ deposite energia $\xi$ por meio de $j$ interações no volume ativo.

A função resposta $R(E, h ; z, r)$ representa a probabilidade por unidade de altura de pulso de que um fóton incidente de energia $E$ gere um pulso de altura $h$ no detetor como o da figura 
4.1. Ela é determinada pela convolução do espectro de energia depositada com a função de resolução como:

$$
R(E, h ; z, r)=T(E) \int_{0}^{\infty} \mathscr{D}(E, \xi, z, r) S(\xi, h, \sigma) d(\xi),
$$

onde $S(\xi, h, \sigma)$ representa a probabilidade por unidade de altura de pulso de que a deposição da energia $\xi$ dê lugar a um pulso de altura $h$, representada por uma gaussiana com dispersão $\sigma=\sqrt{a+b \xi}$, em que os parâmetros $a$ e $b$ estão relacionados ao ruído eletrônico e ao fator de Fano, respectivamente.

A função reposta analítica de detetores permite a deconvolução de espectros contínuos com um processamento mais leve que os gerados com simulações Monte Carlo.

\subsection{Modelos por simulação Monte Carlo}

As simulações Monte Carlo (MC) se baseiam em um método de cálculo iterativo que permite emular processos reais por meio de estimativas que dependem de variáveis aleatórias. $\mathrm{O}$ esquema da figura 4.2 sintetiza a organização de uma simulação, que tanto o MCNP quanto o PENELOPE usam, com pequenas diferenças de metodologia.

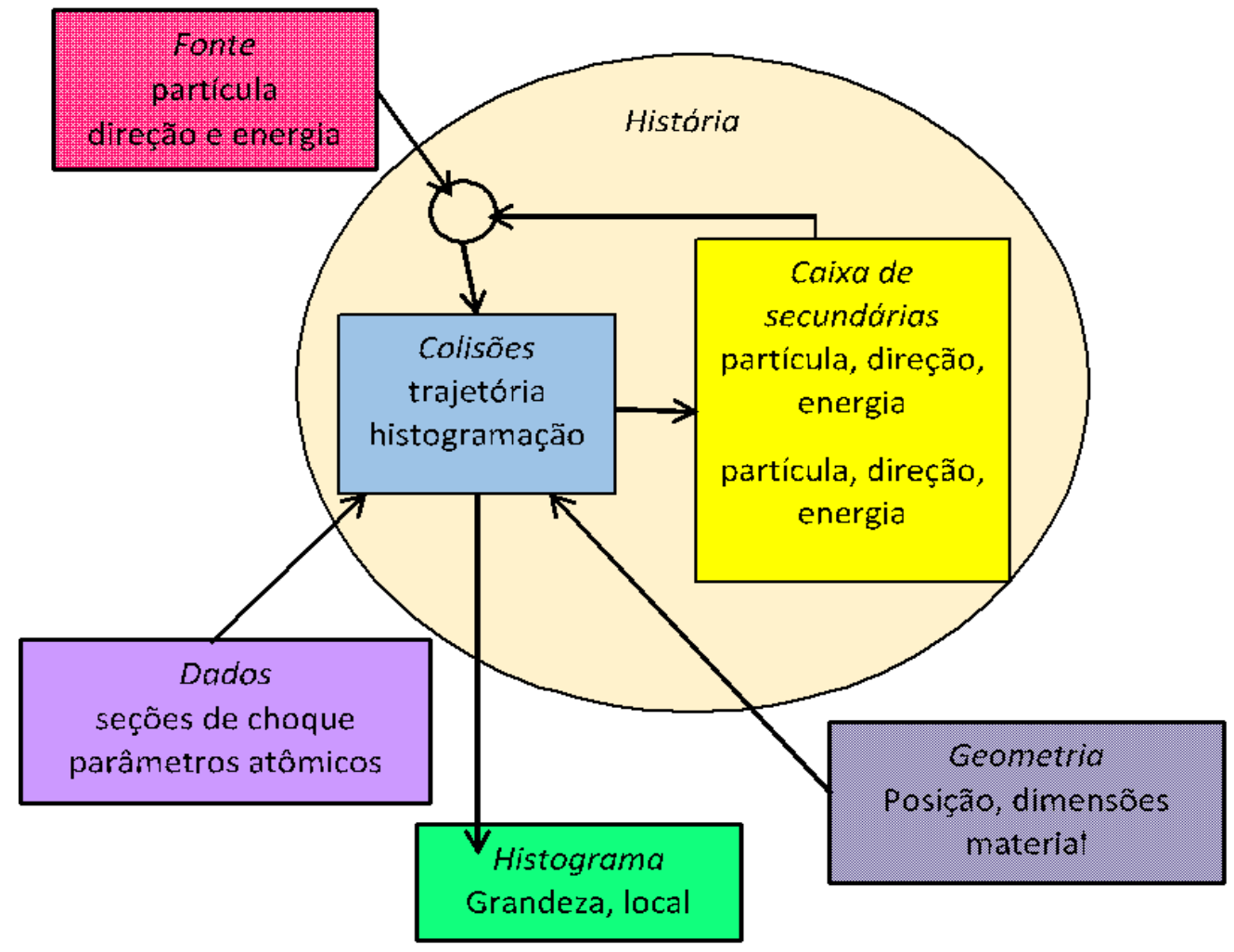

Figura 4.2: Representação esquemática simplificada do código Monte Carlo para simulação do transporte de fótons e elétrons na matéria, válida para o PENELOPE e o MCNP.

Uma simulação inicia-se com a definição dos objetos em estudo. É feita uma representação geométrica dos corpos que formam o arranjo de interesse. Interseções entre planos, cilindros e esferas são especificadas pelas fórmulas analíticas das superfícies que limitam os volumes 
de cada um desses corpos, e é especificado o material que compõe cada um deles, com suas densidades.

A fonte de partículas deve ser definida. Entre os dados a ser inseridos no programa, se encontram a posição e volume da fonte, a distribuição angular (intensidade, direção e sentido) e a distribuição de probabilidade de energia da radiação.

Os cálculos de simulação precisam das secções de choque dos processos de interação. Os projéteis ou partículas acompanhadas podem ser fótons, elétrons, pósitrons e, no MCNP, também nêutrons. No caso dos fótons, são consideradas as seções de choque de espalhamentos coerente e incoerente, incluindo os parâmetros do perfil Compton para levar em conta o movimento dos elétrons atômicos, a absorção fotoelétrica e a produção de pares; e para os elétrons e pósitrons, as seções de choque para colisões elásticas, ionização atômica por impacto, produção de fótons de bremsstrahlung e aniquilação (dos pósitrons). Todos esses dados de secções de choque se encontram em bibliotecas, incorporadas e escolhidas nos programas e rotinas de simulação.

A emissão fluorescente após uma interação que ioniza um átomo, também é considerada, de modo que os dados incluem, para cada elemento químico, as configurações dos átomos, as energias de ionização, e os parâmetros de relaxação atômica para as camadas internas.

Conhecida a probabilidade de interação ou secção de choque para uma partícula com uma dada energia no material em estudo, se calcula, de acordo ao número sorteado, se ela irá interagir com o meio, como será essa interação, se irá depositar total ou parcialmente a energia, e, caso deposite parte da sua energia inicial, calcula-se, com um novo sorteio, a direção que o produto da interação irá adotar, para sortear novamente onde será a próxima interação e assim por diante.

Acompanha-se cada partícula secundária até o depósito total de energia. Em aqueles casos em que a partícula escapa do material, se contabiliza a energia depositada no trajeto no material em estudo.

Se a intenção for agilizar os cálculos, pode-se forçar que sejam adotadas certas simplificações ou especificar certos volumes de interesse com maior detalhe de prioridade de cálculo. Outra maneira de otimizar o tempo de cálculo é escolher o ângulo sólido em que a fonte pode emitir, isto é, se a fonte emite partículas em $4 \pi$ esfero-radianos isotropicamente, pode-se limitar o ângulo sólido de emissão que contenha exclusivamente o volume em estudo.

O tipo de informação que se deseja conhecer, como número de partículas que atravessam uma superfície, suas trajetórias, a energia que depositam em certo volume será a opção de saída do cálculo. Normalmente, a informação de saída é disposta em forma de histograma, com o número de eventos para certos intervalos de energia, cujas larguras são especificadas a priori, como no caso do depósito de energia.

O resultado dos cálculos feitos por esses códigos sempre deve ser validado com os resultados experimentais, já que os modelos físicos incorporados podem estar longe da realidade física da interação das partículas e materiais do arranjo em estudo.

Também pode ser avaliada a incerteza do resultado, já que a precisão depende do número de histórias e das incertezas das secções de choque, embora, na prática a incerteza na seção de choque é raramente propagada para o resultado final.

As etapas seguidas para gerar uma história da simulação formam um loop e podem ser 
resumidas assim:

1. Considerando a fonte primária, sorteia-se o tipo de partícula, sua direção de emissão e energia;

2. Sorteia-se o percurso da partícula até interagir e o tipo de interação ocorrida;

3. De acordo com o tipo de interação, define(m)-se a(s) partícula(s) secundária(s) e sorteiamse suas propriedades (direção de movimento e/ou energia), armazenando as informações relevantes - tipo, energia, direção - em um arquivo, identificado como caixa de secundárias na figura 4.2 ,

4. Se a energia da partícula está abaixo de um mínimo especificado nas definições, todo o resto de energia é depositado no local da interação; caso contrário, repetem-se os itens 2 a 4 para ela;

5. Se a caixa de secundárias estiver vazia, o loop termina e alimenta-se o histograma de interesse, se não, a primeira partícula dessa caixa é usada como entrada no item 2 e a iteração continua;

Todo o processo se repete até concluir o acompanhamento das partículas secundárias geradas por estas. O resultado final corresponde aos histogramas construídos a partir de um grande número de histórias. 
$\overline{0}$ 


\section{Capítulo 5}

\section{Investigação da resposta de detetores semicondutores}

Este capítulo relata as pesquisas sobre a resposta dos detetores de fótons independentemente do seu uso, para fótons de energias:

- acima de $4 \mathrm{MeV}$ (HPGe coaxial, grande volume).

- entre $100 \mathrm{keV}$ e $4 \mathrm{MeV}$ (HPGe coaxiais).

- menores que $100 \mathrm{keV}$ (HPGe planares, Si(Li) e SDD).

\subsection{Eficiência e resposta a energias acima de $4 \mathrm{MeV}$}

Com a intenção de usar o microtron como fonte de elétrons com energias de dezenas de $\mathrm{MeV}$, como estava planejado na época, os mestrados de Cesar Guimarães [37] e de Diogo Tridapalli [89], orientados pelos Profs. Vito Vanin e Paulo Pascholati, respectivamente, focaram na medida da eficiência de detetores HPGe para fótons de 4 a $12 \mathrm{MeV}$ com reações (p, $\gamma$ ) em ${ }^{27} \mathrm{Al} \mathrm{e}{ }^{23} \mathrm{Na}$, e ${ }^{19} \mathrm{~F}(\mathrm{p}, \alpha \gamma){ }^{16} \mathrm{O}$, respectivamente, e na função resposta de um detetor HPGe. Nesses trabalhos, colaborei na simulação dos arranjos experimentais a fim de otimizá-los e na determinação da resposta dos detetores usando o código MCNP [86]. As irradiações foram feitas no LAMFI, com prótons de energias correspondentes às ressonâncias de cada reação. As correntes usadas variaram de 30 a $100 \mathrm{nA}$, e os tempos de medida variaram entre 3 e $6 \mathrm{~h}$, a fim de obter espectros cujos picos de interesse possuíssem boa estatística. As simulações consideraram a câmara do LAMFI e o detetor, como pode ser visto na figura 5.1, em que está representado em verde o cristal de Ge, em azul claro, o separador plástico que isola eletricamente o detetor da câmara de irradiação e, em azul escuro, o flange onde está fixada a folha de Ta (em preto) em que foi depositado o alvo (em vermelho).

As figuras 5.2 mostram a geometria simulada para o trabalho de Tridapalli [89] em escala, com cortes nos planos horizontal e vertical. Os parâmetros internos do detetor foram melhor ajustados graças a radiografias feitas no detetor, procedimento comentado no item 3.2.5.1. O detalhe que ilustra a importância dessa prática de radiografar os detetores foi a descoberta do 


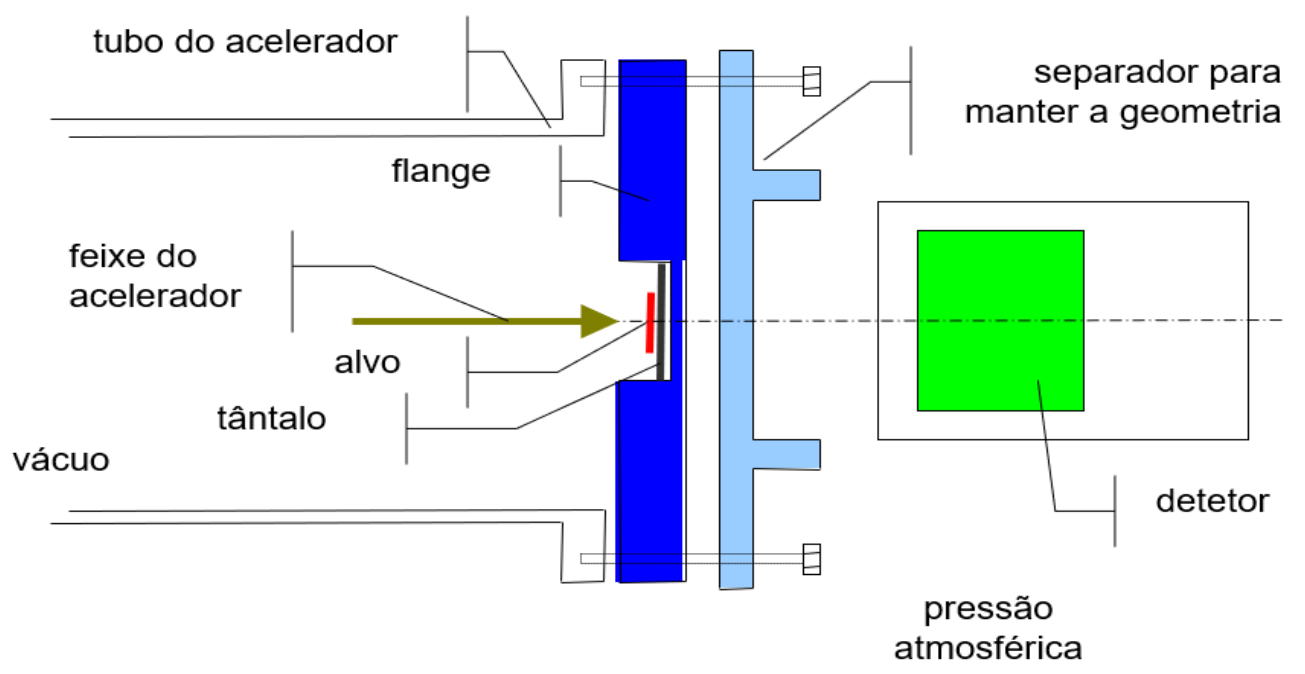

Figura 5.1: Esquema do alvo, flange, separador e detetor na posição de irradiação do LAMFI na medida dos espectros das reações (p, $\gamma$ ) em ${ }^{27} \mathrm{Al} \mathrm{e}{ }^{23} \mathrm{Na}$ [37], usado na simulação da resposta do detetor.

desalinhamento do cristal em relação à cápsula do detetor, como pode ser observado na figura 3.14 que se vê reproduzida no corte vertical da figura 5.2.

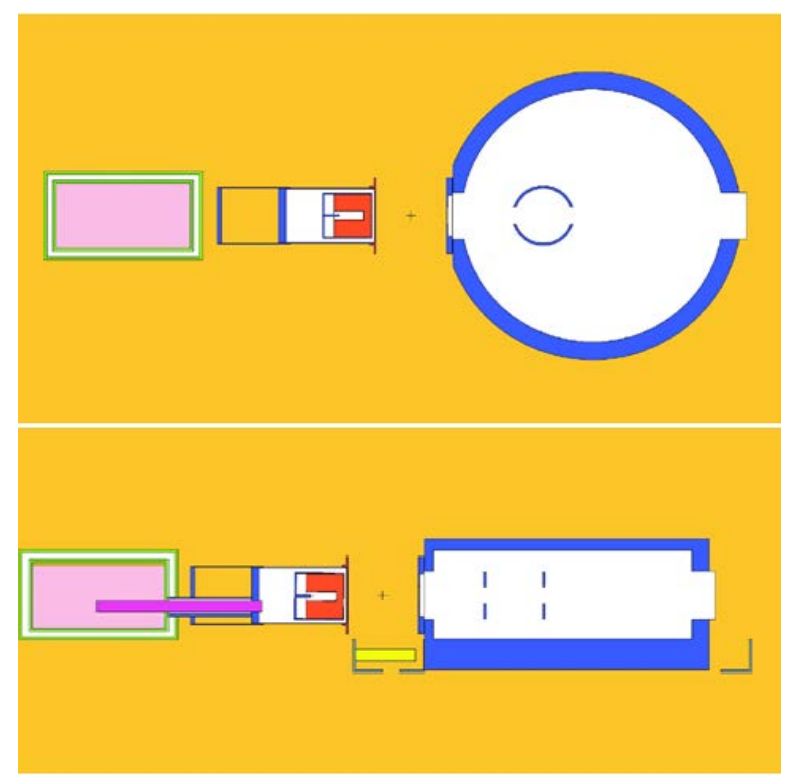

Figura 5.2: Esquemas da geometria simulada na medida do espectro de gamas da reação ${ }^{19} \mathrm{~F}(\mathrm{p}, \alpha \gamma){ }^{16} \mathrm{O}$. A figura de cima é um corte no plano horizontal, e a de baixo, no plano vertical. As superfícies em azul representam o $\mathrm{Al}$ da câmara, a cápsula que contêm o detetor e a parte externa do dedo frio; em vermelho, o cristal de Ge, em roxo o cobre do dedo frio e em rosa o nitrogênio líquido [89]. Nesses esquemas, também pode ser apreciado o desalinhamento do detetor mostrado na figura 3.14

As simulações buscavam encontrar a energia depositada nos cristais de Germânio e foram realizadas com o código MCNP5, usando a função Tally F:8P (histograma de altura de pulso) com canais de $1 \mathrm{keV}$ de largura. A figura 5.3 mostra os histogramas de eventos em função da energia, para fótons monocromáticos do decaimento do ${ }^{60} \mathrm{Co}$, com 1173 e $1332 \mathrm{keV}$, e energias de $2 ; 4 ; 6 ; 8 ; 10 ; 12$ e $14 \mathrm{MeV}$. 


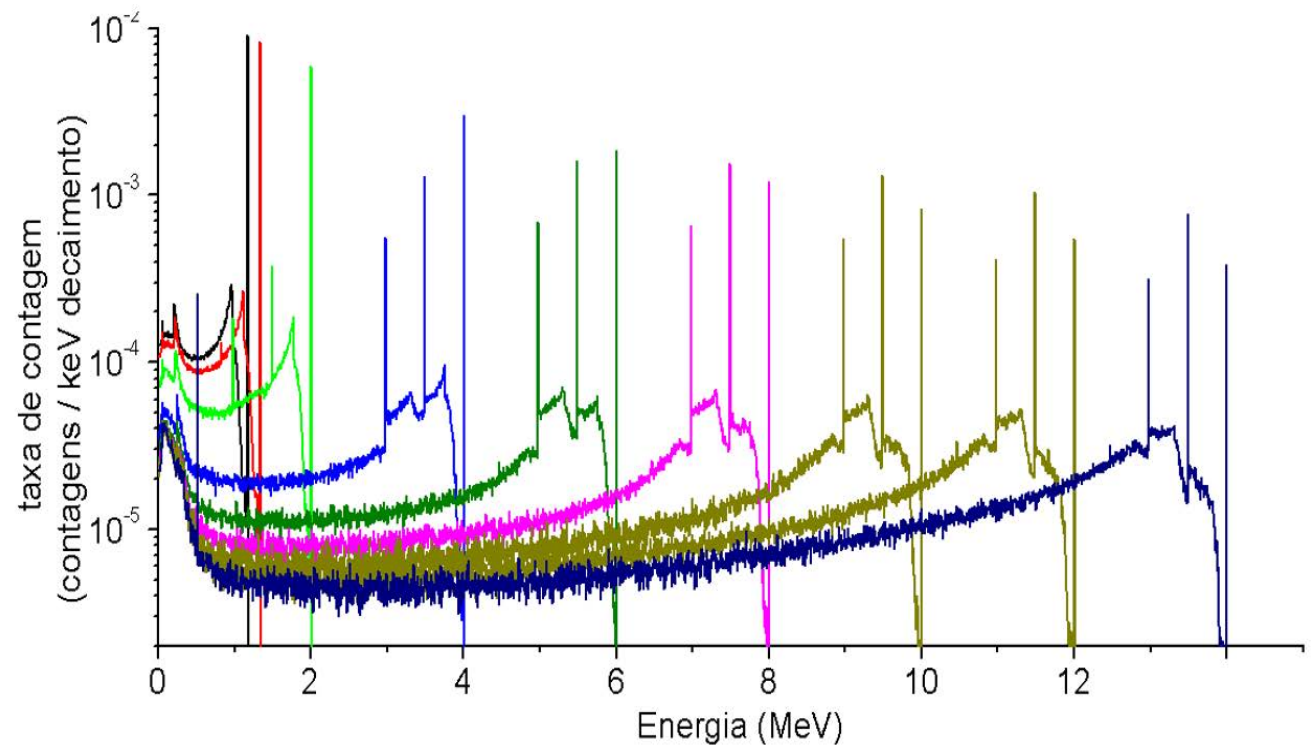

Figura 5.3: Espectros provenientes de fótons monocromáticos de 1,173; 1,332; 2; 4; 6; 8; 10; 12 ; e $14 \mathrm{MeV}$ simulados pelo MCNP. Na ordenada é representada a eficiência absoluta para uma região do espectro [37].

Na figura 5.3 se observam os picos de absorção total (FE), primeiro (SE) e segundo escapes (DE) com energias 511 e $1022 \mathrm{keV}$ abaixo do pico de absorção total, característicos da deteção de fótons com muitos $\mathrm{MeV}$ de energia, como discutido na seção 2.4.3.

$\mathrm{Na}$ simulação, o arranjo experimental foi descrito com todo o detalhe mostrado nos esquemas da figura 5.2 a fim de procurar reproduzir a proporção entre as eficiências total e de pico, significativamente maiores no experimento que na simulação de um detetor isolado do ambiente. Embora tenha se verificado que os elementos do arranjo contribuem para a eficiência total, a mudança foi insuficiente para explicar o resultado experimental. Uma série de simulações mostrou que é possível reproduzir a eficiência total ou a eficiência de pico, ou, ainda, as razões entre o SE/DE, usando dimensões diferentes do elemento ativo do detetor para cada um desses propósitos, mas não existe um mesmo conjunto de dimensões que responda por todas essas propriedades. A investigação desse problema foi deixada para trás, porque outro fenômeno chamou nossa atenção e foi investigado, como será descrito abaixo. Posteriormente, a meta de energia de elétrons do Microtron foi reduzida, e outras necessidades foram atendidas, de modo que a pesquisa acerca da dificuldade em simular corretamente as eficiências de pico e total com um mesmo conjunto de parâmetros continua em aberto.

\subsubsection{O terceiro escape - o que é e primeiras buscas}

Nesses espectros, observamos, além dos SE e DE, um pico que se destaca do contínuo a uma energia $511 \mathrm{keV}$ abaixo do DE, para todas as energias de fóton incidente acima de $2 \mathrm{MeV}$, ao qual chamamos terceiro escape (TE); naquele momento, não achamos na literatura nenhum relato acerca da existência do TE.

Nessa época, foi lançado o código MCNPX, assim comparamos os resultados fornecidos pelos códigos MCNP5 e MNCPX [86]. Verificamos que em simulações com os dois códigos, usando os mesmos arquivos da geometria e funções, as áreas obtidas para o TE se mostravam 
diferentes, possivelmente por um tratamento diferenciado ao acompanhar as trajetórias ou pelo uso de bibliotecas de secções de choque diferentes, sem que essa mudança entre uma versão e outra do código tenha sido divulgada.

O trabalho relatando a busca experimental pelo terceiro escape foi submetido à 10th International Symposium on Radiation Physics, Coimbra - Portugal, 17-22 de Setembro de 2006, com o título Search for the triple-escape peak in HPGe detectors, que foi apresentado como poster. $\mathrm{O}$ artigo completo relacionado a ele foi publicado nos Proceedings desse congresso [63].

Essa publicação [63] relatava a expectativa de observar o terceiro escape, a comparação dos resultados das simulações com os dois códigos e de um modelo analítico que forneciam valores diferentes para a intensidade do pico, e um experimento destinado à sua detecção, cujo resultado foi negativo, de modo que o dado experimental consistiu no limite superior para sua intensidade.

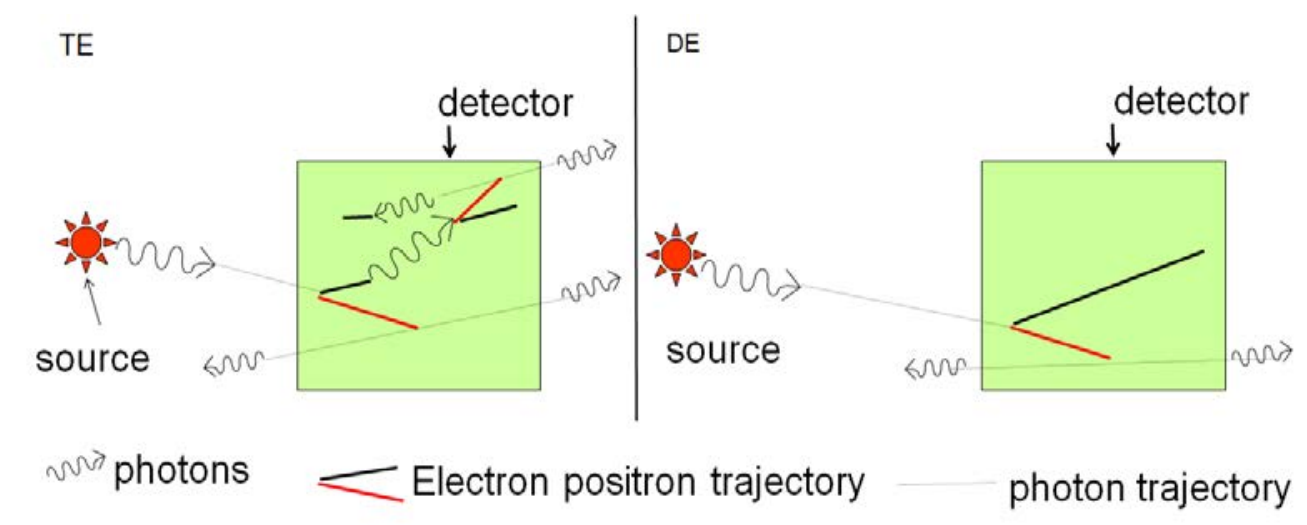

Figura 5.4: Diagrama que descreve os modelos empíricos de formação do terceiro escape no lado esquerdo e do segundo escape no direito. A legenda dos símbolos está na parte inferior da figura [63].

A fim de obter o espectro experimental, irradiou-se no LAMFI um alvo de $\mathrm{CaF}_{2}$ com uma corrente de $50 \mathrm{nA}$ de prótons com 1,378 MeV, energia suficiente para alimentar as ressonâncias em 1,371 e 1,348 MeV da reação ${ }^{19} \mathrm{~F}(\mathrm{p}, \alpha \gamma){ }^{16} \mathrm{O}$. Os prótons perdiam energia ao atravessar a espessura do alvo, de modo que essas duas ressonâncias contribuíam para o espectro. $\mathrm{Na}$ simulação da resposta do detetor para fótons de energia $6,128 \mathrm{MeV}$, provenientes do decaimento do ${ }^{16} \mathrm{O}$, considerou-se que o alargamento do pico do TE fosse igual ao do duplo escape. Na figura 5.5 pode-se comparar os picos estimados nas simulações com o MCNP5 e MCNPX com o espectro experimental, em que não aparece pico algum.

O modelo analítico que desenvolvemos teve o objetivo de estimar o quociente entre o TE e o DE para fótons de energia $E_{0}$, baseado no mecanismo ilustrado pela figura 5.4, em que o elétron ou o pósitron produzem um fóton de bremsstrahlung no volume ativo que produz um segundo par elétron-pósitron. Esse novo par, por sua vez, produz outro par de fótons de aniquilação, de modo que, além do pico TE, correspondente ao escape do volume ativo de três fótons de aniquilação, prevê também a existência de um quarto escape (QE), em que os quatro fótons de aniquilação escapam. Nesse cálculo, $n\left(E_{e}, E_{0}\right)$ representa a probabilidade, por unidade de energia, de produção de um elétron de energia $E_{e}$ quando o par é produzido por um fóton de energia $E_{0}$, e $P_{S}\left(\mathrm{E}_{\gamma}\right)$, a probabilidade de detecção do pico SE no volume ativo do detetor. A 
partir dessa probabilidade, calcula-se primeiro a razão TE/DE no processo em que o DE do primeiro par elétron-pósitron é seguido pelo SE do outro par elétron pósitron, como [64]:

$$
\begin{aligned}
\left.\frac{I_{T E}}{I_{D E}}\right|_{D E \rightarrow S E}= & \int_{2 m_{e} c^{2}}^{E_{0}} n\left(E_{e}, E_{0}\right) d E_{e} \int_{E_{e}}^{2 m_{e} c^{2}}\left(-\left.\frac{d E}{d x}\right|_{E^{\prime}}\right)^{-1} d E^{\prime} \\
& \int_{2 m_{e} c^{2}}^{E^{\prime}} B\left(E_{\gamma}, E^{\prime}\right) P_{S}\left(E_{\gamma}\right) d E_{\gamma}
\end{aligned}
$$

sendo: $B\left(E_{\gamma}, E^{\prime}\right)$ a densidade de probabilidade de que um fóton de Bremsstrahlung com energia $E \gamma$ seja produzido por um elétron de energia $E^{\prime} ;\left.\frac{d E}{d x}\right|_{E^{\prime}}$ a taxa de perda de energia do elétron ou pósitron de energia $E$. A probabilidade $P_{S}(E \gamma)$ foi deduzida do valor da eficiência de detecção experimental para fótons de energia $E \gamma$ provenientes da fonte de calibração, posicionada frente ao detetor e sobre o eixo dele. $\mathrm{O}$ valor da eficiência experimental foi obtido da calibração com medida de fontes radioativas e reações (p, $\gamma$ ) num intervalo entre 1,3 e $14 \mathrm{MeV}$ [37]. O subíndice $D E \rightarrow S E$ se refere à sequência de eventos: escape duplo do primeiro par seguido por um escape simples do segundo par.

A contribuição para a razão TE/DE no espectro a partir dos elétrons ou dos pósitrons deve ser similar, dado que o fóton de Bremsstrahlung pode ser produzido por qualquer um dos elementos do primeiro par, porque o espectro de energia destas partículas poderia ser considerado similar [94], assim como a respectiva produção de fótons [83], respeitando o modelo citado que dá origem a uma contagem do TE. Como o TE pode ser produzido pela sequência de eventos $\mathrm{SE} \rightarrow \mathrm{DE}$, para contabilizar a contribuição de ambos os processos devemos calcular:

$$
\left.\frac{I_{T E}}{I_{D E}} \cong 2\left(\left.\frac{I_{T E}}{I_{D E}}\right|_{D E \rightarrow S E}+\left.\frac{I_{T E}}{I_{D E}}\right|_{S E \rightarrow D E}\right) \cong 4 \frac{I_{T E}}{I_{D E}}\right|_{D E \rightarrow S E}
$$

em que a última igualdade se deve a que os dois termos dentro dos parênteses são aproximadamente iguais, uma vez que a intensidade do quociente SE/DE é independente da energia [37].

Nesses cálculos, adotamos o espectro de Bremsstrahlung produzido pelo elétron do trabalho de Seltzer [83], e supôs-se uma distribuição uniforme de energia do pósitron, independente da energia das partículas, $E_{e}$.

Nas condições do espectro medido não observamos o TE. A figura 5.5 mostra o pico de terceiro escape esperado da simulação sobre o contínuo medido, na região onde o TE deveria estar. Os picos foram estimados da intensidade do quociente TE/DE obtido por simulação com o MCNP5 multiplicado pela área experimental do DE do fóton incidente de 6,128 MeV, ambos alargados pelo modelo gaussiano da largura de picos.

O modelo empírico não considerou distribuições angulares das partículas criadas, nem os efeitos de borda do cristal. Essas suposições levam a superestimar o resultado, de maneira que esse modelo analítico fornecia só um limite superior da estimativa de grandeza, mas foi suficiente para mostrar que o MCNP5 superestimava a detecção do processo que leva ao TE. 


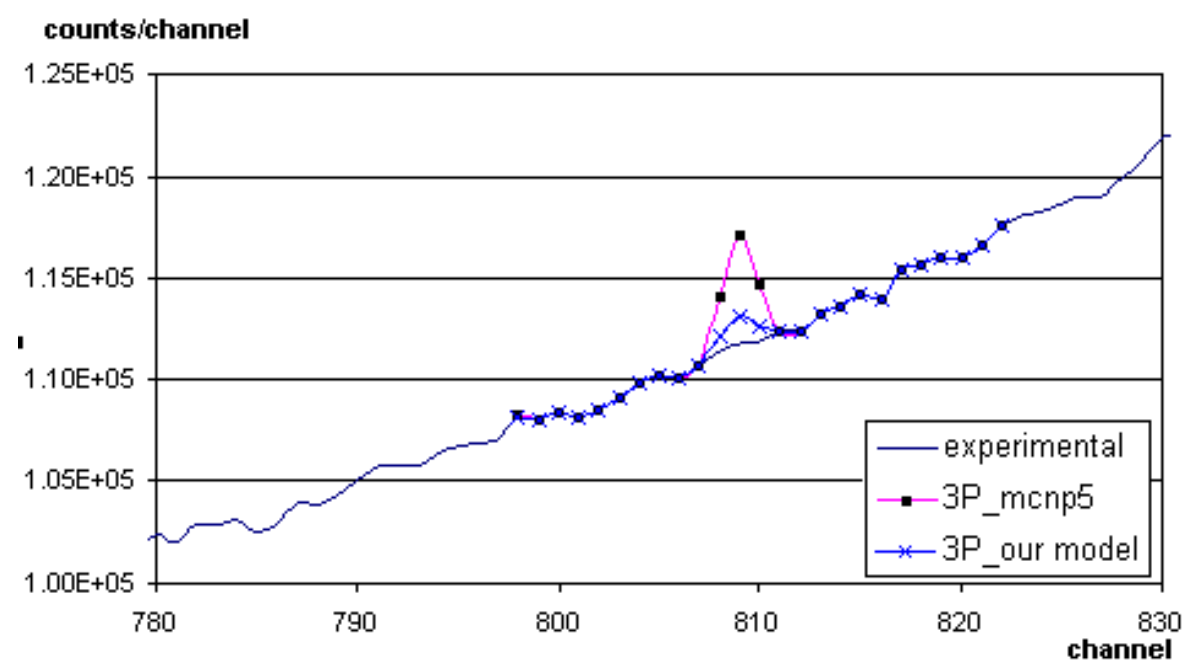

Figura 5.5: Comparação do pico do terceiro escape esperados na simulação sobrepostos ao contínuo e experimental, onde não se observa dito pico. A dispersão em energia do espectro é 7,5 keV/canal [63].

\subsubsection{Determinação experimental da intensidade do terceiro escape}

A busca pelo terceiro e quarto escapes iniciou um novo tema de pesquisa. Fizemos várias irradiações tentando encontrá-los. Em todas elas, usamos a reação ${ }^{19} \mathrm{~F}(\mathrm{p}, \alpha \gamma){ }^{16} \mathrm{O}$ nas mesmas condições de irradiação que as usadas por Tridapalli [89], sem obter resultados observáveis. Concluímos que a melhor maneira de observar o pico era diminuir consideravelmente as contagens do contínuo na região em observação, o que mostrou a necessidade de trabalhar em coincidência com outros detetores que observassem os gamas de aniquilação. Além dessa característica, o novo arranjo experimental usou um alvo especial, em que o $\mathrm{CaF}_{2}$ foi recoberto por $300 \mu \mathrm{g} / \mathrm{cm}^{2}$ de Au. Essa camada de Au retinha a maior parte dos núcleos de ${ }^{16} \mathrm{O}$ da superfície do alvo que recuavam em direção a câmara (oposta à posição do detetor), reduzindo o alargamento Doppler do pico de interesse, como descrito na seção 3.5.2, figura 3.31, o que também contribuiu para o sucesso na observação do TE.

Foi assim que iniciamos medidas com o detetor Canberra dos trabalhos anteriores, rodeado por um detetor anular formado por seis detetores de Germanato de Bismuto (BGO), normalmente usados para suprimir os efeitos do espalhamento Compton no germânio, descrito no trabalho de Alcantara e colaboradores [4]. A simulação do arranjo experimental foi realizada com o código PENELOPE.

A fim de evitar a detecção de elétrons e pósitrons de alta energia do decaimento por formação interna de pares do estado excitado do ${ }^{16} \mathrm{O}$ com spin e paridade $0+$ e $6.05 \mathrm{MeV}$ de energia de excitação, foi colocado um absorvedor formado por chapas de $\mathrm{Al}, \mathrm{Cu}, \mathrm{Cd}$ e $\mathrm{Pb}$, de maneira similar ao reportado por Kramp [51]. Além disso, foi montada numa blindagem de $\mathrm{Pb}$ de $4 \mathrm{~cm}$ de espessura, para atenuar a detecção direta dos fótons de alta energia nos BGO sem alterar a detecção dos fótons em estudo no cristal de HPGe. Esse arranjo é destacado nas figuras 5.6 .

O gatilho da medida em coincidência foi a detecção simultânea de um evento no HPGe em coincidência com eventos em pelo menos dois eventos dos seis segmentos cintiladores, com qualquer energia, com uma diferença de tempo menor que 200 ns entre a detecção do fóton pri- 


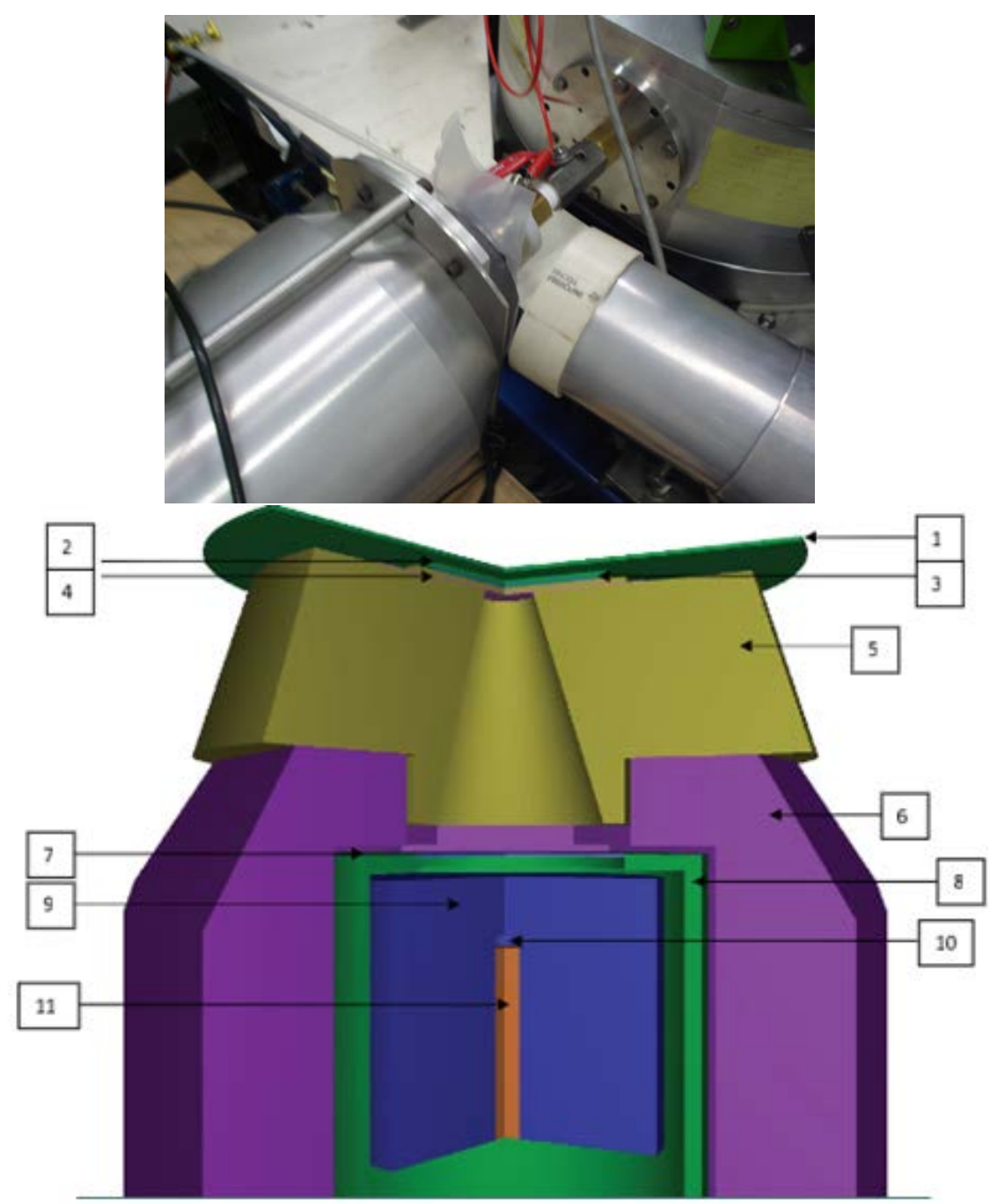

Figura 5.6: Arranjo experimental usado na detecção do terceiro e quarto escapes. Acima, uma imagem dos detetores, o que está alinhado com a saída do feixe possui os BGO em volta, o detetor de HPGe que aparece à direita do colimador é o que registrou o espectro simples mostrado na figura 3.31. O esboço de baixo representa o arranjo experimental simulado com o código PENELOPE, onde os números representam: atenuadores $1(\mathrm{Al}), 2(\mathrm{Cu}), 3$ $(\mathrm{Cd}), 4(\mathrm{~Pb}) ; 5$ colimador e absorvedor de Pb; 6 detetores de BGO; 7 janela de Be do detetor de HPGe; 8 end cap do HPGe em Al; 9 Cristal de Germânio; 10 furo interno e 11 dedo frio de Cobre. [64].

mário e a dos fótons espalhados; essa janela de tempo é bem maior que a resolução temporal, variando entre 15 a $25 \mathrm{~ns}$, a fim de permitir uma correção precisa das coincidências acidentais. Os eventos registrados continham informação sobre a energia depositada em cada BGO, no HPGe, e as diferenças de tempo entre a detecção em cada BGO e o HPGe. A irradiação durou 3 dias, foram coletados $2,6 \times 10^{7}$ eventos em coincidência, a uma taxa de aproximadamente 150 contagens/s. Todos os detetores foram calibrados em energia, e a largura a meia altura do pico do fóton de aniquilação nos BGOs variou entre 49 e $62 \mathrm{keV}$. Esse arranjo nos permitiu observar o pico do terceiro escape quando, nas matrizes de coincidência do HPGe com $n$ detetores de BGO, foi selecionada a região definida pela expressão:

$$
\sum_{i=1}^{6} \frac{\left(E_{i}-m_{e} c^{2}\right)^{2}}{\sigma_{i}^{2}} \leq \chi_{\alpha, n}^{2}
$$


onde $E_{i}$ e $\sigma_{i}$ são as energias e larguras observadas para o pico do gma de aniquilação no $i$-ésimo detetor. A plica do somatório indica que a soma deve ser restringida aos $n$ eventos simultâneos dentro de uma resolução temporal do circuito de coincidência de 100 ns. O parâmetro $\chi_{\alpha, n}^{2}$ está relacionado à fração $\alpha$ de eventos no pico multidimensional incluído na janela de tempo. Dado que os picos nos BGOs podem ser aproximados por gaussianas, a fração $\alpha$ da área do TE pode ser avaliada pela função distribuição cumulativa de $\chi^{2}$ para $n$ graus de liberdade, onde $\chi_{\alpha, n}^{2}$ é o valor para a porcentagem $\alpha$. Essa expressão permite quantificar a fração de eventos coletados na janela multidimensional [64].

O programa PENELOPE foi alterado para corresponder à medida em coincidência. Os resultados do quociente TE/DE e QE/DE obtidos nas simulações resultaram concordantes com os experimentais dentro das incertezas.

Na reação ${ }^{19} \mathrm{~F}(\mathrm{p}, \alpha \gamma){ }^{16} \mathrm{O}$, o núcleo composto ${ }^{20} \mathrm{Ne}$ fissiona emitindo uma partícula alfa, que pode possuir várias energias diferentes, deixando o ${ }^{16} \mathrm{O}$ a estados excitados, com 6,1, 6,9 ou $7,1 \mathrm{MeV}$, todos eles decaindo por um gama para o estado fundamental com $100 \%$ de probabilidade, ou no estado com 6,05 MeV que decai por formação interna de pares $e^{+} e^{-}[46,24$, 28] e obrigou ao uso do absorvedor de pósitrons já mencionado. Um espectro simples do HPGe foi obtido com outro detetor, posicionado a $90^{\circ}$ do feixe de prótons. A eletrônica associada usou um espectrômetro digital DSPEC com um tempo de subida de pulso de 3,0 $\mu$ s, flat-top de $1,6 \mu$ s, e parâmetro cusp de 0,5 . A escolha desses parâmetros permitiu reduzir o tempo morto a aproximadamente $20 \%$ para altas taxas de contagem, $\approx 18 \mathrm{kHz}$, e uma resolução bem aceitável, como pode ser observado na figura 2.11. Os níveis de 6,9 e 7,1 MeV possuem meias vidas de 4,7 e 8,3 fs, respectivamente, de maneira que os fótons são emitidos em voo ainda dentro do alvo, no recuo do ${ }^{16} \mathrm{O}$ após a fissão do ${ }^{20} \mathrm{Ne}$. À esquerda do pico de $7,1 \mathrm{MeV}$ aparece o de 6,9 MeV, também alargado, e a esquerda deste o primeiro escape do mais energético, seguido (para a esquerda) pelo primeiro escape do 6,9 MeV. O segundo escape do 7,1 se encontra no pé do pico de 6,1 MeV e o segundo escape do 6,9 MeV está sob a borda Compton do pico de 6,1 MeV. Os picos de absorção total de energia, primeiro e segundo escapes do 6,1 MeV são bem visíveis, assim como as bordas Compton deles.

A figura 5.7 mostra o terceiro escape no cristal de HPGe quando 3 BGO foram atingidos em coincidência. Os graficos b e c mostram o QE com lógica de 3 ou 4 BGOs atingidos, respectivamente [64].

$\mathrm{Na}$ busca de publicações que pudessem reportar o TE ou QE, encontramos a de Wilkinson e Alburguer [93] que, usando a mesma reação de prótons no ${ }^{19} \mathrm{~F}$ e analisando o gama de 6,128 MeV, tinham observado, no limite da precisão, o QE durante a busca pela criação consecutiva de dois pares $e^{+} e^{-}$desse fóton por um processo de eletrodinâmica quântica de alta ordem, quando dois pares são criados simultaneamente. Assim, eles estabeleceram um valor máximo para esse processo. Mas Robertson, Kennett e Prestwhich [74], quatro anos mais tarde, com um arranjo diferente e fótons de energia algo maior, encontraram um valor para a razão produção de par duplo para simples, $\sigma_{\pi \pi} / \sigma_{\pi}$ aproximadamente igual a $(1.82 \pm 0.58) \times 10^{-5}$. Dado que nosso trabalho havia incluído simulações da detecção do fóton de $6,128 \mathrm{MeV}$ e que o programa de simulação não inclui nas rotinas a dupla criação de pares, estimou-se que a produção do QE pela razão medida por Robertson seria $(0,5 \pm 0,2) \times 10^{-10}$ eventos/fóton [62], de 

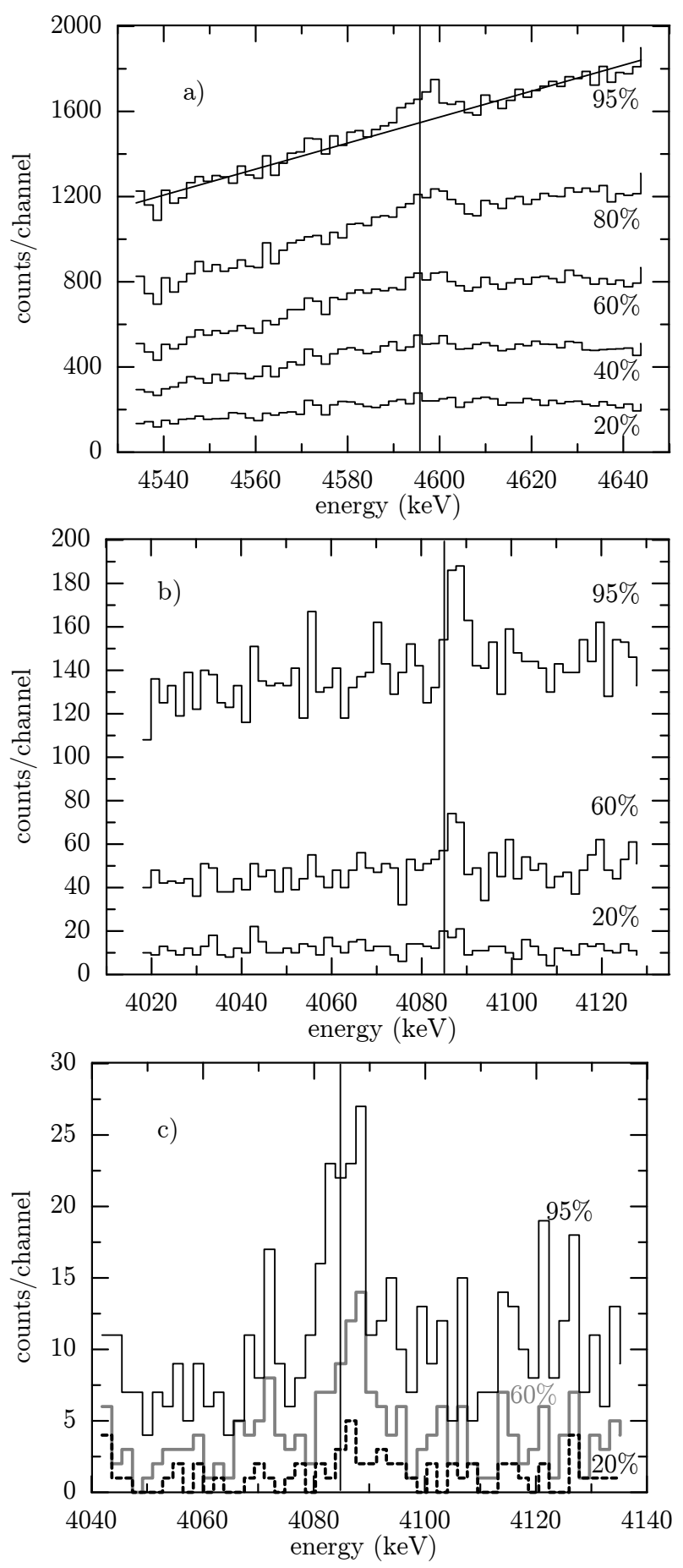

Figura 5.7: Terceiro e quarto escapes nas coincidências com $n=3$ BGOs (figuras a e b, respectivamente) e quarto escape no espectro de coincidências com $n=4$ BGOs [64] (figura c).

modo que aproximadamente $10 \%$ dos eventos de QE de3vem ter originado dupla criação de par, o que se encontra no limite da precisão experimental. 


\subsection{Eficiência e resposta de detetores para fótons de $100 \mathrm{keV}$ a $4 \mathrm{MeV}$}

Os detetores de fótons para energias acima de $100 \mathrm{keV}$ costumam ter elementos ativos coaxiais. Estudamos a resposta de um desses detetores com a intenção de usá-lo não só nas medidas de bremsstrahlung de elétrons de $6 \mathrm{MeV}$, como planejado à época, mas também nas medidas que seriam (e foram) realizadas na câmara de $100 \mathrm{keV}$ do Microtron [61]. Nesta seção, descrevemos em detalhes a caracterização desse detetor, o que incluiu medidas experimentais e simulações em diversos arranjos experimentais. Na medida da distribuição angular do bremsstrahlung, o feixe de fótons é colimado a fim de definir o ângulo de emissão do raio-x, de modo que uma das preocupações que conduziram esta investigação foi localizar a posição do colimador para a qual a resposta do detetor pudesse ser determinada melhor. Assim, após a radiografia e gamagrafia do detetor, seções 3.2.5.1 e 3.2.5.2. que permitiu verificar as informações do fabricante e completá-las, a primeira etapa foi mapear a resposta para fótons incidentes nas diferentes regiões do detetor, tanto frontal (paralelo ao eixo) quanto lateral (perpendicular ao eixo).

\subsubsection{Mapeamento frontal}

\subsubsection{Resultados experimentais}

O mapeamento frontal permitiu-nos comparar a eficiência de detecção nas diferentes regiões do volume sensível e sua dependência com a energia dos fótons incidentes [61]. Foram obtidos mais de 400 espectros do mapeamento da superfície frontal, realizado com uma fonte de ${ }^{133} \mathrm{Ba}$ da Amersham, posicionada atrás do colimador de metal pesado de forma irregular, que teve o eixo posicionado paralelo ao eixo do elemento ativo do detetor descrito no item 3.4 . $\mathrm{O}$ colimador foi movimentado com a ajuda do sistema automático descrito no item 3.4 .2 (veja o conjunto de imagens da figura 3.23). Analisaram-se os fótons das transições com energias de 30,$9 ; 35,1 ; 81,0 ; 276,4 ; 302,9 ; 356,0$ e $383,8 \mathrm{keV}$ que seguem o decaimento do ${ }^{133} \mathrm{Ba}$. Todo o conjunto detetor, colimador e sistema de movimentação foi colocado dentro de uma blindagem de $\mathrm{Pb}$ que tinha um lado aberto. $\mathrm{O}$ centro da superfície frontal da cápsula foi localizado com a ajuda de um nível a laser.

Após as medições, a posição do Eixo Geométrico (EG) do detetor foi determinada usando a média das posições $\left(x_{i}, y_{i}\right)$ mapeadas, ponderadas pelas áreas dos picos $A_{i}$ em cada posição $i$ do mapeamento, de forma análoga à que se realiza quando se calcula o centro de massa de um objeto:

$$
x_{\mathrm{EG}}=\frac{\sum A_{i} x_{i}}{\sum A_{i}}
$$

com uma expressão similar para a coordenada $y$. Encontrou-se assim que a posição do eixo geométrico estava dentro de $\pm 0,2 \mathrm{~mm}$ em relação ao centro da cápsula, para todas as energias analisadas.

O mapeamento da resposta com pincéis de fótons incidindo nas superfícies frontal e lateral do detetor, usando a fonte de ${ }^{133} \mathrm{Ba}$, teve por objetivo também a determinação da espessura de 
camadas mortas.

A variação da eficiência de pico relativa do detetor para diferentes energias pode ser apreciada nos gráficos das figuras 5.8 a 5.10 e 5.12 a 5.14 . Nessas figuras, os valores $x$ e $y$ são as coordenadas $x-y$, em mm e a escala vertical corresponde ao número de contagens no pico de transição gama selecionado. As curvas de nível são equi-espaçadas nos gráficos das figuras 5.8 . 5.9. 5.12 $\mathrm{e} 5.13$.

Em todas as medidas, pode-se verificar a simetria cilíndrica do volume ativo do detetor, diferente do que foi observado em outros trabalhos [6, 19]. Verificamos detalhadamente a resposta do detetor na região arredondada (buletizado) da superfície frontal com a lateral, pela análise das áreas de fótons de baixa energia, em que ocorre também o fenômeno de escape dos raios-X $\mathrm{K}$ do $\mathrm{Ge}$, cerca de $10 \mathrm{keV}$ abaixo do pico associado aos fótons incidentes, seguido da transição que identifica o fóton incidente. A figura 5.8 mostra o mapeamento frontal experimental da intensidade dos picos de escape dos raios-x $\mathrm{K} \alpha$ do ${ }^{133} \mathrm{Cs}(\mathrm{em} 31-10=21 \mathrm{keV})$ que seguem o decaimento do ${ }^{133} \mathrm{Ba}$, o quociente entre os picos raios-x $\mathrm{K} \beta(35 \mathrm{keV})$ e $\mathrm{K} \alpha(31 \mathrm{keV})$ do ${ }^{133} \mathrm{Cs}$ e o quociente entre escape do raios-x $\mathrm{K} \alpha(\mathrm{em} 21 \mathrm{keV})$ e $\mathrm{K} \alpha(31 \mathrm{keV})$. Note o detalhe do aumento na intensidade do escape na borda, decorrência da forma arredondada das bordas da face frontal. Como boa parte da região mapeada da periferia é formada por zeros (em azul-escuro na figura da esquerda), foi necessário eliminar essa região nos gráficos das razões (figuras do meio e da direita).
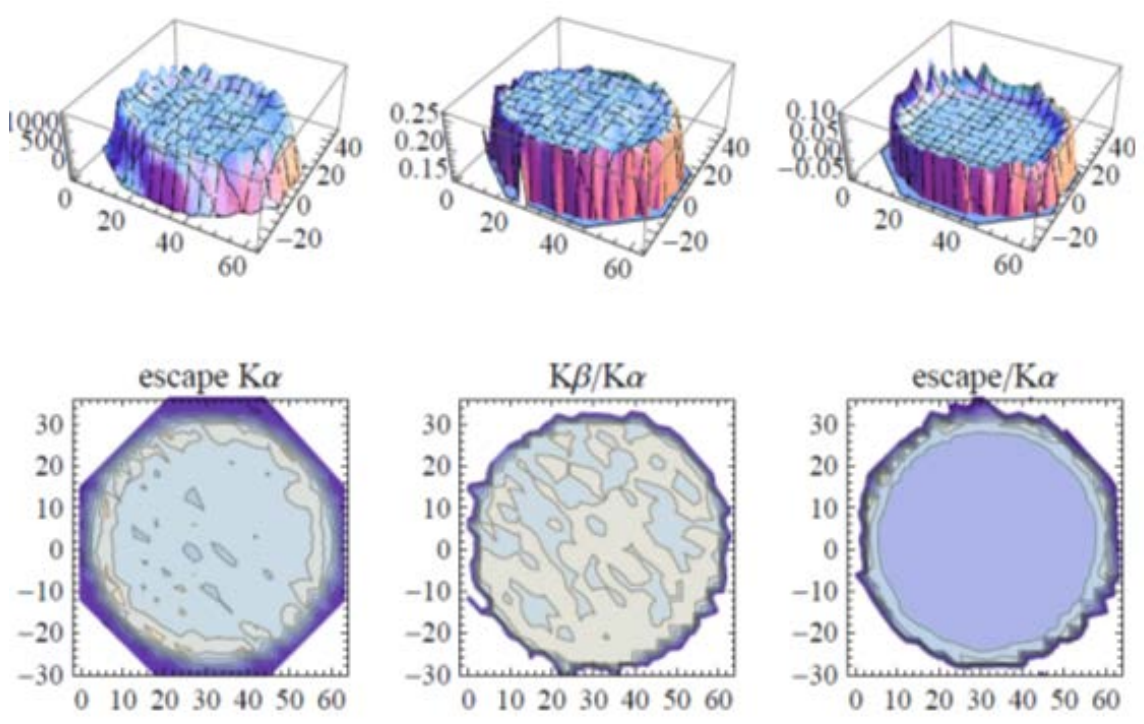

Figura 5.8: Eficiência de pico para o mapeamento frontal dos picos de escape dos raios-x K $\alpha$, quociente entre os picos raios-x $\mathrm{K} \beta$ e $\mathrm{K} \alpha$, e quociente entre escape do raios-x $\mathrm{K} \alpha$ e $\mathrm{K} \alpha$ (valores de $x$ e $y$ em mm).

Já na figura 5.9. pode ser apreciada a diminuição da eficiência para energias acima dos $81 \mathrm{keV}$ no centro do detetor (região do furo central), o que fornece um dado adicional na análise da profundidade do furo central relacionado ao coeficiente de absorção do $\mathrm{Ge}$, assim como nas bordas do volume ativo do detetor, fenômeno já apontado anteriormente por Aguayo et al. [3], que interpretam esse efeito como resultado da coleção parcial das cargas na região de transição entre o volume ativo e a camada morta. Por outro lado, Andreotti [5] reforçou esta ideia ao comparar medidas com simulações, incluindo nestas últimas, camadas mortas que variam com 
a energia. Nessa figura, de maneira similar as outras, os valores $x$ e $y$ são as coordenadas $x-y$, em mm, mas o zero corresponde ao centro geométrico do cristal e as ordenadas representam o número de contagens no pico correspondente à transição gama selecionada.

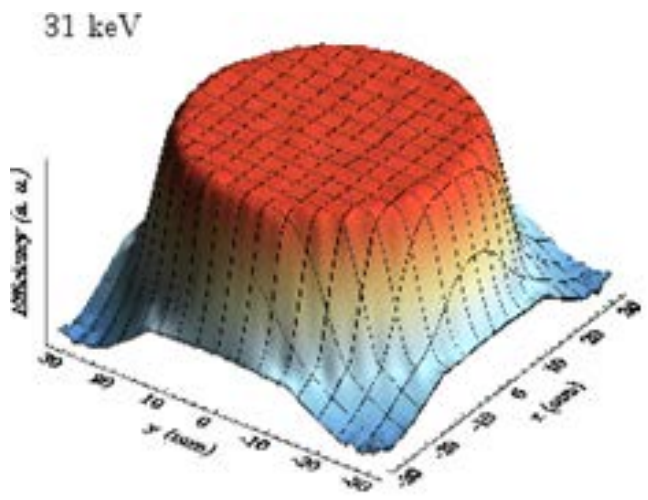

$276 \mathrm{keV}$

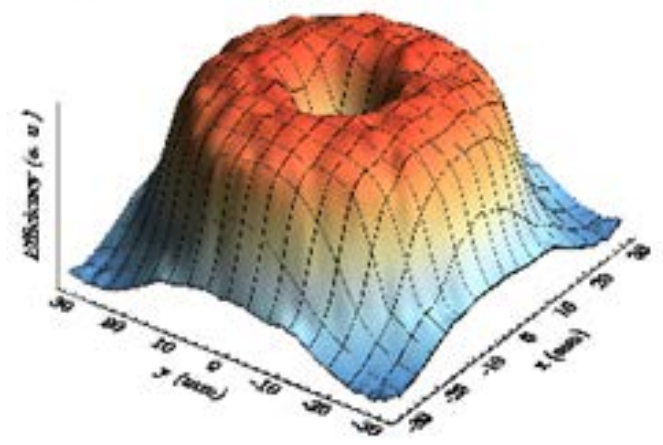

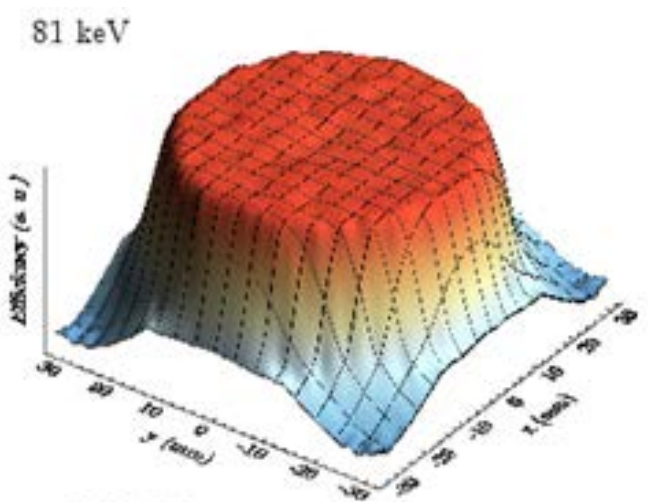

$356 \mathrm{keV}$

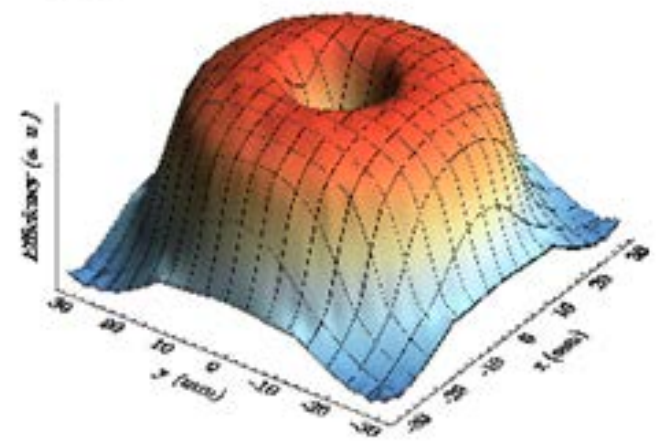

Figura 5.9: Eficiência de pico para as energias de 31, 81, 276 e $356 \mathrm{keV}$, correspondentes a fótons que seguem o decaimento do ${ }^{133} \mathrm{Ba}$, em função da posição $x-y$ da superfície frontal, obtidas com o mapeamento automático do detetor coaxial.

\subsubsection{Resultados da simulação}

Como ponto de partida na simulação, adotaram-se dimensões físicas do elemento ativo e sua cápsula especificadas pelo fabricante, como aparecem na figura 3.11, acrescentando a descrição detalhada do dedo-frio, obtida conforme apresentado na 3.2.5.1.

A figura 5.11 mostra o esboço da geometria criada a partir das dimensões especificadas no manual e usada na simulação: na cor roxa se observa o cristal de Germânio, em azul o Alumínio da capa, em verde a janela de Carbono (que dada sua espessura não se consegue distinguir na figura), em azul escuro o furo central e em vermelho, o dedo frio de Cobre, com uma inserção no furo de acordo aos dados da placa da figura 3.17, assim como o arredondamento da superfície frontal externa e à do furo central, com os raios conforme especifica o manual do detetor, da figura 3.11 . Não podem ser apreciadas as camadas mortas externas e internas, mas foram incluídas na simulação.

Uma vez verificado que o detetor apresenta simetria cilíndrica em relação ao eixo coaxial, não há necessidade de simular o depósito de energia no volume ativo do detector para cada um dos pontos do mapeamento, uma vez que apenas a distância do centro do colimador ao eixo do 


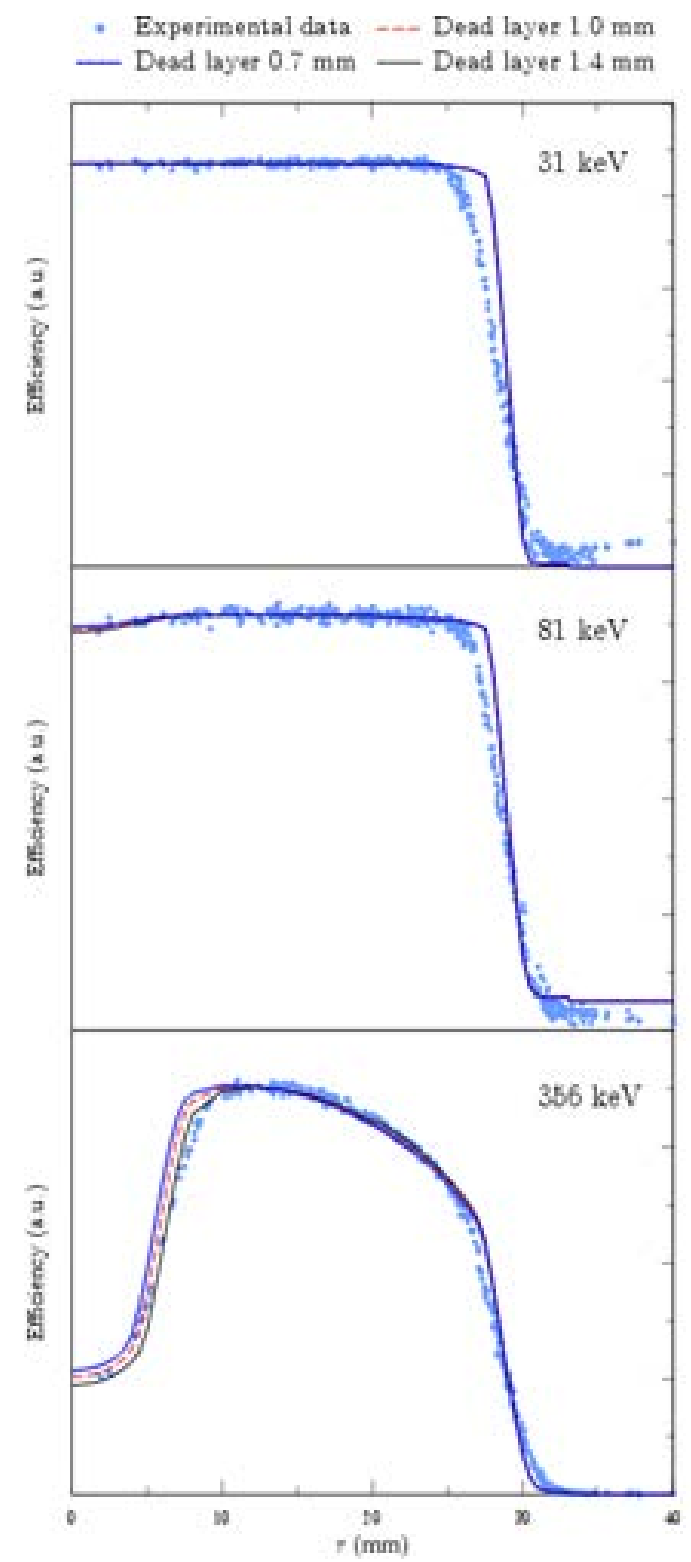

Figura 5.10: comparação da eficiência de detecção experimental e simulada em função da distância ao eixo central do elemento ativo. As linhas contínuas representam os valores simulados para a espessura da camada morta especificada pelo fabricante e espessuras iguais a 0,7 e $1,4 \mathrm{~mm}$ e a linha tracejada, 1,0 $\mathrm{mm}$.

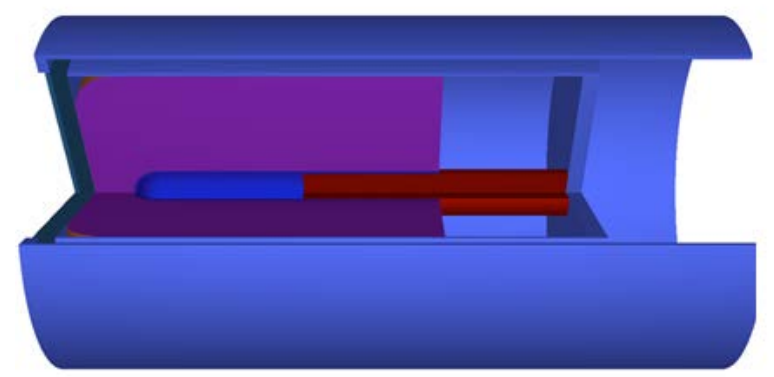

Figura 5.11: Desenho dos componentes do detetor de HPGe simulado, com um corte longitudinal para apreciar as diferentes partes. O cristal de Ge está em roxo, destacando o furo interno em azul, o dedo frio de cobre em vermelho e em azul o alumínio da capa externa. 
detetor é importante. Esse procedimento exige, na prática, a interpolação dos valores simulados ao longo de um raio, testado da seguinte forma. Inicialmente, fizemos dois grupos de simulações de espectros de fótons, um com o colimador posicionado varrendo uma corda, e outro, varrendo um raio. Comparamos as áreas de pico dos espectros simulados ao longo da corda com aquelas obtidas por interpolação dos valores obtidos ao longo do raio. Constatamos que um bom acordo exige que a simulação seja feita para posições equi-espaçadas em $0,5 \mathrm{~mm}$ ao longo de um raio e que a interpolação linear fornece resultados melhores que splines de ordem maior, de maneira que esse procedimento - separação de $0,5 \mathrm{~mm}$ ao longo do raio e interpolação linear - foi usado em todas as simulações e suas análises.

A fim de comparar os resultados dos espectros medidos com os simulados, é necessário realizar uma normalização. Escolhemos como referência o valor médio das áreas de pico de cada energia estudada na região onde a eficiência é máxima e aparentemente independente da distância ao centro do detetor, isto é, numa região intermediária entre a região onde o furo central deixa de ter influência na absorção até aquela a meio-caminho da borda externa do detector $(11,9 \mathrm{~mm} \leq r \leq 14,5 \mathrm{~mm})$.

Os gráficos da figura 5.10 comparam a eficiência de detecção em função da distância ao eixo coaxial para os espectros experimentais e simulados, com três diferentes espessuras de camada morta na região próxima ao furo central. O gráfico para energia de $356 \mathrm{keV}$ sugere que a camada morta nessa região tenha o dobro da espessura do valor indicado pelo fabricante.

Nas figuras 5.12 e 5.13 são comparados os gráficos decorrentes do mapeamento frontal experimental do detetor com os simulados, usando uma fonte de ${ }^{133} \mathrm{Ba}$. As curvas de nível serrilhadas dos espectros medidos decorrem da separação mínima $(3 \mathrm{~mm})$ entre as posições de incidência do feixe. Na região do furo central, pode-se observar, assim como na região da borda do detetor, que há pequenas diferenças entre os valores medidos e simulados, ou seja, a redução da eficiência de pico próxima às bordas é devido a algum fenômeno que a simulação não consegue levar em conta.
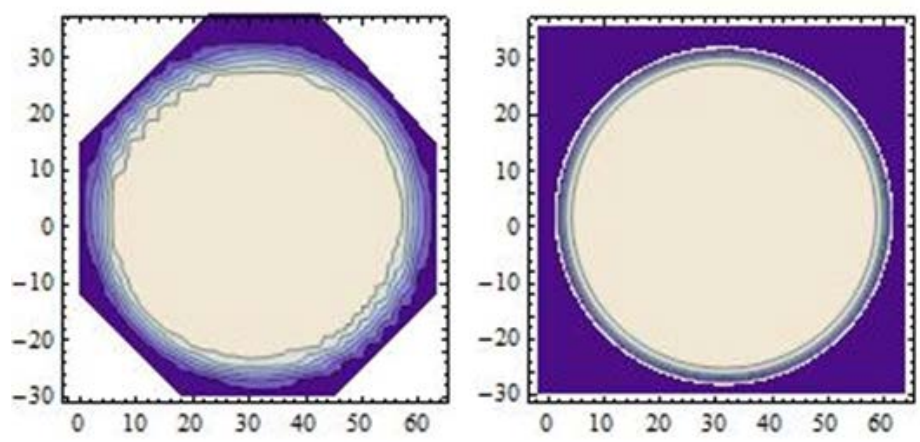

Figura 5.12: Comparação da resposta para o mapeamento frontal experimental (esquerdo) e simulado (direito) para o pico de raios- $x$ de $35 \mathrm{keV}$ que segue o decaimento do ${ }^{133} \mathrm{Ba}$ (valores de $x$ e $y$ em mm).

\subsubsection{Simulação de espectros de ${ }^{137}$ Cs colimados ao longo de um raio}

Esta simulação teve o propósito de encontrar a posição ideal do colimador da figura 3.19 a ser usado nas medidas da distribuição angular de bremsstrahlung. Para isso usou-se a mesma 

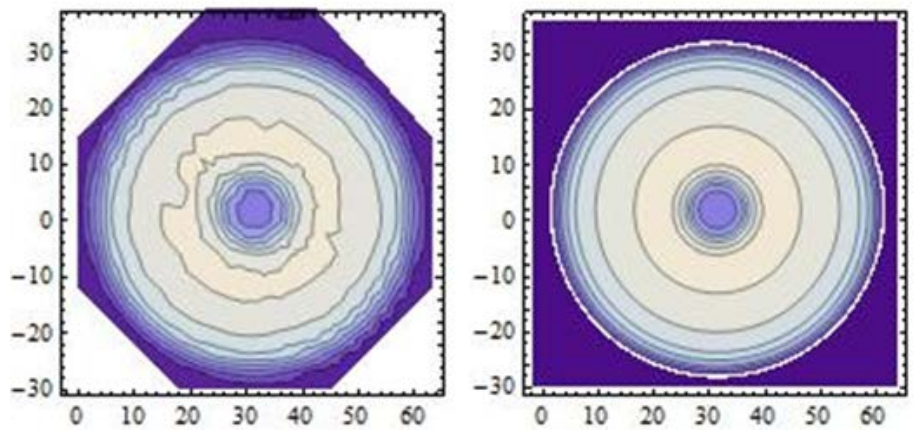

Figura 5.13: Comparação da resposta para o mapeamento frontal (esquerdo) e simulado (direito) para o pico gama de $356 \mathrm{keV}$ que segue o decaimento do ${ }^{133} \mathrm{Ba}$ (valores de $x$ e $y$ em mm).

geometria usada na simulação do mapeamento frontal, com o colimador de $2 \mathrm{~mm}$ de diâmetro interno e a fonte de fótons de $661 \mathrm{keV}$. Procurou-se pela região do detetor com maior proporção de eventos no pico de absorção total de energia. As simulações varreram um raio do detetor, com espaçamento de $0,5 \mathrm{~mm}$ entre cada ponto.

A figura 5.14 mostra o quociente entre a área do espectro no intervalo de energias entre 180 e $220 \mathrm{keV}$ e a área do pico de absorção total de $661 \mathrm{keV}$ de cada espectro. A linha superior corresponde à simulação com camada morta interna de 1,4 $\mathrm{mm}$ e a inferior com 1,0 mm. Como era esperado, a razão total para pico não é constante ao longo do raio do detetor. Neste e em outros quocientes analisados se observa uma queda mais acentuada na região do furo central para a simulação de camada morta 1,4 mm (seta vermelha). Este é um resultado interessante, já que poderia se encontrar a espessura da camada morta interna com medidas de uma fonte de Cs colimada, como a desta simulação. Os gráficos para diferentes regiões da área integrada forneceram figuras similares.

\subsubsection{Varredura lateral com uma fonte de ${ }^{137} \mathrm{Cs}$}

Este mapeamento consistiu em determinar a eficiência de pico para fótons de 31 e $662 \mathrm{keV}$ emitidos por uma fonte de ${ }^{137} \mathrm{Cs}$, que incidiam em uma direção perpendicular ao eixo cilíndrico do volume ativo do detetor. Foi mapeada toda uma grade de pontos separados por $3 \mathrm{~mm}$ tanto na horizontal quanto na vertical, de modo que foram obtidos aproximadamente 700 espectros. $\mathrm{O}$ resultado aparece na figura 5.15, em que a) corresponde à eficiência para as energias dos raios- $\mathrm{x} \alpha$ de $\approx 31 \mathrm{keV}$ e mostra uma estrutura bem marcada e mostra que essas estruturas não são o resultado de um efeito de camada morta, mas sim de atenuação de radiação por suportes necessários para fixar a posição o cristal cuja massa é de $\approx 1 \mathrm{~kg}$, o que é um resultado inesperado, uma vez que o manual não informa acerca da sua existência. Já a figura b) foi obtida com fótons de $662 \mathrm{keV}$ Por um lado, este resultado deve influir na especificação da geometria simulada, uma vez que estas estruturas deveriam ser consideradas, apesar de que provavelmente só tenham efeito na detecção de fótons de baixa energia. Por outro lado, a cápsula do detetor não identifica claramente qual lado deve ser mantido para cima, e da imagem deduz-se que esse suporte não deve segurar o detetor se ele for rodado $180^{\circ} \mathrm{em}$ torno do eixo. Assim, agora identificamos qual lado deve ser mantido para cima, tanto para evitar deslocamento do volume 


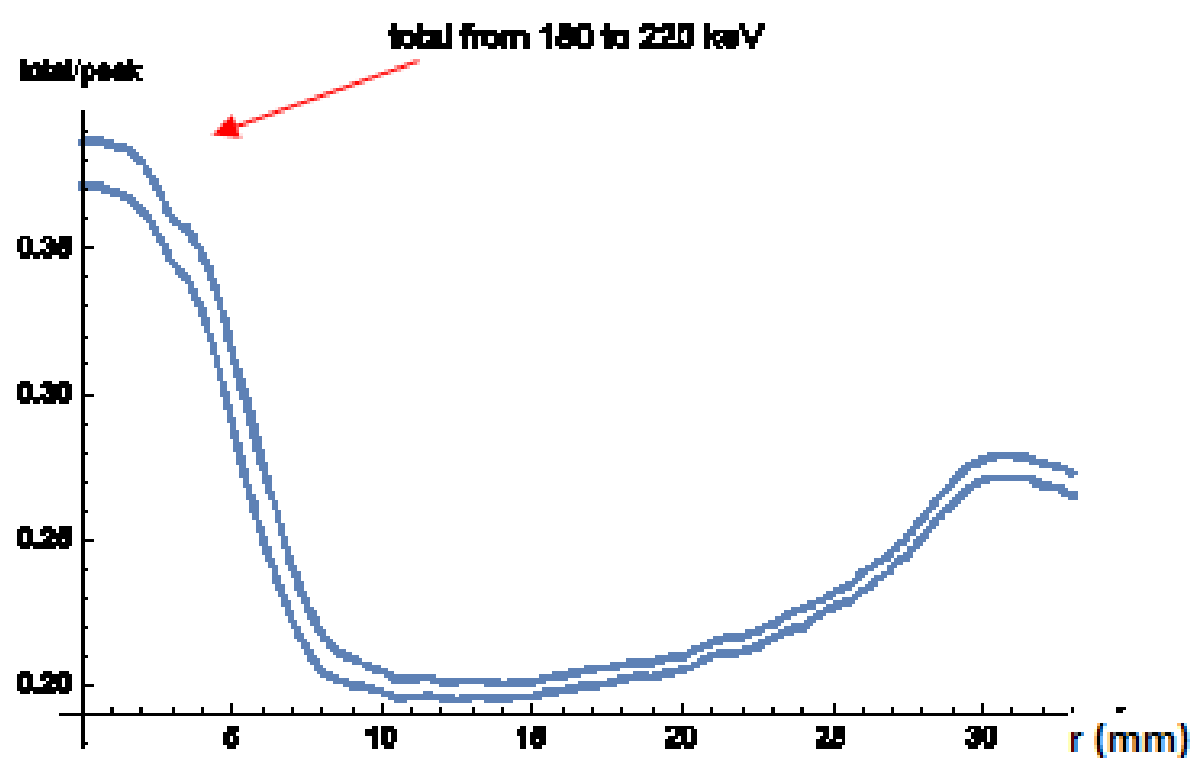

Figura 5.14: Razão entre a área do espectro no intervalo de energias entre 180 e $220 \mathrm{keV}$ e a área do pico de absorção total do ${ }^{137} \mathrm{Cs}$ em função da posição do feixe em relação ao centro do cristal. A curva superior corresponde à simulação com camada morta interna de 1,4 mm e a inferior, 1,0 mm. Do gráfico, deduz-se que um colimador de $1 \mathrm{~cm}$ de diâmetro deve ter seu eixo posicionado entre 13 e $15 \mathrm{~mm}$ de distância do eixo do detetor a fim de maximizar a relação entre a eficiência de pico e a total.

ativo, quanto para sermos capazes de simular realisticamente o conteúdo da cápsula do detetor

Outro resultado inesperado, com maior probabilidade de relacionar-se com as diferenças mostradas é a diminuição na resposta para $662 \mathrm{keV}$ no centro do detetor, que na figura $5.15 \mathrm{~b}$ ) - demarcada pelo retângulo em vermelho - se observa como um vinco pronunciado na curva de nível. Não há justificativa para essa diminuição de eficiência na região entre 1 e $3 \mathrm{~cm}$ para dentro da superfície anterior do cristal, tendo em consideração que a espessura entre a superfície frontal e o furo é $8,3 \mathrm{~mm}$.

\subsubsection{Medida experimental e simulação da detecção usando um colima- dor comprido de metal pesado}

Foram medidos espectros de fontes de calibração com o feixe de fótons ingressando pela superfície frontal do detector, tanto na sua totalidade quanto com o colimador de metal pesado descrito na seção 3.3 e esquematizado na figura 3.19, posicionado entre o furo do dedo frio e a superfície externa, de acordo com os resultados da simulação relatados na seção 5.2.1.3. $O$ detetor recebeu uma blindagem adicional de cobre que possuía um furo descentrado, para garantir que o colimador estivesse posicionado de acordo com o esboço da figura 5.16. Todo o conjunto foi inserido em uma blindagem de chumbo, cujas dimensões internas eram 400 x 400 x $185 \mathrm{~mm}^{3}$, com $10 \mathrm{~cm}$ de espessura.

A figura 5.17 apresenta as geometrias de duas medidas diferentes, a da esquerda, com a fonte observando toda a superfície frontal do detector e a da direita, do arranjo experimental com colimador que foi reproduzido nas simulações. Nessa figura se observa: em verde-escuro a blindagem de chumbo; em amarelo, o ar entre o chumbo e o detetor: em rosa (quase invisível), 

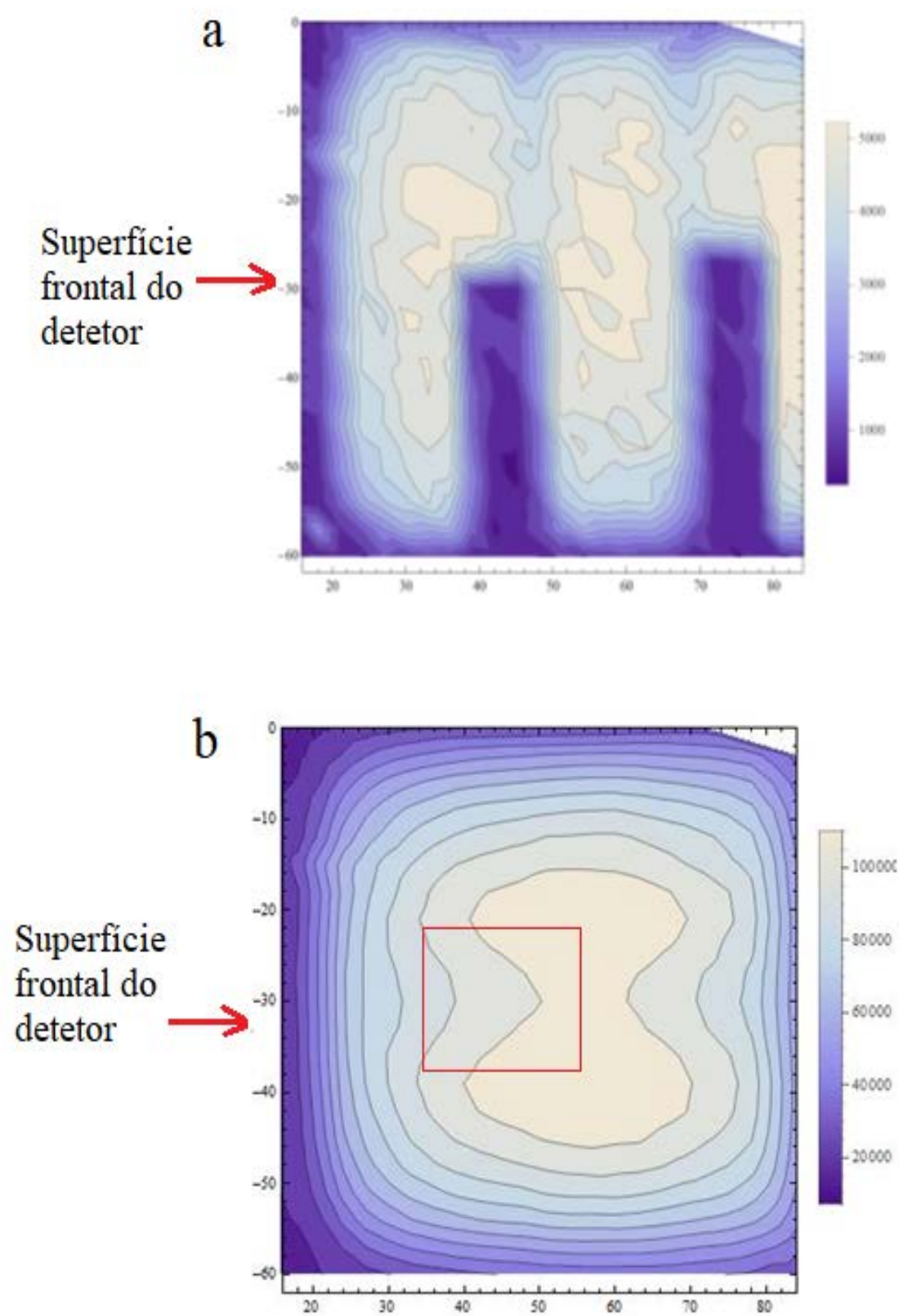

Figura 5.15: Mapeamento lateral da eficiência de pico para fótons de a) 31 e b) $662 \mathrm{keV}$ do ${ }^{137}$ Cs. As cotas das curvas de nível estão desenhadas conforme a barra lateral colorida, e os valores das coordenadas $x$ e $y$ estão em $\mathrm{mm}$. O eixo do detetor é paralelo ao eixo $x$ e ocupa a cota $y=-30 \mathrm{~mm}$, aproximadamente.

o Al da cápsula do detetor, em verde mais claro e em roxo claro, a região de vácuo e em roxo escuro, o próprio cristal de Germânio que considerou as dimensões físicas do arranjo experimental. As simulações das medidas com a fonte de ${ }^{137} \mathrm{Cs}$ contemplaram os raios-x que seguem seu decaimento $(31,8174,32,1939,36,3292$ e 37,332 keV) assim como o raio gama de 661,657 keV. Os espectros foram comparados após normalizar a área do pico de absorção total na energia de $662 \mathrm{keV}$, no espectro simulado, para o valor medido experimentalmente.

Os espectros medido e simulado, para uma distância fonte-detetor de $17 \mathrm{~cm}$ sem colimação, 


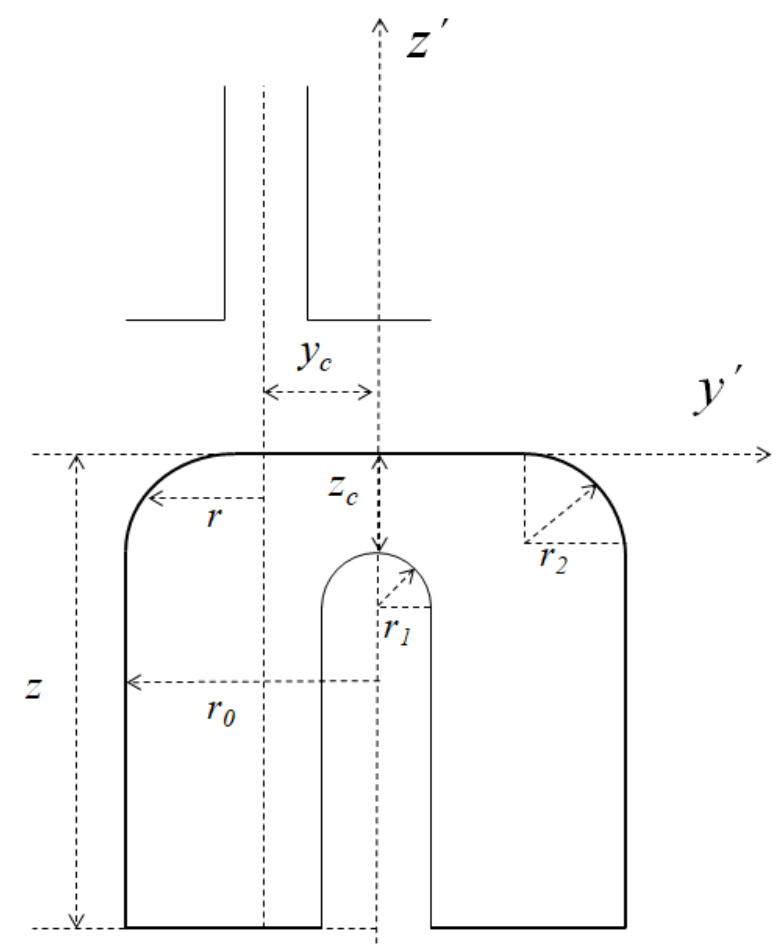

Figura 5.16: Esquema do posicionamento do colimador frente à superfície frontal do detetor coaxial.

podem ser observados na figura 5.18. Da mesma forma que nos trabalhos do terceiro escape os espectros simulados foram manipulados, introduzindo um alargamento e normalização para poder comparar com os espectros medidos. Como pode ser observado, a forma de ambos os espectros é similar, com diferenças importantes na região entre o pé à esquerda do pico de absorção total para $662 \mathrm{keV}$ e na região de espalhamento múltiplo, as energias abaixo da borda Compton.

Os espectros simulado e experimental com o colimador de metal pesado com a geometria da figura 5.17 (imagem da direita), se observam na figura 5.19. Com o intuito de pesquisar a causa da diferença do contínuo no espectro, alteraram-se as secções de choque para o espalhamento Compton em $+2 \%$ e $-2 \%$ os espectros correspondentes aparecem também na figura 5.19 . Essas alterações não foram significativas. À esquerda do pico de absorção total se observa uma tendência a diminuir as contagens quando a secção de choque para espalhamento Compton é reduzida em $2 \%$, mas a medida que diminui a energia, essa tendência muda, aparecendo um pouco maior o número de contagens para essa alteração, com relação ao espectro sem modificações. O tratamento de alargamento dos picos e a normalização pela área do pico de absorção total medido experimentalmente também foram implementados nestes espectros a fim de facilitar a comparação. As áreas dos picos foram determinadas pela integral das contagens do pico à qual foi subtraída a área referente ao contínuo como a soma das contagens de igual número de canais aos lados do pico. 

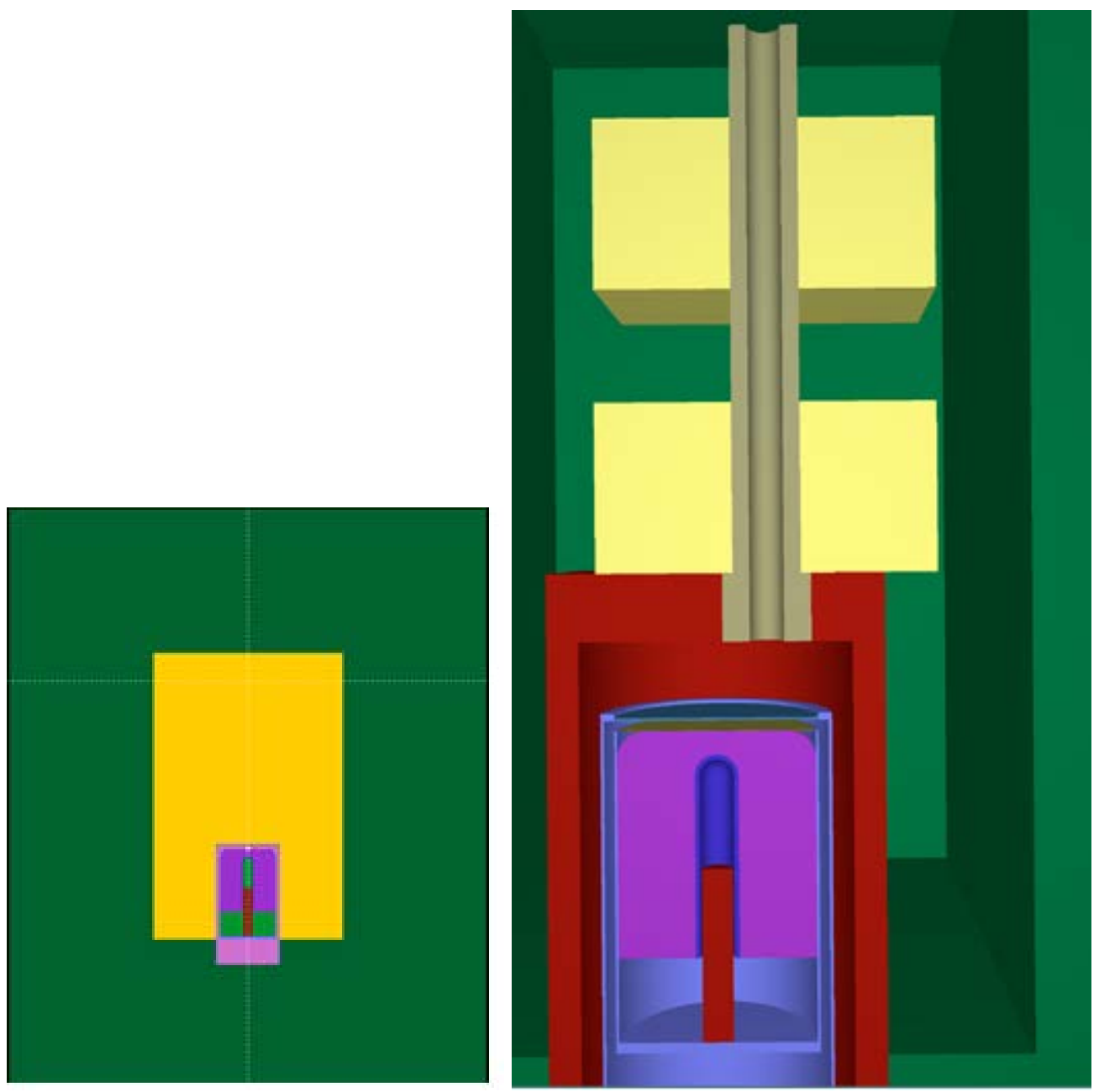

Figura 5.17: À esquerda, a geometria simulada do detetor dentro da blindagem de chumbo, com a fonte enxergando a totalidade da superfície frontal do detetor. À direita, a geometria simulada do detetor com colimador de metal pesado dentro de uma blindagem de $\mathrm{Pb}$.

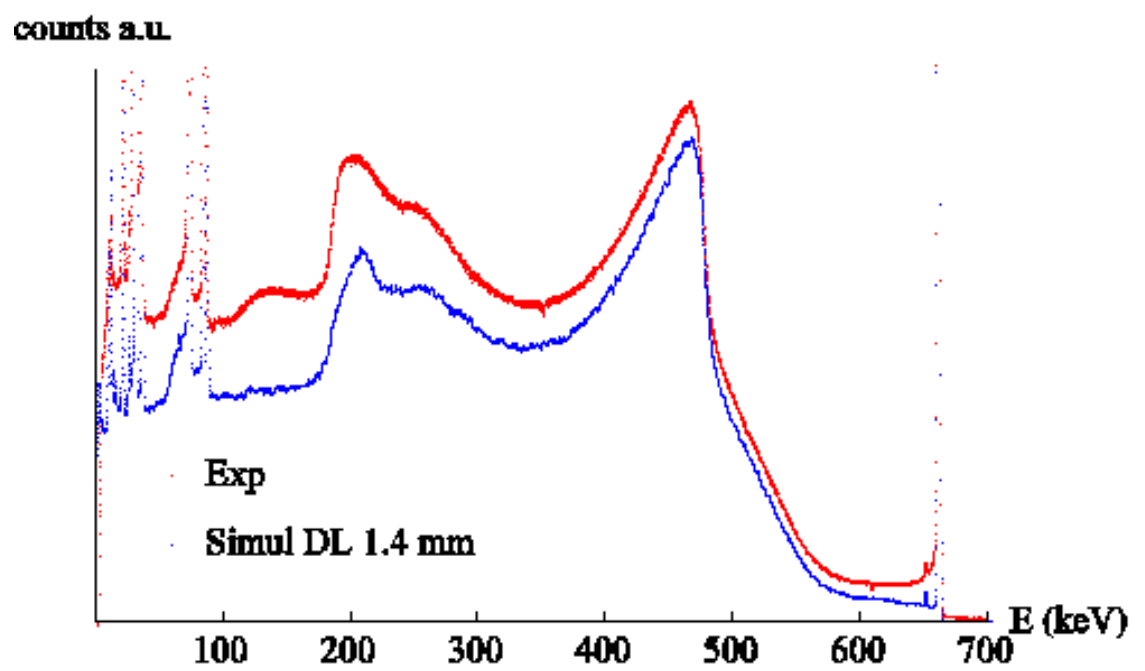

Figura 5.18: Espectro de deteção no HPGe de uma fonte de ${ }^{137} \mathrm{Cs}$ medido e simulado, com a imagem esquerda da geometria da figura 5.17 . 


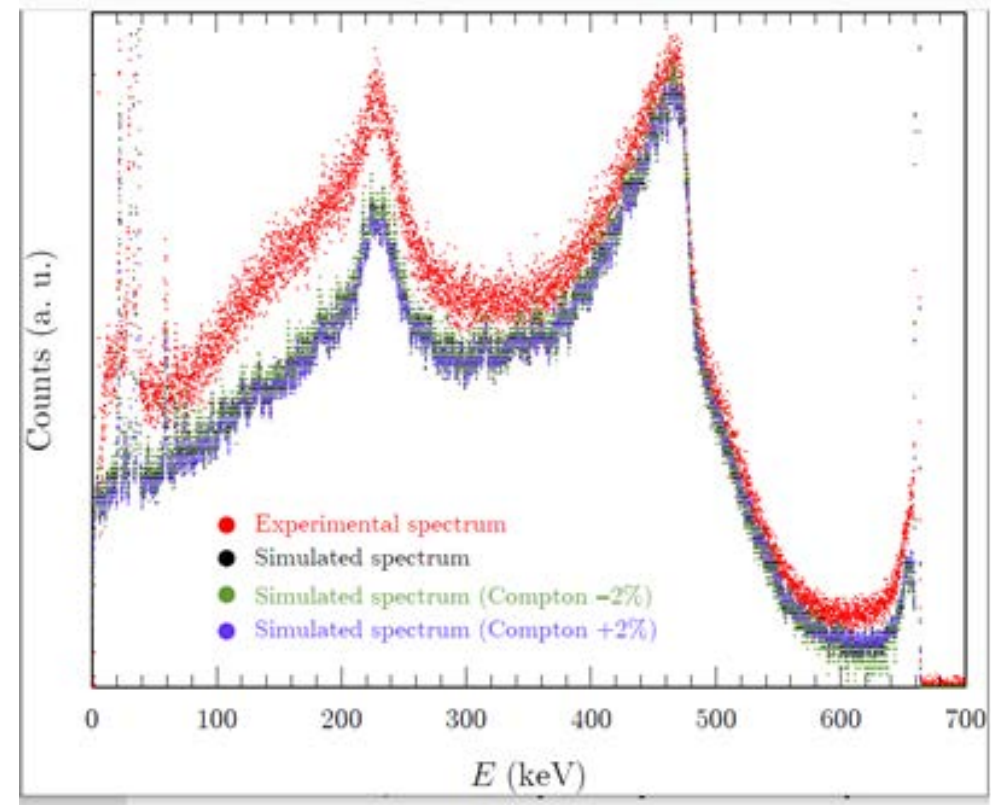

Figura 5.19: Espectros de detecção no HPGe de uma fonte de ${ }^{137} \mathrm{Cs}$ medido e simulados, com as secções de choque Compton das tabelas e com modificações de $+\mathrm{e}-2 \%$ delas, com o conjunto fonte-detetor dentro de uma blindagem como a da configuração direita da figura 5.17 A radiação de fundo no espectro experimental foi subtraída.

Estes estudos tinham a intenção de conhecer a resposta do detetor com o colimador longe da influência da superfície externa lateral e do furo central, de maneira a poder considerar geometrias com feixes paralelos incidindo perpendicularmente à superfície frontal do detetor, como posteriormente iria ser abordado no trabalho da função resposta analítica deste detector e usado no trabalho da medida de secções de choque do Bremsstrahlung de elétrons [30, 32, 34. 33]. Note-se que a simulação aproxima melhor o espectro com colimador (5.19) do que sem colimar (5.18), provavelmente pela supressão do espalhamento na blindagem, difícil de simular corretamente, mas o acordo ainda está longe de ser obtido, corroborando mais uma vez a dificuldade em simular simultaneamente as eficiências de pico e total com o mesmo conjunto de parâmetros.

\subsection{Detetores de fótons com energias menores que $100 \mathrm{keV}$}

Do observado na Figura 2.4 que mostra as secções de choque para diferentes processos de interação em função da energia do fóton, abaixo dos $100 \mathrm{keV}$ o processo dominante é o efeito fotoelétrico, com uma seção de choque pelo menos uma ordem de grandeza maior que a do espalhamento Compton. Nos detetores planares, $\mathrm{Si}(\mathrm{Li})$ ou SDD, dada a pequena espessura ou tamanho em geral, a contribuição das colisões Compton para a resposta é dominada por processos em que há uma única interação, razão pela qual é possível construir expressões analíticas que fornecem a eficiência de detecção e a função resposta, ao contrário das que tratam fótons com energia maior e cristais com maior volume. Nossas publicações acerca da escolha e teste dessas expressões analíticas nessa faixa de energias [60, 20, 30, 8] serão detalhadas a seguir.

Nas pesquisas onde se pretendia medir a secção de choque de Bremsstrahlung de elétrons 
na linha de 10 a $100 \mathrm{keV}$ do Microtron [91] iriam se usar detetores para raios-x e um detetor coaxial de janela fina de C. Por outro lado, os trabalhos que pretendiam determinar a secção de choque de ionização de camadas de certos elementos iriam observar energias na ordem dos 10 a $70 \mathrm{keV}$. Ambas as linhas de pesquisa precisavam da função resposta dos detectores em que aplicamos as funções analíticas que desenvolvemos.

\subsubsection{Detetor planar $5 \mathrm{cc}$}

Este trabalho foi prévio àquele onde se determinou a camada morta irregular [60]. Tínhamos observado a forma não esperada da curva de eficiência que era aparentemente composta pela soma de duas componentes. Como essa curva de eficiência possuía um comportamento atípico, e que um segundo pico de eficiência começava em $60 \mathrm{keV}$ chegando a um máximo em $\approx 80 \mathrm{keV}$, era necessário caracterizar melhor esse comportamento. Usou-se então a fonte de ${ }^{198} \mathrm{Au}$ descrita na seção 3.25, que emite raios-x de energias muito próximas às dos raios-x de Au que foram medidos nos trabalhos [45, 27], de modo que essa medida foi suficiente para garantir a precisão na determinação de eficiência de detecção nesse experimento.

$\mathrm{Na}$ determinação da eficiência de detecção usaram-se fontes pontuais de ${ }^{133} \mathrm{Ba},{ }^{152} \mathrm{Eu},{ }^{207} \mathrm{Bi}$ e ${ }^{241} \mathrm{Am}$ obtidas da Amersham e de ${ }^{57} \mathrm{Co}$ e ${ }^{137} \mathrm{Cs}$ confeccionadas entre duas folhas de polietileno, fixadas por anéis de Al, do Laboratório de Metrologia Nuclear, descritas no item 3.24 do capítulo Instrumentação. A calibração de eficiência abrangia um intervalo de energias entre 13 e $136 \mathrm{keV}$, onde as fontes observavam a totalidade da superfície frontal do detetor, e mostrou um comportamento atípico, com uma "corcova" entre 70 e $110 \mathrm{keV}$, diferente ao detalhado nos manuais dos detetores e na figura 2.7 -- a eficiência deveria apresentar um plateau entre aproximadamente 30 e $80 \mathrm{keV}$, região em que o valor da eficiência é máximo. Concluiu-se que o detetor devia ter uma camada frontal irregular, com uma estrutura almofadada, de maneira que a eficiência de detecção estava composta pela soma de duas componentes, como pode ser visto no gráfico 5.20. Esse comportamento pode ser verificado com um mapeamento da eficiência da superfície frontal para pincéis de fótons bem colimados e analisando o comportamento das áreas dos picos de fótons com baixa e média energia.

O mapeamento foi realizado de acordo ao detalhado no item 3.4 . Segundo o relatado na publicação [60], a região frontal com camada morta fina foi estimada com o quociente das áreas dos picos de 14 e $59 \mathrm{keV}$, considerando que os coeficientes de atenuação para esses fótons valem $\approx 600$ e $0,1 \mathrm{~cm}^{-1}$, respectivamente. Esse quociente era constante na região central, sugerindo uma camada morta fina, $d_{\text {thin }}=2,04(16) \mu \mathrm{m}$, com um raio $r_{\text {thin }}=8,02(4) \mathrm{mm}$, mas ambos os picos desapareciam na região anular intermediária, indicando uma camada morta grossa, $d_{\text {thick }}=2,3(4) \mathrm{mm}$ e raio $r_{\text {thick }}=9,28(18) \mathrm{mm}$, seguidas por outra totalmente insensível, que se pode observar na figura 5.21 .

A fim de obter os valores de espessura e raio de camadas mortas, foi usado o modelo de Seltzer [81], que calcula as eficiências de pico das diferentes energias das fontes radioativas usadas na calibração. Esses valores de eficiência foram comparados com os valores medidos. As espessuras das camadas mortas foram determinadas mediante um ajuste de mínimos quadrados para os parâmetros do modelo de Seltzer. 


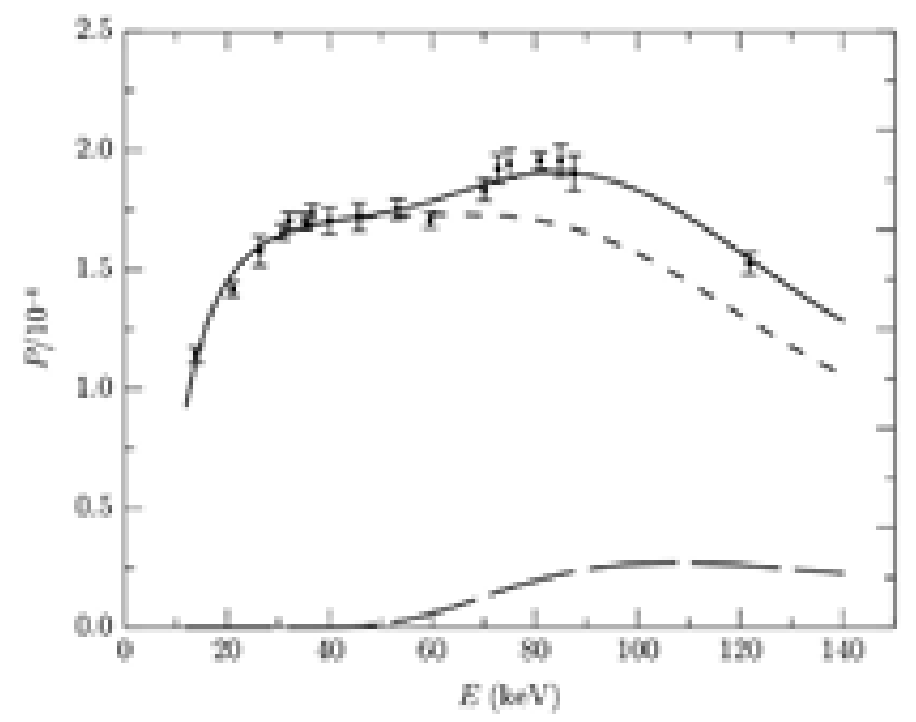

Figura 5.20: Eficiência de detecção do detetor planar de 5 cc [60].

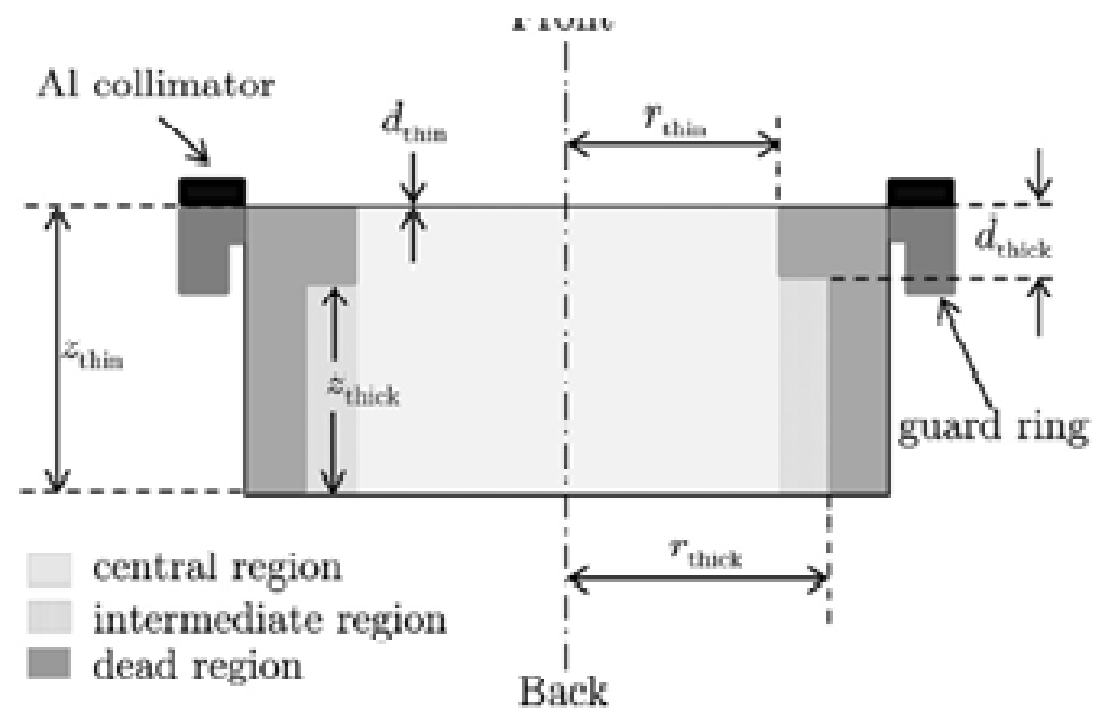

Figura 5.21: Modelo de camadas mortas do cristal do detetor planar de 5cc [60].

Uma vez encontradas a dimensão da camada morta frontal e a espessura do volume ativo do cristal, fizeram-se simulações com o código PENELOPE, para determinar a eficiência do detetor. Pequenas mudanças na espessura da camada morta frontal forneceram resultados coincidentes com os valores obtidos pelo modelo de Seltzer da publicação anterior [20, 60].

No decorrer da pesquisa, o modo de abordar o problema e a solução proposta foram mudando. Determinamos experimentalmente a eficiência do detetor de raios-X usando fontes radioativas e adaptamos o modelo analítico de Seltzer [81], para calcular a eficiência de detecção usando apenas parâmetros físicos do detetor: espessuras das camadas mortas, diâmetro e comprimento do cristal de Ge. Determinamos, realizando um ajuste de mínimos quadrados, quatro parâmetros: as espessuras das camadas mortas da área frontal e os correspondentes ângulos sólidos subtendidos pela fonte radioativa. Essa camada morta irregular foi descoberta pelo ma- 
peamento da superfície frontal descrito na seção 3.4. Assim, mostramos que é possível melhorar o desempenho de um detetor com camada morta frontal irregular, com o uso de um colimador que limita a observação dos fótons àqueles que atravessam sua superfície pela região de camada morta fina. Esse trabalho [60] fornece um guia para identificar e solucionar o problema de encontrar um detetor com camada morta variável.

A partir desses resultados, a nova montagem na câmara incluiu o colimador de Cobre dentro de um bloco de Cobre de modo a iluminar unicamente a parte central do cristal, onde a camada morta é fina. Imagens desse arranjo, da metodologia para alinhar o colimador, e do detetor montado dentro dos discos de acrílico assim como uma vista de cima onde se observa a inclinação do eixo do detetor que compensava o desalinhamento do cristal e do colimador de $2 \mathrm{~mm}$ estão na figura 3.33 , imagem da direita abaixo.

Continuamos pesquisando a função resposta dos detetores, agora mediante um modelo analítico [32] descrito na seção 4.3.2, que focou na determinação da função resposta (FR) para um feixe bem colimado do mesmo detetor planar do trabalho anterior [60], para energias entre 10 e $100 \mathrm{keV}$. A função resposta analítica foi comparada com simulações de PENELOPE. Porém, nos cálculos da contribuição à função resposta percebeu-se que os efeitos devidos à absorção de fótons na janela de Be e dos fotoelétrons representavam perdas ou contribuições menores que $1 \%$ para essa faixa de energia. A contribuição do espalhamento Compton inicia-se a partir dos $20 \mathrm{keV}$ e aumenta, mas não supera $3 \%$. Isso está representado na figura 11 da publicação [32]. Os testes feitos e comparações com simulações Monte Carlo concluíram que dito modelo de FR pode ser usado na deconvolução de espectros contínuos de raios-x, ao fornecer resultados acurados dos espectros de emissão e valida o modelo de Seltzer para a faixa de energias de 10 a $100 \mathrm{keV}$. Por outro lado, estima-se que o modelo possa servir para calcular a FR de detetores de $\mathrm{Si}(\mathrm{Li})$.

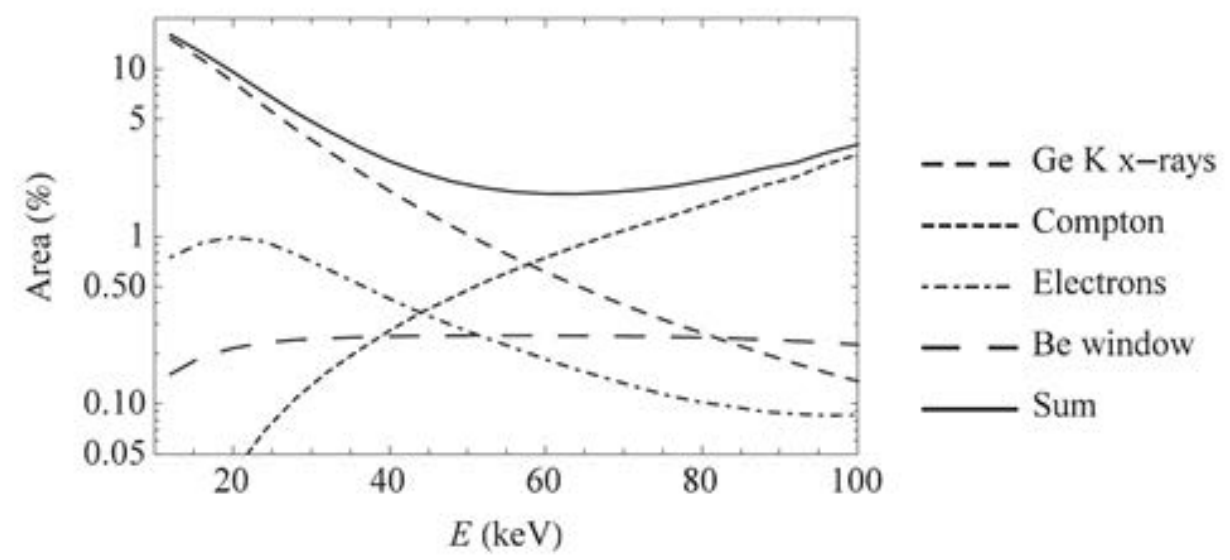

Figura 5.22: Frações do número total de eventos detetados devidos aos diferentes mecanismos de deposição de energia em função da energia do fóton incidente [32]. 


\subsubsection{Detetores de Si(Li) e SDD}

Esses detetores têm boa resolução em energia, de modo que a largura natural das transições de raios-x característicos afeta a forma dos picos. Assim, enquanto os picos de absorção total dos gamas foram ajustados usando funções-modelo Gaussianas, os de raios-x são ajustados por funções de Voigt.

Não se encontram na literatura muitos valores padronizados de intensidade de transição para nuclídeos que emitam raios-x ou gamas na região de mais baixa energia, o que aumenta a demanda por modelos para determinar a eficiência de detecção com funções analíticas. Por outro lado, o predomínio do efeito fotoelétrico na atenuação dos fótons facilita a construção desses modelos. De toda maneira, é necessário verificar a qualidade do modelo comparando o resultado com alguns valores experimentais. Frequentemente, a eficiência de detecção do pico de absorção total determinada com funções analíticas baseadas em processos físicos fornece melhores estimativas que a obtida pela interpolação ou extrapolação de uma função ajustada com dados experimentais para espectros de raios-x entre 6,4 e $100 \mathrm{keV}$, uma vez que, nessa região, a eficiência de pico não é monotônica, como ilustrado pela figura 2.7 .

O trabalho de Barros [8] calculou a eficiência de pico para dois detetores: um SDD e um $\mathrm{Si}(\mathrm{Li})$ (SLP) adaptando dois formalismos diferentes, o de Seltzer e o de O'Meara-Campbell [70], com o objetivo de obter os parâmetros do ajuste da curva de eficiência e então compará-la com os dados experimentais. Ambos detetores, cujas caraterísticas estão listadas no item 3.2.4. são usados para espectrometria de raios- $\mathrm{x}, \mathrm{o} \mathrm{Si}(\mathrm{Li})$ para energias até $\approx 100 \mathrm{keV}$ e o SDD até $\approx 30 \mathrm{keV}$. O trabalho de Seltzer [81] propõe que seu método seja usado para feixes colimados, de maneira que os fótons atinjam a superfície frontal do detetor perpendicularmente a ela. Nas medidas deste trabalho, ambos os detetores não usaram um colimador externo, mas como as fontes de calibração foram posicionadas afastadas do detetor (a 37(2) e 240(5) mm, respectivamente, para elementos ativos com 2,3 e $5 \mathrm{~mm}$ de raio), os fótons incidem na superfície frontal do detetor em uma direção suficientemente próxima da normal para que o cálculo aproxime bem a eficiência de detecção.

Aplicando ambos os modelos a nossos dados experimentais, verificamos que os dois se aproximam dos valores nominais declarados pelos fabricantes, dentro das incertezas. Os resultados indicam que, para o SDD, os modelos de Seltzer e O'Meara-Campbell são compatíveis no intervalo de energias de 6 a $40 \mathrm{keV}$; entretanto, para o $\mathrm{Si}(\mathrm{Li})$, o modelo de Seltzer se manifestou mais robusto, já que compara bem com os resultados experimentais em toda a faixa de energia entre 6 e $100 \mathrm{keV}$, enquanto o modelo de $\mathrm{O}^{\prime}$ Meara-Campbell tem boa precisão na faixa de energias de 6 a $60 \mathrm{keV}$. 


\section{Capítulo 6}

\section{Pesquisas que usaram o estudo dos detetores}

As secções de choque de bremsstrahlung de elétrons e as de ionização de camadas atômicas por impacto de elétrons são medidas a partir da irradiação de alvos com o feixe de elétrons no Microtron [91], cuja energia é bem definida. As áreas de certas regiões desse espectro de raios-x, composto por um espectro contínuo de fótons de bremsstrahlung com energia máxima igual à energia cinética dos elétrons do feixe, sobre o qual se observam picos característicos de cada material, devem ser quantificadas [11, 12] a fim de extrair essas grandezas. Esse espectro deve ser tratado para recuperar o espectro de emissão original, considerando os efeitos que cada fóton produz no detetor, em um processo chamado deconvolução, que abordaremos na seção 6.1.4. A deconvolução pode ser feita de várias maneiras, mas requer a eficiência de detecção de pico e a função resposta do detetor em uso bem parametrizadas, como descrito no capítulo 4 , já que as incertezas desse processo influenciarão no resultado.

No presente capítulo, iremos ver aqueles resultados que, de uma ou outra maneira usaram as ações descritas nos capítulos 4 e 5 como base para melhorar os resultados. As seções deste capítulo estão divididas entre os seguintes itens:

a) Pesquisas que usaram os resultados dos trabalhos listados no capítulo 5 .

- secções de choque duplamente diferenciais do Bremsstrahlung de elétrons no Microtron.

- secções de choque de ionização de camadas internas e distribuição angular dos raios$\mathrm{x}$ L em alguns elementos.

b) Experimentos com fontes incomuns:

- Radioatividade natural (fonte extensa, baixa atividade). 


\subsection{Secções de choque de Bremsstrahlung de elétrons com energias entre 10 e $100 \mathrm{keV}$}

Valores calculados das secções de choque de produção de Bremsstrahlung duplamente diferenciais (em energia e ângulo) estão apresentadas em forma de tabelas separadas por elemento químico, energia do projétil e ângulo de emissão, calculadas segundo a teoria de ondas parciais. Nas tabelas clássicas de Seltzer e Berger [82] e Kissel et al. [48] há alguns elementos para os quais essas secções de choque foram calculadas, mas a maioria deles tem esses dados interpolados a partir dos valores calculados para sete elementos. Recentemente foi publicada uma nova tabela que referencia o trabalho de García-Álvarez [33], onde os valores foram calculados para elementos com $\mathrm{Z}$ entre 1 e 100 e elétrons entre $10 \mathrm{eV}$ e $3 \mathrm{MeV}$ [73].

É difícil avaliar a precisão desses cálculos, os autores mencionam $10 \%$, mas não especificam se isso vale para todos os elementos, energias e ângulos da tabela, em particular se os valores tabelados para os elementos de referência são mais precisos, comparados com os que tiveram seus valores interpolados. Assim, somente medidas experimentais precisas fornecerão uma avaliação dessa precisão.

O trabalho de doutorado de García-Alvarez [30, 34, 33] focou na medida de alguns dos elementos cujas secções de choque duplamente diferenciais do Bremsstrahlung para elétrons calculadas são referência, como Al, Ag e Au e elementos cujas secções de choque são interpoladas como C, Te e Ta.

\subsubsection{A irradiação e o arranjo experimental}

Os fótons do espectro de bremsstrahlung de elétrons foram observados por três detectores localizados em ângulos específicos, com relação à direção do feixe primário, dentro de ângulos sólidos pequenos, definidos pelos colimadores (veja seção 3.3). Um esquema do posicionamento dos detetores pode ser observado no esboço fora de escala da figura 6.1. onde aparece o detetor planar de $8 \mathrm{cc}$ a $35^{\circ}$, o planar de $5 \mathrm{cc}$ a $90^{\circ}$ e o coaxial ORTEC a $131^{\circ}$ com relação ao feixe de elétrons. Também se destacam o copo de Faraday, o anel de $\mathrm{C}$ que observa elétrons do feixe espalhados entre 12 a 21 graus e o alvo no centro da câmara, inclinado com relação ao feixe para evitar que a detecção dos fótons pelos detetores seja impedida por parte da moldura. Relatos e imagens do alinhamento dos detetores, assim como a eletrônica usada com cada um deles aparecem nos itens 3.7 $\mathrm{e} 3.2 .2$, respectivamente.

A medida simultânea da seção de choque diferencial nos três ângulos escolhidos, garante que a energia do elétron é a mesma nas três medições, mas, de todo modo, há uma série de cuidados essenciais para realizar uma medida precisa. Em particular, os alvos precisam ser muito finos a fim de evitar o espalhamento angular dos elétrons, que borraria a distribuição, de modo que o elemento de interesse estava depositado em um substrato de $\mathrm{C}$ que, apesar de produzir pouca radiação, precisava ser levado em conta. Para alcançar a precisão esperada nos resultados, elaborou-se a seguinte rotina de irradiação que procurava também minimizar o tempo total de medida para o conjunto dos elementos de interesse:

1. Os alvos eram montados na torre como mostrado na figura 3.7. Lá podem ser vistos os 


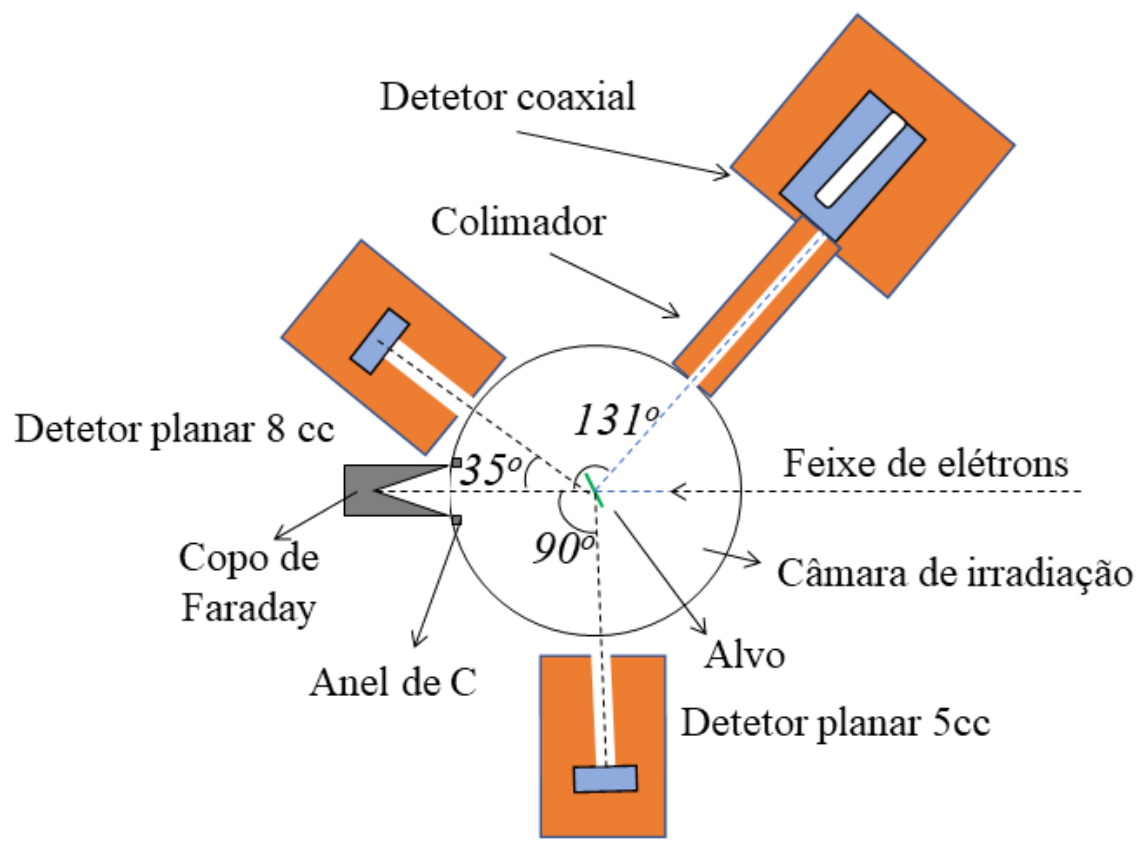

Figura 6.1: Esquema da câmara (fora de escala) e posicionamento dos detetores.

alvos desde o slot 1 a 3 e na posição 4 colocava-se uma moldura com o filme fino de $\mathrm{C}$ sem depósito de outro elemento. No 5 aparece uma moldura vazia com um furo interno com diâmetro de $8 \mathrm{~mm}$, igual ao diâmetro do depósito dos elementos a estudar, e na posição 6 uma moldura com um furo de diâmetro normal, $10 \mathrm{~mm}$.

2. Uma vez escolhida a energia de interesse e corrente no canhão de elétrons, o operador do Microtron ajustava o foco do feixe com o auxílio da luminosidade que devolvia (ver figura 3.8 o view screen. Esse ajuste consistia em deixar o spot o menor e mais circular possível, dentro das primeiras linhas transversais à cruz do centro.

3. Após acertado o foco, a torre era elevada e se centrava a moldura na posição 6 e media-se o quociente entre a soma das correntes integradas no anel mais a câmara e a corrente total. Depois, seguia-se o mesmo procedimento com o alvo na posição 5, comparavam-se os resultados e, quando os quocientes eram idênticos, iniciava-se a irradiação. Isto tinha como objetivo verificar se o feixe estava com um halo que fizesse com que uma certa porção dos elétrons incidisse sobre a moldura, produzindo bremsstrahlung indesejado.

4. Quando aquele quociente era considerado satisfatório iniciava-se uma irradiação com o feixe no centro do alvo de $\mathrm{C}$ (posição 4) para descontar o espectro devido ao Bremsstrahlung de elétrons no filme de $\mathrm{C}$ e outros fótons que pudessem ser produzido por de elétrons espalhados na câmara.

5. Seguia-se com a irradiação do alvo nas posições 3,2 e 1. Os tempos de irradiação variavam de acordo com a energia do feixe e da corrente que passava pelo canhão de elétrons, entre 20 a 90 minutos. 
6. Medido o espectro emitido pelos quatro alvos, voltava-se ao view screen para acertar o foco do feixe de outra energia e corrente de elétrons.

\subsubsection{Correções do espectro experimental}

As taxas de contagem dos espectros do alvo durante a irradiação atingiram 8000 eventos/s que, devido aos tempos de análise dos pulsos pelo multicanal, produziram empilhamento. Esse fenômeno foi corrigido usando o algoritmo do trabalho de Nascimento et al. [68].

Os espectros obtidos durante a irradiação incluíam eventos provenientes do bremsstrahlung no substrato do alvo e da radiação de fundo natural, que foram subtraídos canal por canal previamente ao processo de deconvolução.

O número de contagens do espectro da irradiação do substrato de $\mathrm{C}$ era aproximadamente uma ordem de grandeza menor que a do alvo para o mesmo tempo de contagem, e os espectros foram obtidos com tempos de medida três ou quatro vezes maiores que o da irradiação do alvo em estudo. A medida do fundo natural levou aproximadamente 15 dias com taxas de contagens de poucos fótons por segundo, e a necessidade de corrigir esse fenômeno decorre das diferenças entre os três detetores usados. Um dele tinha volume muito maior que os demais e apresentava, portanto, muito mais contagens devido à radiação natural. Assim, a radiação de fundo foi subtraída tanto do espectro do alvo quanto do substrato, antes de eliminar a contribuição do substrato na irradiação do alvo.

Como as taxas de contagem do alvo de interesse, do substrato de Carbono e da radiação de fundo são totalmente diferentes, levou-se em conta o tempo vivo de aquisição de cada um desses espectros na determinação dos fatores de normalização.

\subsubsection{Determinação da energia do feixe}

Os elétrons do feixe, pelas características da máquina, não são monocromáticos, mas têm uma distribuição aproximadamente Gaussiana, com intensidade máxima na energia $E_{e}$ (que também representa a energia média do feixe) e uma dispersão $\sigma_{e}$. Usando esse perfil de intensidade do feixe de elétrons, modelou-se a região do tip do espectro experimental como a convolução do espectro de bremsstrahlung obtido das tabelas com o perfil do feixe, que é uma função de três parâmetros: $E_{e}, \sigma_{e}$ e intensidade. Esses parâmetros foram ajustados pelo método dos mínimos quadrados, alcançando uma precisão na energia média dos elétrons em torno a $50 \mathrm{eV}[30]$.

\subsubsection{Deconvolução dos espectros}

A deconvolução dos espectros de bremsstrahlung exigiu cálculos e simulações da função resposta dos detetores usados. De posse do espectro de emissão mais provável para as variadas energias dos elétrons que atingiam o alvo e com os valores de corrente integrada durante o tempo de medida, foi possível determinar as secções de choque correspondentes.

O espectro emitido pelo material alvo da interação com os elétrons do feixe é observado como um conjunto de dados discreto, que será representado nas equações abaixo por um vetor 
coluna E. A fim de equacionar o espectro medido com o emitido, definimos um vetor coluna $\mathbf{B}$, em que cada elemento corresponde à seção de choque integrada nas energias correspondentes a cada canal do espectro E. De acordo ao processo de medida, podemos dizer que:

$$
\mathbf{E}=\mathbf{R} \mathbf{B}
$$

em que $\mathbf{R}$ é a matriz de resposta do detetor, e cada linha dessa matriz corresponde à integral da função resposta do capítulo 4 para um fóton com energia $\left(E_{x}\right)$ dentro de um canal.

Conhecida $\mathbf{R}$ e tendo medido $\mathbf{E}$, podemos isolar $\mathbf{B}$ como

$$
\mathbf{B}=\mathbf{R}^{-1} \mathbf{E}
$$

A precisão do resultado irá depender das precisões do espectro medido e da função resposta. Inicialmente, no trabalho de López-Pino [56], essa matriz foi construída com linhas correspondentes à resposta do detector para canais com $50 \mathrm{keV}$ de largura e energias entre $100 \mathrm{keV}$ e $2 \mathrm{MeV}$, o que resultava em uma matriz de 38 linhas por 38 colunas, cuja inversa, ao ser multiplicada pelo vetor $\mathbf{E}$, fornecia o espectro de emissão mais provável, com uma dispersão de $50 \mathrm{keV}$. Apesar dessa granularidade alta, o cálculo demandava um enorme trabalho de simulação. Por outro lado, foi constatado que o MCNP subestimava em $\approx 9 \%$ a parte contínua do espectro, razão pela qual nos resultados foi introduzida uma correção na cauda à esquerda dos picos de absorção total. Com o objetivo de obter uma melhor precisão na região do tip, no intervalo de 1700 a $1910 \mathrm{keV}$, foi realizado o mesmo processo, mas com passos de $5 \mathrm{keV}$. A escolha desse intervalo permitiu simplificar a função resposta ao evitar considerar a região da borda Compton, que para uma energia de $1910 \mathrm{keV}$ aparece em $1685 \mathrm{keV}$.

Já no trabalho de García-Álvarez [30], descrito em detalhe nesta seção, a diferença do trabalho anteriormente descrito, foi usada a função resposta analítica, e como estávamos trabalhando na faixa de energia de 10 a $100 \mathrm{keV}$ a largura de cada canal de energia pode ser muito menor. A dispersão em energia do espectro medido original foi alterada de maneira que se trabalhou com aquela resultante do agrupamento de 57 ou 40 canais (para os planares e o coaxial, respectivamente), de maneira que cada canal do espectro contraído ficou em $1 \mathrm{keV}$, ainda longe da resolução em energia, igual ou menor que $0,5 \mathrm{keV}$ para todos os detetores.

\subsubsection{Resultados}

Os resultados da secção de choque duplamente diferencial na região do tip para $\mathrm{C}, \mathrm{Al}, \mathrm{Te}, \mathrm{Ta}$ e Au foi publicada em 2017 no Journal of Physics B [34] e as medidas absolutas das secções de choque duplamente diferenciais do Bremsstrahlung de elétrons para esses mesmos elementos, comparadas com os resultados do modelo de ondas parciais no intervalo de energias entre 20 e $100 \mathrm{keV}$, nos três ângulos de medida, foi publicada no artigo de 2018 [33], alcançando uma precisão entre 3 e $5 \%$, sendo algumas destas inéditas. A incerteza reduzida decorreu das boas 
precisões na medida da espessura dos alvos, na determinação da função resposta dos detetores e na consideração ao respeito dos efeitos produzidos pelos colimadores, na subtração do fundo radioativo e na correção precisa do empilhamento de pulsos. Dado que a contribuição do espectro de bremsstrahlung produzido no substrato de $\mathrm{C}$ dos alvos foi considerada e subtraída do espectro da irradiação do alvo, foi realizada a deconvolução do espectro medido, chegar deduzindo o espectro de emissão com o qual calcularam-se as secções de choque buscadas. Em seguida aos artigos[34] e [33], foi publicada uma nova tabela de seções de choque de bremsstrahlung, em que o mesmo modelo usado na tabela anterior [82] foi aplicado a todos os elementos e para mais ângulos [73], sendo que o autor compara seus resultados com os dos nossos trabalhos.

\subsection{Secção de choque de ionização de camadas internas por impacto de elétrons}

Os avanços na instrumentação e o aperfeiçoamento das condições experimentais implementadas no Mícrotron e na confecção dos alvos permitiram uma medida precisa dessa grandeza. Como a determinação dessa seção de choque depende da quantificação da produção dos raios-X característicos, ela não requer a deconvolução do espectro, mas uma boa calibração da eficiência de pico. Assim, ao longo dos experimentos efetuados, foram realizadas mudanças no arranjo e na análise que permitiram avançar na precisão relativa dos resultados, de cerca de $10 \%$ a 4-5\%, como descrito a seguir.

Nossos primeiros trabalhos que relatam medidas de seções de choque de ionização de camadas atômicas internas por impacto de elétrons foram os realizados por Jahnke [45], e a publicação que relata essas medidas está na referência [27]. As medidas foram feitas na câmara originalmente fora usada no trabalho de López [56] nos experimentos com o feixe de 1,9 MeV, mas esta vez sem energizar as duas estruturas aceleradoras do Microtron (veja figura 3.1), de modo que os elétrons chegavam com a energia fornecida pelo canhão de elétrons, simplesmente. As lentes ao longo da linha de transporte do feixe (quadrupolos, dipolos, solenoides e steerings) podem ajustar o foco, posição e corrente do feixe se ele vier desde o canhão, sem ter sido acelerados nas estruturas.

Foi este trabalho que usou o detetor de camada morta irregular (planar $5 \mathrm{cc}$ ), descrito em detalhe na seção 3.2.4. A fim de corroborar o complicado modelo de eficiência adotado, usou-se a fonte de ${ }^{198} \mathrm{Au}$, descrita na seção 3.5.2, que permitiu medir a eficiência de pico exatamente para os raios-x de interesse dessa reação. Desse experimento, deduziu-se a seção de choque de ionização relativa à de bremsstrahlung, porque não se conseguiram medidas de espessura por RBS confiáveis, tanto porque os alvos raramente suportavam todo o manuseio envolvido nas duas irradiações (no tandem do LAMFI e no Microtron) como por falhas na rotina de medida de RBS.

Esse experimento mostrou a necessidade de construir um linha de $100 \mathrm{keV}$ próxima ao canhão, que garantiu feixes melhor focalizados e foi usada em todos os demais experimentos. O copo de Faraday foi construído de modo a reduzir o retroespalhamento do feixe que ele coleta e minimizar o fundo de fótons na região do alvo, e a câmara de irradiação foi construída 
com maior diâmetro, pelas mesmas razões. Além disso, a câmara foi isolada eletricamente, de modo a permitir a medida da carga do feixe coletando também toda a carga espalhada no alvo e pelo copo de Faraday. A torre de Al foi substituída por uma feita em fibra de carbono, como à da figura 3.7, com capacidade para 6 alvos mais o view screen. Ao longo das medidas de seção de choque de ionização por impacto de elétrons subsequentes: camadas $\mathrm{L}$ do $\mathrm{Au}$, primeiro na faixa 50-100 keV em relação ao bremsstrahlung [10] e depois desde o limiar de ativação até os $100 \mathrm{keV}$, usando a espessura do alvo medida por RBS [11]; camadas K de Te, Ta, Bi desde o limiar de ativação até os $100 \mathrm{keV}$ [91, 79], os alvos e as fontes de calibração foram sendo melhorados gradativamente, até serem construídos como descrito nas secções 3.6 e 3.5.3. Também resolveram-se os problemas na medida de espessura por RBS. Com todos esses recursos e completado o desenvolvimento da função analítica usada na calibração dos detetores de raios-x, mediu-se o alinhamento atômico do Ta, W e Au na ionização da subcamada $\mathrm{L}_{3}$ [12].

\subsection{Determinação absoluta do Potássio na infusão de Chá por espectroscopia gama}

Este trabalho começou como tema de iniciação científica. Pretendíamos determinar a quantidade de potássio em diferentes alimentos e comparar seus conteúdos com os fornecidos pelas tabelas internacionais. A ideia de verificar a quantidade de potássio em amostras de chá solúvel foi o primeiro objetivo. Partimos para comparar a quantidade de potássio ingerida por xícara de chá preto, quando preparado desde o chá em folhas secas. O procedimento experimental está explicado na publicação de 2009 [62]. Usamos o isótopo radioativo natural do potássio, o ${ }^{40} \mathrm{~K}$, sabendo que ele representa $0,0117 \%$ do potássio natural [16], para determinar a quantidade de Potássio lixiviada na preparação da infusão de chá. As amostras foram colocadas em caixas cilíndricas de polietileno, com dimensões de 28,3 mm de altura, 70,3 $\mathrm{mm}$ de diâmetro e $1,8 \mathrm{~mm}$ de espessura de parede. $\mathrm{O} \mathrm{KCl}$ usado como padrão, amostras de duas variedades de Chá preto e de pó instantâneo para preparar chá, foram colocados em caixas separadas de mesmo tamanho. A figura 6.2 mostra as caixas com dois desses elementos.

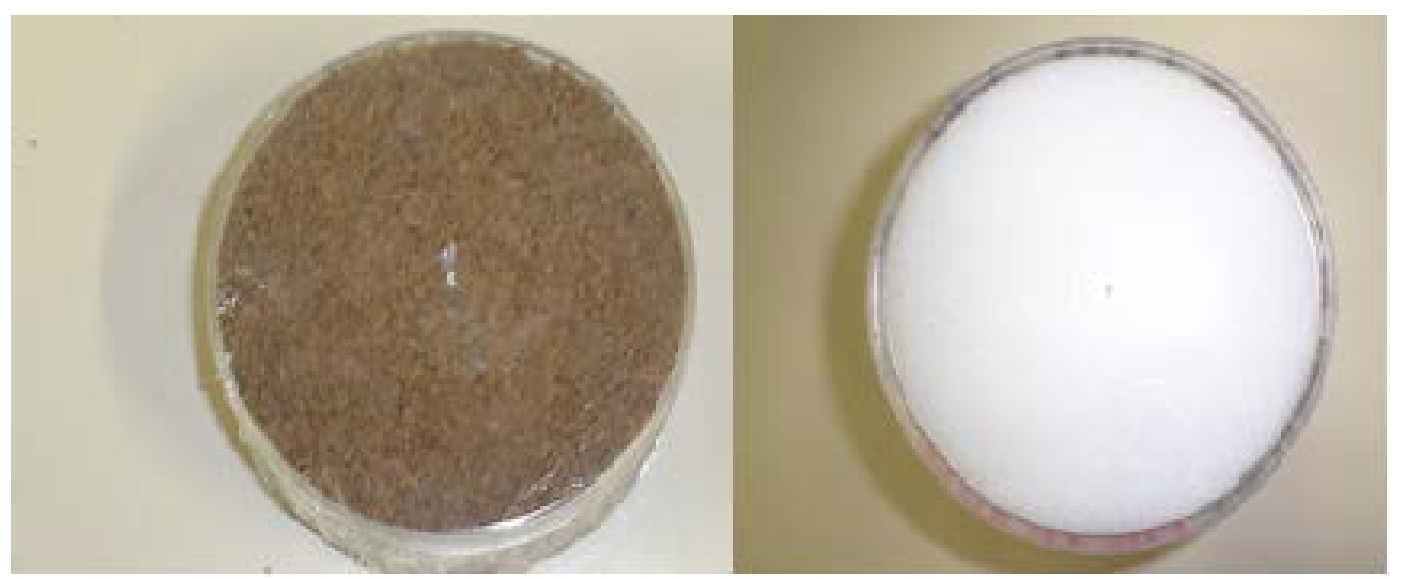

Figura 6.2: A imagem da esquerda mostra o cha em um recipiente cilíndrico de polietileno, a imagem da direita o $\mathrm{KCl}$ em um recipiente idêntico ao anterior. 
A metodologia consistiu em obter os espectros do fundo natural, da caixa contendo $\mathrm{KCl}$, de duas amostras, de diferentes procedências, de chá em folhas secas e a do chá em pó. Todas as amostras foram pesadas. Procedeu-se a fazer a infusão com as folhas e, após os 5 minutos de espera, coaram-se as folhas de chá com um papel de filtro de café. As folhas de chá foram pesadas tanto antes de preparar a infusão quanto após secas, assim como o filtro de papel usado para coar a infusão. Mediram-se os espectros gama de todas essas amostras e iniciou-se o processo de análise.

Vale destacar que, antes de optar por esse procedimento experimental, buscamos liofilizar a infusão e medir o espectro do pó, mas não conseguimos um laboratório que fizesse a extração da água de modo que o potássio não evaporasse com ela. Foi assim que optamos por uma metodologia usando espectroscopia gama e a subtração da área do pico de absorção total de interesse para tempos iguais de contagem.

O pico a analisar foi o da transição gama de $1461 \mathrm{keV}$ que segue o decaimento do ${ }^{40} \mathrm{~K}$ (meia vida $1,277(8) \times 10^{9}$ anos) com uma intensidade de $10,67(13) \%$ por decaimento. A quantidade de potássio na amostra de $\mathrm{KCl}$, usada para verificar a eficiência de pico, foi determinada por estequiometria sabendo que as massas molares do K e de $\mathrm{KCl}$ são 39,0983(1) g e 74,551(2) g, respectivamente.

Todas as amostras medidas conformavam fontes extensas, com auto-atenuação de fótons significativa. O procedimento padrão consiste em misturar uma solução radioativa na amostra e calibrar a eficiência com essa amostra radioativa. Uma vez terminado o trabalho, essa fonte deve ser descartada, o que tem custo elevado e representa um risco ambiental de prazo longo (séculos), uma vez que as fontes radioativas padronizadas têm meias-vidas longas. A fim de evitar esse procedimento, a eficiência de pico para fótons do ${ }^{40} \mathrm{~K}$ na amostra de interesse foi determinada por simulação com o código MCNP5, o que é fácil e relativamente rápido. A validação desse resultado exige comprovação experimental, o que foi realizado em duas etapas.

Primeiro, a fim de validar a correção de atenuação dos fótons de $1461 \mathrm{keV}$ do decaimento do ${ }^{40} \mathrm{~K}$ pelas folhas de chá, comparou-se o resultado da medida da eficiência de pico dos gamas de $1408 \mathrm{keV}$ de uma fonte de ${ }^{152} \mathrm{Eu}$ colocada sobre a amostra de chá. Com a geometria desse arranjo, simulamos o processo usando o Tally F:8 (altura de pulso do depósito de energia) no elemento ativo do detetor com toda a estrutura interna fornecida pelo fabricante, isto é o raio do furo interno, as camadas mortas externa e interna. A simulação com esses parâmetros não reproduzia o dado experimental, de modo que alguns desses parâmetros foram ajustados até que a eficiência de detecção simulada do gama de $1408 \mathrm{keV}$ do ${ }^{152} \mathrm{Eu}$ coincidisse com a determinada experimentalmente.

A determinação por simulação da eficiência de pico dos fótons de $1461 \mathrm{keV}$ do decaimento do ${ }^{40} \mathrm{~K}$ em uma amostra extensa como a usada também precisa validação. Para isso, determinouse experimentalmente a eficiência de pico usando a amostra de $\mathrm{KCl}$ e esse experimento também foi simulado. O resultado foi semelhante ao descrito no parágrafo anterior - a simulação com os dados do fabricante não reproduz o experimento, mas é possível ajustar alguns desses parâmetros de modo a obter-se o valor experimental.

Finalmente, buscou-se um conjunto de parâmetros que reproduzisse ambos os dados experimentais - transmissão de fótons de $1408 \mathrm{keV}$ pela amostra de chá e eficiência de pico do ${ }^{40} \mathrm{~K}$ de 
uma amostra de $\mathrm{KCl}$-, usado para determinar a eficiência de pico na amostra de folhas de chá. Na figura 6.3 podemos observar o pico de $1461 \mathrm{keV}$ do ${ }^{40} \mathrm{~K}$ para o chá antes e após preparada a infusão, do filtro de papel e do fundo natural.

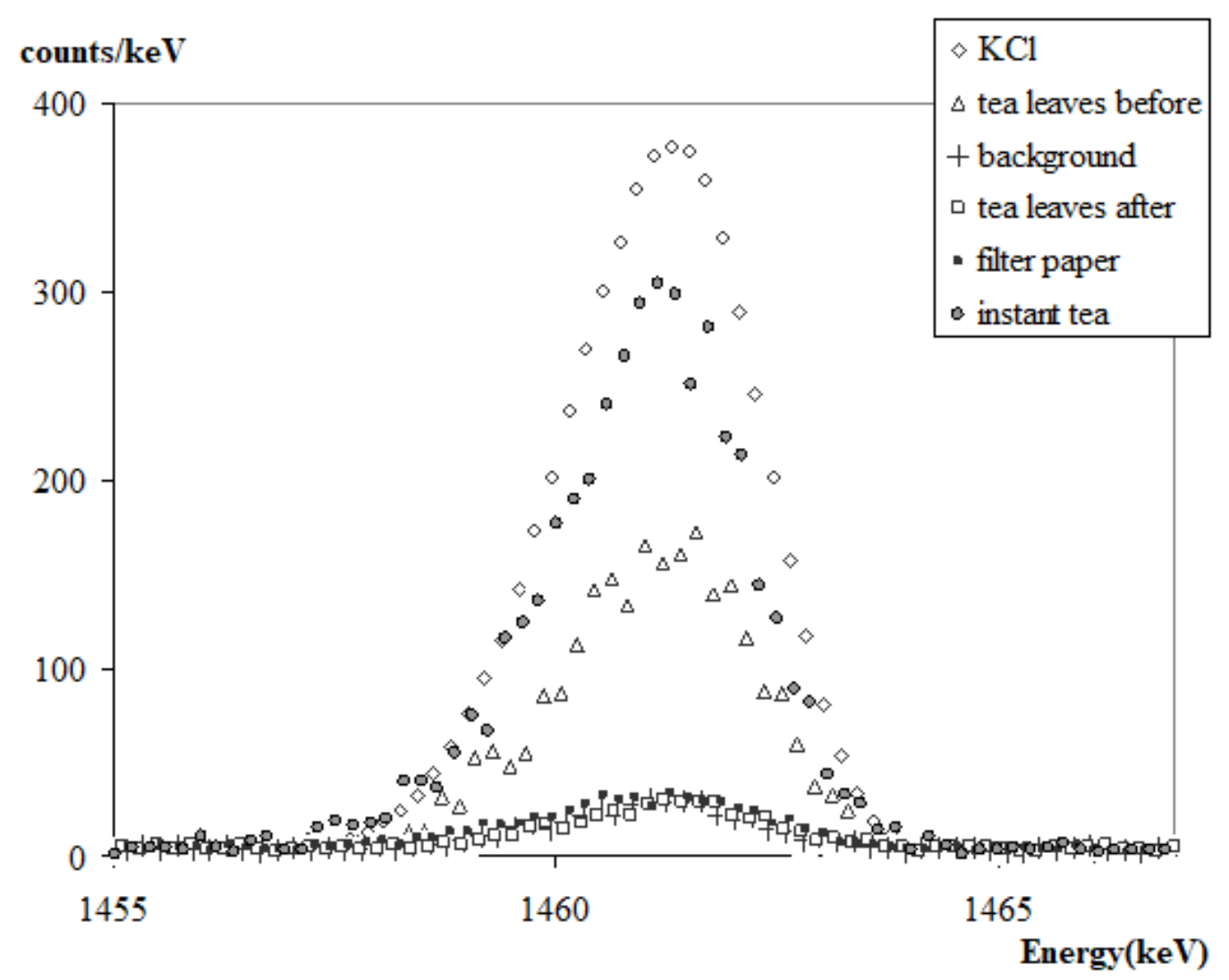

Figura 6.3: Espectro dos fótons de $1461 \mathrm{keV}$ que seguem o decaimento do ${ }^{40} \mathrm{~K}$ nas folhas de chá antes e após preparada a infusão, no filtro de papel e no fundo natural [62].

Com as áreas dos diferentes espectros, da amostra de $\mathrm{KCl}$, das amostras de chá e da eficiência de detecção, e sabendo a quantidade de Potássio do padrão de $\mathrm{KCl}$ e as massas das amostras de chá, foi determinada a quantidade de potássio contida em cada amostra.

Finalmente, os resultados obtidos da quantidade de Potássio ingerido por xícara de chá coincide, dentro das incertezas experimentais, com os valores das tabelas internacionais.

A constatação de que o fabricante fornece características que não permitem a explicação dos dados experimentais por simulação do detetor motivou a procura tanto por determinar essas características físicas (por meio do mapeamento, dos raios-x e da gamagrafia) quanto compreender melhor os mecanismos de transporte da radiação usados nas simulações, além de apontar a importância da validação experimental dos cálculos de simulação de detetores antes da adoção dos resultados na análise de dados. 


\section{Capítulo 7}

\section{Conclusão}

Os diversos detetores de fótons dispersivos em energia descritos neste trabalho tiveram sua eficiência e resposta determinadas com precisão, a partir de modelos teóricos analíticos e de simulação de Monte-Carlo, apoiados e validados por uma variedade de experimentos. No curso dessa investigação, foi possível observar, explicar e quantificar um efeito secundário de deteção que ainda não estava descrito na literatura especializada: a formação dos picos de Terceiro e Quarto Escapes de fótons de aniquilação de pares elétron-pósitron em detetores de HPGe para fótons com energia acima de $4 m_{e} c^{2} \approx 2 \mathrm{MeV}$.

Esses detetores também foram usados em medidas inéditas de secções de choque duplamente diferenciais do Bremsstrahlung de elétrons, de ionização de camadas atômicas internas por impacto de elétrons, e do alinhamento atômico de alguns elementos após a ionização da camada $\mathrm{L}_{3}$ por impacto de elétrons entre 10 e $100 \mathrm{keV}$.

O mapeamento da eficiência dos detetores de HPGe foi um passo importante no conhecimento desses instrumentos. Constatou-se que a simulação não consegue fornecer resultados em acordo com o perfil experimental obtido no mapeamento frontal, embora no conjunto o acordo seja satisfatório. Verificou-se que o uso de um colimador permite limitar a incidência dos fótons à região em que o acordo entre a simulação e os resultados experimentais é melhor, permitindo que a simulação forneça uma aproximação melhor da resposta. Um detetor que, por causa da idade, tinha uma camada morta frontal irregular continuou a ser usado com excelente estabilidade e confiança pela adoção de um colimador que só permite a detecção dos fótons de interesse na área onde a camada morta frontal continuava a ser delgada. Os resultados do mapeamento lateral efetuado sugerem que esse procedimento, com fótons de energias maiores, permitirá observar as características e estruturas ocultas pela cápsula ou pelo volume ativo. Ficou demonstrado que a eficiência e resposta de detetores de HPGe varia com o tempo, mas é necessário aprofundar o estudo a fim de reduzir o esforço necessário para lidar com esse fenômeno.

Na descrição dos modelos dos experimentos detalhados no capítulo 4 , destaca-se a necessidade de realizar simulações Monte Carlo e desenvolver funções analíticas que reproduzem adequadamente a resposta e eficiência de detecção, junto com experimentos que validem os resultados obtidos. Na busca do Terceiro Escape, a simulação com o MCNP apontou corretamente a existência de um efeito ainda desconhecido, mas errou a estimativa da sua intensidade 
por ordem de grandeza. Na simulação da detecção de fótons por detetores semicondutores, ficou claro que os parâmetros que ajustam a eficiência de pico são diferentes daqueles que ajustam a eficiência total, de modo que não existe um conjunto de parâmetros que permita simular corretamente toda a função resposta, o que constitui um problema ainda em aberto.

A simulação mostrou-se indispensável na quantificação do K no chá, ao avaliar a autoatenuação dos fótons em uma amostra de grande volume, dispensando a inconveniente construção de uma fonte radioativa específica para o experimento, que precisaria ser descartada após o uso.

Em todos esses casos, foi fundamental validar experimentalmente os resultados da simulação do transporte de fótons e elétrons na matéria; os resultados só se mostraram adequados após modificações na parametrização original, guiadas pelos resultados experimentais. A inexistência de fontes radioativas padronizadas para fótons a energias abaixo de $5 \mathrm{keV}$ sugere investir na confecção de fontes de calibração não convencionais, de modo a suprir essa deficiência e permitir testar a resposta dos detetores nessa faixa de energia.

Uma série de fatores influenciaram para que os resultados das medidas de secções de choque tivessem incertezas menores que $10 \%$ :

- A técnica de construção dos alvos para irradiação foi mudando, passando do uso de molduras de aço a $\mathrm{C}$, com filmes autoportantes depositados sobre filmes finos de $\mathrm{C}$ através de uma máscara.

- A medida da espessura dos alvos por RBS.

- A caracterização dos detetores e as técnicas tanto analíticas quanto de simulação da resposta dos detetores, que permitiram a deconvolução do espectro medido do Bremsstrahlung de elétrons.

- A confecção de fontes radioativas calibradas não convencionais.

- A melhora nos arranjos pela adoção de blindagens e colimadores.

Todos esses trabalhos permitiram concluir com sucesso diversas pesquisas acerca das interações dos fótons e elétrons com a matéria. 


\section{Bibliografia}

[1] S. Agostinelli et al. "Geant a simulation toolkit". Em: Nuclear Instruments and Methods in Physics Research Section A: Accelerators, Spectrometers, Detectors and Associated Equipment 506.3 (2003), pp. 250-303. ISSN: 0168-9002. DOI: https : / / doi .org/ 10. 1016/S0168-9002(03) 01368-8. URL: https : / / wWw . sciencedirect . com / science/article/pii/S0168900203013688.

[2] S. Agostinelli et al. "Geant4-a simulation toolkit". Em: Nuclear Instruments and Methods A 506.3 (2003), pp. 250-303. DOI: doi .org/10.1016/S0168-9002(03)01368-8.

[3] E. Aguayo et al. "Characteristics of signals originating near the lithium-diffused N+ contact of high purity germanium p-type point contact detectors". Em: Nuclear Instruments and Methods in Physics Research Section A: Accelerators, Spectrometers, Detectors and Associated Equipment 701 (2013), pp. 176-185. ISSN: 0168-9002. DOI: https://doi. org/10.1016/j .nima.2012.11.004. URL: https : //wwW . sciencedirect . com/ science/article/pii/S0168900212012752.

[4] J.A. Alcantara-Nuñez et al. "SACI - a $4 \pi$ plastic phoswich array ancillary detector system of a $\gamma$-ray spectrometer". Em: Nucl. Instrum. Methods A 497.2 (2003), pp. 429-439. DOI: $10.1016 / \mathrm{S} 0168-9002(02) 01926-5$.

[5] E. Andreotti et al. "Determination of dead-layer variation in HPGe detectors". Em: Appl. Rad. Isot. 87 (2014), pp. 331-335.

[6] R.G. Arns, S.E. Caldwell e W.G. Monahan. "Geometrical attenuation factors for directional correlation experiments". Em: Nucl. Instrum. Meth. B 78 (1970), pp. 295-299.

[7] J. Baró et al. "PENELOPE: An algorithm for Monte Carlo simulation on the penetration and energy loss of electrons and positrons in mater". Em: Nucl. Instrum. Meth B 100 (1995), pp. 31-46.

[8] S.F Barros et al. "Full-energy peak efficiency of Si drift and $\mathrm{Si}(\mathrm{Li})$ detectors for photons with energies above the Si K binding energy". Em: X-Ray Spectrometry (2016). DOI: 10.1002 /xrs. 2724 .

[9] S.F Barros et al. "Ionization cross sections of the L subshells of Au by 50 to $100 \mathrm{keV}$ electron impact”. Em: J. Phys. B: At. Mol. Opt. Phys.s 48 (2015), p. 175201. DOI: 10 . 1088/1361-6455/aa98d3. 
[10] S.F. Barros. Ionização atômica da camada L de Au e Ta por impacto de elétrons com o acelerador Microtron de São Paulo. 2014. DOI: 10 .11606/ D . 43 . 2014 . tde 29092014-090341. URL: https://teses.usp.br/teses/disponiveis/43/43134/ tde-29092014-090341/publico/texto_dissertacao_BarrosSuelen.pdf

[11] S.F. Barros. "Medida do alinhamento atômico de Ta, W e Au por impacto de elétrons pela distribuição angular dos raios x L". Tese de dout. 2018. DOI: 10 . 11606 / T . 43 . 2018.tde-14062018-103044. URL: https://teses.usp.br/teses/disponiveis/ 43/43134/tde-14062018-103044/publico/teseComCapa.pdf.

[12] S.F. Barros et al. "Atomic alignment of ${ }^{73} \mathrm{Ta},{ }^{74} \mathrm{~W}$, and ${ }^{79} \mathrm{Au}$ after $L_{3}$ subshell ionization by 10-100-keV electron impact". Em: Phys. Rev. A 100 (2019), p. 062705. DOI: 10 . 1103 / PhysRevA . 100 .062705. URL: https : / / link . aps . org/doi / 10 . 1103/ PhysRevA.100.062705.

[13] S.F. Barros et al. "Energy-dependent dead-time correction in digital pulse processors applied to silicon drift detector's x-ray spectra". Em: Jr. Synchrotron Radiation 25 (2 2018), pp. 484-495. URL: https ://doi .org/10.1107/S1600577517018318.

[14] S.F. Barros et al. "Ionization cross sections of the Au L subshells by electron impact from the L3 threshold to $100 \mathrm{keV".} \mathrm{Em:} \mathrm{Jr.} \mathrm{Phys} \mathrm{B} \mathrm{-} \mathrm{Atomic} \mathrm{Molecular} \mathrm{And} \mathrm{Optical} \mathrm{Physics}$ 51 (2018), pp. 1-10. URL: https://doi.org/10.1088/1361-6455/aa98d3.

[15] M.M. Bé et al. "Table of Radionuclides - (Vol. 8 - A = 412 to 198)". Em: (). Ed. por Bureau International des Poids et Mesures. URL: https://www. bipm. org/documents/ 20126/53814638/Monographie+BIPM-5+-+Volume+8+\%5C\%282016\%5C\%29 . pdf / eba9482a-d7df-942c-a757-93948e957603.

[16] J.K. Böhlke et al. "Isotopic Compositions of the Elements, 2001". Em: J. Phys. Chem. Ref. Data 34.1 (2005), pp. 57-67. URL: https://aip.scitation.org/doi/10.1063/ 1.1836764 .

[17] J. Boson, G. Agrenand e L. Johansson. "A detailed investigation of HPGe detector response for improved Monte Carlo efficiency calculations". Em: Nuclear Instruments and Methods in Physics Research Section A 587.2-3 (2008), pp. 304-314. DOI: 10.1016/ j. nima.2008.01.062.

[18] B.H. Bransden e C.J. Joachain. Physics of atoms and molecules. Ed. por Pearson Educational Limited. Edimburg Gate, 2003. ISBN: 0-582-35692-X.

[19] R. Brendt e P. Mortreau. "Monte Carlo modelling of a N-Type coaxial high purity germanium detector". Em: Nuclear Instruments and Methods in Physics Research A 694 (2012), pp. 341-347.

[20] L. Brualla, N.L. Maidana e V.R. Vanin. "Determination of the detection efficiency of a planar HPGe detector with a non-uniform frontal dead layer”. Em: X-Ray Spectrometry wileyonlinelibrary.com (2014). DOI: $10.1002 /$ xrs. 2580 .

[21] E. Clementi e D.L. Raimondi. "Atomic Screening Constants from SCF Functions". Em: Journal of Chemical Physics 38 (1963), pp. 2686-2689. DOI: 10.1063/1.1733573. 
[22] E. Clementi, D.L. Raimondi e W.P. Reinhardt. "Atomic Screening Constants from SCF Functions. II. Atoms with 37 to 86 Electrons". Em: Journal of Chemical Physics 47 (1967), pp. 1300-1307. DOI: 10.1063/1.1712084.

[23] K. Debertin e U. Schotzig. "Coincidence Summing Correction in Ge(Li)-Spectrometry at Low Source-to-Detector Distances”. Em: Nucl. Instr. and Meth. 158 (1979). DOI: 10. 1016/S0029-554X (79) 94845-6.

[24] D. Dieumegard, B. Maurel e G. Amsel. "Microanalysis of Fluorine by nuclear reactions: I. ${ }^{19} \mathrm{~F}(\mathrm{p}, \alpha \gamma){ }^{16} \mathrm{O}$ reactions". Em: Nucl. Instr. and Meth. 168.1-3 (1980), pp. 93-103. DOI: 10.1016/0029-554X(80)91237-9.

[25] J. Eberth e J. Simpson. "From Ge(Li) detectors to gamma ray tracking arrays-50 years of gamma spectroscopy with germanium detectors". Em: Prog. Part. Nucl. Phys. 60.2 (2008), pp. 283-337. DOI: $10.1016 / \mathrm{j} \cdot \mathrm{ppnp} .2007 .09 .001$.

[26] P. Felice et al. "Fast Procedures for Coincidence-Summing Corrections for Ray Spectrometry”. Em: Appl. Radiat. Isot. 52.3 (2000), pp. 745-752. DOI: 10 . 1016/S09698043(99) 00239-0.

[27] J.M. Fernández-Varea et al. "Cross sections of K-shell ionization by electron impact, measured from threshold to $100 \mathrm{keV}$, for Au and Bi”. Em: J. Phys. B: At. Mol. Opt. Phys. 47 (2014), p. 155201. DOI: 10.1088/0953-4075/47/15/155201.

[28] A. Fessler et al. "Thick target photon yields and angular distributions for the ${ }^{19} \mathrm{~F}(\mathrm{p}$, $\alpha \gamma){ }^{16} \mathrm{O}$ source reaction at incident proton energies between 1.5 and $4.0 \mathrm{MeV}$ ". Em: Nucl. Instr. Meth. B 450 (2000), pp. 353-359. DOI: 10.1016/S0168-9002(00)00303-X.

[29] R.B. Firestone. Table of Isotopes. 8th. Budapest, Hungary: Wiley, 1996. ISBN: 963-7775$55-2$.

[30] J.A. García-Alvarez. "Secções de choque de bremsstrahlung de elétrons, estudo experimental no Acelerador Microtron de São Paulo". Tese de dout. 2016. DOI: 10.11606/ T . 43 . 2016 . tde-30112016-095354. URL: https : / / teses . usp . br / teses / disponiveis/43/43134/tde-30112016-095354/publico/TeseJAGarciaAlvarez. pdf.

[31] J.A. García-Alvarez, N.L. Maidana e V.R. Vanin. "Analytical response function for a HPGe detector used in bremsstrahlung electrons cross section measurements". XIX Escola de Verão Jorge André Swieca de Física Nuclear Experimental, 11 a 23 de janeiro de 2016. 2016. URL: http://www.sbfisica.org.br/〜evjasfne/xix/.

[32] J.A. García-Alvarez et al. "Analytical response function for planar Ge detectors". Em: Radiat. Phys. Chem 121 (2016), pp. 23-34. DoI: doi.org/10.1016/j.radphyschem. 2015.11.032.

[33] J.A. García-Alvarez et al. "Electron-atom bremsstrahlung cross sections in the 20-100 $\mathrm{keV}$ energy region: absolute measurements for $6 \leq \mathrm{Z} \leq 79$ and comparison with theoretical databases". Em: J. Phys. B:At. Mol. Opt. Phys. 51 (2018), 225003(21pp). DoI: doi.org/10.1088/1361-6455/aae6e 
[34] J.A. García-Alvarez et al. "Measurement of doubly differential electron bremsstrahlung cross sections at the end point (tip) for C, Al, Te, Ta and Au". Em: J. Phys. B:At. Mol. Opt. Phys. 50 (2017), 155003(14pp). DOI: doi.org/10.1088/1361-6455/aa7ac4

[35] E.R. van der Graaf, P. Dendooven e S. Brandenburg. Em: Review of Scientific Instruments 85 (2014), p. 065110.

[36] C. Grupen e I. Buvat (eds). Handbook of particle Detection and Imaging. SpringerVerlag, Berlin Heidelberg, 2012. DOI: 10.1007/987-3-642-13271-1.

[37] C.O. Guimarães. "Eficiência de detetores HPGe para fótons de 4 a 10 MeV". Em: (2005). URL: https : / / teses . usp . br/teses/disponiveis/43/43134/tde - 28072005$114921 / \mathrm{pt}-\mathrm{br} . \mathrm{php}$.

[38] J. Hardy et al. "Precise efficiency calibration of an HPGe detector: source measurements and Monte Carlo calculations with sub percent precision". Em: Appl. Radiat. Isot. 56.1-2 (2002), pp. 65-69. DOI: 10.1016/S0969-8043(01)00168-3.

[39] E. Haug e W. Nakel. The Elementary Process of Bremsstrahlung. World Scientific Lectures Notes in Physics: Volume 73. Suite 202, 1060 Main Street, River Edge, NJ 07661: World Scientific Publishing Co. Pte. Ltd, 2004. ISBN: 981-238-578-9.

[40] R. Helmer et al. "Precise efficiency calibration of an hpge detector up to $3.5 \mathrm{Mev}$, with measurements and Monte Carlo calculations”. Em: Appl. Radiat. Isot. 60.2-4 (2004), pp. 173-177. DOI: $10.1016 / \mathrm{j}$. apradiso.2003.11.012.

[41] R.G. Helmer et al. "The use of monte carlo calculations in the determination of a ge detector efficiency curve". Em: Nucl. Instr. and Meth. A 511.3 (2003), pp. 360-381. DOI: 10.1016/S0168-9002(03)01942-9

[42] N.Q. Huy. "The influence of dead layer thickness increase on efficiency decrease for a coaxial HPGe p-type detector". Em: Nucl. Instr. and Meth. A 621.1-3 (2010), pp. 390394. DOI: $10.1016 /$ j.nima.2010.05.007.

[43] N.Q. Huy, D.Q. Binh e V.X. An. "Study on the increase of inactive germanium layer in a high-purity germanium detector after a long-time operation applying MCNP code". Em: Nucl. Instr. and Meth. A 573.3 (2007), pp. 384-388. DOI: 10.1016/j .nima.2006. 12. 048.

[44] International Atomic Energy Agency - IAEA-ONU. X-Ray and Gamma-ray standards for detector calibration. IAEA-TECDOC-619. IAEA, 1991.

[45] Viktor Jahnke. Medidas das secções de choque de ionização da camada $K$ de Au e Bi por impacto de elétrons. 2012. DOI: $10.11606 / \mathrm{D}$.43.2012 .tde-08032013-123636. URL: https : //teses . usp . br/teses/disponiveis/43/43134/tde-08032013$123636 / \mathrm{pt}-\mathrm{br} \cdot \mathrm{php}$.

[46] R.A. Jarjis. "On the determination of fluorine concentration profiles in magnesium alloy scales using the ${ }^{19} \mathrm{~F}(\mathrm{p}, \alpha \gamma){ }^{16} \mathrm{O}$ reaction". Em: Nucl. Instr. Meth. 154 (1978), pp. 383-387. DOI: $10.1016 / 0029-554 \mathrm{X}(78) 90426-3$ 
[47] M. Jurado-Vargas e A.L. Guerra. "Application of PENELOPE code to the efficiency calibration of coaxial germanium detectors". Em: Appl. Radiat. Isot. 64 (2006), pp. 1011. DOI: $10.1016 / \mathrm{j}$. apradiso.2006.02.037.

[48] L. Kissel, C. A. Quarles e R. H. Pratt. "Shape functions for atomic field bremsstrahlung from electrons of kinetic energy $1-500 \mathrm{keV}$ on selected neutral atoms $2 \leq \mathrm{Z} \leq 92$ ". Em: Atomic Data and Nuclear Data Tables 28 (1983), pp. 381-460.

[49] G.F. Knoll. Radiation Detection and Measurement. 3rd. New York: John Wiley \& Sons, Inc., 2009.

[50] F.G. Kondev e et al. 2021. URL: https://people.physics.anu.edu .au/ ecs103/ chart/.

[51] J. Kramp et al. "Nuclear two-photon decay in 0+ $\rightarrow 0+$ transitions". Em: Nuclear Physics A 474.2 (1987), pp. 412-450. DOI: doi .org/10.1016/0375-9474(87) 90625-7.

[52] M.O. Krause e J.M. Oliver. "Natural widths of atomic K and L levels, K $\alpha$ X-ray lines and several KLL Auger lines”. Em: J. Chem. Reference Data 8 (1979), pp. 329-338.

[53] N. Krishnan et al. "Assessment of the inactive dead layer thickness of old high-purity germanium detector: A study by Monte Carlo simulations and experimental verification". Em: Radiation Protection and Environment 40.2 (2017), pp. 69-72.

[54] W.R. Leo. Techniques for Nuclear and particle Physics Experiments. Springer-Verlag Berlin Heildelberg, 1987. ISBN: 3-540-17386-2.

[55] M. Lépy et al. "Intercomparison of efficiency transfer software for gamma-ray spectrometry”. Em: Appl. Radiat. Isot. 55.4 (2001), pp. 493-503. DOI: 10 . 1016/S09698043(01)00101-4

[56] N. López-Pino. "Bremsstrahlung de elétrons no microtron do IFUSP: medidas, simulação e proposta de aplicação ao estudo da ressonância fluorescente nuclear". último acesso 20 Jan 2021. Tese de dout. 2011. DOI: 10 .11606/T . 43 .2011 . tde-30092011-152216. URL: https : / / teses . usp . br/teses/disponiveis/43/43134/tde-30092011152216/publico/neivy.pdf

[57] T.R. Mackie et al. "Generation of photon energy deposition kernels using the EGS Monte Carlo code". Em: Phys. Med. Biol. 33.1 (1988), pp. 1-20. URL: https://doi .org/10. 1088/0031-9155/33/1/001.

[58] N.L. Maidana. "medida de secções de choque para reações de captura de nêutrons no ${ }^{57} \mathrm{Co},{ }^{137} \mathrm{Cs}$ e ${ }^{241} \mathrm{Am}$ considerando a formação de estados isoméricos". último acesso 29 Jan 2021. Tese de dout. 2000. URL: http : / / pelicano . ipen . br / PosG30 / TextoCompleto/Nora\%5C\%20Lia\%5C\%20Maidana_D.pdf.

[59] N.L. Maidana et al. "Absolute determination of soluble potassium in tea infusion by gamma-ray spectroscopy". Em: Food Chemistry 116 (2009), pp. 555-560. DOI: 10 . $1016 /$ j.foodchem.2009.03.005 
[60] N.L. Maidana et al. "Efficiency calibration of x-ray HPGe detectors for photons with energies above the Ge K binding energy". Em: Nucl. Instr. and Meth. A 729 (2013), pp. 371-380. DOI: $10.1016 /$ j.nima.2013.07.033

[61] N.L. Maidana et al. "Experimental HPGe coaxial detector response and efficiency compared to Monte Carlo simulations". Em: Appl. Rad. Isot. 108 (2016), pp. 64-74. DOI: $10.1016 / \mathrm{j}$.apradiso.2015.12.001.

[62] N.L. Maidana et al. "Observation of double electron-positron pair production by $\gamma$ rays reexamined”. Em: Phys. Rev. C 79 (2009), p. 048501. DOI: 10.1103/PhysRevC . 79. 048501 .

[63] N.L. Maidana et al. "Search for the triple-escape peak in HPGe detectors". Em: vol. 580. 1. 2007, pp. 106-109. URL:http://dx.doi.org/10.1016/j.nima.2007.05.020.

[64] N.L. Maidana et al. "Triple- and quadruple-escape peaks in HPGe detectors: Experimental observation and Monte Carlo simulation”. Em: Nucl. Instr. and Meth. A 615.3 (2010), pp. 285-294. DOI: $10.1016 /$ j.nima.2010.01.073

[65] M.N. Martins, N.L. Maidana e V.R. Vanin. "The São Paulo Microtron: Equipment and Planned Experiments". Em: AIP Conference Proceedings 947.1 (2007), pp. 413-421. DOI: 10 . 1063/1.2813843, eprint: https : / / aip . scitation . org/doi/pdf / 10 . 1063/1 . 2813843, URL: https : / / aip . scitation . org/doi/abs/10 . 1063/1. 2813843 .

[66] E. do Nascimento et al. "Coincidence Doppler Broadening of Positron Annihilation Radiation in Fe". Em: Jr. of Phys. Conference Series 443 (2013), p. 012024. DOI: 10.1088/ 1742-6596/443/1/012024.

[67] E. do Nascimento et al. "Positron Annihilation Spectroscopy Techniques Applied to the Study of an HPGe Detector". Em: AIP-Conference Proceedings 1529 (2013), pp. 103109. DOI: $10.1063 / 14804096$

[68] E.do Nascimento et al. "Monte Carlo Simulation of Pileup Effects in the Electron-Positron Annihilation Peak". Em: AIP Conference Proceedings 1351 (1 2011), pp. 216-219.

[69] NIST. Star data base. último acesso 12/08/21. URL: https : //physics . nist .gov/ cgi-bin/Star/ap_table.pl.

[70] J.M. O’Meara e J.L. Campbell. "Corrections to the conventional approach to Si(Li) detector efficiency". Em: X-Ray Spectr. 33.2 (2004), pp. 146-157. URL: https : //doi . org/10.1002/xrs.728.

[71] C. Ozben e E. Emirhan. "A hybrid method to determine efficiency curve of hpge detectors”. Em: Appl. Radiat. Isot. 67.6 (2009), pp. 1110-1113. DOI: 10.1016/j .apradiso. 2009.01 .085

[72] F. Piton et al. "Efficiency Transfer for Coincidence Summing Corrections for GammaRay Spectrometry". Em: Appl. Radiat. Isot. 52.10 (2000), pp. 791-795. DOI: 10.1016/ S0969-8043(99)00246-8. 
[73] Andrius Poškus. "Shape functions and singly differential cross sections of bremsstrahlung at electron energies from $10 \mathrm{eV}$ to $3 \mathrm{MeV}$ for $\mathrm{Z}=1-100$ ”. Em: Atomic Data and Nuclear Data Tables 129-130 (set. de 2019). ISSN: 0092-640X. DOI: 10.1016/ J . ADT . 2019.03.002. URL: https://www.osti.gov/biblio/22852454.

[74] A. Robertson, T. J. Kennett e W. V. Prestwich. "Double positron-electron pair production by $6.6 \mathrm{MeV}$ gamma rays". Em: Phys. Rev. C 13 (1976), pp. 1552-1565. DOI: 10.1103/ PhysRevC.13.1552, URL: https://link . aps .org/doi/10.1103/PhysRevC.13. 1552 .

[75] P.A. Russo e D. T. Vo. Gamma-ray detectors for nondestructive analysis. Rel. técn. LAUR-05-3813. URL: https : / / www . lanl . gov/org/ddste/aldgs/sst-training/ _assets / docs / PANDA $\% 5 \mathrm{C} \% 202007 \% 5 \mathrm{C} \% 20$ Addendum $/ 1 . \% 5 \mathrm{C} \% 20$ Gamma - ray $\% 5 \mathrm{C} \%$ 20Detectors.pdf.

[76] F. Salvat, J.M. Fernández-Varea e J. Sempau. PEnELOPE, a Code System for Monte Carlo Simulation of Electron and Photon Transport. NEA/OECD, Issy-les-Moulineaux, 2011.

[77] I.A. Santos et al. "Espalhamento Compton e retoespalhamento - Simulação e experimento". Em: Simpósio Internacional de Iniciação Científica, 14. São Paulo, Brasil, 2006, SIICUSP, 2006. URL: https://repositorio.usp.br/item/001585913.

[78] I.A. Santos et al. "Espalhamento Compton e retroespalhamento, simulação em MCNP e experimentação". Em: Simpósio Internacional de Iniciação Científica, 14. SIICUSP, 2006. URL: https://repositorio.usp.br/item/001585913.

[79] O. C. B. Santos et al. "Experimental and theoretical cross sections for $K$-shell ionization of ${ }_{52} \mathrm{Te},{ }_{73} \mathrm{Ta}$, and ${ }_{83} \mathrm{Bi}$ by electrons with energies up to $100 \mathrm{keV}$ '. Em: Phys. Rev. A 100 (2019), p. 022703. DOI: 10.1103/PhysRevA.100.022703, URL: https ://link.aps. org/doi/10.1103/PhysRevA.100.022703.

[80] J.H. Scofield. "Relativistic Hartree-Slater values for K and L x-ray emission rates". Em: Data Nucl. Data Tables 14 (1974), pp. 121-137.

[81] S.M. Seltzer. "Calculated response function of intrinsic germanium detectors to narrow beams of photons with energies up to $\approx 300 \mathrm{keV}$ ". Em: Nuclear Instruments and Methods 188.1 (1981), pp. 133-151. DOI: 10.1016/0029-554X (81)90332-3

[82] S.M. Seltzer e M.J. Berger. "Bremsstrahlung energy spectra from electrons with kinetic energy $1 \mathrm{keV}-10 \mathrm{GeV}$ incident on screened and orbital electrons of neutral atoms with $\mathrm{Z}=1$ - 100". Em: Atomic Data and Nuclear Data Tables 35 (1986), pp. 345-418.

[83] S.M. Seltzer e M.J. Berger. "Bremsstrahlung spectra from electron interactions with screened atomic nuclei and orbital electrons”. Em: Nuclear Instr. and Methods B 12.1 (1985), pp. 95-134. DOI: $10.1016 / 0168-583 X$ (85)90707-4

[84] J. Sempau et al. "An algorithm for Monte Carlo simulation of coupled electron-photon transport". Em: Nuclear Instruments and Methods B 132 (1997), pp. 377-390. 
[85] O. Sima e D. Arnold. "Self-attenuation and coincidence-summing corrections calculated by Monte Carlo simulations for gamma-spectrometric measurements with well-type germanium detectors". Em: Appl. Radiat. Isot. 47.9-10 (1996), pp. 718-723. DOI: 10 . 1016/S0969-8043(96)00082-6.

[86] X-5 Monte Carlo Team. MCNP-A General Monte Carlo N-Particle Transport Code. Version 5, volume I: Overview and Theory, LA-UR-03-1987. 2003. URL: https: // laws. lanl.gov/vhosts/mcnp.lanl.gov/pdf_files/la-ur-03-1987.pdf

[87] K. Thompson. Silicon Drift Detectors. último acesso 22 Jan Set 2021. 2012. URL: http: // tools . thermofisher . com/ content/sfs / brochures / TN52342_E_0512M_ SiliconDrift_H.pdf.

[88] D.R. Tilley, H.R. Weller e C.M. Chevesac. "Energy levels of light nuclei A = 16-17". Em: Nuclear Physics A 564.1 (1993), pp. 1-183. DoI: doi .org/10 . 1016/03759474 (93) 90073-7.

[89] D.B. Tridapalli. último acesso 21 Set 2020. URL: https : / teses . usp . br/teses / disponiveis/43/43134/tde-28032007-171124/publico/DissertacaoDiogoT. pdf.

[90] H. Utsunomiya et al. "Surface channel effect on $\gamma$-ray response functions of coaxial germanium detectors". Em: Nucl. Instr. and Meth. A 548.3 (2005), pp. 455-463. DOI: 10.1016/j.nima.2005.04.062.

[91] V.R. Vanin et al. "The 10-100 keV beam line of the São Paulo Microtron electron accelerator”. Em: Radiat. Phys. Chem. 154 (2019), pp. 26-31. DOI:10.1016/j.radphyschem. 2018.03 .013

[92] D.H. Wilkinson. "Evaluation of E0 pair transitions". Em: Nuclear Physics A 133 (1969). URL: https ://doi .org/10.1016/0375-9474(69)90444-8

[93] D.H. Wilkinson e D.E. Alburger. "Double Positron-Electron Pair Creation by Photons: An Experimental Limit at $\mathrm{E}_{\gamma}=6.13$ MeV”. Em: Phys. Rev. C 5.3 (1972), p. 719. DOI: 10.1103/PhysRevC.5.719.

[94] L.E. Wright, K.K. Sud e D.W. Kosik. "Calculation of pair production by 10 and $20 \mathrm{MeV}$ photons". Em: Phys. Rev. C 36.2 (1987), p. 562. DOI: 10.1103/PhysRevC.36.562. 